University of San Diego

Digital USD

1998

\title{
Shared Governance in the British Columbia Post-Secondary Education System: The Boards' Role in Decision-Making
}

\author{
Edwin Deas EdD \\ University of San Diego
}

Follow this and additional works at: https://digital.sandiego.edu/dissertations

Part of the Leadership Studies Commons

\section{Digital USD Citation}

Deas, Edwin EdD, "Shared Governance in the British Columbia Post-Secondary Education System: The Boards' Role in Decision-Making" (1998). Dissertations. 635.

https://digital.sandiego.edu/dissertations/635

This Dissertation: Open Access is brought to you for free and open access by the Theses and Dissertations at Digital USD. It has been accepted for inclusion in Dissertations by an authorized administrator of Digital USD. For more information, please contact digital@sandiego.edu. 


\section{UNIVERSITY OF SAN DIEGO}

\section{Shared Governance in the British Columbia \\ Post-Secondary Education System: \\ The Boards' Role in Decision-Making}

A dissertation submitted in partial fulfillment of the requirements for the degree Doctor of Education

by

\section{Edwin Deas}




\section{(c) Copyright by}

\section{Edwin Deas}

1998 


\section{ABSTRACT}

In 1995, the membership of governing boards in colleges in British Columbia changed from lay persons appointed by the provincial government. The new boards consisted of fewer lay appointees with the addition of elected faculty, staff, and students, together with the college presidents and education council chairs as non-voting members. The presence of employees and students on boards was viewed by most observers as likely to enhance the quality of decision-making in general. However, that same presence could introduce an element of real or potential conflict of interest (Flanigan, 1994).

The broadening of input and decision-making brought about in the shared governance model, assuming the constituents could effectively manage the actual sharing of power, was expected to lead to improved quality of decisions and also to greater acceptance by stakeholders (Draper and Van Groningen, 1990). Moreover, boards were also the final authority for setting institutional budgets and were the legislated employers. The established culture of boards had changed and had affected the boards' role in general matters through the sheer presence of different constituents. In matters of finance and labour relations, boards had to find ways to fulfill their obligations while maintaining their integrity and credibility.

This quantitative study reported the views and experiences of board members concerning three aspects of leadership through shared governance in three decision-making contexts. The study explored the different views and 
experiences among seventeen colleges and between the six constituent groups of board members, and also identified differences which had emerged since a similar study conducted by the researcher in $1995 / 96$. Colleges were found to differ significantly in philosophies and practices toward shared governance, particularly in relation to conflict of interest and the existence of clear policies and procedures. Presidents were found to be troubled by internal members' lack of independence from their constituencies. The generally negative views overall of shared governance by presidents, although cited as common by Baliles (1996), were in marked contrast to the earlier study. In contrast, internal members had generally reported more positive opinions with the passage of time, while external members had remained consistently positive toward shared governance. 


\section{WITH SPECIAL THANKS}

To my wife Lynda and our children Christopher, Nicholas, and Lindsay who gave me support throughout and did their share of the little chores which made it all possible...

To Malaspina University College and President Rich Johnston for giving me the opportunity and support...

To my Dissertation Committee and, especially, Bill Piland for helping me turn my dissertation topic from a personal interest to an academic work of which I am proud...

To the faculty and staff of the University of San Diego, San Diego State University, and Malaspina University College for putting up with my demanding ways in the quest for knowledge...

To Diny van Beers my technology guru and sounding board on so many issues and questions...

And, to my study buddy Judith Knapp who was always there to help, encourage, and finally celebrate our endeavors. 


\section{TABLE OF CONTENTS}

Page

CHAPTER I THE PROBLEM

Introduction

....1

Statement of the Problem

$\ldots . .3$

Background of the Problem

....3

Importance of the Study

....9

Purpose of the Study

Conceptual Framework

$\ldots .18$

Research Questions

...22

Statement of Hypotheses

Assumptions of the Study

Delimitations of the Study

Limitations of the Study

Specific Terminology

Organization of the Study

\section{CHAPTER \| REVIEW OF LITERATURE}

Introduction

Definition of Shared Governance 
1. Institutional Planning and for What?

2. A Climate of Confrontation

3. State/Provincial Centralization

$$
\text { of Boards' Responsibilities }
$$

Discussion of the Issues

Shared Governance in General

1. Roles to be Played

2. The Influence of the President

3. Consensus and Representation

4. The Scope of Involvement in Shared Decision-Making

5. An Advisory or Decision-Making Role and the Impact on Middle Managers

6. Structures and Relationships

7. The Importance of Shared Governance for Students

8. Faculty and Support Staff Attitudes

Shared Governance in Financial Affairs 
The Advantages and Disadvantages of Shared Governance ...117 Advantages of Shared Governance $\quad$...118

Disadvantages of Shared Governance $\quad$...119

Summary

CHAPTER III RESEARCH METHODOLOGY

Introduction

$\ldots 126$

Methodological Overview

$\ldots 127$

Research Design

$\ldots 128$

Validity and Reliability

$\ldots 131$

Data Collection

$\ldots 132$

Entry to the Population

$\ldots 132$

Selection of Sites/Subjects

Protection of the Subjects

Instrumentation

$\ldots 138$

Approach to Data Analysis

$\ldots 144$

Background of the Researcher

$\ldots 148$

Summary 
CHAPTER IV PRESENTATION AND DISCUSSION OF THE FINDINGS

OF THE STUDY

Introduction

Presentation and Discussion of the Descriptive Statistics

Summary of Questionnaire Returns

Summary of Board Experience

Summary of Data, by Decision-Making Context. Aspect of Leadership. and Percentage-Frequency Distribution

Summary of the Assessment of Own Boards' Effectiveness in Aspects of Leadership and Percentage-Frequency Distribution

Summary

Presentation and Discussion of the Comparative Statistics

Summary of Data by Decision-Making Context and Aspect of Leadership

Summary of the Assessment of Own Boards' Effectiveness in Aspects of Leadership

Practical Significance of the Study

Summary 
CHAPTER V SUMMARY, CONCLUSIONS, AND RECOMMENDATIONS

$\begin{array}{ll}\text { Introduction } & \ldots 270\end{array}$

Summary $\quad \ldots 271$

$\begin{array}{ll}\text { Conclusions } & \ldots 281\end{array}$

Recommendations $\quad \ldots 295$

Suggestions for Implementation and Further Pursuit of the Findings of the Study $\quad$...296

Suggestions for Areas of Further Research $\quad$....299

$\begin{array}{ll}\text { REFERENCES } & \ldots 304\end{array}$

$\begin{array}{ll}\text { APPENDICES } & \ldots 320\end{array}$ 


\section{LIST OF APPENDICES}

Page

A. Invitations to Participate in the Study-Current Members,

Past Members, and Malaspina University College

Internal Members

B. Study Questionnaire

C. Consent to Act as a Research Subject

D. Follow-Up/Thank-You to All Participants

E. Follow-Up to Board Chairs and College Presidents

F. Summary of Questionnaire Returns, by Constituency Group

G. Summary of Questionnaire Returns, by College (A to Q)

H. Summary of Board Experience, by Years

and Percentage-Frequency Distribution

I. Summary of Data by Decision-Making Context,

Aspect of Leadership,

and Percentage-Frequency Distribution

J. Summary of the Assessment of Own Boards' Effectiveness

in Aspects of Leadership

and Percentage-Frequency Distribution

K. Summary of Data by Constituent Group,

Decision-Making Context, and Aspect of Leadership 
L. Summary of the Assessment of Own Boards' Effectiveness in Aspects of Leadership, by Constituent Group

M. Summary of Data by College (A to $Q$ ), Decision-Making Context, and Aspect of Leadership

N. Summary of the Assessment Of Own Boards' Effectiveness in Aspects of Leadership, by College (A to $Q$ )

O. Summary of Matched Statements in the 1995/96 and 1997/98 Studies, by Constituent Group

P. Summary of the Most Positive and Least Positive Attitudes in General Toward Shared Governance, by College and Constituent Group

Q. Comparison of the Two Studies on Question 9: The composition of my board makes an effective contribution to the governance of the institution

R. Comparison of the Two Studies on Question 10: The way my board operates makes an effective contribution to the governance of the institution

S. Comparison of the Two Studies on Question 37: I feel my board effectively discharges its labour relations responsibilities under the College and Institute Act 


\section{LIST OF DIAGRAMS}

Page

1. Changes to the College and Institute Act of British Columbia as a Result of Bill 22

2. Study of the Aspects of Leadership in the Context of Certain Decision-Making Areas

3. Study of aspects of Leadership in the Context of Certain Decision-Making areas, examined through Three Lenses

4. Location of Significant Differences in the Study 


\section{CHAPTER I THE PROBLEM}

\section{Introduction}

The governing boards of colleges and university colleges in British Columbia, Canada have been required to face hitherto unaddressed challenges in fulfilling their decision-making roles by virtue of recent, far reaching changes in their membership. Colleges are two year institutions which offer a wide range of programs in the areas of university transfer, vocational and trades, career and technical, adult education, and non-credit community education. University colleges are a recent creation in British Columbia and are unique in Canada. They are essentially comprehensive community colleges with the additional mandate to offer baccalaureate degrees.

In 1995, an amendment, known as Bill 22, was made to the College and Institute Act of British Columbia which is the founding legislation of colleges and university colleges. This amendment resulted in the composition of the boards being changed from entirely that of lay community members appointed by the provincial government. In its place, the new boards consist of fewer lay appointees and the notable addition of faculty, staff, and students elected from within their own constituencies, together with the president of the college and the chair of the education council as non-voting, ex-officio members. The education 
councils are faculty dominated, senate-like bodies which were created under the new legislation and have prescribed advisory (to boards), joint (with boards), and final authority roles in various areas of decision-making, all of which previously came within the sole purview of the boards.

The presence of employees and students on the governing boards is seen by most observers as a positive move by the provincial government and likely to enhance the quality of decision-making in areas of general responsibility for boards. However, it is possible that an element of real or perceived conflict of interest may enter the climate of boards in matters of finance and labour relations. Consequently, the former could lead to tension among board members in reaching decisions on budget allocation, be it in times of growth in resources or in times of retrenchment, due to the vested interest of the employee and student members in determining the locus of budget changes. Similarly, the latter may be fertile ground for dispute when collective agreements are being negotiated and administered, again because of the vested interest of the employee and student members. In some cases, those employee and student board members may even wear two hats simultaneously when also serving as officers in their trade unions or student associations. 


\section{Statement of the Problem}

The problem under investigation in this study was how boards of colleges and university colleges in British Columbia have dealt with the change in their composition, which now includes employees and students, in selected aspects of boardsmanship applied to areas of decision-making in general matters, financial matters, and labour relations matters. The aspects of boardsmanship explored in this study are the sharing of power, the effectiveness of the shared decisionmaking process, and how the real or perceived conflict of interest of employee and student board members has been addressed. The views and experiences of board members since this significant change in the composition and power base of boards, as expressed by the members themselves, was the focus of this study.

\section{Background of the Problem}

Colleges have had a relatively short history in British Columbia, while university colleges are a very recent innovation. For the first half of the twentieth century, post-secondary educational opportunity in the province was extremely limited.

The University of British Columbia was established in 1915. Enrolment in 1945 was 3,000 , and by 1953 reached just over 5,000 . One satellite 
college was established in the capital city of Victoria, and these two campuses, as well as one small private college, represented the sum total of post-secondary education in British Columbia until 1965. In addition, a number of vocational training schools were constructed in the province by the Ministry of Education.

The sixties saw an increase in the college age population as a result of the baby boom experienced in Canada after World War II, and the percentage of this population seeking higher education was growing. In British Columbia, the numbers reached “...18 per cent by 1961 , compared to 12 per cent in Canada as a whole and 40 per cent in the United States, with projections to 25 per cent by 1971 . The University of British Columbia was projecting an enrolment of 30,000 by 1970 --an unacceptable figure in the view of most academics of that day" (Dennison, 1986, p. 25).

Community colleges, already established in the United States, were suggested as the answer although academics were split on their suitability for British Columbia. However, the newly appointed president of the University of British Columbia, Dr. John B MacDonald, provided the lead in his report Higher Education in British Columbia and A Plan for the Future. He suggested that government create new universities in heavily populated areas, as well as encourage the establishment of regional colleges across the province. His reasons were twofold: (1) to take the 
pressure off the universities which were certain to grow; and (2) to create post-secondary educational opportunities for people in rural areas of British Columbia. MacDonald stressed the community orientation of the new institutions "Two requirements are fundamental to the promotion of excellence in British Columbia's higher education. These are first, diversification of opportunity, both in respect to the kinds of education experience available and the places where it can be obtained. The second requirement is self-government of individual institutions in respect to setting objectives, standards, admissions, selection of staff, curricula, personnel policies, administrative structure, and all the other things that go to make up the operation of a college. These two elementsdiversification and self-government- together will not ensure excellence, but in their absence an excellent system of higher education in British Columbia would be unattainable" (MacDonald, 1962, p. 19).

The government was quick to respond. Victoria College was made into a degree granting institution in 1963 , becoming the University of Victoria, and construction of Simon Fraser University commenced in 1964. The first community college, Vancouver Community College, was created in 1965 to be followed by Selkirk College the following year. Today, British Columbia boasts twenty two community colleges, university colleges, institutes and the Open Learning Agency. 
In 1988, a government study, known as The Access Report, revealed that British Columbia was producing fewer students with undergraduate degrees ( 3.07 per 1,000 of population) than the national average $(4.5$ per 1,000$)$. This was partly attributed to the lack of student spaces at the three provincial universities. As a result, the government responded in 1989 with the "Access for All" initiative which saw the creation of the University of Northern British Columbia in Prince George and the conversion of four community colleges into university colleges. A fifth university college was created a few years later. The new institutions have sought to create a unique image for themselves rather than simply try to emulate traditional universities. The focus of their degree development has been in applied fields which represents an extension of their training tradition gathered as community colleges. However, as Dennison (1997) noted, they face pressure from the university sector to conform to more regular higher education standards; " Sustained innovation in the post compulsory education sector has been relatively rare in Canada. Many institutions, established with optimistic flourish and noble goals, have been forced into more conventional formats over time. The university colleges have maintained their commitment to access, responsiveness, teaching quality, and curricular comprehensiveness. By any yardstick, they are innovative institutions" (p. 5). (van Toor, 1997) 
The College and Institute Act of British Columbia, under which the colleges and university colleges in this study operate, clearly articulates specific decision-making roles for governing boards and education councils. Indeed, although the scope of the roles did change with the arrival of education councils, the locus of decision-making was clearly specified both before and after the legislative amendment known as Bill 22. In effect, these roles are delegated by the Minister of Advanced Education, Training, and Technology to the boards and education councils and the roles cannot, in turn, be delegated to any other parties. With reference to boards, in some areas, such as the setting of general policy and the establishment of academic rules, the broadening of input and decision-making brought about by the shared governance model is likely not only to lead to improved quality of outcomes but also to acceptance by a greater number of the stakeholders in the institutions. Consequently, shared decisions, in theory, should lead to ease of implementation of the outcomes; and those outcomes may well be consistent with the values expressed in the legislation. However, these positive outcomes anticipated are based on the assumption that boards can effectively manage the basic task of sharing power among the constituents to deal with matters of common institutional interest.

Among the boards' other prescribed responsibilities are finance and labour relations. Boards are the final decision-making authority in setting the institutional budgets and ensuring that appropriate resources are allocated to all departments in the institutions. Additionally, boards are also the employers of 
reference as defined in the provincial labour code and, as such, are one of the parties to every collective agreement. Both these roles require boards to take a higher moral stance when dealing with the legitimate vested interests of faculty, staff, and students. The problem may manifest itself when those vested interests actually infiltrate the boards and their decision-making processes. The erstwhile independent, disinterested nature of the boards is now being potentially compromised. In fact, the long established culture of boards has changed and has even affected the boards' role in general matters by virtue of the shear presence of different constituents. As a result of the new composition of boards, when it comes to the more overtly troublesome matters of finance and labour relations, boards have had to discover new ways to fulfill their obligations while maintaining their integrity and credibility as well as their cohesion. This they have done by interpreting provincially legislated guidelines and establishing local bylaws and procedures. 


\section{Importance of the Study}

The undernoted diagram highlights the main changes that occurred to the College and Institute Act as a result of the legislative amendment Bill 22:

Diagram 1: Changes to the College and Institute Act of British Columbia as a result of Bill 22

\begin{tabular}{|c|c|}
\hline Before Bill 22 & After Bill 22 \\
\hline $\begin{array}{l}\text { Objects of a College } \\
\text { To provide comprehensive } \\
\text { (a) courses of study at the first and } \\
\text { second year levels of a baccalaureate } \\
\text { program, } \\
\text { (b) post-secondary education or } \\
\text { training, and } \\
\text { (c) continuing education. }\end{array}$ & $\begin{array}{l}\text { Objects of a College } \\
\text { Same as before Bill } 22 .\end{array}$ \\
\hline $\begin{array}{l}\text { Objects of a University College } \\
\text { No reference before Bill } 22 .\end{array}$ & $\begin{array}{l}\text { Objects of a University College } \\
\text { To provide comprehensive } \\
\text { (a) courses of study for a } \\
\text { baccalaureate degree program, } \\
\text { (b) post-secondary education or } \\
\text { training, and } \\
\text { (c) continuing education. }\end{array}$ \\
\hline $\begin{array}{l}\text { Board Composition } \\
5 \text { or more members appointed by the } \\
\text { Lieutenant Governor in Council (in } \\
\text { practice, boards generally comprised } \\
\text { around } 11 \text { members) } \\
\text { No employee or student shall be } \\
\text { appointed to, or continue as a member } \\
\text { of, the board. }\end{array}$ & $\begin{array}{l}\text { Board Composition } \\
8 \text { or more persons appointed by the } \\
\text { Lieutenant Governor in Council, } \\
1 \text { elected faculty member, } \\
2 \text { elected students, } \\
1 \text { elected support staff member, } \\
\text { The president, and } \\
\text { The chair of the education council. }\end{array}$ \\
\hline
\end{tabular}


Term of Office

Not specified, but generally terms of 1 , 2 , and 3 years for a total of 6 years. However, there were numerous exceptions.
(Selected) Powers of Board

Shall manage, administer, and direct the affairs of the institution.

Shall manage and promote the educational or training programs.

Shall administer funds, grants, fees, endowments, and other assets.

Student Union (Association)

No reference before Bill 22.

Advisory Role of the Education Council No reference before Bill 22.
Term of Office

Appointed: Same as before Bill 22, Faculty and support staff: 3 years, and may be elected to further terms, Students: 1 year, and may be elected to further terms, and President and chair of education council: ex-officio.

(Selected) Powers of Board Shall manage, administer, and direct the affairs of the institution, subject to the powers of the education council.

Shall manage and promote the educational and training programs, subject to powers of the education council.

Same as before Bill 22.

Student Union (Association)

Board will assess and collect student union fees, subject to certain financial reporting requirements.

Advisory Role of the Education Council An education council must advise the board, and the board must seek advice from the education council, on development of education policy on

(a) mission and goals,

(b) implementation of courses and programs,

(c) reports after implementation of noncredit courses and contract programs, (d) implementation priorities for new courses and programs,

(e) cancellation of courses and programs,

(f) evaluation of programs and educational services,

(g) policies concerning library and resource centres, 


\begin{tabular}{|c|c|}
\hline & $\begin{array}{l}\text { (h) setting the academic schedule, } \\
\text { (I) policies on faculty member } \\
\text { qualifications, } \\
\text { (j) procedure for student discipline } \\
\text { appeals, } \\
\text { (k) terms for affiliation with other post- } \\
\text { secondary bodies, } \\
\text { (l) consultation with community and } \\
\text { program advisory groups, } \\
\text { (m) qualifications for admission } \\
\text { policies, } \\
\text { (n) criteria for awarding certificates, } \\
\text { diplomas, and degrees, and } \\
\text { (o) other matters specified by board. }\end{array}$ \\
\hline $\begin{array}{l}\text { Powers of the Education Council } \\
\text { No reference before Bill } 22 \text {. }\end{array}$ & $\begin{array}{l}\text { Powers of the Education Council } \\
\text { (a) make bylaws, } \\
\text { (b) set policies on examinations and } \\
\text { student evaluations, } \\
\text { (c) set policies on student withdrawal } \\
\text { from courses, programs, and the } \\
\text { institution, } \\
\text { (d) set criteria for academic standing, } \\
\text { academic standards, and the grading } \\
\text { system, } \\
\text { (e) set criteria for awards recognizing } \\
\text { academic excellence, } \\
\text { (f) set policies and procedures for } \\
\text { appeals by students on academic } \\
\text { matters and establish a final appeal } \\
\text { tribunal for these appeals, and } \\
\text { (g) set curriculum content. }\end{array}$ \\
\hline $\begin{array}{l}\text { Joint Board and Education Council } \\
\text { Approval } \\
\text { No reference before Bill } 22 .\end{array}$ & $\begin{array}{l}\text { Joint Board and Education Council } \\
\text { Approval } \\
\text { (a) curriculum evaluation for } \\
\text { equivalency from other institutions, } \\
\text { (b) curriculum evaluation for } \\
\text { equivalency between departments of } \\
\text { the institution, and } \\
\text { (c) other responsibilities of the board } \\
\text { that, on the initiative of the board, the } \\
\text { board and education council agree are } \\
\text { subject to joint approval. }\end{array}$ \\
\hline
\end{tabular}


Bill 22 provided a framework for the introduction of shared governance in British Columbia. While quite prescriptive in some areas, there are also other areas which are very loosely written and allow for local interpretation and implementation at each institution. A good example is the advisory powers of the education council on policies. It is not clear whether the powers relate only to the development of policies or also extend to the implementation of such policies. The language is ambiguous. This begs the broader question "Is the role of the education council one of governance or administration?". Such ambiguity was a stated intention when the legislation was drafted. As a result, it is highly likely that institutions have differed in their approach to constructing the shared governance model, particularly in areas where they were given the greatest discretion; and this was explored in the study.

Bill 22 had quite a checkered history from its inception as part of the election manifesto of the then party in opposition in the British Columbia Legislature to the final amendment to the College and Institute Act. The purpose of adding internal constituents to hitherto external boards of governance was deemed to "...put the community back into community colleges" by the Canadian Federation of Students $(1992$, p. 2$)$ in one of many submissions from interest groups solicited by the new government once the change in legislation came to be drafted. However the Advanced Education Council of British Columbia (1994), representing the institutional boards of the day, argued that colleges were owned by their communities, that is the external communities-at-large not the 
employees and students. Consequently, it felt that boards appointed by the provincial government, i.e. the status quo, best reflected the nature of community ownership. Others saw the change to governance in colleges coming as a direct result of the recent creation of university colleges and their closer relationship and resemblance to universities. Malaspina University College (1993), in a paper contemplating its elevation to degree granting status, suggested that the credibility of such degrees would be dependent upon a more formal involvement of internal interests, notably those of faculty, in decision-making. In particular, it saw the then proposed education councils on academic affairs as being the formalization of curriculum committees which university colleges had voluntarily moved quickly to establish in order to satisfy standards' requirements in the university sector.

The volatile educational climate in British Columbia at the time of the drafting of Bill 22 provides an interesting backdrop to the eventual legislation and the focus of this study. Collective bargaining, which had been conducted locally between individual boards/administrations and union locals throughout the history of colleges in British Columbia, was being legislated into a two-tier model of provincial negotiations on monetary items and local negotiations on the more professional type of items contained in collective agreements. It is fair to say that this change was more favoured by trade unions looking for a larger, more productive bargaining arena than it was by boards and administrations. The College and Institute Educators' Association of British Columbia (1994), in a 
submission to the drafters of Bill 22, drew very clear comparisons between the planned changes in labour relations and governance. The Association advocated collaboration between trade unions and student unions (associations) and interaction between unions and college boards, particularly once the latter included faculty, staff, and student members. Interestingly, the Canadian Federation of Students (1992) suggested to the provincial government that government appoirited board members inevitably yielded to "...partisan political pressure" in order to ensure re-appointment whereas elected internal members would have no such temptation (p. 2). The Federation further argued that "...student unions are akin to labour unions in that their primary purpose is to collectively negotiate for and represent their members" (p. 4). There emerged, therefore, a clear indication of a faculty, staff, and student alliance to pursue a government legislated shift in power simultaneously in both the labour relations and governance fields.

The submissions which were made to the provincial government as it drafted Bill 22 were quite polarized in nature and reflect much of the diversity which has emerged in North American literature on the subject of shared governance in general. Firstly, it is important to note the elements of the political manifesto of the New Democratic Party (1990) which formed the basis for the whole legislative change:

- There will be multi-year budgeting [i. e. funding] for colleges [this has not been enacted by 1998]; 
- There will be internal representation on college boards and senates [enacted in 1995];

- Tuition and supplementary fees will be frozen [eventually implemented in 1996 and still in force in 1998];

- Funding for continuing education administration will be restored [not enacted] and funding will be provided to private business and community groups to deliver non-credit continuing education [enacted]; and

- Private institutions will be brought under governmental control [enacted]. (pp. 1-13)

The manifesto clearly represented a significant change to the status quo as far as governance was concerned. And it brought somewhat predictable responses. A special task force comprising representation from boards, administration, faculty, staff, and students struggled for consensus but eventually managed to stress the need for clear legislation, whatever the eventual composition and role for college boards. In addition, it was suggested that internal members should only form a minority on boards; and clear guidelines as to conflict of interest and accountability would be required. Furthermore, it called for government to provide clear expectations of the roles of boards, education councils, and presidents (Report of the Committee on Governance in Colleges and Institutes, 1993). In a more direct retort, the Advanced Education Council of British Columbia (1994), representing boards consisting solely of appointed members at 
that time, advocated little change. It suggested that boards, with a minority of internal members, should consult with constituency groups but should retain final decision-making power on all matters over which they had legislated jurisdiction. Further, constituency groups might include educational councils. Each institution should have the discretion whether or not to create such a body.

The trade unions were obviously more supportive of the notion of shared governance than existing boards but were less prescriptive as to what the legislation should look like. What was clear, however, was the expectation that internal members would play a full voting role on boards and education councils, the latter dominated by faculty, and would have extensive decision-making power on academic matters and perhaps even on other matters. In addition, it was suggested that the unions should develop "...appropriate conflict of interest guidelines as a model for consideration by locals, institutional boards, the Advanced Education Council, and the Ministry [of Advanced Education, Training, and Technology]" (College and Institute Educators' Association Committee on Governance Implementation, 1994). At the end of the day, the finalization of Bill 22 assumed legendary status with the most popular version being that the legislation was penned by representatives of government and the academic faculty unions, behind closed doors and to the exclusion of all other interested parties.

One significant aspect of the legislation is the absence of any formal evaluation of the change that it brought. While institutions go through a routine 
self evaluation every five years where examination of governance is included, it is but one of many areas of focus and, subsequently, it is unlikely that the new governance models would be reviewed in any great depth. This lack of evaluation is all the more regrettable because each college is likely to have developed a slightly different structure and modus operandi. This study, therefore, focused on the views and potential differences of the board members themselves as a first step in discerning whether the intent of the legislated change has been effective in certain aspects and contexts of decision-making. Thereafter, the study examined what might be the leadership implications for engaging this new collection of members who come from a variety of campus constituencies.

\section{Purpose of the Study}

The purpose of this study was to determine the extent to which the new composition of boards influences three aspects of leadership through shared governance: 1.) The sharing of power, 2.) The effectiveness of the shared decision-making process, and 3.) How real or perceived conflict of interest because of the employment or student status of some of the board members has been addressed. These aspects of leadership were studied in three particular contexts, namely board decision-making in general matters of business, in financial matters, and in the field of labour relations. 
The impact of the change in membership of the boards as a result of Bill 22 was explored through the anticipated differing views and experiences of the board members themselves. The researcher sought to find if differences emerged among colleges based on the likelihood that they have adopted different strategies in interpreting the legislation. Further, the potential for differences among members was examined, by virtue of the constituency from which they emanate, namely appointed members; elected faculty; elected staff; elected students; ex-officio presidents; and ex-officio chairs of education council. Finally, the results of the study were compared with a similar study conducted by the researcher in early 1996 to see if the passage of time since Bill 22 was enacted had changed board members' views.

\section{Conceptual Framework}

Boards of governance in colleges play a definite yet unusual role. Clearly, the boards have power, much of which is established by legislation, and, through their decision-making role, they have the ability to set the direction for colleges and achieve long term impact through their policy formulation role was noted by Piland (1994). And yet, the boards sometimes seem to lead from behind because colleges have very democratic cultures, far more so than other organizations outside of the education sector. In a college, there are many leaders including administrators, both individually and collectively, and, faculty 
who tend to assume power collectively on matters such as academic standards and to wield power individually on matters such as curriculum.

Leadership in colleges is, therefore, quite fragmented and the power that is vested in those leadership roles is held quite jealously. The notion of ownership in decision-making in specific areas, e.g. curriculum for faculty and budget for board and administration, and the reluctance to concede it is central to the power struggle noted by many authors including Edelfelt (1982) and Kanter (1994). This somewhat tense, web-like structure functions through the existence of a clear, consistently applied process of consideration of issues and decision-making. Indeed, process is paramount to the peaceful climate of a college campus and, frequently, the nature of the process appears to be more important than the actual decision itself. When process breaks down, a college moves into a turmoil where the legitimate leadership is quickly called into question.

As noted earlier, this distributed leadership/power model is unique to the three levels of education--schools, colleges, and universities. The uniqueness comes from the sense held by the faculty, staff, and students of having a right to be involved in decision-making, whereas, in other organizations, devolution of power remains a voluntary action on the part of those occupying traditional leadership roles. Trust plays a significantly important part in shared governance and Lovas (1994) noted "... it ] requires that everyone have integrity in dealing with other groups which is hard when there are conflicting loyalties as we often 
find in the collegial environment" (p. 22). Moreover, inclusion of employees and students on college boards in British Columbia represented a major move forward from the leadership roles which these internal members previously had held. This is because of the nature of board business and the consequences of its outcomes. The entrance by internal members into new areas of decisionmaking with the attendant issues that arise was one of the major focuses of this study. Faculty, staff, and students clearly have a different interest in matters of finance and labour relations than do appointed lay members of a board because the decisions to be made by that board will potentially affect their employment or program of studies. In addition, there may be other more general issues of decision-making that also have the same affect on employment and studies. Employee and student board members, therefore, have strong vested interests in board decisions. But, does that represent conflict of interest? Can boards function independently, with the expected degree of integrity and accountability, while containing members who stand to gain or lose from the decisions they make? The legislation, which created shared governance in British Columbia, assumed that boards could function appropriately. But, it then left individual colleges to make the necessary arrangements according to their own culture and history with only limited guidelines on conflict of interest. The potential for differing outcomes was, therefore, worthy of review.

This study investigated the three aspects of board leadership, namely the sharing of power among quite different constituents, often with a history of 
tension and confrontation; the existence of decision-making process in the shared governance model; and how the real or perceived conflict of interest of employee and student board members has been addressed. These aspects of boardsmanship were viewed through three contexts of decision-making in the expectation that differing results might be generated. These decision-making contexts were general board matters, financial matters, and matters of labour relations; for the literature suggests that shared governance can be very successful in the first context but can be difficult to sustain in the second and third contexts.

\section{Diagram 2: Study of the Aspects of Leadership in the Context of Certain Decision-Making Areas}

Aspects of Leadership through Governance

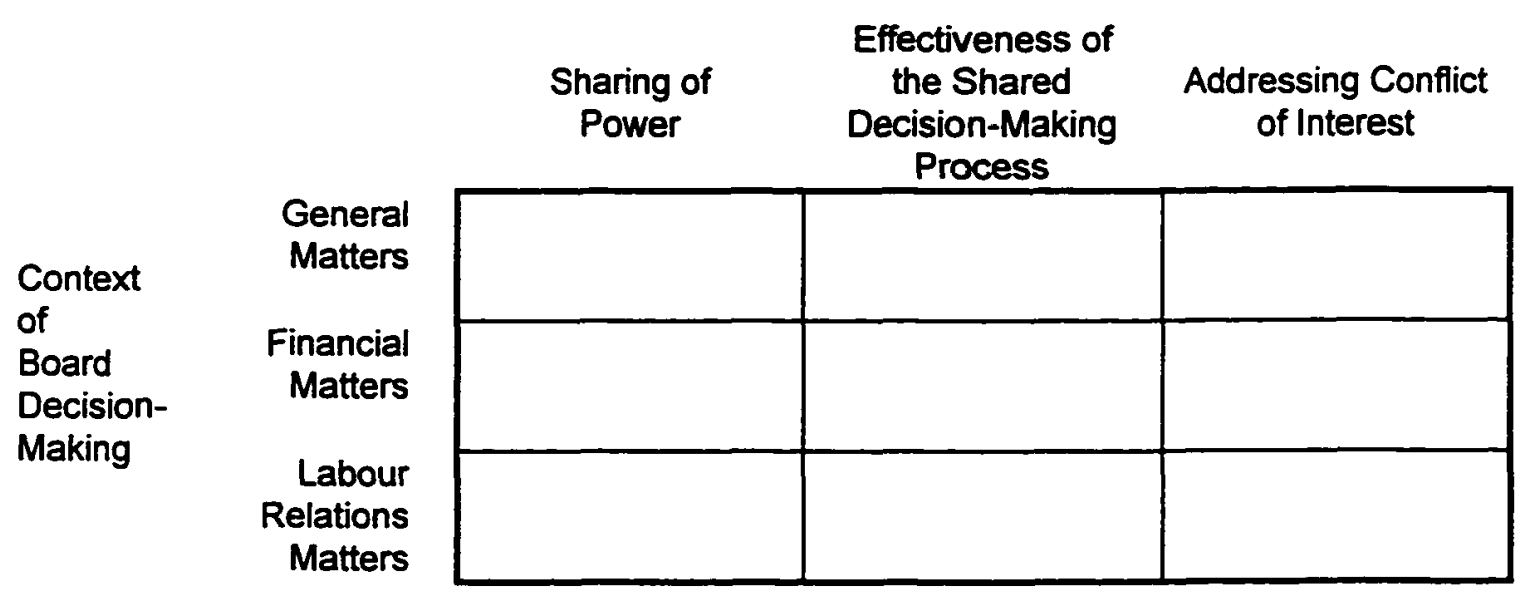




\section{Research Questions}

This study sought to answer the following questions in relation to selected aspects of boardsmanship required in the shared governance model in the context of selected areas of decision-making:

1. Is there a difference among British Columbia colleges in certain aspects of boardsmanship, namely the sharing of power, the effectiveness of the shared decision-making process, and how real or perceived conflict of interest of employee and student board members has been addressed when it comes to decision-making in respect to general matters of business, financial matters, and labour relations matters?

2. Is there a difference among board members, according to the constituency from which they are drawn, i.e. appointed members; elected faculty; elected support staff; elected students; presidents; and education council chairs, in certain aspects of boardsmanship, namely the sharing of power, the effectiveness of the shared decision-making process, and how real or perceived conflict of interest of employee and student board members has been addressed when it comes to decision-making in respect to general matters of business, financial matters, and labour relations matters?

3. Is there a difference between the views elicited from this study and those from an earlier study in respect to certain aspects of boardsmanship, namely the sharing of power, the effectiveness of the shared decision-making process, and 
how real or perceived conflict of interest of employee and student board members has been addressed when it comes to decision-making in respect to general matters of business, financial matters, and labour relations matters.

\section{Diagram 3: Study of Aspects of Leadership in the Context of Certain Decision-Making Areas, Examined through Three Lenses}

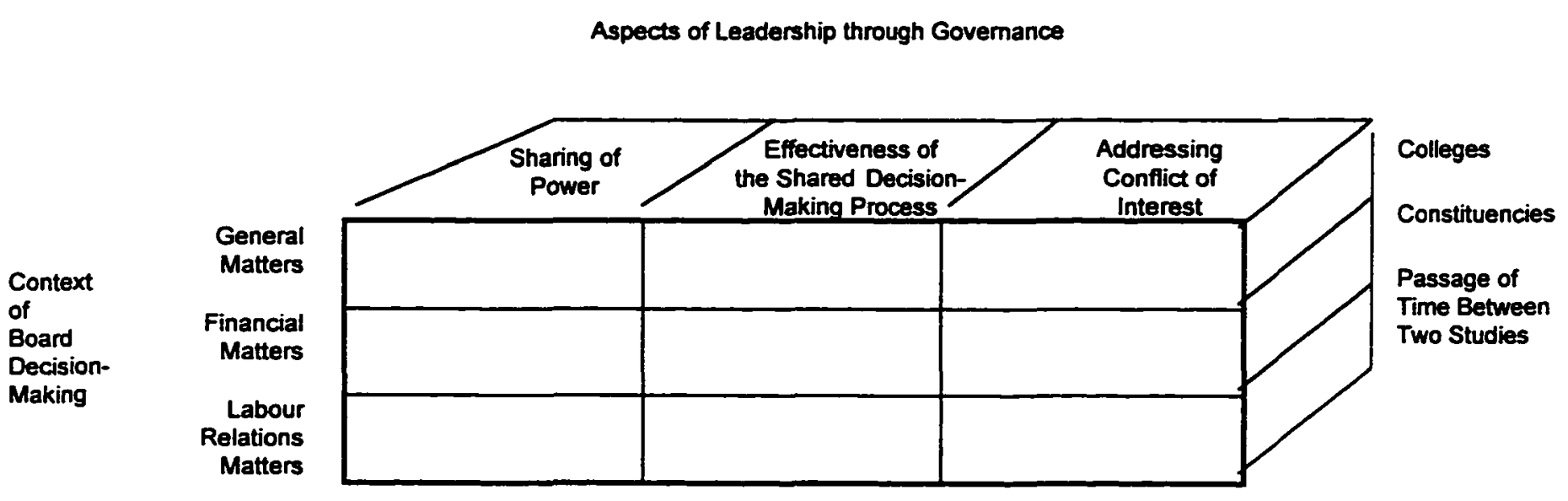

\section{Statement of Hypotheses}

The legislative amendment which brought shared governance to British Columbia is alternatively prescriptive and liberal in detail, therefore, it is conceivable that differing outcomes might have emerged in how institutions have chosen to operate. In addition, the disparate backgrounds of the boards' memberships might also lead to differing views on how the shared governance model functions. However, there is also a good deal of literature to suggest 
predictable outcomes based on experiences in other provinces and states.

Accordingly, the following hypotheses are stated in the null form:

H1. There is no significant difference, at the .05 confidence level, among British Columbia colleges concerning the sharing of power in the shared governance model for decision-making in general matters of business, financial matters, and labour matters.

H2. There is no significant difference, at the .05 confidence level, among British Columbia colleges concerning the effectiveness of the shared decision-making process in the shared governance model for decision-making in general matters of business, financial matters, and labour matters.

H3. There is no significant difference, at the .05 confidence level, among British Columbia colleges concerning how real or perceived conflict of interest of employee and student board members has been addressed in the shared governance model for decision-making in general matters of business, financial matters, and labour matters.

H4. There is no significant difference, at the .05 confidence level, among board members, according to the constituency from which they are drawn, i.e. appointed members; elected faculty; elected support staff; elected students; presidents; and education council chairs, concerning the sharing of power in the shared governance model for decision-making in general matters of business, financial matters, and labour matters. 
H5. There is no significant difference, at the .05 confidence level, among board members, according to the constituency from which they are drawn, i.e. appointed members; elected faculty; elected support staff; elected students; presidents; and education council chairs, concerning the effectiveness of the shared decision-making process in the shared governance model for decisionmaking in general matters of business, financial matters, and labour matters. H6. There is no significant difference, at the .05 confidence level, among board members, according to the constituency from which they are drawn, i.e. appointed members; elected faculty; elected support staff; elected students; presidents; and education council chairs, concerning how real or perceived conflict of interest of employee and student board members has been addressed in the shared governance model for decision-making in general matters of business, financial matters, and labour matters.

H7. There is no significant difference, at the .05 confidence level, between the views elicited from this study and those from an earlier study concerning the sharing of power in the shared governance model for decision-making in general matters of business, financial matters, and labour matters.

H8. There is no significant difference, at the .05 confidence level, between the views elicited from this study and those from an earlier study concerning the effectiveness of the shared decision-making process in the shared governance model for decision-making in general matters of business, financial matters, and labour matters. 
H9. There is no significant difference, at the .05 confidence level, between the views elicited from this study and those from an earlier study concerning how real or perceived conflict of interest of employee and student board members has been addressed in the shared governance model for decision-making in general matters of business, financial matters, and labour matters.

\section{Assumptions of the Study}

This study was predicated on the belief that there is need to expand the body of knowledge on shared governance in general in the education setting and, in particular, to start building a body of knowledge based on the experience of introducing shared governance into the college and university college sectors of British Columbia. It is assumed that, in the absence of specific formal evaluation tools attached to the governance legislation, board members would acknowledge this shortcoming and would view the study as warranted and useful. Consequently, it was anticipated that at least a representative number of board members would choose to participate in this study. Representation in this context extended both to the potential of seventeen institutions and six constituencies of membership, namely lay appointees by the provincial government, elected faculty members, elected support staff members, elected student members, and the ex-officio positions of college president and chair of the educational council. 
Further, it was assumed that the office of the researcher did not adversely influence participation in the study. The researcher holds a senior administrative position in a British Columbia university college and, consequently, plays an active part in the shared governance model at his institution. In addition, a further potential complication was his position vis-à-vis the employee and student members of his institution's board which can be characterized as indirectly supervisory. However, it is assumed that participation in the study was based on willingness to be involved in an academic exercise rather than any implied obligation that might be construed due to the nature of the researcher's status.

\section{Delimitations of the Study}

The study focused entirely on members of the boards of governance of the colleges and university colleges of British Columbia. Its purpose was to elicit board members' views of and experiences with the shared governance models that have been developed in response to Bill 22. The impact of the legislation might reasonably be expected to extend to other stakeholders, including legislators, media, the general public, and constituencies from which some members have been elected, i.e. the faculty, support staff, and student populations at large. However, that speaks to further fields of study, and this particular study was deliberately confined to board members. 


\section{Limitations of the Study}

Participation in the study was entirely voluntary and called for donation of time by board members who virtually all have other occupations and commitments. In addition, membership of boards is fairly volatile and any number of new members may have felt that they did not have the experience of college boardsmanship necessary to complete the survey instrument. This possibility was addressed to some extent by trying to include former board members rather than new members where the replacement took place in the weeks immediately prior to the study.

In the two month period before and during the study, five presidents announced their resignation or retirement. This is an abnormally high number out of a total of seventeen. While it would appear that these significant decisions did not affect willingness to participate in the study, it is possible that the data provided by the individuals was affected by their recent decisions. However, it is impossible to ascertain the impact of these events.

Concurrent with the study has been a concerted effort on the part of boards, trade unions, and student unions to lobby government about the funding crisis facing the British Columbia post-secondary education system. The time has been described as a crossroads for education and has prompted an advocacy alliance among the players which is virtually unheard of in British Columbia. This initiative may have had an affect on the study. While some 
boards may have seen the study as an opportunity to further express concerns, others may have seen it as the less important of two tasks and declined to participate. Again, it is impossible to quantify the possible impact.

In the period of follow-up to initial returns of questionnaires, when board members who had not participated were being encouraged to think again about doing so, Canada was faced with the prolonged threat of a postal strike. Ultimately, the strike did take place and lasted seventeen days. This may have had some negative impact on further participation. An alternative method of returning questionnaires by fax was initiated but may not have been convenient for all potential respondents.

Finally, it must be recorded that the researcher's closeness to the subject matter through his employment may have influenced the choice of some board members to participate. In this regard, separation of the roles of research and employment was stressed as much as possible to the potential participants in all correspondence and material pertaining to the overall study and questionnaire.

\section{Specific Terminology}

For the purposes of this study, the undernoted terms are defined thus:

Shared governance: a structure of leadership involving employees and students as well as provincially appointed trustees which has full, legislated decision-making powers in defined situations. 
Post-Secondary Education Institutions: colleges, university colleges, institutes, and universities. Note, this study was confined to the first two institutions and one example of the third. In the study, they are often referred to collectively as colleges, unless some distinction is to be made.

Board: a body empowered by the College and Institute Act of British Columbia to govern an institution in prescribed areas.

Education Council: a body of employees and students empowered by the Act to govern and administer in an institution other than a university in certain prescribed areas and in others at the discretion of the board.

College and Institute Act: legislation which establishes and regulates postsecondary institutions in British Columbia with the exception of universities. Bill 22: the amendment to the Act which introduced and specified shared governance.

Appointed Board Member: a member of the community, who is not an employee or student, appointed to the board by the provincial government.

Elected Board Member: an employee (faculty member or support staff member) or student who is elected to the board by his/her constituency.

Constituency: the sector of the college population or the general community from which a board member has been appointed or elected or qualifies for an exofficio position on the board.

Constituent: an appointed, elected, or ex-officio board member who has been drawn from one of the six constituencies noted in this study, i.e. government 
appointed lay persons, faculty, support staff, student, president, or chair of the education council.

\section{Organization of the Study}

Chapter I contains the statement of the problem, the background of the problem, the importance of the study, the purpose of the study, the conceptual framework within which the study was constructed, the research questions to be examined, statement of the hypotheses, assumptions of the study, delimitations of the study, limitations of the study, and specific terminology used in the study. Chapter II contains a review of literature including the definition of shared governance, description of the background to the development of shared governance, discussion of the issues surrounding shared governance, and the advantages and disadvantages of shared governance. Chapter III contains a methodological overview, the research design of the study, discussion of the validity and reliability of the data, entry to the population participating in the study, selection of the sites and subjects, protection of the subjects, approach to the data analysis, and background of the researcher. Chapter IV contains presentation and discussion of the findings of the study including focus on the descriptive statistics, comparative statistics, and the practical significance of the study. Chapter $V$ contains the conclusions, i.e. the relationship between the hypotheses and the findings, and the recommendations regarding 
implementation of the findings and suggestions for further research. The main chapters are followed by a reference list and appendices containing documentation used in the study and the tabulated analysis of the raw data obtained from the questionnaires. 


\section{CHAPTER II REVIEW OF LITERATURE}

\section{Introduction}

Shared governance in a broad sense is a popular topic for discussion and study. It ties into contemporary views on leadership as they move away from models of exclusiveness, the great man theories, towards models of inclusiveness and collaboration. In addition, there are obvious links to the quality movement based on the premises that an organization will be more effective through shared decision-making, and the individual participant will be more motivated through a sense of contribution and belonging.

The sharing of powers traditionally held in an organization by the board and the chief executive officer is occurring throughout the public and private sectors to varying extents. The experience in education differs somewhat in that the university sector has a long tradition of limited shared governance which stems more from the culture of a community of learning than other organizational cultures. The school and college sectors have gradually followed the university path with accelerated progress occurring in the last twenty-five years but with the fundamental difference that these sectors have, at the same time, become unionized to a far greater extent than their senior counterpart. This potential clash of cultures provided a strong undercurrent in this study as the sharing of 
power among participants who have a history of confrontation was explored. The decision-making tasks of boards fall into two categories, those where internal and external members have no particular vested interest and those where the internal members would appear to have vested interest on account of their employee or student status. The former may still cause tension between internal and external members if power sharing and decision-making procedures are not carefully planned. However, the latter will almost certainly cause tension unless the real or, at least, perceived conflict of interest on the part of the internal members is handled in a way which is satisfactory to all board members.

Boards and senior management traditionally play significant roles in the financial affairs and labour relations of an organization. This is especially true in the education sector. Shared decision-making in these areas would appear to take on far greater significance with the likelihood of conflict than, say, curriculum or student affairs where the locus of ownership is not so fiercely contested.

This review of literature explored the views and experiences of educators and governors in shared governance models across North America. It focused on the research questions which were posed in this study:

1. Is there a difference among British Columbia colleges in certain aspects of boardsmanship, namely the sharing of power, the effectiveness of the shared decision-making process, and how real or perceived conflict of interest of employee and student board members has been addressed 
when it comes to decision-making in respect to general matters of business, financial matters, and labour relations matters?

2. Is there a difference among board members, according to the constituency from which they are drawn, i.e. appointed members; elected faculty; elected support staff; elected students; presidents; and education council chairs, in certain aspects of boardsmanship, namely the sharing of power, the effectiveness of the shared decision-making process, and how real or perceived conflict of interest of employee and student board members has been addressed when it comes to decision-making in respect to general matters of business, financial matters, and labour relations matters?

3. Is there a difference between the views elicited from this study and those from an earlier study in respect to certain aspects of boardsmanship, namely the sharing of power, the effectiveness of the shared decision-making process, and how real or perceived conflict of interest of employee and student board members has been addressed when it comes to decision-making in respect to general matters of business, financial matters, and labour relations matters.

The information derived from the literature was intended to provide a backdrop to the drama of shared governance and to offer experiential insight and opinion on the aspects of leadership in three contexts of decision-making under review in this study. 
This chapter contains the definition of shared governance, background to the development of shared governance, discussion of the issues surrounding shared governance central to this study including a general perspective and those of financial affairs and labour relations, and the advantages and disadvantages of shared governance. The issues of a general perspective discussed include roles to be played, influence of the president, consensus and representation, the scope of involvement in shared decision-making, an advisory or decision-making role and the impact on middle managers, structures and relationships, the importance of shared governance for students, and faculty and support staff attitudes.

\section{Definition of Shared Governance}

Shared governance is not a precise science with universal application. It is a sharing of power brought about by changing processes to suit the culture of the organization and, thus, will differ accordingly in terms of approach, expectations, and outcomes. Lovas (1984) noted that "...shared governance is both an opportunity and a risk...[it] truly means shared responsibility and authority but not necessarily equally shared power or decision-making" (p. 22). Therefore, it is immediately noted that there is no standard approach. Draper and Van Groningen (1990) suggested that there is quite a range to the degrees of power sharing: 
There are many definitions of shared governance circulating in the field. At one end of the continuum are formalized structures of process and procedure; at the other end are largely informal and simple means for getting people involved in decisions. Leadership styles are often the key, but district history - particularly with collective bargaining - seems to play a major role in determining to what extent shared governance is formal or informal, and to what extent it can succeed. (p. 11)

This issue of formal/informal structure, often expressed as the right to make decisions versus the right to offer advice to those who would make the decisions, is an important one which will be explored later in greater detail.

Reil and Soderman (1993) noted the underlying philosophy upon which shared governance is founded:

Wisdom and common sense tells us that decisions based on shared values and made by the stakeholders in those decisions who are responsible for acting are going to have more commitment and chance of success than those that don't. Along with common sense, there is a good deal of research, both in and out of schools, that corroborates this basic tenet. (p. 2)

Accordingly, decisions made by those most affected and grounded in common values are likely to be successful. Wood (1991), in a study of internal board members in a shared governance model in a college system, found "Most institutional members and the presidents of their associations considered the 
composition of their boards to be an important reflection of values and beliefs about collegiality, participation, and professionalism in higher education organizations" (p. 360). Inclusion of interested parties is one thing, arriving at common values may be another. Inevitably, a sharing of power brings together players of disparate backgrounds and beliefs, not to mention goals and objectives. For a decision-making model to function under these conditions, there is a fundamental requirement that trust pervade the entire culture. This was noted by Draper and Van Droningen (pp. 12-13) and many other authors. Bogen and Moskus (1992) compared shared governance to a marriage and suggested both require to be "...a relationship based on a strong commitment, mutual support, shared understanding of roles, honest communication, and trust" ( $p$. 11).

The values of shared decision-making are consistent with those of progressive educational institutions. Later in this chapter, the correlation will be noted between student success, faculty satisfaction, and the sharing of power. Mahon (1994) drew the comparison between shared governance as a process and total quality management as a process of continuous incremental improvement based on the Japanese concept of Kaizen. However, he noted "I cannot stress enough that TQM and shared governance are processes. They are not quick fixes" (p. 9).

Education is not a static entity. Education is about change. Freire (as cited in Harris, 1996) described education as an agent of action as opposed to being a 
simple provider of knowledge, for its own sake. In this vein, Rost (1993) opined that shared governance is leadership that leads to real, intended change, while management is more about efficiently and effectively maintaining the status quo. This notion of change and innovation being linked to shared decision-making is further supported by Lau (1996), "The need for shared governance is not as great when resources are available to support the majority of the program requests" (p. 5). Therefore, the need for innovation when times are tough can be met through the collaborative governance structure. From this, change can be brought about because of the stakeholder inclusiveness. Such change is often not dramatic but, rather, is a gradual process of building small success stories, one at a time. In due course, systemic change can occur incrementally through participative decision-making (Lappe and DuBois, 1994).

It has been seen that shared decision-making can exist in different forms and is generally reflective of the organization's established culture. The differences that exist between universities, where shared governance is firmly established, and schools and colleges, where it is still in the process of being established, were explored. Clearly the cultures of these educational subsectors differ and this may have significant affect on the sharing of power. Southern Methodist University (1979) observed in a report that governance of universities is unlike that of corporations in that power tends to reside in the faculty and is directed upward, whereas, in the latter, power resides in the board and senior management and is directed downward. This very unique climate of universities 
might be considered to readily facilitate the concept of shared governance in an informal sense and even encourage its formalization. It was found that colleges and schools are considered more akin to corporations than universities in their governance structure, and hence the experience of sharing differs accordingly.

\section{Background to the Development of Shared Governance}

\section{Institutional Planning and For What?}

"Shared governance may be the only way to restore order, tranquillity, and morality in our public institutions" espoused Thomas (1979, pp. 1-2). He then went on to list the characteristics, and not from a perspective of strengths, of institutions as seen by social scientists:

1. Most of our public institutions, once established, tend to spend a great deal of time and money to maintain themselves;

2. Public institutions, in their concern to maintain themselves, tend to forget their original purpose for which they were established;

3. Leadership in public institutions has a tendency to forget that the institutions were set up to benefit clients and not the personal goals of their leaders;

4. Public institutions, like schools, tend to create conflicting interests between teachers and administration; 
5. Accountability in public institutions is difficult to achieve; and

6. Public institutions talk a great deal about equity and justice but have difficulty establishing it.

Munitz (1995) found that views of educational institutions have not changed much from those of public institutions fifteen years on. He stated "Surveys show that voters in many states now view public colleges and universities much as they do other public agencies: self-regarding bureaucracies wasting too many taxpayer dollars" (p. 10). Is this a system swaying on its philosophical and moral principles? By adjusting the locus of power and decision-making, can the foundation principles be reinforced? There is strong suggestion that decisionmaking based on consensus of all stakeholders tends to be more ethically principled than when based on power alone. Whether the introduction of shared governance does begin to address the systemic shortcomings leveled at education were further explored.

Decision-making is an important contributor to the climate of an institution. Roueche and Baker (as cited in Deas, 1994) noted that it ranked along with leadership, motivation, and communications as the keys to a climate for excellence. Thus, it is suggested that the model of decision-making is crucial to achievement of excellence. Many of the shortcomings attributed to education are to do with its inability or unwillingness to engage in long term planning. The historically short tenure of college presidents probably precludes their adopting anything other than a short term perspective, suggested Boggs (cited in Baker, 
1995), however, boards could and should be able to take a long term view in institutional planning (pp. 33-34). While the apparent favouring of short term, multi-directional goals may also be the result of a lack of governmental commitment and consistency, it tends to reinforce the notion of educational selfcenteredness. Phelan, Kirkland, and Freed (1993) cited six areas of inhibition towards long term institutional planning:

1. A majority of institutions plan from year to year rather than for long term. Crisis management becomes the norm. No formal mechanism integrates departmental or institutional efforts;

2. The external environment is evaluated infrequently...and the institution does not have the broad view necessary to make appropriate decisions. Leaders may be unaware of external factors posing threats or offering opportunities;

3. The internal environment is seldom assessed. Thus, the institution is unable to identify its own strengths and weaknesses;

4. The relationship between institutional resource allocation and goals is commonly ignored. Consequently, the institution is unable to respond to emerging needs;

5. Institutions often evaluate their performance on revenues and expenditures, encouraging spending rather than working to achieve goals; and 
6. Institutional mission statements are not used to guide the organization. Rather than providing a pragmatic guide for the future, mission statements simply adorn college catalogs and presidential offices. (p. 3).

The need for change within an institution frequently comes from external pressure, and a commitment to long term and strategic planning affords the institution the opportunity to control and influence the change. This would appear to suggest a likely correlation between a commitment to planning and a shared governance structure made up of those who will be affected by the change. Thus, the governance structure may itself be seen as the change agent. However, Dennison (1994) noted that colleges do not historically have well established shared governance structures. This is due to colleges having their roots in the public school system, as opposed to the university system, with the consequent lack of professionalism among the faculty and a preponderance of trade unionism (pp. 32-33). This absence of tradition in shared decision-making was strongly suggested by Giles (1981) as contributing to ineffectual college boards. She opined that external, lay board members lack the investment in the college enterprise and are not prepared to spend the time necessary. "Good governance is a full time job" (Giles, p. 22). Wood (1991) concurred with Giles' view, "The power of the boards of governors is limited by a number of factors such as their part-time involvement, the expertise of the presidents, and the 
technical nature of the decision-making. A number of research studies conducted in a variety of settings support this analysis" (p. 333).

The message that emerged, therefore, is that colleges have not been seen as strong on long term planning because of several internal and external factors. Boards were viewed as being capable of adopting the necessary long term view, however, authors tended to doubt the boards' ability and commitment, especially in the 1970's and 1980's. It was evident that the arrival of shared governance, with the inclusion of committed and knowledgeable internal members, was seen as the way to bring about improvement of institutional planning performance.

\section{A Climate of Confrontation.}

As a concept, the sharing of governance is relatively simple. Where the difficulties appear to develop is how it is perceived, and how the participants choose to behave. Rather than a sharing, there is much to suggest that governance changes represent more of a shift in power. This was noted by Lovas (1994) and as faculty and administrators both perceive the shift, and corresponding gain/loss of power, the author questions whether true sharing is ever possible. Mitchell, Grant, and Rossa (1992) also acknowledged the shift in power but suggested that there are mutual obligations among boards/administrators and faculty, "Those in positions of power need to let go of 
their concentrated authority, and those newly participating need to look at problems and solutions from a college wide perspectiven (p. 21). The notion of ownership in decision-making in specific areas, e.g. curriculum for faculty and budget for trustees and administration, and the reluctance to concede it is center to the power struggle noted by many authors including Edelfelt (1982) and Kanter (1994).

It would appear that a sharing of decision-making, perhaps presenting a win-win situation to the confrontationists, is more likely to occur in an informal setting rather than under prescriptive legislation. Kanter (1994) observed that the early 1990's experience among community colleges going through the development of shared governance in California was that "...when behaviour is legislated, issues become polarized and often much more complicated than they were originally envisioned" (p. 229). Certainly, as noted by Lovas (1994), rigidity of positions is the antithesis of effective power sharing ---"Blessed are the flexible, for they shall not be bent out of shape" (p. 14). This holding of power is often effected by committees with specific responsibilities. As a result, they tend not to acquire a big picture perspective but, rather, jealously hold onto their authority in a narrow context. Acebo (1992) suggested that colleges are not by nature collegial:

While the concept of a team is easily grasped, and most people have experienced at least some aspect of the power of the team, the collegial setting has precious few of them. Instead, colleges generally have an 
abundance of committees, and committees are not teams-nor are academic divisions, administrative cabinets, and boards of trustees. (p. 9) This lack of cohesion frequently leads to confrontation between groups on campus. The "...turf wars between governing boards, senates, and unions" was an example of confrontation cited by Nussbaum (1995) where overlapping interests collide. This tension will be further explored in the context of decisionmaking in a labour relations environment.

What is the nature of the traditional college and school governance and administrative structures that it makes it seem so difficult to change? Reyes and McCarty (1986) observed that while educational institutions are sometimes seen, and this is an image which they themselves encourage, as a community of scholars in which governance is shared, this is more true of universities than colleges and schools. The latter are quite bureaucratic in nature, particularly where there is a heavy union presence (pp. 1-24). This observation was echoed by Piland and Butte (1991, p. 6).

The main characteristic of a bureaucracy is a power base founded on a top/down principle, where decision-making resides at the top and involvement of others is generally on an advisory basis if there is a role at all. The notion of a community and its involvement in governing the institution is not prevalent in a bureaucracy:

The concept of community within the institution of higher learning cannot survive if the power of administration is thought of as a supreme echelon 
in a hierarchy of authority. If the concept of hierarchy is acceptable within a college, the administration becomes the fount of authority from which faculty, students, and alumni draw their respective roles and under whose direction and control all activity is performed. Such a concept of authority...is alien to the great social purpose of higher education and does not conform with the facts of academic life. On the other hand, when the power of administration is conceived as a constituent element of a community of power, then the functions of that power are more definitely prescribed, and the limitations of that power are more clearly understood. (Mann, 1968, p. 2)

Thus, the concepts of community, consensus, and social purpose are established in contrast to the absolute power of a hierarchical bureaucracy. Furthermore, Lau (1996) noted, "Genuine involvement produces identifiable results capable of providing satisfaction separate from the decisions themselves. The results are then the product of the whole, and accountability to the affected groups are from those groups that were involved in the process. The interdependency of the relationships within the organization maintains a state of balance between the competing groups" (pp. 3-4).

Notwithstanding the common good that may be seen to derive from shared governance, there remains the clash of confrontation and consensus seeking. While the latter is noted as the academic way by Polishook and Naples (1989, p. 2) and provides the foundation to the shared governance model, a 
stark anomaly can occur when it is situated in a confrontational unionized environment. The anomaly is that faculty and support staff players may be called upon to simultaneously adopt positions of opposite value, consensus in decisionmaking and confrontation in collective bargaining.

In this tense arena of alternating collaboration and confrontation, one common theme pervades the literature as being absolutely essential to the success of shared governance. That theme is trust. Its importance is constantly stressed, and yet its absence is frequently noted with sadness. Mitchell, Grant, and Rossa stated "...shared governance depends upon trust, a trust that is best built upon positive experiences with the process and a sincere conviction that the advantages of having the best minds collectively steer a course for the college far outweigh any disadvantages, real or imagined" (p. 22). However, the doubts exist. Dennison (1994) observed that questions of conflict of interest and the relationship between internal board members and the constituencies from which they are drawn are so often raised without satisfactory answers as to seriously undermine the shared governance structure (pp. 26-27). Indeed, Nussbaum (1995) found, in a study of the views of both college presidents and senate presidents, that neither believed that trust and cooperation had been enhanced with the advent of the shared decision-making model (p. 24). Furthermore, Trani (1997) suggested that the ongoing, perhaps escalating, tension that has been associated with shared governance has caused noticeable weakening of the institutional presidency. "The authority of the university and college presidents is 
being undercut by all of its partners--trustees, faculty members, and political leaders" (p. 16).

Wirth (1991) also identified the potential weakness in participative decision-making that exists because only relatively few faculty and staff are likely to have lead roles and thus, they have the opportunity to impose their own will,"...it is all too easy to take advantage of the power vacuums which temporarily exist in the early stages of shared governance and impose one's own view without appropriate consultation with other faculty" (p. 4). Even in a climate of consensus seeking there may exist, therefore, the natural tendency to assume individual power. Several authors, including Nussbaum (1995), suggested the need for institutions to develop a code of ethics to guide the behaviour of participants (pp. 57-58). While this may appear to go against the desire to avoid prescriptive legislation noted earlier, it may be the answer. For, it is clear that the internal constituents of colleges--administration, faculty, staff, and students-are not necessarily natural partners. A history of confrontation and the continuing tension of industrial style labour relations may mean that it will take more time than regulations, or perhaps a combination of the two, before the necessary trusting relationships between the traditional appointed or elected boards of governors are established. 


\section{State/Provincial Centralization of Boards' Responsibilities.}

A third and final setting to be considered in the issue of shared decisionmaking at the institutional level is the amount of actual decision-making that is possible. During the period of the last twenty five years of local democratization, there has also been a change in the relationship between institutions and states/provinces. Hodgkinson (1974) noted two important shifts, the effect of each moves in the opposite direction "...students began to be included on faculty senates and other campus-wide decision-making bodies, as well as on boards of trustees, [while] more and more decision-making power was taken over by statewide coordinating agencies and influenced by legislative politics" (p. 1). Piland and Butte (1991) discerned from trustee views concerns about the trend towards state centralization of decision-making, particularly where it concerned funding schemes. Cohen (1996) noted the differing impact of this centralization tendency on various areas of decision-making:

As the states become more involved with college policies, gaps in interinstitutional cooperation will be filled and criteria for student matriculation and progress will be set. These pressures will result in efforts to micromanage the administrative functions of community colleges, but they will have minimal effect on classroom instruction and student services The thrust of state-level coordination focuses on reporting, compliance with 
regulations, and accountability for numerous aspects of institutional operations. (p. 2)

Stevens and Piland (1988), in a study of Californian educators, noted further concern at the local level about the degree of centralization in general and in specific areas of decision-making. They recorded strong disagreement with the suggestion that the California community college system should be administered as a unified system by a state board. While there was agreement that the state should establish uniform systems of budgeting and accounting for local districts, there was strong disagreement that the state should have comprehensive authority with regard to academic affairs. It is interesting to note that trustees had stronger opposition to centralization than presidents, but both groups were agreed on the locus of responsibility and authority:

The concept of increasing state control...is opposed by the locally elected trustees, and to a lesser extent, the colleges' chief operating officers. However, both groups want the state board to assume a considerable amount of accountability and responsibility while authority is maintained at the local level. (pp. 255-259)

It would appear that the trend towards centralized decision-making has occurred in the areas which have tended to be the purview of trustees and administration at the local level and which faculty, staff, and students sought jurisdiction over in the call for shared governance. Dennison and Gallagher (1986) observed in the Canadian case that colleges have never really enjoyed the degree of 
independence associated with the universities, “Canada's colleges have never fully been the master of their own destiny. Since their inception, the degree of their mastery has steadily declined, with the power and influence of provincial and federal governments gradually became more dominant" (p. 189). This centralist tendency has become even more prevalent in British Columbia in the 1990 's and is one of the undercurrents which was examined in this study in relation to shared decision-making. Dennison and Gallagher were in no doubt about the limitations of college board decision-making power, irrespective of the boards' composition, and the dependency of the boards upon the two levels of government:

Power and decision-making authority are a serious business to and for Canada's colleges. Both their current effectiveness and their potential are intimately connected to the relationships that will be established between both levels of government and the institutions. However college board membership is determined, and whatever powers these boards may acquire, in the final analysis, the colleges are instruments of governments which have created and supported them. What confidence provincial governments place in college boards, and how the two levels of government work out their relationships as they pertain to post-secondary education, will surely have a major impact on the future direction of colleges in Canada. (p. 194) 
It is clear, therefore, that college boards in both the USA and Canada have experienced a gradual but definite diminution of their authority and scope of decision-making. This shift in power has coincided with the development of shared governance and, consequently, has left the more democratically represented boards with less room in which to exercise that democracy. There is no particular evidence to suggest that boards consisting of internal and external members are better suited to establish effective relationships with government, than were the former boards consisting only of external members. However, the forging of relationships with government, given the systematic centralization of decision-making power, is absolutely necessary to maintain the status of the colleges, and the task appears to have fallen on the chief executive officers. "Presidents must take the lead both in communicating frequently with legislators at the local, state, and federal levels and in keeping the board members aware of the important legislative issues" (Boggs, 1995, p. 33). The literature would appear to suggest that the advent of shared governance might have resulted in a weakening of the powers of the presidency within the colleges but a corresponding strengthening of those powers outside the colleges. 


\section{Discussion of the lssues}

\section{Shared Governance in General}

\section{Roles to be Played}

Shared governance involves individuals coming together in specific groups such as the board of trustees, traditional administrative groups, and multirepresentative groups such as senates. The movement away from exclusive decision-making bodies, usually involving only trustees and senior administrators (the corporate management structure) to bodies incorporating all stakeholders in an educational institution is dramatic and likely to be chaotic. "Although trustees may have backgrounds in private business, they will soon realize that colleges cannot be run like private business enterprises" (Nason, cited in Boggs, 1995, p. 35). This is because of internal and external restrictions. Internally, constituent groups such as faculty and students have a traditional interest in being involved in decision-making. And, externally, "State/[provincial] and federal laws restrict the freedom of judgment of both the president and the board" (Boggs, 1995, p. 35). Mitchell, Grant, and Rossa (1992) also differentiated between participatory business management and shared educational governance, with the latter involving more extensive structures, more formal roles, and the sense of right-tobe-there held by the participants--the faculty, staff, and students 
(p. 21).

Shared governance, as has been frequently noted in this review, is viewed as a natural progression in colleges and schools. It is considered logical that the time honoured practices in the universities should flow down to the junior branches of education. Furthermore, this sense of impending destiny contrasts somewhat with moves towards participatory management in the business sector which are very much at the discretion of boards and senior managers. However, Baliles (1996) suggested that the transition to shared governance in colleges is still much dependent on the philosophy and actions of the presidents (p. 11). The influence that presidents can exert starts to shape the governance model into a functional structure. Lau (1996), drawing on the California community college model, illustrated such a structure:

All policies and most of the strategic decisions flow from the board of trustees to the president/superintendent for implementation. The president/superintendent interprets the policies and, with the approval of the board, allocates resources in order to operationalize the strategic plans. Decision-making and power on both these levels, policy making and operations, are shared among several competing groups. (p. 2) This pivotal role for presidents is interesting and contrasts with the views of Trani (1997), who posited the weakening of the presidencies as a direct result of shared governance (p. 16). Lau further noted the requirement of boards that they develop policies and guidelines which provide senates with the mandate and 
strength to "...administer academic and professional standards, course approval and curricula, and other academic matters" (p. 7). Nussbaum (1995) expanded on the senate role in states where it is only nominally advisory to the board. He suggested that boards should "...consult collegially with senates on academic and professional matters and, while the boards make the final decision, they should rely on the advice and judgment of the senates" (p. 10).

The volatility of the educational environment and the strong expectations of inclusiveness held by the constituency groups has been recorded extensively. Hence, there is considerable support in legislation for the need for clarity and definition of roles. Both Hodgkinson (1974) and Allen (1991) emphasized the need for clear enunciation of what the participants in a collaborative structure are supposed to do, and perhaps more importantly what they are not required to do. The latter noted that "...administrators and teachers are not accustomed to this type of [shared] governance and it is hard for them to function in new, often unprecedented roles in their schools [or colleges], and easy to fall back into traditional, familiar roles" (p. 13). Lovas (1994) noted the important distinctions of authority and responsibility/accountability and stressed the need to identify who had what in a structure. The consequence of failing to do this is likely to lead to unclear decision-making steps and a lack of ownership in the results.

Mitchell, Grant, and Rossa (1992) cited the first step toward shared governance as the "...delineation of the roles, responsibilities, and relationships among all the major committees involved in the governance of the college" ( $p$. 
21). And yet, while delineation is called for, there is frequent reference in the literature to caution against prescription of shared decision-making procedures. However, Allen and Glickman (1992) continued the call for clarification, "Shared governance is an elusive process with many pitfalls. Participating schools [and colleges] must first define the process and identify the players and then clarify and resolve the issues" (p. 80). Baliles (1996) echoed this need and suggested it be done sooner rather than later (p. 11). Moreover, and not for the first time in the literature, he identified the presidents as playing a key role in the delineation process, noting "...[they] should lead the board and faculty through a process of clarifying the precise nature of shared governance on each campus and reducing ambiguities in authority and decision-making processes" (p. 8). The complexity of educational governance has been stressed over and over again and is at the root of the apparent need for clarification of roles in order to make shared decision-making successful. The nature of that complexity is never more evident than in the relationships between boards, senates, and trade unions, the latter particularly in the case of faculty unions. Sumner (1991) advocated the necessity of developing policy which clarifies processes and roles in relation to governance, administration, and collective bargaining. She observed the potential overlap of interests but highlighted the need to prevent discussion of a matter spilling over from one arena to another with the possible outcome of unofficial views and even unofficial decisions emerging. Seitz (1993) echoed this sentiment and suggested that such clarification must be openly articulated in 
formal documents like policies or memoranda of understanding to which all parties have agreed.

Kanter (1994) noted that "...the institutional challenge--is for administrators and faculty both to identify specific areas of responsibility and authority before decisions are made and actions are taken" (p. 230). However, Allen and Glickman (1992) offered that the very tendency to want to avoid being prescriptive on roles and procedures is what leads to dysfunctional boards in the educational system (p. 80). Dennison (1994) observed in the Canadian context that, where provincial ministries have declined to develop detailed regulations on shared governance and have left it upto individual colleges, they have ended up with quite different models from institution to institution (p. 27). Whether clear role definition can be achieved at the local level on a voluntary basis is questionable. Deas (1996) suggested that shared governance is more likely to be effective where it is legislated at the state/provincial level with prescribed roles for the players and built-in controls to prevent ambiguity and turf wars.

Piland (1994) offered that true sharing of power is only achieved when the board of trustees and the senate can come together in a joint decision-making role. However, Hodgkinson (1974) noted the traditional differences: ...relationships between boards and senates are quite confused and often threatening to both sides. Board members often may see the senate as a group attempting to wrest power and authority away from the president. The senate, on the other hand, may see the board as a distant, unthinking 
group of businessmen[/women] who get together only two or three times a year and try to solve all the institution's problems on the basis of that limited exposure. (p. 147)

The Academic Senate for California Community Colleges (1996) underscored the tension between the disparate players. It expressed particular caution around the acceptance of advisory governance councils in place of what it saw as the legitimate decision-making roles of the academic senates and faculty unions within their respective jurisdictions. Moreover, the suggestion was made that senates and unions should engage in active collaboration so as not to be undermined by boards, administrations, and advisory councils (p. 4). This call to arms very much resembles the strategy adopted by unions in British Columbia around the introduction of shared governance in colleges and university colleges and which provided a backdrop to this study.

Piland and Butte (1991), in a study of trustees, noted a strong view that boards should not be involved in college administration. In a deeper analysis, they concluded that elected trustees have a tendency to want to get more involved in administrative matters than do appointed members (pp. 9-10). In another study of trustees' views, Deas (1994) found that boards described their role as "...rubber stamping the work of the administrators. This was not intended in a negative context, but reflected the high-level role of trustees and their trust in administration..." (p. 47). Such a relationship was possible through "...the existence of well designed policies...to steer [ board and administration ] through 
the processes of management" was noted by Jasiek, Wisgoski, and Andrews (cited in Deas, 1994).

In summary, the potential acceptance and success of shared decisionmaking processes seems, on balance, to be dependent upon a clear set of definitions as to roles and procedures. There is, however, much discussion around a prescriptive, top down approach to this need for clarification with a lot of support for development of the guidelines at the local level, among all the players. The college president is seen in an important leadership role in this context. On the other hand, much has been written about the widely differing models, and differing success rates, that emerge when state and provincial governments do not set minimal standards.

\section{The Influence of the President}

The change that is shared governance is an example of leadership. And leadership, even if it involves all stakeholders, is directly associated with the beliefs and actions of the college president or school principal. Gulassa (1989) noted that leadership which inspires others to outperform is determined by the style of the CEO. Edelfelt (1982) observed "...that programs [of teacher involvement] in schools in which principals were not supportive were not making the progress [towards shared governance] that schools with supportive principals were making" (p.7). Thus, the importance of leadership from the top towards 
sharing of power was identified, albeit in a collaborative manner as noted by Hackmann and Berry (1994), “...while top administrators cannot create effective change by themselves, they can and must be an integral part of the process as they facilitate change" (p. 2).

The role of the president is obviously crucial in the transition to shared decision-making. His/her own characteristics play an important part in this. The president is clearly aligned to the board of trustees, indeed Deas (1994) noted that trustees view their president as a colleague first and an employee second. The president can also be seen as a catalyst in change of governance. A smart president will, however attempt to hone him/herself as an educational leader and, consequently, an ally of all the constituents-faculty, staff, students, and fellow administrators. This is, of course, not an easy task and speaks to the necessary juggling skills of the ringmaster in the educational circus.

One of the considerations of power sharing explored in this study is the financial stewardship context which is commonly associated with the board of trustees and may appear to be much sought after by faculty, staff, and students. He who holds the purse strings holds the real power. Here, the president's role in change is not so clear as Deas (1994) found that "...while trustees noted that faculty are less desirous of being involved in fiscal management but seek the sort of assurances that the board can provide...vice-presidents felt that the buck stopped with them and not the president" (p. 48). Perhaps this confirms that presidents are not natural financial leaders (Wood, 1984 and Taylor, 1988). In 
any case, there is clear suggestion that internal constituents often view the advent of shared governance as the opportunity to get into the budget but do not relish the role if they are given such authority, particularly when it comes to setting priorities for budget cutting.

One important consequence of the move towards shared governance, noted by Lovas (1994), is the frequent elimination of the president's cabinet or similar group of senior administrators which commonly had a key role in administrative decision-making. The impact on these players and how they have responded will be examined later in this review. In addition, the elimination of a close circle of advisors has affected the behaviour of presidents They are now required to be far more consultative and open to other views, and this has called for a different set of leadership skills. In some cases, presidents have been very successful in broadening the consultative and decision-making base while at the same time serving as the titular head of the college. However, in other cases, presidents have grown to feel isolated, with no close allies, and have tended to withdraw from the leadership role in deference to the various constituency bodies which have legislated power and authority in the institution.

\section{Consensus and Representation}

Most contemporary writings lean toward a decision-making structure that is collaborative and constructive rather than a top down authoritarian structure 
where final decisions rest with a few high ranking individuals or even just a board and president. It is important in this new democracy to create the right kind of inclusive environment. Hunt (1984) noted "...there is a growing body of literature which stresses the importance of social context rather than personal characteristics as the main influence on the outcome of social interactions" ( $p$. 170). The creation of such an environment where individuals can contribute to the common good becomes the responsibility of those formerly looked to for exclusive decision-making. "The essential task of management is to arrange organizational conditions and methods of operation so that people can achieve their own goals best by directing their own affairs toward organizational objectives" cited Mann (1968, p. 3). Those organizational objectives, the common good, are a powerful issue in determining the effectiveness of any shared governance model. Lau (1996) stated it plainly with reference to his institution, "Compton Community College was founded for the benefit of society at large, not for the benefit of professors, administrators, students, trustees, or any grouping of constituents. As a result, the governing board represents the public at largen (p. 9). This calls for a coming together of board members in spite of their differing constituencies, social statuses, and values. Seitz (1993) also seemed in no doubt as to the simplicity of the requirement to surrender personal agendas in favour of the common good:

Board members must subordinate personal interests to those of the institution. That stance is essential. The fiduciary relationship in board 
affairs hold members to a standard of good faith and honesty in their actions. Persons reluctant to comply with that standard should seek another pastime. (p. 8)

Alas, despite the calls for board members to act as one, the individualism that many exhibit is probably the greatest knock against shared governance and goes hand in hand with the omnipresence of allegations of conflict of interest. In that respect, therefore, the tendency toward individualism is more often directed at the internal board members-faculty, staff, and students. "The definition of individualism offered by Bellah, Madsen, Sullivan, Swidler, and Tipton (1996, p. 334) where reality or prominence rests in the individual as opposed to the greater society can be applied to a board as a corporate entity representing the larger community but with its members embarking on personal agendas" (cited in Deas, 1997, p. 2). As a result of this behavioural tendency, "...the common good that is the object of a board is sacrificed by an individual member in favour of narrower, more personal values, a tendency which has been observed by Buber (1985)" (cited in Deas, 1997, pp. 2-3). Individualistic behaviour by board members, whether it be the pursuit of personal agendas or the hoarding of power for whatever reason, seriously undermines the effectiveness of a college board. The opposite of individualism, and the ideal state for a functional board, is a group of board members exhibiting relative neutrality. Relative neutrality is seen as the position of compromise that is proposed as the overlapping of self interest and participation stewardship (Abascal-Hildebrand, 1997) and the mean 
of the extremes of excess and deficiency noted by Aristotle over 2000 years ago (cited in Deas, 1997, p. 5). If the charge of individualism that is directed against internal board members is valid, what does it say about their motives? Do they join boards with the express intention of disregarding the group culture in favour of their own objectives? Deas (1997) believed that, generally, there was no overt intention toward individualism but, rather, a tendency on the part of some internal members to fail to recognize the group culture which is directed toward the common good. As a result of this, there is an almost inevitable tendency to lean toward what they know best which becomes something of a personal agenda. "...boards are tending to look upon that kind of virtue of boardsmanship [receptiveness to change] much in the same way as the crew observed Plato's sea captain. They see it but they do not understand it and, consequently, they revert to what they are comfortable with, which in the case of the elected [internal] members are the narrow, short-term issues that most directly affect them and their constituencies" (p. 8).

Are faculty, staff, and students interested in contributing to the common good of the institution? Senge (1996) predicted so with the observation that "...deep within us is a tremendous longing to understand how wholes work. The inability to understand wholes is damaging and dangerous." Hodgkinson (1974), similarly, placed value on the community of decision-making when he noted the direction of senates: 
The campus senate operates on the apparent assumption that faculty, students, and administration can best make decisions in a communitarian environment with each group represented. (p. 4)

Consensus based decision-making may not just be more effective, there are those such as Thomas (1979) who believe that it also upholds ethical principles while exclusive decision-making based on power tends to violate such principles. And yet, clearly, shared governance is steeped in politics and that is not a subject which is generally associated with ethics. The very creation of shared decision-making is generally a politically motivated act, often government initiated in response to pressure from unions and associations of faculty, staff, and students. Moreover, the behaviour of internal and external board members, especially when it is sufficiently polarized to be differentiated, is characterized as political. Boggs (1995) noted that arguments can be made that appointed external members are inherently less political than elected external members and internal members. However, such appointments are generally themselves of a political nature, a reward for services rendered to the party or administration in power (p. 29). Wood (1991), in a study of internal board members, concluded that participation in the governance process is political in nature by all standards of organizational politics literature. Members' behaviour may be influenced by social characteristics, the power of presidents, and expectations of the role but, nevertheless, the strongest factor was the constituency from which they had been elected (abstract, p. 2). 
One of the most important aspects of shared governance, and one which is frequently among the most contentious, is whether members of college-wide decision-making bodies should represent the constituency from which they have emerged or should act more as members-at-large. Hodgkinson (1974) favours the latter and noted "...if senates were always engaged in bloc voting, and decisions were always made in accordance with numbers present from each constituency, the institution-wide perspective might be lost on certain crucial issues" (p. 16). Zald (1969) posited that there is a "...direct relationship between a board's degree of power in relation to an institution's administration and the degree to which board members represent the interests of external groups" (cited in Wood, 1995, p. 41). By interests of external groups, it is assumed that the reference is to the outside community at large, which many authors believe represents the ownership of community colleges. Lovas (1994) also noted the value of independence of membership, “...shared governance requires us to take the time to listen to one another from an institutional as opposed to a constituency perspective" (p. 14). This role for faculty, in particular, may not be a natural one with tradition leaning towards specialization and narrowness of interest and knowledge. Wirth (1991) underscored the need for change of focus, "...individual faculty must acquire a view or perspective broader than his/her department and must be willing to study material and data outside of their own area of interest" (p. 2). It seems that some sort of accommodation has to be made for internal members. For, it is inevitable that they will retain links with their 
constituency; often some are even officers in their trade union at the same time as they sit on a college board (as noted by Wood, 1991, p. 2). Separation of responsibility to board and union is difficult but not impossible. Wood (1995) managed to prescribe such a separation:

All board members, regardless of role, were expected to think institutionally, placing the needs of the whole college over those of specific interest groups. More specifically, institutional members were supposed to act as trustees rather than delegates, but they were encouraged by their board colleagues to facilitate two-way communication and contribute their special knowledge and insights resulting from their participation in the college community. (p. 45)

Further, Wood suggested that internal members should not raise constituency issues at the board table or use their board status to interfere with or influence the administrative processes of the college (p. 48). By taking such a position, he believed that internal members did much to avoid the allegation of conflict of interest. Dennison and Gallagher (1986) concurred with the view that the areas of responsibility can, indeed, be separated:

...the employee members of colleges should be able to contribute significantly to the policies of their institutions and should have full freedom to exercise their professional responsibility to their students. The fact remains, however, that the interests of the personnel of community 
colleges must not take precedence over the judgment of the representatives of the community to be served by the college. (p. 154)

The vision of the decision-making body as a whole is, at the least, as important as that of each of its members. Weisbord (1993) noted the danger that any body, regardless of its membership, faces of becoming insular and accountable only unto itself. He suggested that this can be avoided by maintaining an institutional perspective and concentrating on the big picture rather than getting embroiled in trivial issues or personal agendas. There were numerous references to the difficulty that faculty, in particular, have in remaining with the big picture. And the task becomes even more difficult in a climate of conflict. Filan (1992) observed the dilemma facing the internal members:

Two of the most difficult aspects of the job are learning how to shift one's loyalty from a specific discipline to the institution as a whole and learning the skills to resolve conflict--between faculty in their departments, between faculty and students, between faculty and administration, and between themselves and their faculty. Unfortunately, few institutions provide any kind of formalized training to assist either their new or experienced [participants] to hone these skills. (p. 4)

The lack of training is an important point which will be revisited later in this review. Wood (1995) suggested that presidents, board chairs, and external board members must act in the best interests of the college to create a supportive yet directive climate which serves to persuade internal members that 
their focus should be on institutional, not constituency, affairs (p. 48). In a similar vein, Perley (1995) stated that the problems of boards, made dysfunctional by individualistic behaviour on the part of internal members, have to be solved by all the members themselves. He called for a higher level of professionalism in order to protect the credibility of educational institutions when coming under public scrutiny. In particular, he implored his fellow faculty to demonstrate loyalty to the profession before loyalty to an individual discipline (p. 47).

Broad-based representation on bodies looking for decisions through consensus is democratic, empowering, and likely to produce sound outcomes which will enjoy support throughout an institution. But are such bodies effective? Hodgkinson (1974) was somewhat doubtful about their existence alongside less democratic vehicles emerging in the educational sector of the day:

It is the diversity of background and outlook within and across faculty, student, and administrative groups that makes consensus improbable and strict "representation" ( one person truly speaking as his [/her] constituents would themselves speak ) unlikely. Thus, we tended to see the broadly representative campus senate model as somewhat utopian and romantic, given the hard-nosed styles of adversary bargaining widely used in higher education today. (p. 14)

Regardless of whether a consensus based model can eclipse or at least coexist with adversarial models, and it is probably no clearer today than it was twentyfive years ago, many writers agreed that the consensus model is difficult and 
time consuming to operate. Lovas (1994), in a survey of administrators, noted the three most common knocks against shared decision-making:

1. Shared governance is slow, tedious, time-consuming, and wasteful;

2. More time implementing the shared governance process results in greater difficulty for administrators in implementing new programs and otherwise meeting their responsibilities; and

3. [ Shared governance ] has resulted in chaos, confusion, stalemate, and the inability to make decisions and respond to situations in a timely manner. (p.15)

It would seem, therefore, that shared governance is not a quick fix option and ought not to be entered into with intention of streamlining procedures.

\section{The Scope of Involvement in Shared Decision-Making}

There is a challenge to being a member of a college board. Whether he/she is elected or appointed, internal or external, the challenge exists. Seitz (1993) neatly categorized the challenges for each member as follows:

1. Knowing and properly observing board functions, duties, and relationships;

2. Knowing the nature of education and the unique character of the institution charged to represent; 
3. Knowing the difference between policy making and administration; and

4. Knowing how to assess, foster, and preserve institutional strength and quality. (p. 3)

Meeting those challenges successfully involves the board acquiring a group culture and focusing on a set of high level goals which pursue the common good. "Board agenda and focus primarily [is] on the big picture and on the future, i. e. on major board-realm issues. The board is not involved in management of staff, programs, or facilities" (Gregory, 1996, p. 3-4). And then, there is turf.

In a governance structure, there is turf to be considered, that is areas where a particular constituency has traditionally held sway and likely will view the prospect of sharing that role as giving up turf. Polishook and Naples (1989) revisited the landmark US Supreme Court decision of 1980 in the National Labour Relations Board vs. Yeshiva University case which concluded that "...faculty pervasively control the educational enterprise" (p. 6). However, Collins (1970) in examining faculty views of the student role in shared governance noted that "...faculty enthusiasm for student involvement in decision-making waxed in regard to social matters but waned in regard to academic matters" (p. 11). Perhaps it was getting too close to a turf issue? Certainly, there is overwhelming support in the literature for the notion that academic affairs should be controlled, or at the very least heavily influenced, by faculty. That seems to be the most basic tenet, strongly rooted in the university culture and well established in colleges even before the move to formal shared governance. Munitz (1995) 
confirmed the academic affairs principle that control should rest with the faculty. He opined that in state or provincial situations where the president and trustees do have legal decision-making authority, they should "...concur with the faculty judgment, which can be overruled only in rare instances and for compelling reasons stated in detail" (p.11).

The other side of the coin from academic affairs is financial affairs, long the purview of the board and administration. It has been noted by a number of writers that faculty and faculty dominated bodies still have little or no real power in regard to fiscal matters and the setting of the budget in particular (Mann, 1968; McConnell, 1970; and Flanigan, 1994). There were frequent references to poor input opportunities for other stakeholders and poor communications on this fundamental management issue. Indeed, Gulassa (1989) noted that where there is a truly collaborative approach to budgeting, and examples do exist, shared governance has finally been achieved. Lovas (1994), noting support staff views on financial affairs, also highlighted the need for an open, participative process particularly when a budget reduction exercise is required. There may be a cultural difference here between faculty and support staff with the former wanting greater involvement in decisions related largely to budget growth while the latter appeared more concerned about having a role in the event of budget reduction. Wood (1995) concluded from a study of internal board members that, by and large, they had only achieved limited to moderate power within the board structure (p. 33). In another dimension of the progress of shared governance 
development, Munitz (1995) observed that faculty still control academic affairs, but the board and administration still control the budget and, therefore, progress has been inhibited (p. 11). Progress, here, is taken to mean both progress in the development of the board/senate relationship and in the development of programs, curricula, and teaching methodology. This limited impact by internal members on the decision-making realm of boards may be due to the fact that the internal members function more effectively in the less formal forums that also exist in a college. Allen and Glickman (1992) noted that schools and colleges end up in a shared governance model with overlap between the formal (board, senate) roles and informal (departments, committees) roles (pp. 81-82). Although it will vary according to institution, it is likely that a good deal of real decisionmaking, particularly where it relates to proposed change, is still transacted through the informal network. The final reason for the perception that internal members achieve only limited power in the board environment may be due to a resistance on their part to conform to the expectations of the role. Wood (1991) found that presidents and external members have established clear standards: College presidents and public board members define the institutional members' role as trustee rather than delegate with the explicit or implicit goal of integrating them into the boards' culture, social dynamics, and decision-making priorities and processes. (p. 354)

There is fairly strong suggestion in the literature, and from experience, that the impetus for the call for shared governance comes more from faculty than 
it does support staff and students. Perhaps, as a result, shared decision-making models differ from state to state and province to province. In most cases, however, faculty now have a formal role on college boards while in many cases staff and students are also represented. Wood (1995) observed that faculty are seen by all internal members as having more impact on boards than the other internal constituents (p. 39). Nussbaum (1995) reported that staff, students, and administrators, the latter of which infrequently have a formal role on boards, felt marginalized by the shared governance structure (p. 23). Perhaps also, this feeling of marginalization can de attributed to the strong impact and influence of faculty. However, Wood (1991) observed that "...the institutional [internal] members appear to me to be less powerful members on the board than othersthe other board members do not look to our institutional members to be highly influential " (p. 279). Interestingly, the second comment by Wood (1991) may be the more telling and speaks to an ongoing dichotomy of opinion on shared governance.

Wood (1995) suggested that the boards' focus on the community good and the tendency of internal members to hang onto personal values and interests may be a reason for the limited impact that internal members have made on boards:

The presidents' and public members' frequent emphasis on the good of the college in their discussions of role expectations for institutional members illustrated their desire to establish a unity of interests within the 
board and to divorce themselves from the interests of the college's constituent groups. At each college [in the study] this tendency toward social cohesion and unanimity limited the influence of institutional members by restricting their opportunity to pursue interests they defined as important and to introduce dissenting opinions. (p. 42) However, Wood (1991), in a study of internal board members, observed "...most employee and student members consciously sought to achieve credibility in the eyes of their board peers by working within the role expectations with the goal of gaining influence in that way" (p. 357). It is probably not so surprising that observations of shared decision-making reveal internal members adopting strategies which allow them to pursue their personal interests. Certainly, it causes boards to exhibit the sort of moral conflict, identified by Ricouer (1992), when an organization struggles with competing values (cited in Deas, 1997, p. 10). However, Deas suggested that internal members are "simply playing out the roles [which they have been accustomed to and] which have been entirely natural to the culture of post-secondary education system ${ }^{n}$ (p. 10). Only time and experience may change that natural tendency, if indeed it does change.

Clearly, the issue of scope of involvement in areas of decision-making which have a tradition of being effectively controlled by one constituency has only been addressed to a limited extent in the power sharing progress of the last twenty-five years and today remains something of a bone of contention. A common concern expressed by authors, internal board members, and external 
board members alike is the lack of orientation or training given to new members. If boardsmanship is largely cultural and procedural, and the literature would suggest so, it does seem shortsighted, or perhaps a little Machiavellian, not to prepare new members for the rigour of shared decision-making. Seitz (1993) called for an extensive program of orientation for new members and identified the president to be responsible for ensuring that it takes place (p. 13). Further to the need for board training, there also exists the chance to craft board cultures and procedures that are unique to community colleges. This would appear appropriate given the uniqueness of those institutions. However, as Dennison and Gallagher (1986) noted:

...community colleges have had a clear opportunity to test new forms of internal governance, but they have tended to forfeit this opportunity. Young as they are, most have moved very quickly to institutionalize their forms of government, their administrative structures, and their organizational patterns. The ambiguity of their role, their lack of public support, and the general insecurity of their status have prompted many colleges to cast in stone their styles and forms of management all too quickly. (p. 154)

It must be concluded, therefore, that the scope of involvement by constituent members in the shared governance model is not consistent or well defined. The varying degrees of impact by faculty, staff, and students and the ongoing clash between the boards' focus on high level, long-term issues and the internal 
members' tendency toward promotion of personal values and issues would confirm the uncertainty of the external members' involvement. It has been suggested that more orientation and training of board members might bring about more cohesion to the groups in the future.

\section{An Advisory or Decision-Making Role}

\section{and the Impact on Middle Managers}

Crucial to much discussion around shared governance is the status of the participants, more specifically, do they have the right to provide input to those who will make the final decision or do they have the right to actually participate in making the decision? While much power can be derived from the former, it would appear to be the goal of the aspirants to shared governance to acquire the latter. Allen and Glickman (1992) stressed the importance of making it clear to the participants in any shared governance model who, precisely, has the authority to make the final decision on any given issue. Moreover, they opine that there is nothing more demoralizing for a group to enter a process believing it is decisionmaking, only to find that it has an advisory role (p. 84).

Many faculty models revolve around an advisory role noted Collins (1970) although there has been a tendency towards an actual decision-making role since that time. 
Shared governance has replaced participatory governance in our current lexicon. There has been a substantive shift from a governance model in which all constituents have a right to participate to one in which these same parties have a right to collaborate in making those decisions. The difference in the degreeism of involvement can be illustrated between the right to comment and the right to vote. (Lau, 1996, p. 8)

Collins also noted, and this probably remains more true today, that student involvement has largely been confined to an advisory role (pp. 5-6).

Hodgkinson (1974) observed that participation in decision-making is often seen in a different light by administrators from faculty, staff, and students:

One is also led to believe that the meaning of participation for central administration is quite different than participation as interpreted by students and faculty members who characteristically want to be near the center of the decision-making process. Thus, the administrative perspective on participation emphasizes not shared decision-making but rather the possibility of access to the decision-making process in the form of senate recommendations. For many students and faculty, this a big shock when they come to realize that they are not actually going to decide things. (pp. 135-136)

Similarly, Dominguez (1975) noted that “...board members' attitudes towards a faculty role in the decision-making process was limited to the faculty offering advice only. They were unequivocally opposed to faculty participation in major 
decisions" (p. 25). The president's position is often called into question in a shared governance model. There is a considerable school of thought to suggest his/her authority is automatically diminished when other constituents have a decision-making role, particularly in the case of board representation and through the senate. Trani (1997) advised presidents not to operate in isolation but to ensure that they retained their leadership authority:

...presidents must resist academia's insatiable appetite for the kind of excessive consultation that can bring the institution to a standstill; instead, presidents should be given the authority they need to lead their institutions and manage their resources. (p. 1)

One notable impact of the advent of shared governance, whether faculty, staff, and students have an advisory or decision-making role, has been the sense of marginalization among middle managers such as deans and directors (Gulassa, 1989; Lovas 1994). Gulassa noted “...middle management are bypassed or undermined by shared governance-which puts them at a disadvantage, especially in relation to the faculty with whom they must work" ( $p$. 16). Managers' reaction to this affect has been to try to find a place in the new structure. As a result, administrative committees and even senates have been formed for administrators' input. The primary purpose of this approach, as noted by Gulassa, is to make sure that those administrators, e.g. the president or vicepresidents, who do have a prescribed role in the formal (shared) decision-making structure carry to it a consensual administrative view. 


\section{Structures and Relationships}

Shared governance is all about structure of the participants and the relationships that emerge between the bodies involved in the structure and between the jurisdictions from which the participants have been drawn. There is no standard structure, and what has evolved is different structures which reflect the different cultures among educational institutions. McConnell (1970) observed notable differences in structures even among schools within the same state system. In a detailed study of institutions, Reyes and McCarty (1986) categorized structures as collegial, political, or bureaucratic. They noted that organizations where presidents had a strong influence tended toward collegiality while those where deans and other administrators held more sway tended toward political or bureaucratic models. Unionized organizations tended strongly toward bureaucracy. The type of institution was also found to influence the type of governance structure, as follows: major research universities---collegial; minor research universities---collegial/bureaucratic; doctorate granting universitiescollegial/bureaucratic with tendency toward the latter; comprehensive universities-collegial; liberal arts colleges--collegial/political; and two year colleges-highly bureaucratic (pp. 24-26).

On the assumption that a governance structure is generally based on the philosophical nature of the culture of the institution, it is interesting to examine some of the participants' views. McConnell (1970) quoted the American 
Association of University Professors' principle of shared authority and responsibility:

Among the faculty, administration, and governing board there is an inescapable interdependence and these three components have joint authority and responsibility for governing the institution. The essential and overriding idea is that the enterprise is joint and there must be adequate communication among those components and full opportunity for appropriate joint planning and effort. (p. 4)

This view is sound as far as purpose goes, but is not totally inclusive as it contemplates no role for students or support staff. Gulassa (1989) espoused that faculty and staff should be seen as both the means and the ends to the educational enterprise; in other words, faculty and staff should serve the institutional goal of educating students through the governance structure but that same structure should in turn serve faculty and staff. Epp (1992) characterized this model as serving mutual needs and suggested it is the "...process by which administrators may shift their administrative style away from the pyramid toward the web" (p. 3).

Lovas (1994) cited the undernoted characteristics of any effective shared decision-making process:

1. The process should strive to be authoritative and anti-authoritarian;

2. The process should seek to understand and explicitly recognize the differing kinds of authority among participants; 
3. The process should encourage that decisions to act occur closest to where the greatest authority for that action exists in the organization;

4. The process redefines "authorship", establishing an ethic and a practice that ideas are not credited and owned by individuals in a collaboration; and

5. The process demands creating new ways of acknowledging individual participation and contribution to the outcomes and products of shared decisions and organizational collaborations. (pp. 11-12)

Bergquist (1993) noted that a governance model based on shared decisionmaking is constructed on open dialogue. He related this to the post-modern foundation of voice rather than the modernist concept of vision and underscored the attendant need for internal communication within the decision-making body and externally with all the stakeholders of the institution. It would appear that the relationships within a shared governance structure have a degree of reliance and trust built into them. Wood (1995) observed "...the public [external] members' lack of experience with educational institutions and their part-time, volunteer status made them very much dependent upon the information they received from the president and senior administrators" (pp. 41-42). Moreover, internal members bring special qualities to their relationships within the collaborative structure. Scherr (1994) highlighted the value of insider status, of knowing how the prevailing culture of an organization functions, and being able to apply that knowledge to the decision-making process. 
Trust plays a significantly important part in shared governance. As Deas (1994) noted, relationships between board and administration, even in vastly differing institutions, are recognized as effective and lasting where there is a discernible trust in one another (p. 51). In the case of a governance model that extends beyond the board and administration to include other jurisdictions such as faculty, staff, and students, the need for trust and respect among the participants is viewed as absolutely crucial (Mann, 1968; Draper and Van Groningen, 1990; and Lovas, 1994). Draper and Van Groningen noted that "...mutual trust...does not necessarily imply total agreement by all participants" (p. 11). In a similar vein, Lovas observed "...shared governance requires that everyone have integrity in dealing with other groups, which is hard when there are conflicting loyalties as we often find in the collegial environment" (p. 22).

Ricouer (1992) has identified a norm of reciprocity, i. e. an obligation to others which will be returned, in organizations intent on attaining the good life [common good]. Alas, the obligation does not seem to be in evidence in the culture of college boards. (cited in Deas, 1997, p. 6)

Liontos (1994) believed that shared decision-making itself has the potential to build trust among the participants by challenging them to engage each other rather than work in isolation in the traditional "...egg-crate organization of schools $^{n}$ (p. 1).

Shared governance in colleges and schools has evolved over more than twenty-five years. In many cases, it amounted to a logical, natural progression 
for the institution and was entered into on a voluntary basis. Generally the change, at first, consisted of providing access for faculty, staff, and students to offer input into decision-making by the board of trustees and administration. Gradually, however, this has progressed through to the point where all the stakeholders have an active part in most areas of decision-making, if not in all. in other state and provincial settings, shared governance has been legislated from on high and, consequently, its nature has been far more prescriptive and involuntary. However, regardless of the route by which an educational institution has arrived at a collaborative decision-making structure, Carver (1990) noted "...no single relationship in an organization is as important as that between the board and its chief executive officer" (cited in Boggs, 1995, p. 27). The overriding principle in effective boardsmanship which seems to emerge from the literature is that the board makes policy and the president interprets and operationalizes the policy. This principle stands firm throughout various different models of shared governance. Hence, Carver's contention that the "...board should think of itself as having only one employee, the CEO" (cited in Boggs, 1995, p.28) begins to make sense.

Views differ on the impact of legislated change to governance. Draper and Van Groningen (1990) believed that loose, enabling legislation allows an institution to develop a local governance model in an "...open, deliberate, and collegial manner" (p. 30), thereby, providing opportunity for the participants commensurate with their knowledge and responsibility. Draper and Van 
Groningen did note, however, that there has to be some order to the process of delegating formal power:

As long as a body that is legally responsible for a function retains the power to make, modify, or revoke a delegation of its authority regarding that function, the body has the means to control the performance of the particular function. On the other hand, if the delegation of authority is fixed by some external entity, the body with legal responsibility is without the means of controlling the exercise of the particular function through its own delegation of authority and revisions thereof. (p. 30)

In a study of two separate education systems where loosely legislated shared governance had become totally bogged down in the initial years on issues of mandate, jurisdiction, powers, and procedures, Deas (1996) concluded that "...legislated shared decision-making should be more prescriptive. The control built in at the outset will allow the participants to work with the process rather than get all hung up in the early stages and cause near fatal doubts to emerge [among the participants]" (p. 13). However, Kanter (1994), in relation to the experience of Californian community colleges, suggested that "...when behaviour is legislated, issues become polarized and often much more complicated than they were originally envisaged" (p. 229). She espoused "...the fewer rules the better. Rules reduce freedom and responsibility. "Where differing views do, however, converge is in the need for clarity of mission, no matter how it is achieved. Draper and Van Groningen (1990) noted "...if a person or body is 
given a clear statement of responsibility, a clear grant of authority, the resources necessary, and adequate time, it is entirely reasonable to hold that person or body fully accountable for the performance of responsibility" (p. 31).

There may be examples where an organization is effective through the sheer energy created by conflict within its ranks. Most views, however, of shared governance in education are that in order to achieve any success there must be a climate conducive to sharing. Comer, Haynes, Joyner, and Ben-Avie (1996) noted "...a post-modern shared decision-making environment has a consensus climate rather than one of competition. They describe such a climate as embracing collaboration, consensus, and communication". To that, one might add a fourth " $c$ ", the characteristic of caring as suggested by Starrat (1996).

Gulassa (1989) made the important distinction between collaboration and consultation in a culture of shared governance. While the latter is the general first step, facilitating access for stakeholders to provide input to decision-making, the former signifies the de facto sharing of power. He cited consultation as being a vehicle of the vertical structure while collaboration signifies a horizontal or flattened structure. Gulassa went on to note that integration, the goal of shared governance, can be an effective counteraction to conflict:

Integration means that...interests of all parties merge. Defensive strategies dominate, e.g. preservation of the organizational entity and protection of the interests of the members. The more management and union view each as competitors for coveted power and resources, the 
greater the need for strong unions and an equally strong management class. But if players can be persuaded to see beyond the horizons of their own organizational interests to the needs of the institution as a whole-idea integration---then all sides profit. The welfare of each discrete organization is biologically dependent on the health of the host institution. (pp. 3-4)

Lovas (1994) noted that the necessary coming together is not easily achieved, nor is it a swift process:

For me, shared governance requires careful consideration of...differing kinds of authority, arranging structures and processes to ensure the most authoritative members of the organization participate in the decisions appropriate to their authority. This notion is relatively easy to conceptualize, but quite difficult to operationalize. I think it's the major reason that shared decision-making seems so ponderous, so timeconsuming, and sometimes quite ineffective. The problem lies not in the notion of sharing but in the particular authorities of those doing the sharing. (p.11)

In addition to definition of roles, there is also a need to ensure that the players in those roles are competent. Clearly faculty, staff, and students bring something different to the party compared to trustees and administrators. However, there has to be an understanding of one another's values and history. Hodgkinson (1974) questioned "...do faculty and students have a wide enough 
perspective to actually engage in policy-making for an institution?" (p. 6).

Perhaps not in the initial stages. Hackmann and Berry (1994) note that it cannot be presumed that faculty inherently possess leadership skills, [accordingly] any change model must provide for leadership development" (p. 2).

Lovas (1994) noted the need for training and staff development for all participants in shared decision-making bodies. Wirth (1991) suggested the need for all round tolerance:

Administrators have to become teachers again, exercising great patience, giving participants time to discover and develop. Individuals and groups who formerly did not share in decision-making must agree to spend sufficient time and energy learning new skills. (p. 2)

Flanigan (1994) echoed this statement and noted, in particular, the need for professional development "...which enhance[s] team facilitation, conflict management, decision-making, and leadership skills" (p. 10). In contrast, Young and Thompson (1982) recognized the need for trustees to understand the principle of academic freedom and the culture from which faculty emerge to share in governance (pp. 124-126).

Almost as important as a consensual climate and, indeed, one of the vehicles of consensus building is communication. Many authors cited good, effective communication as absolutely crucial to shared decision-making, both down and across the organizational structure as noted by Lovas (1994). Nussbaum (1995) warned against the balkanization effect that can occur, 
particularly in complex shared governance structures. Where there are several advisory councils, often representing each of the constituency groups, effective communication between them is essential to prevent them operating in a vacuum and developing their own, self-serving positions (p. 20). Further, Messina, Cearfoss, Trueblood, and Young (1994) cited communication as the virtual foundation for successful governance.

Consistent with good communication is visibility of decision-making. Stakeholders of an institution have to see decision-making as open and feel that they are well informed as to process, issues, discussion, and outcomes. Nason (1982) highlighted the important status of the college board, describing it as "both a bridge and a buffer between the college and the community" (cited in Boggs, 1995, p. 34). Gulassa (1989) noted that "...at any point where the decision-making process stream flows underground, bad things begin to happen, and those bad things include cynicism, paranoia, and distrustfullness" (p. 3).

\section{The Importance of Shared Governance for Students}

While one might point to the concept of a community of learning and increasing the body of knowledge, or even to an educational institution as a player in the economic community, it is generally accepted that schools' and colleges' main reason for existence is students. It is, therefore, reasonable to question what the impact of shared governance has been on the student 
population. First, one must consider whether students are actually to be part of the shared governance or not, and opinions and outcomes differ on that question. Nason (1982) was quite emphatic that the concept of a student trustee is inherently flawed; he noted that "students serve too short a time to master all they need to know and will not be around long enough to live with the consequences of their decisions " (cited in Boggs, 1995, p. 30). In contrast, the Canadian Federation of Students (1992), in its lobby of the British Columbia Government regarding student representation on college boards, was able to make the point that representation was justified on the grounds that students comprise by far the largest segment of the college community (p. 2).

Liontos (1994) believed that the primary purpose and goal of shared decision-making should be student success. "Using it as a means to shift accountability or abolish a top-heavy central office staff will simply make shared decision-making a buzzword. Student success and achievement must be kept in the forefront of our thinking as the reason to implement it" (p. 1). Mahon (1994) similarly justified shared governance being about and for students by tying it to the inverted pyramid of the total quality movement which places students at the top.

The Southern Methodist University (1979), in designing a new shared governance model, was adamant, and embodied it in the principles of the model, that students would henceforth play a significant role in the governing body of the school. Many other instances exist of institutions, of their own volition or 
through prescribed legislation, moving to include student representatives in all facets of governance and decision-making. There remain, however, lingering doubts as to whether they are welcomed by the other stakeholders. Collins (1970) noted:

The faculty, administration, and trustees were described as dubious champions of student rights and freedoms. Without reliable protectors within the academic community, it was concluded that students had the options of securing their rights and freedoms by the exercise of raw power, by finding means to participate in the decision-making process, or by seeking judicial protection through a student bill of rights and freedoms. Since confrontational politics has been talked to death and since guarantees of students' rights and freedoms...seems remote in [the] political climate, primary focus has been on the second option, inclusion of students in the power structure. (pp. 10-11)

Hodgkinson (1974) noted a trend during the middle and late sixties which is seeing itself repeated in the nineties---1) students began to be included on faculty senates and other campus-wide decision-making bodies, as well as on boards of trustees, and 2) more and more decision-making power was taken over by statewide[/provincial] coordinating agencies and influenced by legislative politics" (p. 1). Thus, it may be said that the Lord giveth and the Lord taketh away, twice around. 
Has shared governance had a positive impact on students? A number of studies would appear to offer a positive response. Richardson and Wolverton (1994) found that one of the eight characteristics of high performing institutions was the existence of often loosely defined, participative governance structures. Lesser performance was clearly linked to either complex, highly structured and controlled decision-making environments or the absence of shared governance altogether (p. 46). Manilla (1979) questioned, however, if students were not likely to get hurt in a shared decision-making model which really only represented a power struggle between administrators and faculty. Thomas (1979) lauded consensus decision-making and noted empirical evidence that conflict in an institution leads to lower achievement as evidenced by test scores.

Interestingly, there is a commonly held view that benefit to students comes not so much from their involvement in shared governance directly but rather from the fact that faculty are involved (Mann, 1968 and Gulassa, 1989). Gulassa noted "...the more a college invests in the intellectual and scholarly development [in the context of power sharing] of its faculty the greater the difference in the meaning of life and professional work and the greater the success with students" (pp. 2-3). 


\section{Faculty and Support Staff Attitudes}

In general terms, the jury is still out on the success of shared governance at the college and school level. Experiences have differed from site to site, and outcomes have greatly depended on the reasons for introducing it in the first place (voluntary or involuntary), the existing culture, the presence or otherwise of unions, and the general attitudes and behaviour of participants. Furthermore, there may be differing views among the constituents about the actual level of participation. Drummond and Reitsch (1995) observed "It appears that there is some difference of opinion between faculty and administrators with regard to decision-making and the level of shared governance present at the institution. Administrators report more faculty involvement in governance procedures than do faculty respondents" (p. 53). Drummond and Reitsch noted that these findings from their study of faculty and administrator attitudes toward shared governance models touched on a statement made as long ago as 1918 by Veblen (1957)"...administrative use of faculty committees-for-the-sifting-of-the-sawdust give the appearance, but not the reality of participation, and are a nice problem in selfdeception, chiefly notable for an endless proliferation" (cited in Drummond and Reitsch, p. 53).

Debow-Makino, Hill, Atwood, Murdoff, and Westphal (1993) highlighted the divergence of views which appears to be quite common: 
...on many of the questions related to sharing of decisions there are sharp differences among the staff sub-groups. For example: a majority of fulltime faculty members believe committees have little influence on major decisions, but a majority of managers are persuaded they do; and a large majority of the College's managers believe the administration is making efforts to expand participation in decision-making, but only small minorities of the other groups agree. (p. 6)

Much of the literature suggests that faculty, at least a majority of them, are really not too bothered about power sharing or getting involved in it. Dominguez (1975) referred to the "...pervasive ambivalence in faculty attitudes toward participation in decision-making" (p. 11) and noted that teachers have had a historical reluctance to actively engage in the type of politics necessary to acquire a place in democratically elected decision-making bodies. There are even some views that all this focus on sharing of power with regard to institutional matters has had a negative affect on academic matters:

Management attention to collective bargaining and reorganization (internal threats) and state level control of funding and curriculum (external threats) was perceived as inattention to instructional matters. (Stamm, 1989) Faculty and support staff performance in shared decision-making has frequently been criticized by authors, trustees, and administrators. Several recurring difficulties have been noted, the most basic of which Filan (1992) addressed was constant open competition between faculty and administration at 
the board table. He remarked that the ongoing rivalry represents a challenge for the board chairs to adjudicate. Furthermore, Wood (1991) reported that "support staff [board] members over time have lived a little close to home, that is, focused on internal matters and have lacked the...visionary breadth" (p. 276). A further example of faculty difficulties, which speaks to the testing of allegiances, was stated by Munitz (1995), "They [faculty board members] frequently worried that we were cutting [the budget] too much across the board, and not singling out whole programs for elimination. Yet, they could not develop a consensus on which programs should go" (p. 11). All three examples of difficulties ascribed to faculty and support staff board members appear to be connected to their internal constituency status and personal closeness to the issues faced by college boards. This closeness, which at times develops into perceived or real conflict of interest, was, of course, one of the principal areas of inquiry in this study.

At the front and centre of all views on the progress in sharing governance is the continuing lack of trust among the participants. There is certainly suggestion that faculty and administrators, in particular, have such marked differences in their values of what an institution should represent that suspicion and defensiveness are almost inevitable. Flanigan (1994) noted "...despite this increased involvement [of faculty on institutional committees], both [CEOs and Senate Presidents] also agree that the levels of cooperation, trust, and shared values, quality of committee meetings, and quality of committee reports and recommendations to the board of trustees have not changed much with shared 
governance" (p. 9). It should be suggested, however, that much of the ambivalence or even hostility to shared governance expressed by faculty is directed to the context of shared governance in an advisory capacity and perhaps reflects that satisfaction can only be attained with full decision-making power.

One of the big complications in the development of shared governance is its parallel existence with the development of trade unionism in the college and school sectors. The two institutions (governance and unionism) appear different yet related, independent yet overlapping, and cause a high level of confusion and tension which is worthy of examination in this study. There is much in the literature to suggest that the interests of both institutions are best served when they are kept apart. However, The Academic Senate for California Community Colleges (1996), in its position paper Developing a model for Effective Senate/Union Relations, favours a much more collaborative approach. For example, it suggests that senates and unions should set out their objectives with regard to academic and professional policies and conditions of employment respectively. Thereafter, "...it is essential that the two bodies communicate regularly, settle their differences directly, and do not let outside forces [unspecified] pit the two organizations against one another" (p. 4). Moreover, the statement is made that "Faculty are best served by having two strong organizations, both promoting faculty interests and their commitment to 
academic excellence and integrity" (p. 5). There appears to be clear indication here of the link between shared governance and the perceived welfare of faculty.

One of the major barriers to getting faculty and staff involved in shared decision-making is considered to be the low level or non-existence of release time from regular duties. Flanigan (1994) cited lack of release time, along with distrust between the participants, and faculty interest as the three key barriers to a faculty role in shared governance. Liontos (1994) suggested that release time is the single greatest barrier. However, there is another side to the argument as noted by Wirth (1991):

Teaching and learning may become secondary priorities. Representatives [engaged in shared governance] miss time away from work or the classroom. This is a major problem and creates havoc with scheduling and program/curriculum development. Some shared governance participants become more interested and involved in the coordination effort than their instructional or work assignments. (p. 2)

Obviously, the issue of too little or too much release time is really an extension of the issue of what is the purpose of shared governance, is it sharing of power or a shifting of power?

Support staff views to some extent mirror those of faculty, but there is also a status thing with, perhaps, staff not being as convinced about their acceptance in the shared governance structure. Wirth (1991) noted that "...classified participants report that there is a feeling that their participation may be token, 
that even though they may speak, their voices may not be heard or considered" (p. 2). However, in states where colleges have created a series of councils or senates to individually represent constituency groups, Nussbaum (1995) found that support staff had generally taken the opportunity to form classified councils or senates. He explained "The notion has been that collective bargaining framework is not the appropriate arena into which to bring shared governance and the broad spectrum of policies in running a college" (p. 14).

Wirth (1991) discussed whether participation in shared decision-making is really all that attractive to faculty and staff. She noted that, although participation is likely to satisiy affiliation and esteem needs in Maslow's Hierarchy of Needs (1954), participation, in itself, is unlikely to produce the self-actualization that can only come from a role that offers opportunity for achievement, growth, development, and challenge (p. 4). Perhaps this explains the results of studies reported by McConnell (1970) that suggested two thirds of faculty tend never to get involved in any advisory or decision-making capacity. However, Drummond and Reitsch (1995), in a study of faculty and administration attitudes toward shared governance, found that more satisfaction was expressed by both groups when the level of shared governance in which they participated was greater when judged against the authors' scale of constituency involvement (p. 55). Drummond and Reitsch noted that faculty sought a sense of real belonging in the decision-making model, not the sense of token inclusion feared by Plante (1989): 
...to one who nurtures contemplative leanings, as many faculty do, no sense of self-worth is enhanced and no feelings of membership in a serious enterprise is promoted when one is asked to interrupt work on a manuscript or on class preparation to join administrators who are acting out of heavy-handed good intentions, or, worse yet, are making a calculated attempt to appear open and nonautocratic, and so think it time to touch base with the faculty. (cited in Drummond and Reitsch, pp. 55-56) Lovas (1994) explored another possible reason why relatively few faculty are motivated to participate in shared decision-making. He suggested the natural tendency of faculty, as spawned from years of scholarship, is toward individual authorship and decision-making. Therefore, there is a reluctance to be involved in what amounts to group authorship through shared decision-making. Certainly, the incentive of reward for involvement in shared decision-making does not seem to be a significant issue for faculty. In a study of faculty at private and public universities, Miller, McCormick, and Norman (1996) found that "...the respondents from the private university were less supportive of the ideal that faculty should be rewarded for participation in the governance process..." (abstract, p. 1). Finally, Hodgkinson (1974) highlighted the dichotomy of adversarial collective bargaining and collaborative decision-making in an institution, often potentially involving the same players, as a disincentive to faculty who are not prepared to do a juggling act with their values and beliefs (cited in Deas, 1996). 
It would appear, therefore, that shared governance is something that is much sought after by faculty and support staff. Once achieved, however, it seems that relatively few employees actually tend to get involved. In addition, there is a complicated link between shared governance and labour relations with many writers suggesting that the two should be kept separate, but members of senate and union executives advocating alliance and collaboration for the common benefit of faculty, in particular.

\section{Shared Governance in Financial Affairs}

Educators have somewhat simplistic views about funding of educationthere is never enough and there should be. However, as Rollins (1972) noted "...when budgets are critically examined, educators naively express surprise, expecting legislators to continue accepting their requests without too much scrutiny and with few strings attached" (p. 2). In the last twenty-five years, there has been a notable tightening of public funding of education along with greater and continuous calls for more accountability.

Faculty, support staff, and students have not traditionally had a prominent role in fiscal priority setting and decision-making in the mature university governance structure or in the emerging college and school structures. Rather, as noted by Deas (1994), they have looked to the board of trustees for the fiscal assurance that all is well. As a result of this practice, financial affairs has been 
one of the strongest components of the close relationship between the board and administration. In addition to general fiscal stewardship, the most important issue dealt with in this relationship has been the setting of priorities and the allocation of resources because in spite of what educators might expect of funding levels, they are never quite sufficient and as Rollins (1972) noted "...community colleges [and other sectors of education] cannot afford to be all things to all peoplen (p. 7).

The need for planning in financial matters is as strong as it is for any other aspect of education, and greater than most. In addition, it cannot be done well if in isolation of other aspects:

It is obvious that fiscal planning which realistically links academic aspirations with revenues available for both a short term and a long term period is sorely needed. It's time for all of us [educators] to fight the battle of the budget together-and not merely by going to the public trough pleading for more and more funds. We need to prove to our publics that we are currently getting a dollar's worth of value out of each dollar spent. (Rollins, 1972, pp. 2-3)

Hence, not only is the case being made for accountability but also for an approach involving all educational constituents when traditionally the power and responsibility has rested solely with the board and administration.

There is not total acceptance that a planned, coordinated, and justified approach to the fiscal development of education is the only way to go. There 
remains, as noted by Rollins (1972), the anti-planning faction which argues that educational growth (and presumably contraction) is solely at the discretion of the politicians, whose constant vacillating renders it pointless to plan extensively. Rollins noted, and experience since then has reinforced it, that a planned approach is necessary, however, to protect the educational share of the public purse, and that approach must be a coordinated one involving all stakeholders: A humanistic view must be incorporated into the whole planning process. Institutional morale is a delicate thing, and if lost through some cold impersonal political and economic process, is difficult to recover.

Therefore, fiscal planning should be sufficiently democratic so that those affected by the decisions have the opportunity to supply input and be involved to the greatest extent possible. (p. 5)

As in other aspects of decision-making, the need for clear, effective communications in financial affairs has been stressed extensively (Rollins, 1972 and Miller, 1993). Never is that need greater than on the, not infrequent, occasion of budget cutting which is perhaps the most traumatic and threatening, and often divisive, event in the educational lifespan.

The classic dilemma facing any institution in a budget reduction exercise is determining the basis of the cuts. The choice between making reductions across the board and targeting specific areas in a strategic manner, based on some sort of sound rationale, can never be made easily (Smith, 1975, Griffith, 1993, and Miller, 1993). Most educational views, although not always shared by 
unions, lean toward strategic reductions rather than starving everyone, the latter described by Smith as "...[leading] to an inevitable weakening of the fabric of the university as a whole--a choice for universal mediocrity or worse" (p. 4). However, if cuts are to be selective, there remains the difficult task of choosing where. Phillips (1996) observed that, of all the aspects in the shared decisionmaking agenda, developing budgets is the least desirable task to be undertaken by teachers in a high school (abstract, p. 1). This reluctance is likely to be largely true of faculty in the college sector as well. Chaffe (1982) noted that behaviour during a period of budget reductions takes on political characteristics, rather than the rational qualities that are looked for in a climate of shared decision-making. It is suggested that, while conventional wisdom advances the involvement of all stakeholders in decisions around cutting budgets, the nature of the task is likely the single greatest threat to shared decision-making itself with the high risk of tearing constituencies apart. Indeed, the problem may rest with the urgency of budget cuts causing Griffith to comment that a financial crisis requires a surgical rather than a consultative response which speaks against the culture of democratic, shared governance.

Smith (1975) offered the view, however, that notwithstanding the urgency and the trauma of deciding budget cuts, more effective decisions will continue to be made when all stakeholders have a role to play. He noted that "...faculty assume primary responsibility for the quality, health, and usefulness of its academic programs. If this is not done [in times of fiscal hardship in particular], 
then the reason for being a community of scholars with general responsibility for the recovery, organization, dissemination, and enhancement of knowledge is abandoned" (p. 4). It is further suggested that the sort of data upon which budget cuts are to be based requires the careful evaluation of programs, thus ensuring the academic credibility which is also required when a more positive financial climate later rolls around. Nussbaum (1995), however, expressed concern that a budget constructed in a shared governance model is "...cobbled together...[and, invariably not] in the best interests of students, the system, and the state" (p. 23). By this, he meant that such a budget is likely to reflect differing views-the board and administration espousing the common good while the senate and unions pursue local vested interests. A budget, after all, is just a numerical reflection of values and objectives and, if there is wide diversity among the value and objectives in a college, the budget will simply reflect that diversity.

There has been a recent tendency, in particular where states and provinces have not pursued policies of centralization, for greater democratization at the local level in regard to fiscal affairs. Institutions are addressing the finding of the balance between the need for traditionally narrow stewardship and the value of shared decision-making on priority setting and resource allocation. The ever changing financial climate facing institutions, especially where the dependence on direct grants is greatest, places a strain on the shared governance structure which only time and experience may ease. However, Nussbaum (1995) placed faith in shared decision-making: 
Running a college, particularly during times of limited budgets, requires countless decisions to be made regarding competing values. Shared governance mechanisms provide the arena where these values can be expressed, where conflicts can be addressed, and where priorities can be established. Through shared governance, communication is enhanced, opportunities for buy-in are increased, and there is a greater likelihood that the decisions are neither arbitrary nor uninformed. (p. 19)

A second consideration in comparing shared governance in a general sense to that of a financial context is the issue of stakeholder involvement on an advisory or decision-making basis. While the general tendency is toward the latter, there remains an argument toward the former in financial matters on the basis of trying to avoid vested interest. A case can be mounted for the neutrality and independence of the board and administration in making decisions around allocation of resources which contrasts with the academic stewardship upon which faculty might base their right to be involved. Breneman (1995) further suggested that the shared governance model is not necessarily best equipped for making difficult financial decisions. "The collegial nature of most colleges and institutions, emphasizing consultation and shared decision-making, seems poorly suited to the sorts of wrenching changes that lie ahead" (cited in Munitz, 1995, p. 12). Certainly, decisions that relate to increases or decreases in budget invariably bring internal board members into the spotlight when their program or department is under review. It is all very well for the faculty, staff, or student 
member to excuse him/herself from discussion and decision-making around that particular issue, but, in reality, all components of a budget are integrated and interrelated, and the member who is in conflict of interest on one issue in the budget is technically in conflict on all issues in the budget. Consequently, if the member is then unable to participate in consideration of the budget at all, then is the member really fulfilling his/her obligations to the board? This question is at the heart of the issue as to whether internal board members are able to function appropriately in general decision-making and, in particular, in financial decisionmaking. This issue is one of the major focuses of this study.

\section{Shared Governance in Labour Relations}

One of the most important, and at times volatile, areas of governance in education is labour relations. This has become increasingly so in the college and school sectors where the growth of unionism has been extensive and profound. In universities, the growth has not been so marked, perhaps because of the long established academic collegiality among the stakeholders. Certainly, the conflict of interest faced by internal college board members in the area of labour relations is well documented. Wood (1995) suggested "Institutional [internal] members should have proportional representation on all board committees, except, in the case of employee members, those dealing with labour relations" (p. 51). It is interesting to note that neither Wood nor, for example, the guidelines 
on conflict of interest of board members issued by the British Columbia Ministry of Education, Skills and Training identified student board members as having conflict of interest in labour matters. And yet, often the decisions made by boards during contract negotiations can lead to strikes or increases to employees' compensation, both of which can ultimately affect students directly. Specifically, the former can interrupt their education while the latter can cause possible increases to tuition fees in order to fund the escalating costs.

Is there permanent incompatibility between collective bargaining and shared governance? Hodgkinson (1974) noted that "...many respondents [in a study] felt that the existence of a collective bargaining unit on the campus would immediately do in the campus senate [the flagship of shared governance]" ( $p$. 153). He also highlighted the dichotomy of adversarial collective bargaining and collaborative decision-making in an institution, often involving the same players (cited in Deas, 1996). Nussbaum (1995) detected some muddying of the waters through legislation in terms of who is responsible for what in collective bargaining. $A B 1725$, the founding legislation of shared governance in the California community college system, prescribed a role for the academic senates (in concert with the boards) on "matters of hiring criteria for new faculty, retreat rights for administrators, and equivalency processes for determining instructor qualifications" (p. 9). These matters might reasonably be considered issues which management and unions would negotiate into collective agreements. Hence, there is a clear overlapping of interests in two separate areas of 
engagement--one purportedly collegial and consultative (boards/senates) and one often confrontational (boards/unions). From a different perspective, Gulassa (1989) reported on the serious concern about the impact shared decision-making on the allocation of resources within the budget process would have on collective bargaining, in effect amounting to a separate set of negotiations away from the bargaining table (p. 7). Thomas (1979) noted that unions face the dilemma of whether to trade shared governance for traditional hard-nosed collective bargaining (pp. 2-3). Again, this suggests that there can only be a dominance of one over the other.

Messina, Cearfoss, Trueblood, and Young (1994) suggested a distinction between the two (shared governance and collective bargaining) and the room for coexistence:

Governance is not intended to interfere in any way with the collective bargaining process, nor should the collective bargaining process interfere in any way with governance. Recommendations regarding collective bargaining matters may not be made by the senates. Efforts shall be made to clarify the distinction between collective bargaining and governance issues affecting faculty and support staff. Further, officers, board members, other representatives or negotiators of collective bargaining units may not serve simultaneously as officers, board members, representatives or in any other elected or appointed capacity of their respective senates. (p. 31) 
A certain clarity and division of responsibilities is suggested but, given the fact that few faculty and staff choose to get involved in either sphere of influence, the division may be difficult to actually achieve. In addition, the division of responsibilities did not occur in British Columbia where, by accident or design, many employee and student board members happened to be ranking officers in their trade or student unions, often serving as presidents. This particular occurrence was examined in detail in the study. Polishook and Naples (1989) cited legislation in the California community college system which attempts to provide a legal distinction between collective bargaining and shared governance in order to keep them apart. However, Douglas (1979) noted that collective bargaining and shared governance inevitably conflict with one another and stated that "...faculties seek to manage and...by their very actions...tend to blur the principle of mutually exclusive spheres of management and employee legitimacy" (p. 4). On the other hand, Lavine and Lemon (1975) observed that "...collective bargaining should be permitted on economic issues related to [faculty and staff] roles as employees, while professional and academic issues should be dealt with through shared governance mechanisms" (p. 15). This might suggest that shared governance should not extend to financial matters and the question of allocation of resources.

Polishook and Naples (1989) noted that the collegial nature of shared governance tends to contrast sharply with the confrontational nature of collective bargaining, although they held out the hope that the existence of both might lead 
to a softening of the relationships at the bargaining table, particularly after a number of years. However, Rhoades (1993) illustrated the existence of retrenchment clauses in collective agreements as an example of the different direction taken to the principle of tenure which would be upheld in a shared governance culture. He cited this as indicative of the clash between confrontational and collaborative values surfacing in educational institutions (pp. 341-343). Further to this seemingly irreversible division, Deas (1996) questioned whether successful shared governance can actually be spawned from confrontational collective bargaining as has been the result of contract negotiations in several college systems.

There are strong suggestions that collective bargaining can have a directly positive affect on shared decision-making, that affect being to "strengthen" (Polishook and Naples, 1989), "underpin" (American Association of University Professors, 1987), and "protect" (Lavine and Lemon, 1975). Lavine and Lemon noted that the typical characteristics of a faculty collective agreement such as no strikes, no lockouts, compulsory binding mediation and arbitration provisions separate it from an industrial contract and speak more to the collegial climate, consistent with shared governance, than they do the traditional labour relations climate in industry (pp. 32-33). (It should be noted that the inclusion of such clauses in collective agreements may not be as typical today). Polishook and Naples cited an example in the California State University system where the collective bargaining and shared governance structures can actually come 
together as happened in the response to state budget submissions by union, faculty senate, and administration in a "tripartite process." There are, however, other examples where the values espoused in bargaining and shared governance are far apart and seem unlikely to be reconciled, as in the case of the National Association of Scholars' charge that the American Association of University Professors' defence of race and gender based hiring jeopardizes the academic freedom that has long been championed by faculty and promoted in shared governance (1995).

So far, this review has focused on the interaction of labour relations and shared governance from the viewpoint of individual faculty members. Unions, reflecting the policy of the body corporate, have tended to be antagonistic toward shared governance noted Polishook and Naples (1989). Piland and Butte (1991), in a study of trustees, were left with a split view on the suggestion that unions work against college goals (pp. 8-9). This may suggest that unions are not natural partners in shared governance. Certainly, Starrat (1996) noted that partners in shared decision-making, as agents of change, are always likely to meet headlong with unions and special interest groups (cited in Deas, 1996). However, Covey (1996) took a different view and saw unions as able to play a role in a collaborative culture:

Trade unionism is merely protectionism, the necessity for which diminishes with the building of trust and the creation of a learning environment. I am not against unionism, I am against management 
practices that cause unionism to flourish. In a progressive learning environment, unions become communication vehicles not barriers or agents of confrontation.

There remains, nevertheless, the lingering doubt, particularly in the university area, that unionism is a threat to the academic ideal. Cameron (1996) stated that "...unionism stands in potential opposition to academic self-government which is, in turn, one of the pillars underpinning academic freedom" (P. 8). Drummond and Reitsch (1995) found that the greater the level of shared governance in an institution, the more the likelihood that collective bargaining will not be as confrontational or as widespread in its scope as would otherwise be the case (p. 57).

Examination of the issues that faculty want included in collective bargaining have [sic] revealed that faculty working in institutions with strong shared governance tend to limit the collective bargaining to salary and work conditions, while those in institutions with weak or unsuccessful shared governance want to extend the bargaining to cover academic issues. [Accordingly]...the more influence a faculty member believes his/her department has over academic issues the less they want to bargain it. (Ponak, Thompson, and Zerbe, 1992, cited in Drummond and Reitsch, p. 57)

Shark, Brouder, and Miller (1975) studied the impact on students of the growth, jointly and severally, of collective bargaining and shared governance. 
They predicted that, just as students have found a legitimate role in the latter, there is room for them in the bargaining process on the basis that bargaining comprises parties with vested interests. It was noted that the process of negotiation affects the quality, content, style, and cost of programs and services; and this has a direct impact on students, hence the notion of vested interest. Furthermore, negotiation of economic benefits for employees tends to have a direct affect on the economic status of students by leading to tuition fee increases (pp. 1-4). In the intervening twenty-three years since Shark's study, the vested interest of students has been consistently confirmed but the evolution of a role for students in the collective bargaining process has not materialized to any extent. Nussbaum (1995) viewed collective bargaining in the college sector as an extension of shared governance in contrast to the virtual unilateral approach to labour relations prior to collective bargaining:

In terms of shared governance, the advent of collective bargaining was a watershed event. Governing boards were not only required to involve an internal constituency (their employees) but also, for the first time, to share their authority to act. Under collective bargaining, the governing board essentially had to have the agreement of the appropriate exclusive representative before it could act on matters within the scope of bargaining. If agreement was not reached and a governing board acted, an elaborate set of external dispute resolution procedures was made available to test the legality of the governing board's action. (p. 7) 
The suggested incompatibility between labour relations and shared governance, which has brought widely contrasting views of agreement and disagreement, perhaps becomes more focused in the actual task of collective bargaining. In the context of governance councils as advisory bodies within shared governance structures, The Academic Senate for California Community Colleges tended to see such councils as a potential threat to undermine academic senates and unions (abstract, p. 1). Furthermore, the danger of collective bargaining issues sliding into the agenda of governance councils was expressed:

If academic senates and bargaining agents choose to participate in such a [governance] council, several factors should be kept in mind. Academic senate members should not be drawn into discussion of bargainable issues in an inappropriate forum such as a governance council. Bargaining agent representatives should not be party to such a council usurping the role of the senate in academic and professional matters. Discussions of the appropriate roles of the bargaining agent and the senate should take place directly between the two organizations. (p. 6) This view speaks again to the formation of alliances between employee players in the shared governance model and their unions, as has been noted in the British Columbia situation and which was examined in this study. Additionally, there is difficulty in determining the ideal representation of management on its side of the negotiating table. Piland and Butte (1991) found that trustees strongly 
disagreed with the notion that they should be directly involved, presumably preferring to leave it to the administration assisted by outside help if required. The notion of the board "...remaining in the background, limiting its role to major decisions, encouragement of the management team, and ratification of the contract" (p. 39) was suggested by Seitz (1993). That administrators have been given this difficult mantle may tend to explain why Polishook and Naples (1989) reported negative administrative views on both shared governance and collective bargaining, citing them as "...forums to provide two bites at the same apple" ( $p$. 5). They noted some dismay among university presidents following the arrival of faculty unions when it was said "...but they promised that the senates would disappear when the union was elected" (p. 6). Administrators would, therefore, appear to be suggesting that there is a not so great distinction between collective bargaining and shared governance. However, Filan (1992) described the attitude toward collective bargaining that participants in a shared governance model expressed as a "balancing act". He contrasted the inclusiveness of shared governance, irrespective of constituency, with the exclusiveness, often hostile, of collective bargaining (p. 4). Piland, Lovell, and Janes (1981) proposed a team management model including faculty and administration that could even include divisional chairs, traditionally elected from the faculty, on the management team for negotiations with the faculty union. They noted that such representation would break down barriers and encourage better understanding of the issues which sometimes get clouded in the heat of the negotiations battle (pp. 17-18). 
However, there remains the huge question as to whether unionized participants, in any collaborative model that touches on collective bargaining, could ever be truly independent. For, as Wood (1991) found, there is a clear expectation on the part of trade unions, and with it pressure is brought to bear, that employee board members will represent the best interests of the unions in board activities and decision-making. This expectation makes it difficult for individual employee board members to live up to the ideal of being members-atlarge with the interests of the whole college, the common good, as their goal ( $p$. 267). Consequently, boards, when dealing with sensitive labour issues, have tended to move much of the business to in-camera meetings with the express intention of excluding internal board members, or at least compelling them to observe oaths of confidentiality (p. 268).

It would appear that the last twenty-five years has not really provided any clear indication of whether labour relations and shared governance can peacefully coexist. In terms of forging a relationship between two apparently disparate cultures, it may be that a longer period of time is required.

\section{The Advantages and Disadvantages of Shared Governance}

It was stated that shared governance is not a precise science, and that has been demonstrated in the many differing observations noted. It can differ from institution to institution and can mean different things to the participants 
depending upon their background and values. It is hardly surprising, then, that there is a fairly even split between advantages and disadvantages of shared governance according to the literature.

\section{Advantages of Shared Governance}

- Fosters greater understanding and acceptance of decisions by the entire institutional community (Draper and Van Groningen, 1990);

- Encourages long term planning in preference to quick, short term decisionmaking (Lovas, 1994);

- Leads to institutions which are better equipped to pursue the common good, both for themselves and for society in general (Carver, 1997);

- Empowers the participants and, by extension, those from whom they are drawn (Wirth, 1991);

- Focuses on utilizing the expertise of professionals within an institution, reflecting the norms and values of an academic community, modeling democratic thought and increasing job satisfaction and commitment (Wood, 1995);

- Leads to more intense commitment on the part of stakeholders to implement the decisions (Draper and Van Groningen);

- Facilitates the development of collegial relationships and an improved environment within the institution (Wirth); 
- Can lead to productivity from faculty and staff as they have ownership in the operation and can lead, consequently, to student success (Gulassa, 1989);

- Provides an avenue for the constituents to develop a greater breadth of understanding of the issues faced by education in general and their institution in particular (Wirth);

- Facilitates increased meeting of employee needs for self-identity, autonomy, achievement, and psychological growth (Draper and Van Groningen);

- Reduces the influence and bias of the president and senior administrators on boards on account of the presence of internal constituency members (Wood);

- Provides opportunities for conflict resolution even in cases of divergent objectives, through consultation and joint decision-making (Draper and Van Groningen);

- May lead to improved communications across campus (Wirth); and

- May lead to leadership training and other professional development for faculty, staff, and students (Draper and Van Groningen).

\section{Disadvantages of Shared Governance}

- Has a time-consuming reputation, for the decision-making process itself as well as for the various groups involved, with a likely significant impact on administrators (Draper and Van Groningen, 1990); 
- Can lead to the 'balkanization' of the decision-making process whereby shared governance slows down and fails to meet the immediate need of a rapidly changing environment (Flanigan, 1994);

- Discriminates between board members because institutions do not provide adequate levels of training for internal members (Filan, 1992);

- Requires recognition of the appropriate role of administrators, faculty, staff, students, and trustees (Wirth, 1991);

- Suffers because it is perceived as costly in terms of time and money (Gulassa, 1989);

- Slows the college response to societal change and community demands, thereby striking at the very purposes of such institutions (Nussbaum, 1995; Baliles, 1996);

- Results in greater difficulty for administrators in implementing new programs and otherwise meeting their responsibilities because they have to spend more time implementing the shared governance process (Lovas, 1994);

- Effectiveness is hampered by the making of decisions by individuals with limited expertise (Draper and Van Groningen);

- Viewed by outsiders as self-serving because special interest groups have a tendency to focus more on their needs than on the global needs of the institution (Flanigan); 
- Systematically undermines and weakens the office of the president through the actions of the other participants in the shared decision-making process (Baliles);

- Runs the risk that teaching and learning may become secondary priorities as representatives spend time away from work and the classroom (Wirth);

- Results in middle managers who are uninformed about matters they will be called upon to implement on account of their potential exclusion from decisions made through shared governance committees (Draper and Van Groningen);

- Tends, itself, to be bureaucratic in nature while shared governance is often cited as the alternative to bureaucracy (Lovas ); and

- Identifying responsibility, authority, and accountability is not always clearly managed among the range of participants and participant groups (Wirth).

\section{Summary}

The passage of time since shared governance became topical in the community college context has made interesting reading in the considerable amount of literature available on the subject. It seems that the tentativeness and philosophical diversity of the 70's was replaced by a dogged determination to make shared governance work in the 80's and that, in turn, has been replaced by a period of reflection and, not a little, doubt in the 90 's. Throughout the three 
decades, authors have divided into proponents, standing on the side of inclusiveness and even moral justification, and detractors, citing the very real issue of self-interest on the part of board members who coincidentally are members of the faculty, support staff, and student constituencies. In some ways the issues of those early days are still with us today and seem no nearer to any satisfactory resolution.

In the midst of the confusion, however, there are several strong themes that emerge from the writings on shared governance which served as the basis for this particular study. One of the most basic issues is the actual role of the board itself. Given that colleges are democratic organizations in which a good many of the stakeholders have the ability to control their own affairs, it might seem that boards are an unnecessary layer of officialdom. However, there is strong indication that the boards play an important role in providing the high level, long term vision that colleges need but are not particularly inclined to explore. Two further points arise from this designated purpose for boards-1) some body has to take the long term view because no one else will, not even the presidents whose tenure is far too insecure to allow anything other than a short term perspective, and 2) it seems entirely appropriate that all the stakeholders have a say in the long term future of institutions, hence the inclusion of internal members on boards. Shared decision-making is seen as being more ethical than any hierarchical form of governance and it is, at the same time, both reflective of and a major contributory to the climate of an institution. 
There are doubts about the ability of boards. Some express concerns about the commitment and knowledge of the external members but acknowledge their independence and connection to the general community. While others acknowledge the commitment and knowledge of the internal members but express concerns about their real or perceived conflict of interest. The two groups, internal and external, certainly seem to exist as separate entities in virtually all the literature. Their differences form the basis of most of the scholarship. Perhaps the reason for the emphasis on differences is the fact colleges are not by nature collegial organizations; and there is a long history of confrontation between boards and administrations on one side and faculty, staff, and students on the other. Consequently, bringing the combatants together in the shared governance model does not necessarily make for a marriage made in heaven. There is much said of the need for trust in the relationships that form the structure of shared governance, but little evidence that the trust is generally there.

Both the USA and Canada have witnessed, along with the growth in shared decision-making, a tendency toward centralization of decision-making at the state or provincial level. Of course, the latter serves to diminish the impact of the former. However, it has also been recorded extensively that participative decision-making tends to undermine the status of presidents who no longer have virtual absolute authority. Conversely, presidents are now viewed as having a more prominent role in dealing with external agencies, and so it is clear that they 
have been at the forefront of change during this period under review. As a result, presidents have had to acquire new sets of leadership skills in order to fulfill the expectations of their office.

One of the most forceful themes to emerge from the literature was the necessity for clear procedures to make shared decision-making work. However, opinions were split on whether such procedures should be developed internally, to reflect the local culture, or externally, to avoid self-interest. There was virtual unanimity that shared decision-making is a tedious, time-consuming process. Willingness to endure such hardships clearly varies according to the degree of philosophical value that the constituents placed on shared decision-making. Again, however, most writers could agree on the need for the decision-making process to be open to scrutiny through extensive communication with all the stakeholders.

The inclusion of internal constituents-faculty, staff, and students--on boards of governance was bound to have an impact on those people. However, the results were surprising. Students seem to have made little headway as a group although test scores would underline the value of a collegial atmosphere in which to study. Support staff seem to suffer something of an inferiority complex in terms of their relationship with external board members, administration and faculty. Staff also appeared to have difficulty sorting out the relationship between unions and governance bodies and the overlap of their interests. The pursuit of self-interests rather than the common good was a 
common charge leveled at staff and faculty board members and forms probably the greatest general argument against shared governance. It was, of course, one of the main themes of this study. Faculty, who were by far the most vociferous champions of shared governance, have also tended to make the greatest contribution toward it from among the internal constituents. However, it is not clear that the advancements over the past twenty-five years have brought any greater degree of harmony and trust to college campuses. This may be because relatively few faculty actually want to get involved in governance in spite of the large-scale interest in the philosophy.

This study of shared decision-making focused on general matters and also those connected with financial affairs and labour relations. The research questions anticipated that board members would profess problems related to the two latter areas. That anticipation was very much underscored by the literature. Internal members faced the strongest charge of conflict of interest in matters of the budget where they have personal interest and several aspects of labour relations, the most notable of which would be contract negotiations. The latter also served to illustrate the overt alliances formed between unions and unionized members of boards which made authors and external members uneasy. Clearly many employees and students have viewed the changes in governance more as a shifting of power than a sharing of power. The evolution of shared governance remains incomplete and should provide fruitful content for study for some time to come. 


\title{
CHAPTER III RESEARCH METHODOLOGY
}

\author{
Introduction
}

This chapter details the research methodology which was applied in the study. In a study which is based solely on the views of a population, in this case the board members of the colleges and university colleges covered by the College and Institute Act of British Columbia, it is important that the process for gathering the views and the instrument to achieve that task are effective, fair, totally inclusive, and easily understandable by the participants. Furthermore, the techniques used to sort and analyze the data obtained from the participants must be statistically sound and accurate. The research methodology in this study contains the highest level of integrity that is obtainable and has been applied with a similar level of rigour.

The survey questionnaire represents a refinement of the instrument used in a similar study carried out by the researcher in early 1996. In addition, the questionnaire was reviewed by colleagues in the British Columbia postsecondary system. Several questions were added, deleted, and modified as a result of input from this source as well as from the researcher's dissertation committee. Further, the process of distributing the questionnaires, arranging for their collection, and following-up to encourage additional participation was similar 
to the approach adopted in the earlier study which had proved successful. As a senior administrator in the British Columbia post-secondary education system, the researcher is both familiar with the system and the structure of governing boards within it. Accordingly, this background facilitated entry to the population and execution of the study.

\section{Methodological Overview}

The purpose of this study was to examine three aspects of leadership through shared governance:

- the sharing of power,

- the effectiveness of the shared decision-making process, and

- how real or perceived conflict of interest on account of the employment or student status of some of the board members has been addressed. These aspects of leadership were studied in three particular contexts:

- board decision-making in general matters of business,

- board decision-making in financial matters, and

- board decision-making in the field of labour relations.

Therefore, the conceptual framework of the study took the form of a matrix with the aspects of leadership interacting with the contexts in which they are placed. 
The views of all board members were sought relative to the contextual aspects noted above and were gathered in such a way as to allow for the following analysis and comparison:

- between colleges, without making distinction between the constituents;

- between constituents, without making distinction between the colleges they represent; and

- by total population, in a form that permitted comparison to the results obtained in a similar study conducted by the researcher in early 1996.

\section{Research Design}

The focus of this investigation was to study the views of board members in the British Columbia college system. The intended outcome of the study, in addition to generally adding to the body of knowledge, was to essentially evaluate the shared governance structure and procedures in the province. Both views and attitudes toward shared governance in general and specific to the participants' own institutions were sought. Accordingly, the technique selected by the researcher to best meet the requirements of the study was an explanatory survey by way of a questionnaire. Ary, Jacobs, \& Razavieh (1990) noted "An explanatory survey is a form of causal-comparative research,... [it] seeks to 
explain attitudes and behaviour on the basis of data gathered at a point in time" (p. 407).The population under review encompasses the potential participation of seventeen institutions and approximately two hundred and fifty-five members. Therefore, the study included the entire population in the hope of obtaining an acceptable level of representation by college and constituency of board members from the questionnaire returns. It was felt by the researcher that even a moderate return through the survey process would provide a richness and breadth of information which could not be achieved using other techniques of a qualitative nature in association with a small sample of the population (Ary, Jacobs, \& Razavieh, 1990, p. 421).

The researcher designed the questionnaire in a series of sections which explore the tenets of the research questions. Each section of questions was contextual, starting with decision-making in general matters of board business, moving into financial matters and, finally, into labour relations. In each section, questions were asked about the three aspects of leadership selected as the focus of this study of shared governance, namely sharing of power, the quality of the shared decision-making process, and how the issue of conflict of interest related directly to the status of the employee and student board members has been addressed. In addition, participants were asked to indicate from a list of suggested themes of effective boardsmanship which, if any, were present in their own board's culture. This approach to eliciting a wide array of information was considered appropriate in order to achieve a meaningful evaluation of the shared 
governance model, including its structure and procedures, from a number of different perspectives. Ary, Jacobs, \& Razavieh (1990) opined that "The most challenging type of survey is one that seeks to measure intangibles, such as attitudes, opinions, values, or other psychological and sociological constructs ${ }^{n}$ (p. 408).

The study was endorsed by the Advanced Education Council of British Columbia in a similar manner to the earlier study in 1996. Such endorsement not only indicated the interest of this organization, which represents all college boards in the province, in the subject matter, but also served to encourage individual board members to participate. The Council has further expressed its interest in the area of shared governance research by inviting the researcher to present findings from studies at several meetings and conferences.

The process of administering the questionnaire and gathering the data was intended to be efficient and fair. It was important that the participants were fully aware of the purpose of the study and the nature of their participation in it. Accordingly, the researcher articulated procedures that not only clearly stated his intentions but also stressed the voluntary nature of taking part and the complete extent to which participants would enjoy personal anonymity. Furthermore, the researcher designed a process that facilitated participation, and while being mindful of their commitment of valuable time ensured that time was the only cost to the participants. 


\section{Validity and Reliability}

Huck and Cormier (1996) noted useful synonyms for validity and reliability. The former was called "accuracy" while the latter was called "consistency". Therefore, the data from a study should be consistent throughout to accurately reflect the views of the participants. The means to achieve both these qualities were through the design and application of the measurement instrument and careful analysis of the resultant data.

This study utilized a questionnaire containing a series of questions that were intended to elicit clear, unambiguous answers from the participants. The questions focused only on the aspects of leadership in the contexts of board decision-making noted earlier. The purpose of the questionnaire was to facilitate measurement of the views of board members in the areas contemplated in the study and was intended to achieve the highest degree of correlation between the accuracy and the consistency of the data obtained. In addition, the importance of presenting the findings of the study, based on the data obtained, in a form that attempts to answer the research questions cannot be overemphasized. The research questions are the raison-d'être of the study, and the findings are directly related to the questions although, in the end, they may not provide the absolute answers. The findings will, nevertheless, contribute to the growing body of knowledge on the subject matter--shared governance in the college setting. 


\section{Data Collection}

This quantitative study of board members' views on aspects of their leadership role within certain contexts sought to determine if differences exist in those views between colleges, between the constituent members, and between the whole population compared to a similar population in an earlier study. The researcher strove for accurate and consistent data to be obtained from the measurement instrument because that was crucial to the integrity of the study. Therefore, the following sections describe how the appropriateness of the data was ensured.

\section{Entry to the Population}

The researcher is employed in the British Columbia post-secondary education system and serves as secretary to his institution's board. Accordingly, he is familiar with the board structure in the province and the changes that have taken place as a result of the 1995 legislative amendment known as Bill 22. This study focused on all college board members in British Columbia and entry to the population was managed in two steps: (1) a general announcement at the annual conference of board members during a presentation of the findings of the earlier study carried out by the researcher in 1996 in which this study was 
portrayed as a natural follow-up, and (2) a letter inviting voluntary participation was sent to every member of each board.

\section{Selection of Sites/Subjects}

In light of the size and diversity of the potential population and the fact that the diversity itself is the basis of one of the research questions, it was not considered necessary to adopt any sampling methods (Huck and Cormier, 1996). Accordingly, the study was open to the entire population of board members in the British Columbia college system, amounting to the potential of seventeen institutions and approximately two hundred and fifty-five members. The breakdown of members was one hundred and fifty-seven lay members appointed by the provincial government, seventeen elected faculty members, seventeen elected support staff members, thirty elected student members (there were four vacancies), seventeen ex-officio presidents of the colleges and university colleges, and seventeen chairs of education councils at each institution. Membership of college boards is fairly volatile. Not only are the student members subject to a one year term, but chairs of education councils who sit on the boards ex-officio also tend to serve fairly short terms, often again one year. In addition, in 1997 there was a much higher turnover of government appointees than usual, including the termination of some members mid-term, due to a policy decision to introduce younger members onto boards. As a result 
of this increased volume of membership changes, the researcher used both current board membership lists and former lists. Where a change had taken place in the two months around the time of the study, the questionnaire was directed to the former member on the basis that his/her greater degree of experience over the replacement would contribute to the richness of the data. It is possible, however, that the attitudes of recently departed members, particularly given the controversial nature of some of the changes, may have influenced willingness to participate and some of the responses.

Participation was entirely voluntary and the voluntary nature was stressed by the researcher even as he endeavoured to make potential respondents fully aware of the nature and importance of the study and the value of their participation.

The researcher followed the undernoted steps in facilitating participation in the study:

- June, 1997; the researcher presented a paper at the Advanced Education Council of British Columbia Annual Conference on the results of his study undertaken in early 1996 related to a preliminary review of the literature for this dissertation. He made attendees aware of the upcoming study and its relationship to both the presentation and to the dissertation work;

- September, 1997, the researcher sent a package to every board member in the province (coming within the parameters of this 
study) containing a letter of explanation of the study and invitation to participate (with clear indication of its voluntary nature)--see Appendix A-, a questionnaire--see Appendix B-, and a statement of informed consent--see Appendix C--to be completed by each participant. The package also contained a mail-prepaid, addressed envelope for the return of the questionnaire and consent statement;

- October, 1997, a letter--see Appendix D-was sent to all board members in the province covered under this study thanking those who had already returned the questionnaire and inviting those who had not to do so or contact the researcher for another copy of the questionnaire;

- November, 1997, in light of a relatively low response rate at that stage (although very close to the sort of return predicted by Ary, Jacobs, \& Razavieh, 1990, p. 408), a letter--see Appendix E--was sent to the president and board chair of each college requesting their assistance in encouraging their members to participate;

The researcher takes the view that the data and, particularly, the analysis and conclusions will be of interest to the participants as well as to the researcher and will endeavour to make the information accessible to the population. 


\section{Protection of the Subjects}

Hawley (1993) noted "If research is to benefit the scientific community and society at large, each researcher must adhere to a strict code of ethics". It is for that reason that this study had two levels of protection of subjects built into it. A protocol statement that detailed the proposed process of protection was submitted to the Committee on the Protection of Human Subjects, University of San Diego for approval and was subsequently granted. In addition, the protocol statement was also submitted, as a requirement of the researcher's own institutional policy, to the Research and Ethics Committee, Malaspina University College, British Columbia and received the necessary approval. Finally, the approved process was described in the statement of informed consent which each potential participant was asked to endorse and return with his/her completed questionnaire.

The population of subjects consisted of lay persons appointed by the provincial government: faculty, support staff, and students elected by their constituencies: and the college president and chair of the education council who hold ex-officio positions on each board of governance. None of the participant groups, in the context of their involvement in shared governance, would appear to fall within the at-risk categories, however, every precaution was taken as follows: 
Level 1 (applied to all participants).

As an addendum to the questionnaire, subjects were asked to identify their college and constituency in order to facilitate two of the three areas of analysis. There is only one president, one chair of education council, one faculty member, and one staff member on each board and, therefore, by identifying themselves they became known to the researcher;

In the analysis of data, conclusions and recommendations, and any other product of the study, the researcher did/will not identify a college other than by an anonymous label and did/will not associate the member of any constituency with any college or otherwise serve to reveal his/her identity. Therefore, while identity might be known to the researcher, complete anonymity was/will be assured in the dissertation and any other report. The completed questionnaires (except as noted in Level 2) remained in the custody of the researcher throughout the process of analysis and writing of the dissertation. Upon completion of the latter, the questionnaires were destroyed.

Level 2 (applied only to the employee and student members of the Malaspina University College Board).

In view of the researcher's position at Malaspina, special protection was afforded those board members who also have even 
an indirect employment or student relationship with the researcher.

Returned questionnaires from the special group, identified by unique marking, were received, processed, loaded into a computer program, retained, and ultimately destroyed by a special associate in Vancouver, BC. This practice permitted the researcher to manipulate the data and perform the analysis without ever knowing details of the responses from any member of the special group.

\section{Instrumentation}

The researcher developed a questionnaire for the study which was, in part, based on his instrument from a similar study carried out in 1995/96. This allowed for comparison over the period of time on specific questions. In addition, questions in the form of statements were designed to obtain board members' views and attitudes which would serve to answer the research questions posed in the study:

1. Is there a difference among British Columbia colleges in certain aspects of boardsmanship, namely the sharing of power, the effectiveness of the shared decision-making process, and how real or perceived conflict of interest of employee and student board members has been addressed when it comes to decision-making in respect to general matters of business, financial matters, and labour relations matters? 
2. Is there a difference among board members, according to the constituency from which they are drawn, i.e. appointed members; elected faculty; elected support staff; elected students; presidents; and education council chairs, in certain aspects of boardsmanship, namely the sharing of power, the effectiveness of the shared decision-making process, and how real or perceived conflict of interest of employee and student board members has been addressed when it comes to decision-making in respect to general matters of business, financial matters, and labour relations matters?

3. Is there a difference between the views elicited from this study and those from an earlier study in respect to certain aspects of boardsmanship, namely the sharing of power, the effectiveness of the shared decision-making process, and how real or perceived conflict of interest of employee and student board members has been addressed when it comes to decision-making in respect to general matters of business, financial matters, and labour relations matters.

The study is three dimensional in nature and, therefore, each research questions leads to three hypotheses. The following shows the assignment of questions contained in the questionnaire--see Appendix B-to each hypothesis:

H1. There is no significant difference, at the .05 confidence level, among British Columbia colleges concerning the sharing of power in the shared governance model for decision-making in general matters of business, financial matters, and labour matters. (Survey questions 1-8, 22-23, 33-35, 44-45) 
H2. There is no significant difference, at the .05 confidence level, among British Columbia colleges concerning the effectiveness of the shared decision-making process in the shared governance model for decision-making in general matters of business, financial matters, and labour matters. (Survey questions 9-15, 24$32,36-40)$

H3. There is no significant difference, at the .05 confidence level, among British Columbia colleges concerning how real or perceived conflict of interest of employee and student board members is dealt with in the shared governance model for decision-making in general matters of business, financial matters, and labour matters. (Survey questions 16-21, 27-29, 41-43, 46)

H4. There is no significant difference, at the .05 confidence level, among board members, according to the constituency from which they are drawn i.e. appointed members; elected faculty; elected support staff; elected students; presidents; and education council chairs, concerning the sharing of power in the shared governance model for decision-making in general matters of business, financial matters, and labour matters. (Survey questions 1-8, 22-23, 33-35, 4445)

H5. There is no significant difference, at the .05 confidence level, among board members, according to the constituency from which they are drawn i.e. appointed members; elected faculty; elected support staff; elected students; presidents; and education council chairs, concerning the effectiveness of the shared decision-making process in the shared governance model for decision- 
making in general matters of business, financial matters, and labour matters. (Survey questions 9-15, 24-32, 36-40)

H6. There is no significant difference, at the .05 confidence level, among board members, according to the constituency from which they are drawn i.e. appointed members; elected faculty; elected support staff; elected students; presidents; and education council chairs, concerning how real or perceived conflict of interest of employee and student board members is dealt with in the shared governance model for decision-making in general matters of business, financial matters, and labour matters. (Survey questions 16-21, 27-29, 41-43, 46)

H7. There is no significant difference, at the .05 confidence level, between the views to be elicited from this study and those from an earlier study concerning the sharing of power in the shared governance model for decision-making in general matters of business, financial matters, and labour matters. (Survey questions 4-8, 33-34)

H8. There is no significant difference, at the .05 confidence level, between the views to be elicited from this study and those from an earlier study concerning the effectiveness of the shared decision-making process in the shared governance model for decision-making in general matters of business, financial matters, and labour matters. (Survey questions 9-10, 25-26, 30-32, 37) H9. There is no significant difference, at the .05 confidence level, between the views to be elicited from this study and those from an earlier study concerning 
how real or perceived conflict of interest of employee and student board members is dealt with in the shared governance model for decision-making in general matters of business, financial matters, and labour matters. (Survey questions $16-20,27,29,42,46$ ) In addition, questions forty-seven to forty-nine on the questionnaire, which are multi-part in nature, explore the characteristics of power sharing, effectiveness of the shared decision-making process, and how conflict of interest has been addressed within the participants' own colleges.

The questionnaire consisted of nine pages, divided into six sections of data together with a final section containing personal details of each participant. The latter included information on the constituency group from which the participant was drawn, the name of their college, and the number of years spent on the board. This information, confidential in nature and carefully guarded throughout the study, was required to manipulate the data to correspond to the research questions.

The questions, numbered one to forty-nine but actually totaling sixty-seven including multi-part questions, were arranged into sections which again corresponded to the focuses of the research questions. These sections included 1) Board decision-making on general matters, but excluding business related to financial matters and labour relations matters; 2) Board decision-making related solely to financial matters; 3 ) Board decision-making related solely to labour relations matters; 4) Board 
effectiveness in the sharing of power; 5) Board effectiveness in shared decision-making; and 6) Board effectiveness in dealing with the real or perceived conflict of interest of employee and student members. The first three sections sought to obtain board members' opinions, views, and values on typical board decision-making tasks in the context of the shared governance environment while the second three sections sought members' views on the existence, or otherwise, of typical shared governance qualities within their own institutions. Thus, the first three sections were somewhat philosophical in nature while the second three sections were more practical. The blend of the two sets of data provided the foundation from which to address the research questions and generally evaluate the legislated shared governance model in British Columbia.

Participants were asked to respond to the questions, expressed in the form of statements, using a Lickert-type attitude inventory ranging from strongly disagree to strongly agree in the first three sections and from non-existence to strong-existence in the second three sections. The use of a Lickert-type attitude inventory was considered appropriate by the researcher because the large volume of data obtained in the study could be made readily quantifiable using this technique, thereby facilitating analysis of the date and determination of the findings (Huck \& Cormier, 1996, p. 556). Both Huck \& Cormier (p. 557) and Ary, Jacobs, \& Razavieh 
(1990, p. 421) discussed the ability to accommodate a high number of

participants and a high volume of data through a Lickert-type

questionnaire, but also noted its weakness was the possibility of

misinterpretation of the questions by some participants. Accordingly, the

researcher compiled the questionnaire using already tested question from

the previous study together with questions which were intended to be

clear statements related to the research questions. The questionnaire was

reviewed in draft form by Dr. William E. Piland, Dissertation Chair, and Dr.

Jerome Della Mattia, Executive Director of the Advanced Education

Council Of British Columbia and several of their suggestions were

incorporated into the final version.

\section{Approach to Data Analysis}

The structure of the measurement instrument was based on the matrix of aspects of leadership in shared governance and decision-making contexts.

Participants responded to a series of questions in the form of statements with answers via a 5-point Lickert scale ranging from strongly disagree, disagree, neutral, agree, to strongly agree. Participants were also asked to indicate from a list of suggested characteristics of effective boardsmanship which, if any, were present in their own board's culture. In addition, there was the option of not responding to any statement, for whatever reason. 
The data were entered by the researcher (except in the case of Level 2 protection of subjects where independent data entry took place) and processed using the Statview SE+ Graphics Program on Apple hardware. The data were manipulated to produce the undernoted levels of analysis which permitted comparison: (1) among colleges, (2) among constituencies, and (3) with data collected in an earlier study. The selected techniques were standard to quantitative research and are discussed by Huck and Cormier (1996) and Ary, Jacobs, and Razavieh (1990):

Level A: Means and Standard Deviations for all Survey Questions This analysis revealed the mean score on each statement for the whole population. Where questions coincide with those included in the earlier study, a time comparison was able to be made.

Level B: Frequency Distributions

This analysis related to the demographics of the respondents. Consequently, a breakdown of returns by constituency and college was revealed.

Level C: One-Way ANOVA for each Question by Constituency The researcher established a level of significance of .05 as appropriate to this type of data analysis, meaning the chances of rejecting a true null hypothesis become equal to 5 out of 100 . If a value of probability statement was revealed at less than .05 it 
indicated incidence of significant statistical difference between the views of the different constituents on a particular question. Such a difference could be between at least the high and low mean scores. However, by doing a Post-Hoc Analysis using the Scheffe type paired contrasts technique, it was possible to determine if a significant difference emerged between any pair of the constituents. The analysis, therefore, revealed any differences between respondents according to constituency.

Level D: One-Way ANOVA for each Question by College A level of significance of .05 was established. A value of probability statement at less than .05 revealed significant difference between the colleges on a particular question. Such a difference could be between at least the high and low mean scores. However, by doing a Post-Hoc Analysis using the Scheffe type paired contrasts technique, it was possible to determine if a significant difference emerged between any pair of the colleges. The analysis, therefore, revealed any differences between respondents according to college.

Level E: One-Way ANOVA for Assessment of Own Board Effectiveness in Aspects of Leadership, by Constituency A level of significance of .05 was established. A value of probability statement at less than .05 revealed significant difference 
between the constituent groups on a particular statement. Such a difference could be between at least the high and low mean scores. However, by doing a Post-Hoc Analysis using the Scheffe type paired contrasts technique, it was possible to determine if a significant difference emerged between any pair of the constituency groups. The analysis, therefore, revealed any differences between respondents according to constituency.

Level F: One-Way ANOVA for Assessment of Own Board Effectiveness in Aspects of Leadership, by College

A level of significance of .05 was established. A value of probability statement at less than .05 revealed significant difference between the colleges on a particular statement. Such a difference could be between at least the high and low mean scores. However, by doing a Post-Hoc Analysis using the Scheffe type paired contrasts technique, it was possible to determine if a significant difference emerged between any pair of the colleges. The analysis, therefore, revealed any differences between respondents according to college.

Level G: Two-Way ANOVA for a Pre/Post Test by Constituency Group Concerning the $1995 / 96$ and $1997 / 98$ Studies A level of significance of .05 was established. A value of probability statement at less than .05 revealed significant difference 
on a particular matched (between the two studies) statement as it related to the pre/post test and/or the constituency groups and /or the interaction between the two sources of study.

\section{Background of the Researcher}

Ary, Jacobs, and Razavieh (1990) noted that a research proposal should demonstrate that the researcher knows what he is looking for, how it will be recognized, and why it is worthwhile looking for it in the first place (p. 462). This researcher trusts that his background and the statements of intent that were explicit in this study have satisfied the requirements called for above.

The researcher is vice president and bursar of a university college in British Columbia. He is an accountant with professional designations from the United Kingdom and Canada. In addition, he holds a master's degree in education with a specialty in leadership. As a member of his college's senior management team and secretary to the board of governors, he has an interest in boardsmanship in general and a particular interest in the implications of the changes in governance which have been taking place over the last three years in British Columbia. The researcher has constantly sought to marry academic research with practical application in his professional capacity. Accordingly, he has conducted research, published, and presented on various aspects of governance including board/administration relationships and shared governance. 


\section{Summary}

This study has the clear purpose of determining the views of board members (based on values and practices) on the impact of shared governance on certain aspects of leadership in prescribed contexts of decision-making. In order to make that determination, it was crucial that the research methodology to be used was sound and directly related to the issues in question. The structure of the survey instrument and the specific questions asked focused solely on the research questions and, consequently, provided accurate and consistent data to allow concise analyses and conclusions.

The process of gathering and processing the data was efficient while providing the appropriate level of integrity, protection, and information to the participants. A goal of the study was to make the participants happy to have played a part in it and to be able to place a value on the results which have ultimately been obtained. Reaction to the findings will confirm attainment of this goal. 


\section{CHAPTER IV PRESENTATION AND DISCUSSION OF THE FINDINGS OF THE STUDY}

\section{Introduction}

This chapter and its related appendices ( $F$ through $O$ ) detail all of the data obtained in this quantitative study; present the data in a format to permit both descriptive and comparative analyses; and discuss the conclusions to be drawn from the data in the context of the three research questions and the hypotheses for each question. Presentation and discussion of the descriptive statistics focus on the response to the questionnaires, analyzed by constituency group and college; the length of experience of board membership among the participants; and the grand mean and standard deviation values for all statements included in the questionnaire (see Appendix B). Presentation and discussion of the comparative statistics focus on the data related to the research questions analyzed by constituent groups and colleges relative to decision-making context, and aspect of leadership; and assessment of the participants' own boards' effectiveness in aspects of leadership, analyzed by constituent groups and colleges. Thereafter follows the practical significance of the study involving the merger of the hypotheses, data, and findings in an attempt to answer the question "What do the results mean?". 


\section{Presentation and Discussion of the Descriptive Statistics}

Reference throughout this section of the chapter is made to the following appendices:

- Appendix F: Summary of Questionnaire Returns, by Constituent Group;

- Appendix G: Summary of Questionnaire Returns, by College;

- Appendix H: Summary of Board Experience, by Years and Percentage-Frequency Distribution;

- Appendix I: Summary of Data by Decision-Making Context, Aspect of Leadership, and Percentage-Frequency Distribution; and

- Appendix J: Summary of the Assessment of Own Boards' Effectiveness in Aspects of Leadership and PercentageFrequency Distribution. 


\section{Summary of Questionnaire Returns}

Appendix F shows the potential count of participants based on the established membership of each board, the actual count of participants, the percentage distribution of the actual count, and the actual count expressed as a percentage of the potential count. Further, the data were analyzed by constituent group and by the population of the study. The distribution of the actual count ranges from $58 \%$ for appointees to $6 \%$ for students. The actual count as a percentage of the potential count shows a range from $77 \%$ for presidents to $20 \%$ for students. Similarly, Appendix $\mathrm{G}$ shows the same data broken down by college. Colleges are named $A$ through $Q$ to protect their identity in this study. The distribution of the actual count shows a range from $10 \%$ of the total count coming from College $M$ to $3 \%$ from College $B$ and College $P$. The actual count as a percentage of the potential count shows a range from $69 \%$ for College $M$ to $21 \%$ for College $P$.

The timing of the study coincided, unfortunately, with an unusually high degree of instability of membership among the college boards in British Columbia. Colleges have been inconsistent in holding elections for employee and student members. Furthermore, education councils have also been inconsistent in the timing of electing their chairs. As a consequence, there were a number of instances in certain colleges where internal members had only very recently joined the boards. The researcher attempted, wherever possible, to 
include the former members of boards rather than new members in order to maximize the experience and knowledge base for the study. There was a potential downside to this approach, however, in that retired internal board members might have felt that their duty was over, or might have been upset by their tenure having come to an end and, consequently, might not have been motivated to participate in the study. The researcher concluded that the potential richness which the experience would bring to the study justified the risk of some non-participation. In a similar vein, the Ministry of Advanced Education, Training, and Technology announced an unusually high number of appointments just before the study was due to commence. While most of these appointees were replacing members who had reached the end of their normal aggregate term of six years, several were replacing members who had not served six years and could reasonably have expected to be routinely reappointed or just left alone depending on how many years they had served on their boards. This latter action came as a result of the adoption of new government policy aimed at increasing the number of young people on college boards. Consequently, this high turnover of appointed members presented the same problem as for internal members and persuaded the researcher to again attempt to include former members rather than new members. However, there also remained the downside of those retired members potentially lacking the motivation to participate in the study. In addition, the potential count of participants was already depleted before the study by several vacancies among appointed 
members (impossible to quantify due to the flexible approach of government toward the optimum number of appointees) and student members (amounting to four or $12 \%$ of the potential participants).

All of these factors noted, in addition to the almost natural resistance to complete "yet another survey", may have served to produce a return rate of $40 \%$. This rate was slightly lower than the return rate in the 1995/96 study conducted by the researcher in 1995/96 and was somewhat disappointing given the publicity this study had received within the provincial college system and the interest shown in it at several education forums. However, as Ary, Jacobs, and Razavieh (1990) noted, typically the return rate from studies adopting an explanatory survey instrument tends to hover around the $40 \%$ level (p. 408). What was crucial, however, to ensure that the study findings were reliable and could be generalized to any extent was a reasonable representation of responses across the constituent groups and colleges because these were two of the key lenses through which the research questions were examined. (The third lens, of course, was the matched statements in the two studies of 1995/96 and 1997/98.) And, as Appendix F shows, fair distribution across the constituent groups was achieved ranging from $77 \%$ of presidents to $20 \%$ of students. The latter return was disappointing considering the presence of students on boards was identified in literature as being probably the most controversial ingredient of shared governance. And, the views of the students would surely have enriched the findings of the study, however, at least six participants was better than none 
at all. The response from the other constituent groups-appointees, faculty, staff, and education council chairs-ranged around the $40 \%$ to $50 \%$ level and, thereby, offered good insight from each constituency. Similarly, as Appendix G shows, all colleges and university colleges in the study were represented in the returns. The response rate ranged from $69 \%$ of the membership of College $M$ to $21 \%$ of College P. Most institutions rated in the $30 \%$ to $40 \%$ range and, therefore, permitted cautious generalization to the whole population within each institution and to the post-secondary system as a whole.

\section{Summary of Board Experience}

The data contained in Appendix $\mathrm{H}$ were gathered to provide a demographic background of the participants in the study. The data did not play any direct part in addressing the research questions of the study. Rather, the purpose of collecting the data was to determine the overall level of experience among the board members and the extent of participation by retired appointed members, who would tend to have served six or close to six years on their boards. From the results, it would appear that relatively few retired members took the opportunity to participate and the absence of their knowledge and experience was regrettable.

The mean experience of 2.909 years and the fact that $47 \%$ of the participants had less than three years experience underscored the high and 
frequent turnover of board members of all constituencies. This is particularly true of elected students whose term is only one year and education council chairs whose term often only amounts to one year due to the high turnover of membership on education councils. In addition, elected faculty and staff members, who can serve a three year term, and presidents came onto boards in 1995 with the introduction of shared governance and now, generally, were in their third year of membership. The present government of British Columbia, which conceived the legislation behind shared governance, has now been in power for almost seven years (after one re-election). As the sole authority for appointing members to boards, it had exercised that right to the extent that there were now very few, if any, members who were appointed by the previous government. This fact was significant to the study and contrasts with the situation when the researcher conducted a similar study in 1995/96 when at least one third of the membership had been appointed by the previous government. If one assumes that appointees, given that they are patronage appointments, generally share something of the same philosophies as the political party which has appointed them, one might reasonably conclude that the present composition of appointees on boards would have an impact on the views of shared governance in principle and, perhaps, in practice at their particular sites.

In the previous study in 1995/96, when shared governance was in its relative infancy in British Columbia, the researcher found that appointees and presidents, interestingly those who might be described as having had to concede 
power, were generally positive toward shared governance in principle and practice, while elected faculty, elected staff, and education council chairs, those who might be described as having gained power, tended to be somewhat negative, or at least cautious in their enthusiasm. Elected students had adopted a very neutral stance, as if sitting on the fence waiting to see what was going to unfold. The changes in the boards' composition among the appointed members, tcgether with the experience acquired by the elected groups might have suggested some shifting in the overall views on shared governance and this emerged in the study findings. What might not have been anticipated, however, was the dramatic change in the views of presidents with the passage of only two years and this was further examined in detail later in this chapter.

\section{Summary of Data, by Decision-Making Context.}

\section{Aspect of Leadership, and Percentage-Frequency Distribution}

Appendix I includes the grand mean and standard deviation values for all statements in the first three sections of the survey questionnaire (see Appendix B). These sections explored selected decision-making contexts-general matters of board business, board financial matters, and board labour relations matters-and selected aspects of leadership-sharing of power, effectiveness of the shared decision-making process and how conflict of interest has been addressed. Further, the range of responses from strongly disagree 
though neutral to strongly agree were tabulated in a percentage frequency distribution.

\section{General Matters of Board Business:}

\section{Sharing of Power}

Responses suggested the overall population was reasonably positive toward this fundamental aspects of operationalizing a shared governance model. In particular, there was a clear tendency toward agreement on the existence of a climate of trust among all the constituents, notwithstanding their backgrounds, and this notably coincided with the statements in literature noted in Chapter II about such existence of trust being absolutely crucial to successful shared governance. Positive views (evidenced by a low percentage of negative responses) on the contribution of all constituency groups and the perception of equality among them spoke further to the emergence of collaborative cultures within the boards across British Columbia. These findings, to some extent, contradicted the conventional wisdom offered in literature where different constituents tended not to view themselves as equals (support staff frequently reported a sense of marginalization), constituents did not feel that they were making an equal contribution (a charge leveled at student members lacking the necessary background and experience), and climates of trust were frequently 
noted as being absent (perpetuating the traditional confrontation of values and beliefs held by faculty and administration).

The appropriateness of the terms of office for appointed and elected board members--an aggregate of six years for appointees, three years for employee members, and one year for student members--also enjoyed general agreement with low incidence of negative responses, in these cases never rising above $25 \%$. It might have been anticipated that the one year term for students, particularly given the fact that five of the seventeen institutions included in the study were four year schools, would be challenged but support for that term was solid among the overall population.

Remuneration brought some interesting, and for the first time contrasting, responses. Literature seemed to be divided as to whether internal board members (as opposed, in this case, to external appointed members) should receive monetary compensation but definitely leaned toward the notion that they should receive release time from their regular instructional or service duties. The results of this study suggested only very marginal agreement that the (currently modest) remuneration for appointees is appropriate. One would assume that the lukewarm support was due to the low level of the stipend rather than any suggestion that it was too high, which is explored later in this chapter. Interestingly, there was more solid agreement that the remuneration paid to students (which is the same as that paid to appointees) was appropriate and the relatively low number of students participating could not have accounted for the 
overall difference in views regarding payment to the two constituencies. There was general disagreement, with a solid $30 \%$ of responses in the strongly disagreement category, concerning the suggestion that faculty and staff members and education council chairs should also be remunerated in the form of a stipend like appointees and students. However, there was a clear tendency toward agreement that those employee members should be given release time, with $76 \%$ of the responses being in the neutral to strongly agree range. Accordingly, these two contrasting views on a stipend and release time were consistent with the common contentions in literature.

\section{Board Financial Matters:}

\section{Sharing of Power}

As Appendix I records, there was a solid tendency toward agreement that internal board members have an inevitable vested interest when dealing with budget issues, with $61 \%$ of participants expressing agreement or strong agreement. However, there was also weak agreement that, based on the participants' own experiences, all board members have equal independence and disinterest with regard to the budget. Moreover, the weakness of the agreement was stressed by the fact that only $40 \%$ of the respondents agreed or strongly agreed. Finally, given the agreement in this study that internal members have vested financial interest and statements to the same effect in literature, the 
question of whether it is more difficult to balance the budget in the period of prolonged fiscal restraint which British Columbia has faced with boards composed of internal and external members was examined. Participants clearly disagreed with the assertion, $69 \%$ falling on the negative side.

It would appear, therefore, that the overall views on the sharing of power and the accepting of roles in the often turbulent arena of financial affairs were that they have been managed effectively by the boards. This, of course, bodes well for institutions which continue to face enormous financial pressures (some small colleges have been unable to balance their budgets as required by statute) in that united boards can play the leadership role expected of them.

\section{Board Labour Relations Matters:}

\section{Sharing of Power}

In spite of strong suggestions to the contrary in literature, participants in the study fairly clearly disagreed with a statement that shared governance as a broad goal is difficult to achieve in a unionized environment. The 1990's has been a period of tense labour relations in British Columbia with a couple of faculty strikes, a good many others headed off at the eleventh hour, and significant power plays involving provincial unions and the provincial government. Much of this has left not only local boards and administrations but also local trade unions feeling marginalized and tending to direct their 
frustrations toward each other. However, the findings of the study were that, in general, the inclusion of internal members, often themselves trade union executives, had not caused division among the members of boards. This harmony might appear surprising and seemed to go against indicators emergent in the overall labour relations climate and experiences noted in literature. Grand means can, of course, mask wide divergences in opinion among constituencies which were explored in the study and were examined later in this chapter.

The role of student members in the boards' involvement in labour relations was addressed in two statements of inquiry. This was particularly relevant given the Canadian Federation of Students' assertion that student unions ought to be treated just like trade unions. The findings were clear agreement that not only should student members play a full part in decision-making on labour relations issues, but also that student members were, indeed, playing a full part in colleges throughout British Columbia. In both cases, around $60 \%$ of the respondents agreed or strongly agreed with the statements and, therefore, it would appear that the students have achieved one of their stated goals since shared governance was first contemplated. 


\section{General Matters of Board Business: \\ Effectiveness of the Shared Decision-Making Process}

The art of good boardsmanship is crucial to the effectiveness of boards. Participants were asked if the composition of their boards, obviously including internal and external members, and the way in which their boards actually operate contribute to the effective governance of their institutions. The study recorded solid agreement with both statements with only $15 \%$ and $11 \%$, respectively, registering disagreement or strong disagreement. Consequently, there was a very similar level of agreement that the conduct of boards does, indeed, constitute good boardsmanship. It should be noted that the term "good boardsmanship" was not defined in the study and was left to the respondents' own interpretation. Moreover, findings suggest that good boardsmanship had been practically exhibited because $82 \%$ of the participants agreed or strongly agreed that their boards had managed to make some difficult decisions in the last two years. The last few years have represented challenges for colleges in British Columbia and have required that difficult decisions be made in many facets of education. If boards were expressing a degree of satisfaction with the process and outcome of those decisions then it is something of a testimony to the arrival of shared governance.

The need for accountability in decision-making is constantly stressed in literature and in the political milieu which surrounds public education. It was 
noted, particularly in the literature, that the public-at-large was skeptical about college boards' accountability and the arrival of shared governance, if anything, had exacerbated that skepticism. It was interesting, therefore, to note that there was a tendency toward strong agreement with the statement that boards were being accountable for their decisions, both to the internal and external communities. Furthermore, there was even more positive contention on the part of the constituents that boards were fulfilling their general obligations under the College and Institute Act. Indeed, only $6 \%$ disagreed or strongly disagreed with this statement. Another set of perspectives on the degree of accountability of college boards, perhaps from the public-at-large, would offer a counterbalance to those of the board members themselves, but that is a topic for further research outside the scope of this study.

Finally, the tendency toward centralization of decision-making was explored. It has been noted extensively in literature that, across North America, there are clear trends of states and provinces transferring decision-making power from local campuses to central control. And, this had occurred, ironically, during the same period when shared governance has taken root at the college level. Such a contradictory trend appears to be occurring in British Columbia. And, this was confirmed in the study with only $13 \%$ disagreeing or strongly disagreeing with the statement that boards' powers were being diminished as decision-making is increasingly centralized at the provincial level. It is not clear what impact the diminution of power was having on the acceptance of shared 
governance. Perhaps the advent of the former actually makes it easier to achieve the latter. Although, there is certainly a school of thought to suggest that local decision-making, even if it is limited, is all the more complicated when other decisions have been made centrally. This would not necessarily provide a smooth path for the development of the shared governance model.

\section{Board Financial Matters:}

\section{Effectiveness of the Shared Decision-Making Process}

The apparent Achilles heel of shared governance, as noted extensively in literature, was the conflict of interest faced by internal members. And, that inherent conflict of interest appeared to become most problematic in matters of finance and labour relations where vested interests were potentially closest to the surface. However, participants in the study tended solidly toward agreement with the statement that internal members have NOT shown bias toward their own constituency when dealing with budget issues. Furthermore, there were strong feelings that boards have effectively discharged their fiscal responsibilities under the College and Institute Act, as evidenced in Appendix I by $82 \%$ of the participants expressing agreement or strong agreement. In a similar vein, the boards' fiduciary responsibility to all students (which is a matter of legal contention on the grounds that boards assess and collect student union fees from all students) when dealing with student unions on financial matters was 
tested. Testing this fiduciary obligation was particularly relevant given the existence of students on boards who are commonly also student union executives. There was virtual agreement that this special responsibility was being discharged effectively by boards.

The boards' role in the often dramatic theatre of budget preparation was examined in the context of the shared governance model. One of the contentious areas of boardsmanship which can be exacerbated in shared governance was the boards' role vis-à-vis that of administration. The statement that the boards' role should be to approve the parameters and underlying assumptions of the budget, but otherwise should leave the assembly of the numbers to administration met with clear agreement, some $78 \%$ expressing agreement or strong agreement. Moreover, respondents solidly agreed that boards do ensure that all stakeholder groups have the opportunity for advisory input to the budget process and that all stakeholder groups have been adequately informed about financial matters. These last two findings were particularly positive because, while stakeholders may not seek an actual decision-making role in budgeting, there is often the accusation that they are also denied access to the process on an advisory or even information sharing basis. 


\section{Board Labour Relations Matters:}

\section{Effectiveness of the Shared Decision-Making Process}

It was established earlier in this chapter that respondents confirmed the tendency toward centralization of decision-making in British Columbia. And, this had been particularly true in labour relations with the advent of centralized collective bargaining and overt and covert instances of direct government intervention in affairs which legally and technically belonged at the campus level. Thus, it was suggested that this tendency of centralization would mean that boards might be spared any difficulties in decision-making due to the presence of internal members. However, participants were virtually split down the middle with equal numbers in agreement, neutral, and disagreement. The response begged for further research to determine if the relative absence of difficulties is due to the shifting in power or other more positive reasons within the boards' culture. Additionally, there was clear agreement that boards had effectively discharged their labour relations responsibilities under the College and Institute Act.

The high level role of the boards in determining the direction of the institutions' labour relations policy and strategy, which was firmly established in literature, was examined in different contexts. A clear majority of respondents, $62 \%$, disagreed with the contention that boards would have adopted a different direction in policy and strategy had the boards not included internal members. However, there was marginal agreement that direction would have been different 
had provincial centralization of decision-making powers not been taking place.

Finally, the suggestion was made that the boards' direction would have differed if neither shared governance nor centralization had existed, however the suggestion was met with a tendency toward disagreement. It would appear, therefore, that board members felt that government control may have influenced their labour relations direction in a negative way, but that the arrival of internal members on their boards had no such negative affect.

\section{General Matters of Board Business:}

\section{How Conflict of Interest has been Addressed}

In this section of the study, the unique status of the presidents and education council chairs was explored. The legislation, which established shared governance in British Columbia, designated non-voting ex-officio positions on college boards for the chief executive officer of the institution and the chair of the education council. The education council is a senate-like body in each institution, which was also introduced in the same legislative amendment, known as Bill 22. There was agreement and strong agreement, drawing $81 \%$ of the respondents, that the non-voting ex-officio status was appropriate for presidents. Indeed, reaction to the suggestion that presidents should be full-voting members was strongly negative with $\mathbf{8 2} \%$ of the respondents expressing disagreement or strong disagreement, the latter attracting $42 \%$. Views on the role of the 
education council chairs mirrored those for the presidents, although not in such strong terms, amounting to $64 \%$ in favour of the non-voting ex-officio status and $61 \%$ in disagreement with full-voting status. The noticeable difference between the strength of the views on the education council chairs compared to the presidents was interesting and perhaps suggested the possibility of voting status for the former in the future, presumably with the rationale that they can represent the academic community in general in the same way as faculty, staff, and student members represent their constituency. The complete anomaly that sees the presidents who are hired by and report to the boards sit on such bodies with the ability to fully participate except for voting remains just that... an anomaly.

From formal and informal feedback during the short life of shared governance in the province, but particularly during its early days, the drafting of bylaws and policies on conflict of interest had been reported as being contentious at the college level. And, the fact that the Ministry of Advanced Education, Training, and Technology eventually stepped in and ordered institutions to adopt prescribed language for their conflict of interest bylaw may have had an impact on the difficulties expressed by colleges. However, in the study it was found that participants were close to agreement that the resultant bylaw and policy, if colleges chose to adopt the latter, were generally accepted by all board members as fair and workable. Accordingly, some $56 \%$ of the respondents agreed or strongly agreed that their board had not experienced any problem with conflict of interest in general matters of board business. 


\section{Board Financial Matters:}

\section{How Conflict of Interest has been Addressed}

The more focused issue of conflict in financial matters was examined in the context of board dealings with student unions on decisions pertaining to tuition fees and other items which were likely to produce friction between the two bodies. In particular, the fact that student board members were deemed not to be in conflict of interest in the provincially prescribed bylaw on such matters was explored. The findings were that the participants tended toward agreement that their boards have dealt effectively with the obvious conflict issue when it comes to decision-making. However, there was a lukewarm tendency toward agreement, involving only $47 \%$ of the respondents, as to the appropriateness of student board members being able to vote on proposed tuition fee increases. In a similar vein, there was relatively weak disagreement with the suggestion that student board members should be disqualified from simultaneously holding office in their respective student unions. It is fair to say that the provincial government gave students more licence than any of the other internal constituents in drafting the legislation around shared governance. The reason for this has never been exactly clear and could stem from recognition that education is all about students at the end of the day and, therefore, they should enjoy a relatively larger share of the shared governance pie or else the student population represented a considerable voter base to be cultivated. 


\section{Board Labour Relations Matters:}

\section{How Conflict of Interest has been Addressed}

Bill 22, the legislative amendment which brought shared governance to British Columbia, included a few surprises for the education community and none more so than the introduction of an oath of office to which all board members were required to swear. The study found more than solid agreement that elected and ex-officio members, notwithstanding any other allegiance which they might hold or even have sworn an oath to, had lived upto their oath in dealing with the boards' role in labour relations. Furthermore, $75 \%$ of the responses agreed or strongly agreed that boards had dealt effectively with the inherent conflict of interest of internal members in matters of administering collective agreements. However, one obvious way of dealing with such conflict, by confining decisionmaking to some form of executive committee from which those in conflict might be excluded, appeared not to have been chosen as only $36 \%$ of the participants attested. Finally, in a statement similar to that directed at student board members vis-à-vis financial matters, there was weak agreement that elected employee members and ex-officio members should be disqualified from simultaneously holding office in their respective trade unions. 


\section{Summary of the Assessment \\ of Own Boards' Effectiveness \\ in Aspects of Leadership \\ and Percentage-Frequency Distribution}

In this section of the study, participants were asked to review lists of the characteristics of typical effective board leadership in a shared governance context. Further, they were asked to indicate the degree of presence of the characteristics in their own boards' culture according to a Lickert-type scale ranging from non-existence through to strong existence. The characteristics were drawn from the themes which formed the basis of the exploratory statements in other sections of the questionnaire (see Appendix B). Thus, the study and the questionnaire were essentially divided into two parts, the first being a series of statements to elicit the views of the respondents based partly on their philosophy and partly on their practical experience, and the second being more of an audit of board cultures in British Columbia as expressed by the members themselves.

\section{Sharing of Power}

Appendix $\mathrm{J}$ shows that some $74 \%$ of the participants attested to the existence of a climate of trust among all board members within their colleges. Trust is, of course, the most fundamental requirement of any effective 
organizational culture and especially so in the case of a shared decision-making model given the disparate backgrounds of the board members and the perception, if not the reality, that members represent often competing constituencies. Perhaps as a consequence of the existence of a climate of trust in many of the colleges surveyed, there was confirmation that, generally, all members have contributed equally to the functioning of their boards in spite of the different values and expertise they brought to the role. The sharing of power was noted in literature as being the most basic and yet most inherently difficult element in the construction of a shared governance model. This was due to a number of factors including the background and sometimes competing philosophy of the board members and also, most importantly, their status within the organization. Many writers noted the difficulties expressed by staff and student members in terms of feelings of marginalization and tokenism and by faculty members in terms of their historical conflict with the institutional establishment represented by board members and administrations. All board members in British Columbia, irrespective of their constituencies, are expected to act as members-at-large with the common good of the institution as their overriding goal. A truly effective shared governance model would have a unified culture rather than one of collective individualism and this was examined in the study. Alas, there was only confirmation of weak existence of all board members maintaining an independence from their individual constituencies when it came to practising boardsmanship. Furthermore, $51 \%$ of the respondents noted that 
board members were not bringing vested interests to the board table in their colleges. There was also similar existence (48\%) expressed of board effectiveness in the sharing of power being enhanced because traditional (confrontational) labour/management relationships were not allowed to infiltrate the expanded boards' culture.

\section{Effectiveness of the Shared}

Decision-Making Process

There was strong existence, identified by $75 \%$ of the participants, of clear rules of boardsmanship which were consistently applied in colleges where shared decision-making processes were considered effective. This characteristic was noted extensively in literature as being important for the orderly transition to and maintenance of shared governance, although there were differing views on how the rules should be drawn up. Similar strong expressions of the existence of accountability for board decision-making and board compliance with the obligations of the College and Institute Act were confirmed in boards which were considered effective. It was suggested that a further characteristic of effective boards would be their ability to cope with the tendency toward centralized decision-making at the provincial level. Subsequently, only $12 \%$ of the respondents recorded no existence of this characteristic at their colleges, suggesting not only widespread recognition of the trend toward taking power 
away from the local boards but also that boards were dealing with the issue. This is a potential area of further research as institutions evolve from being hierarchical organizations with substantial local power to become democratic organizations within a hierarchical education system where the power resides elsewhere.

Strong existence was attested to of both the fact that no bias had been shown by employee board members in dealing with budget issues and the allocation of resources and neither had bias been shown by student board members in the same tasks. The characteristic of members keeping their vested interests in check and acting for the common good of their institution was, of course, central to the success of the shared decision-making model. And, the strong existence of this characteristic spoke well to the likely success of systemic change in the province. Further, some $63 \%$ of the participants recorded existence, within their boards' membership, of an understanding of the distinction between leadership and management and a consequent acknowledgment of the respective roles of the boards and administrations. This confirmed the extent to which the influence of John Carver and his book Boards that make a difference: A new design for leadership in nonprofit and public organizations(2nd ed., 1997) has had on board philosophy in British Columbia. Finally, and one might have anticipated a different answer considering the generally positive responses in this section, there was only very moderate expression of existence of colleges having a history of informal shared governance before the legislation, which 
would have provided a natural launching pad to the formal model and would have tended to make the transition easier. However, the fact that the largest number of respondents, $35 \%$, were neutral on a statement of historical fact might suggest more of a lack of knowledge on the part of the board members, particularly the new external members, than anything else.

\section{How Conflict of Interest}

\section{has been Addressed}

There were a number of references in literature to the need for clear operating procedures and regulations within which the effective shared decisionmaking model would function. Accordingly, some $74 \%$ of the participants noted the existence or strong existence of clearly understood and accepted (by all constituent groups) bylaws and/or policies on conflict of interest relating to the internal members at their institutions. Furthermore, the suggestion that effective boards in a shared governance environment would include internal members who act in an at-large capacity and did not represent their constituencies was recognized, the mean of responses here tending toward strong existence at their institutions. Some $59 \%$ of the respondents cited the existence of the oath of office as a factor which had prevented historical labour /management problems from surfacing among the constituencies of board members. And, only $25 \%$ admitted the existence of an executive committee, from which internal members 
might be excluded, as a possible vehicle to deal with the inherent conflict of interest faced by internal members by simply circumventing them. The apparent importance of the oath of office represented quite a cultural change in a short period of time. Such oaths are not part of the Canadian culture and their introduction was criticized not only on principle but also due to the practical problem that many unionized board members felt that they also owed a sworn or implied allegiance to their unions and should not be compelled to divide their loyalties. This dilemma, of course, illustrated the very difficulty of at-large membership versus representation in shared governance. One is, however, left to wonder how the dilemma of conscience had been resolved, given the finding that the oath of office to the board was viewed as an important characteristic of effective boards.

Finally, participants noted the strong existence of presidents and education council chairs, albeit with their non-voting status or perhaps even because of it, being able to make a full contribution to the execution of board affairs as other characteristics of effective boards in the shared governance model. There was more than a little anecdotal suggestion that, in some colleges, the president and the education council chair have taken their unusual roles within the shared decision-making model and used them to forge close working relationships which have not only contributed to the governance of the institution but also its management. 


\section{Summary}

It was important, in this study of potential differences in the views among constituent groups and among colleges, that both sectors were reasonably well represented in the questionnaire returns. Fortunately, this proved to be the case with all constituent groups covered, ranging from a $77 \%$ return rate for presidents to $20 \%$ for students, and all colleges covered, ranging from a $69 \%$ return rate from College $M$ to $21 \%$ for College $P$. Furthermore, the mean years of experience at 2.909 years underscored the high turnover of board members and relative inexperience of the study participants.

In overall terms, the analysis of the grand means obtained in the study revealed positive views to be held by the board members about various aspects of shared governance. The participants were in agreement with the different lengths of term for constituents but differed on the issue of remuneration. Specifically, they were virtually neutral on the level of stipend currently received by appointees, against faculty, staff, and education council chairs receiving stipends, and in support of those three constituent groups receiving release time as well as students continuing to receive their current stipend.

Positive expressions were made about the contribution of all constituent groups to financial matters including the budget, and the presence of internal members was not seen as a problem in this context. Similarly, participants were positive about all constituents' contribution to labour relations matters. There was 
strong support for student involvement in this area. Members felt that the newly constituted boards were fulfilling their fiscal, labour relations, and general obligations under the College and Institute Act and internal members were not showing any signs of bias in performance of their duties. Participants expressed clarity concerning the role of the board and its relationship to administration and other bodies within the institution.

There was feeling among the participants that the direction of labour relations at the college level has not been overly influenced by the presence of internal members on the boards, but that the provincial government has imposed change that would not have happened naturally. Respondents were in favour of the non-voting ex-officio status of the presidents and education council chairs on boards and strongly against changing to voting status, particularly with respect to presidents.

There were several confirmations that rules around conflict of interest have been effective and few problems had been experienced with this potential sore point of shared governance. The oath of office was also cited as an effective prevention of problems. There was disagreement with the suggestion that student members should be disqualified from simultaneously holding office in their respective student unions but slight agreement that employee members should be barred from holding trade union office. Finally, there was a consistent confirmation of the existence of the typical characteristics of effective shared governance among the participants' own institutions. 
Analysis of the grand mean values establishes global trends in the findings and sets the scene for the more in-depth comparative analysis between constituent groups, colleges, and the studies of 1997/98 and 1995/96 that follows in this chapter.

\section{Presentation and Discussion of the Comparative Statistics}

In this section of the chapter, the data obtained from the survey questionnaire were analyzed to provide the three lenses through which the research questions, noted below, could be addressed:

1. Is there a difference among British Columbia colleges in certain aspects of boardsmanship, namely the sharing of power, the effectiveness of the shared decision-making process, and how real or perceived conflict of interest of employee and student board members has been addressed when it comes to decision-making in respect to general matters of business, financial matters, and labour relations matters?

2. Is there a difference among board members, according to the constituency from which they are drawn, i.e. appointed members; elected faculty; elected support staff; elected students; presidents; and education council chairs, in certain aspects of boardsmanship, namely the sharing of power, the effectiveness of the shared decision-making process, and how real or perceived 
conflict of interest of employee and student board members has been addressed when it comes to decision-making in respect to general matters of business, financial matters, and labour relations matters?

3. Is there a difference between the views elicited from this study and those from an earlier study in respect to certain aspects of boardsmanship, namely the sharing of power, the effectiveness of the shared decision-making process, and how real or perceived conflict of interest of employee and student board members has been addressed when it comes to decision-making in respect to general matters of business, financial matters, and labour relations matters.

The data were, therefore, analyzed by constituency group-appointees, elected faculty, elected staff, elected students, presidents, and education council chairs--, by college (seventeen colleges and university colleges took part in the study), and through several matched questions comparison was possible between this study and a similar study carried out by the researcher in 1995/96. The presentation and discussion of the comparative statistics, which follow, focus on each statement of the questionnaire (see Appendix B) through the three areas of comparison, namely constituency, college, and the passage of time. The data were sorted according to decision-making context and aspect of leadership to complete the three dimensional focus of the study, illustrated in Diagram 3 on page 23.

Reference throughout this section of the chapter is made to the following appendices: 
- Appendix K: Summary of Data by Constituent Group, Decision-Making Context, and Aspect of Leadership;

- Appendix L: Summary of the Assessment of Own Boards' Effectiveness in Aspects of Leadership, by Constituent Group;

- Appendix M: Summary of Data by College (A to Q), Decision-Making Context, and Aspect of Leadership;

- Appendix N: Summary of the Assessment of Own Boards' Effectiveness in Aspects of Leadership, by College (A to Q); and

- Appendix O: Summary of Matched Statements in the 1995/96 and 1997/98 Studies, by Constituent Group. 


\section{Summary of Data by Decision-Making Context \\ and Aspect of Leadership}

In this section, there are nine combinations of decision-making context and aspect of leadership and forty-eight questions contained within them.

\section{General Matters of Board Business:}

\section{Sharing of Power}

\section{1...My board has established a climate of trust among all the members (irrespective of the constituency they come from).}

While all constituents agreed with the statement, presidents were the least convinced, being barely over neutral, and contrasted with students and education council chairs who were the most positive. Among colleges, the oneway ANOVA revealed a significant difference. However, when a post-hoc analysis was carried out, using the Scheffe technique, it failed to identify any significant difference between the pairs of colleges. (The Scheffe test is very conservative in nature and appropriate to this study given the relatively small population sizes at the college level.) However, the findings did reveal a range of views among colleges from disagreement to strong agreement. A climate of trust is the most basic of requirements for effective shared governance and the disparity of views among constituents (relating to the presidents) and, 
particularly, among colleges is worthy of note. Negative views among the colleges were very likely rooted in particular local experiences rather than on any philosophical basis and may be an indicator of other issues of note to emerge later in the study.

\section{2.e. Board members may bring different values and expertise but all generally contribute equally to the functioning of the board.}

This statement, like the previous one, brought a grand mean tending toward agreement but with wide variation among the constituents' responses, falling short, however, of any significant difference. While appointees, staff, students, and education council chairs were solidly in agreement, faculty and presidents tended toward disagreement. In the analysis of college responses, it was again the same story as in the previous statement. Significant difference was revealed in the one-way ANOVA but no significant difference was found between any of the pairs of colleges in the post-hoc test. However, there was again a wide range of responses from almost strong agreement (College $A$, College $G$, and College $K$ as they had indicated on the first statement) to disagreement (College P again). Clearly, even after only two statements, trends were beginning to emerge--constituents were generally positive except for presidents and colleges were showing a wide array of views with the same 
colleges positive toward the introduction of shared governance and the same colleges negative.

\section{Board members view themselves as equals.}

Again, the grand mean was a fairly solid agreement. Faculty were the only constituent group to disagree and the most interesting finding was that staff were the most positive of all the respondents. Yet, literature suggested that support staff often viewed shared governance in a cautious light and complained of feeling undervalued or token representatives. Colleges, on the other hand, behaved very much as they had in the two previous statements. Significant difference was revealed in the one-way ANOVA, which one might have expected to be between at the highest mean score and the lowest mean score. However, the Scheffe test did not identify any pairs of significant difference, probably because of the small population size of the extreme institutions. As before, there was quite a range from strong agreement (College A, College $B$, College $K$, and College $\mathrm{N}$ ) to disagreement (College $\mathrm{P}$ ). College $\mathrm{P}$ provided the fewest returns but, obviously, those who did respond had quite negative views on these very fundamental factors of shared decision-making. 


\section{4..The six year term for appointed board members is appropriate.}

The grand mean and the responses from all groups but the students were solidly in agreement that the aggregate of six years was an appropriate term for appointed members. The term is not embodied in the College and Institute Act (uniike those of employees and students) but has generally been followed by government until, ironically, several appointments of less than six years were not renewed or merely canceled just immediately prior to the study. The views of some of these recently "retired" members may be included in the appointees' responses, which were, nevertheless, solidly in agreement with the six year term. There was a slightly narrower range of responses among colleges compared to previous statements. College $\mathrm{A}$ and College $\mathrm{K}$ were, again, the most positive with mean scores tending toward strong agreement. College $F$ and College $M$ were the only ones to tend toward disagreement. This statement was also subjected to a two-way ANOVA to compare the data from the present study with that of a similar study undertaken by the researcher in 1995/96. Significant difference was revealed between the two studies and among the constituent groups, however, there was no significant difference in the interaction between the two sources of data. The constituents' means showed some interesting shifts over the two studies with faculty and, in particular, education council chairs 
acquiring a more positive view on the subject of the appointees' term of office, while the students retained a negative view.

\section{The three year term for elected board members is appropriate.}

The grand mean was closer to agreement than for the appointees' term and all constituent groups were in agreement. Staff were the most positive in responding to their own situation. Similarly, faculty were solidly in agreement. Colleges were also firmly in agreement, save for one, College $P$, which was in disagreement. This college was clearly at odds with all the other institutions whose means scored in the upper reaches of agreement or strong agreement. Comparison of the two studies revealed no significant difference between the studies, among the constituents, or in the interaction between the sources of data. The means of the constituents showed remarkable consistency over the two-year period between the studies.

\section{6..The one year term for student board members is appropriate.}

For this statement, there was again generally positive response with the grand mean being virtually on agreement. The students were the least positive about their own term. One would assume that the concern was directed to the 
shortness of the duration of one year and the view was perhaps reflective of the fact that five of the seventeen reporting institutions were university colleges, four year schools, which may have fostered the notion of two or even three year terms as appropriate for students. Conversely, education council chairs were the most positive about the one year term, and this, perhaps, reflected the feeling noted in literature among faculty in general that students were not natural (or legitimate) partners in shared governance and, therefore, a one year turnaround was appropriate. Analysis of the colleges' responses again revealed significant difference within the wide range of values. However, the post hoc test did not reveal significant difference between any of the pairs of institutions. College I was strongly in agreement, as were College $\mathrm{N}$ and College $\mathrm{Q}$ to a lesser extent, while College B, College $F$, College $G$, and College $H$ all tended toward disagreement. The university colleges' responses mirrored the overall responses, ranging from strongly agree to disagree, and, therefore, there was no discernible correlation between four year schools and calls for longer terms for students. Finally, there was no significant difference revealed in the two-way ANOVA between the studies, among the constituent groups, or in the interaction between the two sources of data. The views of the appointees, students, presidents, and education council chairs remained fairly consistent over the two years between the studies, however, faculty and staff both amended their views from strong agreement to a weaker tendency toward agreement. The response of the faculty might not support the earlier suggestion that the positive view of 
education council chairs reflected hesitance in seeing students as natural partners in shared governance.

\section{$Z(a)$.eThe remuneration for appointed board members is appropriate.}

The grand mean was a very weak tendency toward agreement, indeed it was closer to neutrality, which masked a fair range of responses. Staff and students were in agreement, while faculty and presidents ended up strictly neutral and appointees, the object of the question, and education council chairs tended toward disagreement. The stipends for board members and board chairs are very modest in comparison to similar remuneration levels for governors in other public sectors. Further research would be necessary, however, to determine if appointees and education council chairs had the same reasons for being negative toward the remuneration level of the former.

In a similar vein to responses to earlier questions, significant difference was revealed by the one-way ANOVA among colleges. However, the Scheffe test did not identify significant difference among any of the pairs of institutions. Responses ranged from agreement (College $B$, College $I$, and College $Q$ ) to strong disagreement (College $D$ and College $G$ ). Stipends for appointees are controlled by the provincial government and are the same at each college irrespective of its size or mandate. The divergence of views among colleges was, 
therefore, probably only a personal reaction on the part of the participants honed into an institutional trend by discussion around the board table.

\section{Z(b)...The remuneration for student board members is appropriate.}

The responses, overall, were slightly more positive toward the level of remuneration being appropriate for students compared to appointees. (Students and appointees receive the same level of stipend.) In this case, the views of the constituent groups were all very similar except presidents, who were slightly more positive in regard to students and education council chairs who moved noticeably from disagreement on appointees to agreement on students. Interestingly, students were in agreement with the level of stipend for both appointees and themselves, while appointees were in disagreement with both. Colleges again revealed a range of responses, without any significant difference from strong agreement (College I and College Q) to strong disagreement (College G). College I and College $Q$ were consistent in their support of the levels of remuneration for both appointees and students, while College $G$ was consistent in its condemnation of the same. 


\section{8(a). Faculty and support staff members and the chairs of the education council should be remunerated by way of a stipend}

The notion of the stipend being extended to faculty, staff, and education council chairs produced a grand mean solidly in the direction of disagreement. (These employee members of boards currently receive no compensation.) Interestingly, only students bucked the trend and were solidly in favour of the notion, however, faculty were mildly in favour and staff were strictly neutral. Perhaps, this was an example of the union solidarity that had been the stated goal of those constituents. Colleges were also fairly consistent in their disagreement with the suggestion. Only College $E$ with a tendency toward strong agreement and College $A$, College $C$, and College $F$ in strong disagreement were outside the main cluster of institutions.

\section{8(b)...Faculty and support staff members and the chairs of the education council should be remunerated by way of release time.}

The suggestion that faculty, staff, and education council chairs should be remunerated for their service to the board with release time from instructional or service duties brought a grand mean tending toward agreement, but the one-way ANOVA revealed significant difference among the constituent groups. A post-hoc analysis, using the Scheffe technique, indicated that the difference existed 
between appointees (agreement) and presidents (strong disagreement), staff (strong agreement) and presidents, and education council chairs (strong agreement) and presidents. Thus, the presidents were revealed to be totally out of line with all the other constituents in their opposition to release time. It should be noted that the presidents had also disagreed with the suggestion of a stipend for the same employee members. Interesting too was the strongly positive position of staff members on release time, because this is not the traditional form of remuneration for this group of employees. Colleges ranged widely from disagreement (College E, College I, and College P) to College B with a perfect mean score of 5.000 indicating strong agreement. The majority of colleges fell into the agreement range of values.

\section{Summary}

Generally, all constituent groups were positive toward elements of power sharing connected with general matters of board business. These elements included boards' climate of trust, members' contribution, members' equity, and the various terms of office of the members. In addition, constituents were positive toward existing levels of remuneration for appointees and students. However, they were not all of one mind on the issue of remuneration for faculty, staff, and education council chairs. While generally negative toward the suggestion of a stipend for the employee members, all but the presidents were in agreement that 
the employees should be granted release time. The presidents were in strong disagreement causing significant statistical difference with three other constituent groups. There was usually a wide range of responses among colleges on each question with a fair bit of variation from question to question. However, in the area of sharing of power overall, College B, College $K$, and College L emerged as the most positive institutions while College $F$, College $G$, and College $P$ were the least positive. In the comparison of the two studies, the only areas of significant difference emerged on the issue of the appropriateness of the six year term for appointees between the two studies and among the constituent groups. In conclusion, participants were generally positive toward the elements of sharing of power which contribute to an effective shared governance environment in the context of matters of general board business.

\section{Board Financial Matters:}

\section{Sharing of Power}

\section{2.e.All members of my board have equal independence and disinterest when it comes to dealing with budget issues.}

The grand mean on this statement showed a very weak tendency toward agreement and reflected similar tendencies from all constituents except presidents who were in solid disagreement. This result proved to be the second of a series of instances where the presidents expressed a negative view that was 
totally different from all of the other participants. The implications of this trend on a value based question such as this are, indeed, troubling. While the views of the other respondents were not particularly positive, the highest being staff with a mean score of 3.571, the fact that the presidents were suggesting that conflict of interest is affecting the budget process may be a harbinger of further issues to come. In a manner similar to the constituent groups, most colleges' mean scores hovered around neutral and marginally toward agreement. However, College $\mathrm{K}$ stood out in absolute agreement whereas College L, College $\mathrm{O}$, College $\mathrm{P}$, and College $Q$ tended toward disagreement.

\section{3...Elected and ex-officio board members have an inevitable vested interest when dealing with budget issues.}

This statement is really a matter of fact and was included to test the level of acknowledgment of such among the constituents. The outcome was general agreement except for the education council chairs who remained neutral. Interestingly, staff provided the most positive responses. Colleges' means were far more widely dispersed than the constituents and included three colleges, College $B$, College $H$, and College $L$, which tended toward strong agreement while College $Q$ came out solidly in disagreement. The disparity of responses on this question was quite surprising and may have influenced some of the more value based questions to follow. 


\section{3.. The composition of the board has made it more difficult to balance the budget in these tight financial times.}

The grand mean tended solidly toward disagreement, suggesting that the composition of boards in this shared governance era has not made it more difficult to balance budgets. Colleges in British Columbia have gone through five years of serious fiscal restraint and have found it increasingly difficult to balance budgets, so much so that in the current year several small colleges have had to request government intervention. Among the constituents, the presidents again stood out clearly by agreeing with the statement, while all the others tended toward disagreement or strong disagreement (the latter espoused by faculty and students). The one-way ANOVA signaled a significant difference but the posthoc analysis did not reveal any significant statistical difference between the presidents and any of the other participants. In the case of the responses from colleges, most means tended toward disagreement, as would be expected from the value of the grand mean. However, College B, College E, College F, and College $Q$ tended toward agreement and College $D$, College $G$, College $H$, College $\mathrm{J}$, College $\mathrm{M}$, and College $\mathrm{O}$ tended toward strong disagreement.

\section{Summary}

The sharing of power in the context of board financial matters was the beginning of consideration of the tension that most likely exists in any shared 
governance model according to literature. The reason for this, apart from the fact that financial affairs can be difficult at the best of times and can bring out extreme bahaviours, was the background and occasional agendas brought to the boards by the internal members. The participants in the study generally agreed that internal members have an inevitable vested interested in matters of the budget, however, all but the presidents agreed that all the constituents had demonstrated independence from their constituencies in actual decision-making and disagreed that the composition of the boards, specifically the inclusion of internal members, had made it more difficult to balance the budget. The presidents were very clearly at odds with their colleagues on the above statements and opined disagreement and agreement, respectively. This isolation of their views, while not amounting to significant difference, was an indicator of the kind of tension which authors noted in literature. However, what was absent in the study was anticipated concurrence with the presidents' views by the appointees. The literature would have suggested that external members would have shared the caution about the sharing of power on financial decisionmaking, but British Columbia appointees did not follow this trend and clearly concurred with the views of the internal members. Colleges continued to produce a wide array of responses on all three statements. Some suggestion of trends continued to emerge with College $\mathrm{G}$, College $\mathrm{J}$, and College $\mathrm{K}$ generally adopting the most positive stance on the issue of power sharing in the context of board decision-making on financial matters. Conversely, College B, College $H_{\text {, }}$ 
and College $P$ were the most negative in this section. Looking at the trends over the two contexts reviewed so far, i.e. general board matters and financial matters, College A, College $K$, and College L emerged as the most positive colleges while College $E$, College $F$, and College $P$ were consistently tending toward negative.

\section{Board Labour Realtions Matters:}

\section{Sharing of Power}

\section{Shared governance as a broad goal is difficult to achieve in a unionized environment.}

The issue of shared governance in a unionized environment was discussed extensively in the literature with most authors identifying ensuing difficulties, although there were some views that the two can coexist and even, in some few instances, stimulate one another. The issue was, of course, particularly pertinent to the college system (and the school system) where unionism has established a strong foothold as opposed to the university system where shared governance has the established position over unionism. In the British Columbia college system, the unions had established a position of considerable strength long before shared governance. And additionally, the introduction of shared governance had coincided with a relative surge in the powers of the unions through the government orchestrated centralization of 
collective bargaining. Perhaps not surprisingly, the statement that shared governance is difficult to achieve in a unionized environment brought a grand mean tending toward disagreement, however, the one-way ANOVA indicated a significant difference with all constituent groups on the disagreement side except for the presidents. The post-hoc analysis revealed significant difference between faculty (strong disagreement) and presidents (agreement) and between appointees (disagreement) and presidents. The latter difference signaled the start of a trend in this study which was completely at odds with the findings in the 1995/96 study. In the earlier study, the researcher found that appointees and presidents, those who might be considered to have conceded power with the advent of shared governance, were noticeably more positive toward the new governance model than the internal members, those who might be considered to have gained power. This alliance of appointees and presidents was not so surprising and was noted in literature as often being the backbone of a shared governance model. However, it was a very clear that a different pattern was emerging in this study with the internal members joining the appointees on the positive side while the presidents were beginning to stand alone on the negative side.

Colleges, again, reported differing values ranging from agreement (College $A$ and College $C$ ) to strong disagreement (College $G$, College $K$, and College P). The majority of colleges tended toward disagreement and one has to assume that their views would be largely built upon their own experiences within 
their own institutions. This statement had also been examined in the 1995/96 study and permitted comparison through the passage of time. The two-way ANOVA revealed no significant difference between the two studies, significant difference among the constituent groups, and no significant interaction between the two sources of study. The trends over the passage of time among the constituents were interesting to note. While appointees and students shifted from positions of agreement to disagreement and faculty shifted from disagreement to strong disagreement, the presidents simply strengthened their agreement with the statement. Thus the movement in values between the two studies had begun to crystallize.

\section{Labour relations, in particular the negotiation and administering of collective agreements, has caused division among the members of my board.}

There was close to disagreement overall on the suggestion that labour relations has caused division among the board members in spite of their disparate backgrounds. But, as has been noted already as a trend, the presidents were out of step even in expressing very weak agreement in contrast to all the other constituent groups who expressed disagreement or strong disagreement in the case of the support staff. Again, in the analysis of colleges, there emerged the now familiar pattern of most colleges being clustered around the mean, in this case signifying disagreement with the statement, and a few 
colleges expressing extreme views. The latter included College C, College $E$, and College $Q$ on the side of neutrality or agreement and College G, College $K$, and College $P$ on the side of strong disagreement. The last named college was absolute in its rejection of the statement scoring a mean of 1.000 .

\section{4.. Student board members should play a full part in decision- making on labour relations issues.}

There was almost universal support for the notion of student board members playing a full part in decision-making on labour relations issues. The Ministry of Advanced Education, Training, and Technology directed all colleges to adopt a prescribed conflict of interest bylaw which provided for students to be involved in decision-making, notwithstanding any direct or indirect conflict of interest which they might be perceived to have. There was agreement from appointees, presidents, and education council chairs; tendency toward strong agreement from faculty; and totally strong agreement from students themselves (scoring a mean of 5.000). However, support staff were in disagreement with the suggestion and, presumably, that part of the legislation. This outcome was interesting and might be due to the somewhat traditional view of labour relations, some would say an industrial view, which staff tend to hold as opposed to faculty who can be quite pragmatic. In that traditional view of labour relations, it was probably difficult to envision a presence for students. 
The one-way ANOVA of college responses revealed a significant difference, however, the Scheffe post-hoc test did not identify any significant difference among the pairs of colleges in spite of the divergent views. The grand mean, which indicated solid agreement with the statement, masked more extreme views including tendency toward strong agreement (College A, College C, College F, College J, College K, College L, and College P) and tendency toward disagreement (College $B$, and College I). This statement, therefore, brought a wider range of responses than most of the statements illustrating the relative uncertainty among institutions on the role of student board members.

\section{Student members on my board de play a full part in decision- making on labour relations issues.}

This statement moved beyond the philosophical focus of the previous statement and rested on the actual role which student board members have assumed in the boards' involvement in labour relations. Because it was based on the actual role of students, one might have assumed that the study would have revealed little dispersion from the mean among constituent groups but the possibility of wider dispersion among colleges depending on their practices. However, while the grand mean among constituents indicated solid agreement with the statement, there was a surprising range of responses from disagreement (from staff, and mirroring their philosophical views) to tendency toward strong agreement (from students). 
There was significant difference indicated among colleges' responses but the post-hoc analysis failed to reveal any significant difference among the pairs of colleges. The views of colleges on this statement very much mirrored their responses on the previous statement suggesting that board members might be able to generally practise what they believe. Accordingly, College A, College C, College D, College J, College $K$, College $O$, and College $P$ expressed tendency toward agreement while College B, College H, College I, and College Q came out on the disagreement side.

\section{Summary}

Three themes were seen to emerge among constituents on the issue of sharing power in the context of labour relations matters at the college board level. The strong view held in literature that shared governance is inherently difficult to introduce into a unionized environment was rejected by all the constituent groups except the presidents, who once again stood alone on this issue. In spite of the disparity in background of the constituencies, and particularly the often strong ties between employee members and trade unions, there was general agreement that labour relations has not caused any serious divisions at the board level. Close examination of the student members' role in labour relations brought interesting results with staff appearing to oppose the legislated role that students have been given while the other constituent groups 
supported the students' involvement. This may speak to the somewhat traditional values that staff hold toward labour relations compared to faculty.

Colleges continued to offer differing views depending on the subject but some trends did emerge on their views of the labour relations environment. College $D$, College $K$, and College $P$ espoused generally positive views on the sharing of power, while College B, College I, and College $Q$ were the most negative. In considering all three contexts of power sharing, i.e. general board matters, financial matters, and labour relations matters, College $D$, College $K$, and College $L$ emerged as most positive and College $E$, College $F$, and College $P$ remained negative.

\section{General Matters of Board Business: \\ Effectiveness of the Shared \\ Decision-Making Process}

\section{9...The composition of my board makes an effective contribution to the governance of the institution.}

The grand mean of responses to this statement about the inclusion of both external and internal members on college boards tended solidly toward agreement. However, the one-way ANOVA indicated a significant difference among the constituent groups which the Scheffe test revealed to be between the students (strong agreement) and the presidents (weak tendency toward 
disagreement). The other constituents were also on the positive side leaving the presidents, once again, on their own. Most colleges were positive in their views with only two, College $F$ and College $P$, tending toward disagreement. There was also strong agreement indicated by College $\mathrm{G}$, College $\mathrm{J}$, and College $\mathrm{M}$.

The two-way ANOVA of matched statements in the 1995/96 and 1997/98 studies revealed no significant difference between the studies or among the constituent groups, but significant interaction between the two sources was recorded. The interaction was likely due to the movement on the part of the students over the two studies. While the appointees, faculty, staff, and presidents all shifted from positions of strong agreement to agreement, the students shifted from a position of agreement to strong agreement.

\section{0..The way my board operates makes an effective contribution to the governance of the institution.}

This statement made the distinction between the composition of boards and how they actually perform. As in the case of the previous statement, there was overall agreement that the way the boards operate makes a positive contribution to the governance of institutions. Again, there was also indication of significant difference among the constituents, but the post-hoc analysis did not identify any pairs where significant difference existed. There was, however, a noticeable range of responses from strong agreement on the part of students all the way to disagreement on the part of faculty. The negative opinion expressed 
by the faculty was the first real indication that this group was not consistently supportive of shared governance in theory and in practice.

The one-way ANOVA of college responses also indicated significant difference among the colleges, but again the Scheffe test did not reveal anything among the pairs. However as usual, there was a fair range among the responses from strong agreement (College A, College D, College G, College J, College K, and College $L$ ) to disagreement (College $E$, College $P$, and College $Q$ ). The analysis of colleges over various statements seemed to consistently produce some quite varied results but also some discernible positive and negative trends on the part of certain institutions. The two-way ANOVA produced a similar set of results to the previous question with no significant difference between the two studies or among the constituents, however, there was significant interaction between the two sources of data. In this case, there was a good deal of shifting among the constituents over the two studies-students moving in a positive direction and appointees, faculty, staff, and presidents moving in a negative direction while education council chairs remained very constant. This interaction affect very much mirrored the affect on the previous statement which related to the composition of boards. 


\section{1.. The conduct of my board represents good boardsmanship.}

This rather open question brought a response grand mean tending toward agreement and this was echoed by all the constituent groups, except the students who were even more positive with a strong agreement. Good boardsmanship, of course, was not defined in the study and it was left to the interpretation of the participants. However, the researcher would assume that most participants would connect the kinds of qualities referred to in the study as the ingredients of good boardsmanship. These qualities would include instilling a climate of trust, making all board members feel equal, accommodating the different constituents' backgrounds and dealing with their inherent conflict of interest in certain aspects of board business, and being accountable as boards to the internal and external communities including government. It was, therefore, reassuring that all constituency groups thought that their boards' conduct was consistent with, at least, most of these values. However, among colleges there was not the same universally positive view. Accordingly, the one-way ANOVA revealed a significant difference. Thirteen of the seventeen institutions expressed positive views with College A, College G, College J, College K, and College $L$ espousing strong agreement. Of the remainder, one college was neutral and College F, College $P$, and College $Q$ disagreed. However, the Scheffe test did not reveal significant difference between any of the pairs of 
institutions. It should be noted that College $F$ and College $P$ had consistently expressed somewhat negative views so far in this analysis and, therefore, their low esteem concerning the conduct of their boards was not altogether surprising.

\section{My board has managed to make some difficult decisions in the last two years.}

This statement was intended to ascertain whether it was possible to attach some practical experience to the more philosophical side of making shared governance work. In other words, the effectiveness of the shared decision-making process has to be measured against actual outcomes. It is fair to say that recent years have been difficult for college boards, having to face the issues of fiscal restraint, inadequate funding, burgeoning demand for educational services, tense labour and governmental relations, and general questions about the relevancy and currency of college missions. Therefore, one would assume that all boards have had to face difficult decisions during this period when shared governance was being established in British Columbia. And the study found that all constituent groups were in agreement or strong agreement that their boards had managed to make some difficult decisions in this period with a grand mean score of 4.141. Alas, there was significant difference even within the overall positive response between the appointees (strong agreement) and the presidents (weakest of those in agreement). It was interesting to note that the students' responses came very close to absolute strong agreement, however 
they were not identified in the post-hoc test probably because of the relatively small population size. It may be the case that their lack of experience at the board level of decision-making would render questionable their interpretation of what would constitute difficult decisions.

In spite of trends emerging from previous statements to suggest inconsistency among colleges as to harmony among constituents and effectiveness of decision-making, all colleges were positive that difficult decisions have been managed at their board tables. Within the positive responses, eleven of the seventeen institutions tended toward strong agreement, indicating a high level of board esteem in actual decision-making.

\section{3.. My board is accountable for its decisions to the internal and external communities.}

The Ministry of Advanced Education, Training, and Technology has been placing increased emphasis on the need for colleges to be held accountable, not only to their government funders but also to the public-at-large. This focus was prominent in the ministry's strategic plan entitled Charting a New Course (1996). This issue elicited a grand mean of strong agreement, and all constituent groups expressed agreement or strong agreement. However, there was again significant difference between the appointees (strong agreement) and the presidents (weakest of those in agreement). This finding continued the emerging trend of a deep gulf between these two constituents, who had been noted in literature as 
natural partners and had been so philosophically close in the 1995/96 study undertaken by the researcher. Analysis of the college responses also indicated significant difference and, while the conservative Scheffe post-hoc test did not identify any pairs of colleges, it was clear that there was a wide range of opinions. Twelve of the seventeen institutions tended toward strong agreement and only one institution, College $Q$, was in disagreement. However College $Q$ was in absolute disagreement (mean score of 2.000) and, clearly, that institution has a problem with its internal or external communications, at least as identified by a sample of board members.

\section{4.el feel my board is fulfilling its obligations under the College and Institute Act.}

There was overall strong agreement that boards are meeting this fundamental requirement, however, again there was significant difference between two of the pairs of constituents. In this case, difference emerged between the appointees (tending toward strong agreement) and the presidents (again the weakest of those in agreement) and between the students (close to absolute strong agreement) and the presidents. Thus, the isolation of the presidents from the other constituent groups was continued on matters not only of a philosophical basis but also of a more practical basis. Responses among colleges very much mirrored those of the previous statement on accountability with all institutions expressing agreement or strong agreement except for College 
$Q$ which was again in disagreement. Conversely, several colleges, including College A, College D, College G, College $K$, and College L, were very close to absolute strong agreement indicating that some boards are fully complying with the obligations of the College and Institute Act.

\section{5.el feel the powers of the board are being diminished as more decisions are being centralized at the provincial level.}

Much has been made in literature of the tendency across North America for provinces and states to be taking decision-making powers away from institutional boards in favour of locating them within the halls of government. Ironically, this centralization trend has been occurring at the same time as the establishment of shared decision-making within the governance structures of colleges. On the face of it, these two trends tend to be somewhat self defeating, and there were signs that they are about to be repeated in British Columbia. The statement was intended to find out if board members were conscious of the shift of power and the affect on boards. The grand mean indicated solid tendency toward agreement among all constituents and, indeed, all of them did confirm that centralization is taking place. The one-way ANOVA of college responses, similarly, revealed that all colleges in the study either agreed or strongly agreed with the statement. Accordingly, there appears to be clear evidence that the very thing which tends to undermine shared governance is happening in the province. One is left to wonder whether politicians consciously plan policies which are self 
defeating or whether they simply emerge accidentally from the labyrinth of political priority setting.

\section{Summary}

Three themes seemed to emerge from the examination of the shared decision-making process in the context of general board matters. The constituent groups were largely positive about both the composition and actions of their boards, although the enthusiasm of the presidents might be described as lukewarm. Furthermore, all constituents were positive about the boards' achievements in making difficult decisions, the boards' accountability to the internal and external communities, and their compliance with the obligations of the College and Institute Act. However, even within these positive responses, there emerged frequent significant differences between the appointees and the presidents with the former espousing strong agreement with the statements while the latter were, at best, lukewarm again. This section of the study really started to underline the gap between the values of the shared governance model held by the government appointed members of the boards and the institutions' chief executive officers. Finally, all constituents confirmed that they felt the powers of the boards were being diminished as more decisions were being centralized at the provincial level. 
The analysis of colleges' responses continued to produce a wide array of views within the overall positive outcomes to the questions. The issue of the shared decision-making process in the context of general board affairs revealed several very positive institutions, namely College $G$, College $K$, and College $L$. However, there also emerged several noticeably negative colleges where the workings of the boards has not been smooth sailing in the shared governance era. These colleges were College $F$, College $P$, and College $Q$. After four of the nine main sections to the study, it was evident that College $G$, College $K$, and College $L$ were tending to consistently express positive views toward the aspects of shared governance, while College $F$, College $P$, and College $Q$ were clearly less enthusiastic about the whole concept of shared governance.

\section{Board Financial Matters:}

Effectiveness of the Shared

Decision-Making Process

24.w feel that elected and ex-officio board members have generally NOT shown bias towards their own department, area, or constituency (trade or student union) when dealing with budget issues.

The grand mean was close to agreement, however, a significant difference among the responses was indicated by the one-way ANOVA. Posthoc testing failed to reveal significant difference between any of the pairs of 
constituents, but it was noticeable that the presidents ended up on one side, tending toward disagreement, while all the others were positive in agreement or strong agreement. The issue of whether internal members of boards show bias toward their own department or constituency in the budget process is one of the fundamental litmus tests of the shared governance models. And, unfortunately, the presidents did not think that internal members had been displaying the necessary degree of independence. This was an important finding and was all the more troubling because none of the other constituent groups, notably the appointees, concurred with the presidents' views. In addition, the strength of the opposing views of the faculty, staff, and education councils made the presidents' views all the more stark.

The one-way ANOVA of colleges' responses brought the now familiar range of views contributing to overall agreement. College $D$, College $K$, College $\mathrm{L}$, and College $\mathrm{N}$ were in strong agreement, while College $\mathrm{A}$, and College $E$ were tending toward disagreement. It was interesting to note that College $A$ had, hitherto, been identified as one of the consistently positive institutions but was obviously troubled by the stance of internal members in budget matters.

\section{I feel my board effectively discharges its fiscal responsibilities under the College and Institute Act.}

There was overall strong agreement that boards are meeting their legislated obligations in fiscal matters, however a significant difference among 
the responses was indicated. Subsequent post-hoc testing did not reveal any significant difference between the pairs of constituents who expressed strong agreement (appointees, faculty, and staff) or agreement (students, presidents, and education council chairs). In the case of colleges, significant difference was indicated among the seventeen reporting institutions, however, the conservative Scheffe technique did not reveal anything between the pairs of colleges. Nevertheless, responses ranged from strong agreement (College A, College B, College C, College D, College G--with a mean score of 5.000 -College $H$, College I, College K, College L, College M, College N. College O, and College P) compared to the neutral stance adopted by College $F$ and College $Q$, both of which had been previously targeted as colleges holding largely negative views of shared governance. A two-way ANOVA was carried out to examine the data from the matched question in the two studies. The analysis revealed no significant difference between the studies, significant difference among the constituents, and no significant interaction between the sources of data. The shifting views of the constituents was worthy of note with appointees, faculty, staff, and students becoming more positive over the passage of time, while presidents and education council chairs became more negative. 


\section{6...My board discharges its fiduciary responsibility to all students from whom it collects student union fees when dealing with that organization.}

This is a rather complex issue wherein, by virtue of the fact that college boards assess and collect student union fees from most, in not all, students, boards have a fiduciary responsibility in law to the students regarding the use of those fees. Therefore, when boards interact with student unions on financial matters, particularly those matters related directly to the fees collected from students, the boards have this unusual and awkward responsibility to take into account the interests of students-at-large even though the students unions would claim that they, too, have the same responsibility. The arrival of student members on the boards, who commonly are student union executives, has just served to complicate an already complicated situation. The constituent groups agreed with the statement of fiduciary responsibility, although the student members remained neutral. It is not clear whether their neutrality was founded on lack of knowledge of the legal obligation of boards or reservation as to its appropriateness or reservation as to whether the boards had discharged the obligation.

Colleges, on the other hand, produced a range of responses among which there was significant difference. The Scheffe test did not reveal significant difference between any of the pairs of institutions. However, the range of 
responses extended from strong agreement (College A, College $C$, College $D$, College $\mathrm{H}$, College I, College $K$, and College $M$ ) through to disagreement (College Q). Again, one was left with the unanswered question in the case of negative responses as to whether the board members believe they have not met the fiduciary responsibility or whether they do not believe they have the responsibility in the first place. Obviously, this question could only be answered with further research. The two-way ANOVA of responses to this matched statement in the studies of $1995 / 96$ and $1997 / 98$ revealed no significant difference between the studies, significant difference among the constituent groups, and no significant interaction between the two sources of data. In regard to the shift in opinions over the passage of time, faculty, staff, and education council chairs became more positive, presidents became more negative, while appointees and students basically maintained the same positions. Accordingly, over the two studies, appointees tended toward strong agreement and students tended toward disagreement, while the other groups were in agreement.

\section{0..The board's role is to approve the parameters and underlying assumptions of the budget, but otherwise to leave assembly of the numbers to administration.}

This statement spoke to the issue of leadership versus management which is never far from the centre of any discussion of boardsmanship in general, and in particular when considered in a shared governance context. The 
issue also touched on the often strong relationship between boards and their senior administrators which have come under closer scrutiny in the era of board decision-making shared with faculty, staff, and students. Prior to the study, one might have expected to find the appointees and the presidents with a more finely honed distinction of the leadership and management roles in the budget process than the less experienced internal members. And, that is how it turned out. There was general agreement with the statement among the constituent groups with the appointees and the presidents (along with staff) being noticeably more affirmative than the others. This proved to be one of the few instances where the appointees and presidents espoused similar strong views throughout the study.

Colleges were similarly positive toward the notion of budget roles, with most colleges in the position of agreement or tendency toward strong agreement. However, College B disagreed with the statement and had, obviously, adopted a different board philosophy toward budget. The leadership/ management distinction was much in keeping with ends and means distinction espoused by John Carver (Boards that make a difference: A new design for leadership in nonprofit and public organizations [2nd ed.], 1997). Carver's philosophy had been adopted by several, but not all, boards in British Columbia. Analysis of this matched statement in the two studies did not produce any significant difference between the two studies, among the constituent groups or any significant interaction between the two sources of data. There was somewhat marked movement in the views of the constituent groups over the two 
years between the studies. Accordingly, the appointees, faculty, students, and education council chairs appeared to become marginally less positive, while the staff and presidents became more positive.

\section{1...My board ensures that all stakeholder groups have advisory input into the budget process.}

The budget process calls for a level of involvement and participation which often goes beyond even the principles of a shared governance model. Many evaluations and studies of colleges, whether they are conducted internally or externally, cite the importance of ensuring that all stakeholder groups have the opportunity to be informed about the budget and to provide input, if even on an advisory basis. The budget is simply the numerical representation of the institution's plans, dreams, and fears. And, it is important that those who have a stake in the institution also have a stake in the exercise of allocating the resources to pursue those plans.

The grand mean indicated tendency toward agreement with the statement that boards did ensure that stakeholder groups have advisory input into the budget process. Appointees and presidents were again the most positive of the constituent groups in agreement. And, only education council chairs were in disagreement. It was interesting that this particular constituent group chose this particular aspect of board activity to express a negative view because, by and large, it had tended to be positive on most aspects of board decision-making in a 
shared governance context. The colleges followed the same sort of pattern as the constituent groups, with fifteen of the seventeen institutions expressing agreement or strong agreement. One college remained neutral, while College $N$ tended toward disagreement.

\section{2 . feel that all stakeholder groups are adequately informed about financial matters.}

This statement was the second half of the issue of involvement of stakeholders in not only the budget but all aspects of financial affairs. Literature had noted how stakeholders looked to the boards for reassurance that all is well in fiscal terms. Therefore, the boards face clear expectations on communications. The constituent groups in the study produced very similar results to those for the previous statement, however, there was a significant difference identified in the one-way ANOVA. Although the post-hoc analysis did not reveal any significant difference between the pairs of constituent groups, it was noticeable that the presidents tended toward strong agreement while the education council chairs tended toward disagreement. Thus, the latter continued their negative view on boards'fiscal accountability and access.

The two-way ANOVA of college responses revealed significant difference but further post-hoc analysis did not identify any pair of institutions. The mean scores ranged from strong agreement (College A, College B, College C, College D, College $G$, College $H$, College I, College $M$, and College P) through to 
disagreement (College F) with the remainder of the institutions tending to be around the weak end of agreement.

\section{Summary}

This section of the study focused on the effectiveness of the decisionmaking process in the context of the boards' role in financial matters. The College and Institute Act of British Columbia prescribes specific fiscal responsibilities for college boards, and, in addition, literature looks to boards to provide fiscal leadership for institutions, generally in association with their administrators. Hence, the importance of the financial environment at the board table was evident. However, the overlay of a shared governance structure likely has a significant impact on fiscal decision-making because the internal members bring different values to the board table. Employee and student members are far more affected by most financial decisions than external board members, whether it be in relation to their employment tenure, working conditions, cost of education, or program options. In addition, the internal members' relationships to the constituencies from which they have been elected would also have a bearing on how they tend to react to boards' fiscal decision-making.

The constituent groups were found to be fairly positive overall toward their boards' financial processes. The lowest level of comfort was related to the most fundamental issue of whether internal members had shown bias toward their 
obvious affiliations when dealing with the budget. Although the grand mean tended toward agreement and faculty even tended toward strong agreement that internal members had NOT shown bias, the presidents tended weakly toward disagreement. This single assessment of the shared governance culture was very important because it touched on its integrity, and if that should be in doubt one could foresee extreme difficulties ahead. Further examination of the boards' role in ensuring accessibility and openness to financial affairs found that it was generally endorsed by the constituents, but with two notable observations. The appointees and the presidents were found by the researcher in the 1995/96 study to be the most positive about the fledgling shared governance model in British Columbia. However, in this study, a very noticeable gap had developed between the two constituents on a number of statements so far, with appointees remaining positive while presidents frequently expressed negative views. This new trend did not occur in these two statements related to the boards' ensuring openness of financial affairs, rather the appointees and the presidents were very positive on their boards' performances. However, the education council chairs, who by and large were positive in this study about shared governance, expressed quite negative views on the openness issue. It is not clear what prompted this isolated negative assessment.

Colleges continued to show variable results on different sections of the study and even on statements within a particular section. This volatility was, no doubt, reflective of the specific nuances present in each institution's board. In 
this section on effectiveness of the shared decision-making process in the context of board financial matters, College $D$, College $G$, and College $H$ appeared to be most positive about their performance, while college $E$, College $F$, and College $Q$ were most negative. On an overall basis having examined five of the nine sections of the study, discernible trends had emerged from the volatile data to suggest that College $D$, College $G$, and College $K$ were most positive toward the shared governance model. Conversely, College F, College P, and College $Q$ had generally expressed the most negative views.

\section{Board Labour Relations Matters:}

Effectiveness of the Shared

Decision-Making Process

\section{Labour relations has largely become a centralized provincial issue hence my board has not experienced any difficulties in decision-making due to the presence of elected and ex-officio members.}

This opening statement in the section of the study on decision-making process in the context of board labour relations matters continued the exploration of the affects of provincial centralization. The statement suggested that the presence of employee members possibly causing difficulty on boards due to their conflict of interest was a moot point anyhow because the centralization of collective bargaining had reduced the boards' involvement. The 
grand mean was a very weak tendency toward disagreement, but really more of a neutral stance. The conclusions from this answer were somewhat ambiguous-it could suggest disagreement that centralization had taken place, it could suggest that the internal members had caused difficulties, and it was unclear whether the two outcomes have been dependent upon one another. Further questions in this section attempted to unravel the mystery. Meanwhile, the constituents' responses were clustered closely around the mean with no discernible trends to interpret. The one-way ANOVA of college responses revealed significant difference and, although the post-hoc test did not identify any pairs of institutions, there was a far greater dispersal from the mean than there had been for the constituent groups. College $K$, consistently one of the most positive colleges, strongly agreed with the statement. Thereafter, eight colleges tended toward agreement while eight colleges tended toward disagreement. Many of the mean scores on both sides of neutral were, nevertheless, very close to 3.000 and the general conclusion on this statement was that constituent groups and colleges were neutral.

\section{7... feel my board effectively discharges its labour relations responsibilities under the College and Institute Act.}

In spite of the fact that much of the colleges' labour relations had come under the control of the provincial government and was being transacted at a central table rather than at each campus, the College and Institute Act does 
clearly lay out responsibilities for boards. The researcher would suggest that the centralization tendency has made the boards' tasks more difficult rather than easier, and it was with that underlying premise that this statement was explored. There was strong agreement that legislative responsibilities have been discharged by boards. However, the one-way ANOVA indicated significant difference among the responses. The post-hoc analysis did not reveal significant difference between pairs of responses, but it was clear that the constituents fell into two camps. The appointees and students tended toward strong agreement while the other groups all tended toward agreement.

All colleges expressed agreement or strong agreement with the exception of College $Q$ which remained neutral. This suggested, very clearly, that notwithstanding the provincial centralization taking place, both constituent groups and colleges were more than satisfied that boards were fulfilling their obligations in an effective manner. The two-way ANOVA of the data from the present study and the earlier study conducted in 1995/96 indicated no significant difference between the studies, but there was significant difference among the constituent groups and significant interaction between the two sources of study. The strong interaction confirmed much position shifting among the constituents over the passage of time. Faculty and education council chairs became marginally more positive over the period, staff and students became notably more positive, while appointees retained just about the same views and presidents became notably less positive. Therefore, the very general trend 
emerging in the study of the presidents losing confidence in the shared governance model manifested itself in this important assessment of boards' performances.

\section{I feel my board would have generally adopted a different direction in labour relations over the last two years if the board did not include elected and ex-officio members.}

The issue of the possible interaction between the centralization of the boards' powers of decision-making on labour relations matters and the impact of local shared governance on such decision making continued to be explored in the next three statements. There was a solid tendency toward disagreement with suggestion that boards' may have pursued different policy on labour matters if their membership had not included employees. However, the one-way ANOVA indicated significant difference among the constituents' responses. The Scheffe test revealed significant difference between the appointees ( tending toward strong disagreement) and the education council chairs (tending toward agreement). This was an interesting opinion from the latter, who were joined on the agreement side by the staff group, because it also was at variance with the views of the faculty group. Most, but not all, education council chairs are elected from the faculty.

Colleges were emphatic in their disagreement with the suggestion that internal members had influenced boards' direction in labour relations. Only 
College $C$ remained neutral, while thirteen institutions tended toward disagreement. What was more notable was the fact that three colleges (College $\mathrm{K}$, College $\mathrm{L}$, and College $\mathrm{P}$ ) expressed strong disagreement and the mean score of the last named was 1.000 . Clearly, there no evidence in the minds of those board members that the boards' integrity toward labour relations had been compromised through shared governance.

\section{9. l feel my board would have generally adopted a different direction in labour relations over the last two years if provincial centralization had not taken place.}

This statement explored the second potential influence on the direction in labour relations adopted by colleges. Centralization has amounted to the creation of two-tier collective bargaining in which the main issues, including all monetary items, were moved from local tables to a provincial setting and an increase generally in the influence of the government and provincial unions to the exclusion of college boards and union locals at the campus level.

There was the weakest tendency toward agreement with the statement, really not amounting to more than a neutral position. However, there was significant difference among the constituents. And, this proved to be between faculty (tending toward strong disagreement) and presidents (tending toward agreement) and between faculty and education council chairs (also tending toward agreement). Again, the disparity between faculty and education council 
chairs was interesting. As was the analysis of the other constituents-the provincially appointed members disagreed with the statement about government influence, while the unionized staff and students agreed with it. Colleges, again, provided a wide array of responses, albeit without any significant difference. College $B$ had a mean score of 4.000 indicating absolute agreement and was joined by seven other institutions tending toward agreement. Conversely, while two colleges were neutral, six tended toward disagreement and College $P$ tended toward strong disagreement. The reason for the difference between College $B$ and College $P$ not being of statistical significance was probably due to the small population sizes.

\section{L feel my board would have generally adopted a different direction in labour relations over the last two years if the board did not include elected and ex-officio members and if provincial centralization had not taken place.}

The final statement in this section of the study pieced together the two factors which potentially had influenced labour relations at the board level. The contention that the direction adopted by boards would have been different if both the influences had been absent was not supported, the grand mean tending toward disagreement. However, there were significant differences, this time again being between faculty (tending toward strong disagreement) and presidents (tending toward agreement) and between faculty and education council chairs (tending toward agreement). College patterns were somewhat 
similar to the previous statement with three institutions in agreement, two remaining neutral, and twelve on the negative side with College $P$ again in strong disagreement. The conclusion, therefore, appears to be that neither shared governance nor provincial centralization had affected the direction that boards had set in relation to their labour relations.

\section{Summary}

The board members' overall views on how boards had met their obligations under the College and Institute Act were positive. This finding was important because boards have a key role in labour relations, the most notable aspect of which is the fact they are the employers of reference under the provincial labour code. Two factors were suggested by the researcher as having had a significant impact on how boards deal with labour matters, namely the trend toward centralization by the provincial government and the presence of employee members on boards as a result of shared governance. The overall responses were fairly firm rejection of the suggestions, however, both the presidents and the education council chairs agreed that boards might have taken a different direction if either or both of the factors had not been present. That said, the other constituent groups were quite clear that boards would not have changed their approach to labour relations in the different circumstances contemplated. Colleges tended to follow the patterns that had been established 
in earlier sections of the study. Consequently, College $G$ and College $K$, two of the three most positive institutions toward shared governance throughout the study, were most positive in this section also, along with College P. Similarly, College $E$ and College $F$, two of the three least positive institutions, were least positive here along with College $\mathrm{M}$.

\section{General Matters of Board Business:}

\section{How Conflict of Interest}

has been Addressed

\section{6.uThe president should be a non-voting ex-officio member of the board.}

This final part of the study looked at conflict of interest as it might affect the internal members in the shared governance structure. In this section, the unusual status of the presidents and the education council chairs, which was of course legislated, was examined. In regard to the non-voting ex-officio status of presidents, there was strong agreement, overall, with education council chairs being the most enthusiastic and the presidents, themselves, being the least enthusiastic, although still in agreement. Colleges were similarly supportive of the status quo with all institutions either agreeing or strongly agreeing. College $\mathrm{G}$ and College $\mathrm{P}$ had mean scores of 5.000 signaling absolute strong agreement. Finally, the two-way ANOVA of responses from the two studies did not reveal 
any significant difference between the studies, among the constituent groups, or in the interaction between the two sources of data. These latter findings suggested that there had been no material shifts in views with the passage of time and, obviously, the experience gained of seeing the presidents function within their prescribed status. However, it is fair to note that appointees, faculty, staff, students and presidents all showed marginal movement toward disagreement with the status, but not to any significant effect.

\section{7...The president should be a full voting member of the board.}

This statement was, of course, the opposite of the previous statement and the researcher anticipated the opposite responses. And indeed, that was the way it turned out, with strong disagreement from all but the presidents, who nevertheless did disagree. Therefore, it can be safely assumed that the constituent groups support the status quo as far as the presidents' role on the boards is concerned. The colleges responded in much the same manner as the constituent groups with all mean scores being in the disagree and strongly disagree range. Two colleges, College $F$ and College $O$, were in absolute disagreement. Interestingly, they were not the institutions which had been in absolute agreement on the previous statement. Finally, there was no significant difference indicated in the comparison between the 1995/96 study and the $1997 / 98$ study. However, appointees, staff, students, and presidents expressed 
very marginal movement toward agreement with the statement and education council chairs actually moved in the opposite direction, although again not in any statistically significant way.

\section{8..The chair of the education council should be a non-voting ex- officio member of the board.}

Attention now turned to the education council chairs. And, the outcome very much mirrored that of the presidents, albeit with less enthusiasm. The grand mean and the means of most the constituents were in the agreement range, but the education council chairs actually tended toward disagreement. The colleges were a little less emphatic on this statement than they had been toward the presidents. Within an overall tendency toward agreement, there were four strong agreements, including a mean score of 5.000 from College P (as it had in regard to presidents). However, there were also two colleges, College $\mathrm{J}$ and College $\mathrm{Q}$, which disagreed with the status quo in this case. The two-way ANOVA of responses from the two studies revealed significant difference between the two studies amounting to a discernible weakening in the degree of overall agreement, but no significant difference among the constituent groups or in the interaction between the two sources. Faculty, staff, students, presidents, and education council chairs all expressed less positive views with the passage of time. 


\section{9.. The chair of the education council should be a full voting member of the board.}

The grand mean on this suggestion that education council chairs should be full voting members of boards was a solid disagreement, but again it was nowhere near as emphatic as it had been for the presidents. All constituent groups were in disagreement except the education council chairs who tended toward agreement. It was noted that the chairs clearly advocated full membership for themselves and non-voting status for the presidents. It would be interesting, in a follow-up study, to ascertain the rationale for the distinction.

The analysis of the colleges revealed some extreme views along with the general opinion of disagreement (expressed by nine institutions). College $Q$, a not infrequent provider of extreme views, was in absolute agreement with the statement, while College $\mathrm{J}$ and College $\mathrm{K}$ tended toward agreement and College I remained neutral. On the negative side, College $D$, College $F$, and College $Q$ tended toward strong disagreement, while College $G$ was in absolute disagreement. Therefore, colleges differed greatly in their views on this issue, although not with any statistical significance, again probably because of the population sizes. Comparative analysis of this matched question in the two studies revealed significant difference between the studies amounting to a discernible weakening in the degree of overall disagreement, but no significant difference among the constituent groups or in the interaction between the two 
sources. All of the constituents, with the exception of the presidents, expressed marginally more positive views over the passage of time on the notion of voting status for the education council chairs.

\section{0..The bylaw and/or policy regarding conflict of interest adopted at my institution is generally accepted by all board members as fair and workable.}

When shared governance was introduced into British Columbia by way of Bill 22, colleges immediately set about drawing up bylaws to manage their process and, in particular, to address the inherent conflict that internal board members brought to the table. Under the College and Institute Act, bylaws are required to be approved by the Minister of Advanced Education, Training, and Technology. Subsequently, government decided to hand down a prescribed bylaw for all institutions to adopt which limited the circumstances in which employee members could be considered in conflict of interest and, virtually, absolved student members in all circumstances. Why the government chose this approach is not known by the researcher, but one can only assume that it was receiving informal feedback from interested parties when colleges were attempting to draft their own bylaws. In any case, a number of colleges felt that, although the government's intentions were clear in its bylaw, the language had ambiguities. Consequently, a few colleges developed custom policy to expand 
the position on conflict of interest contained in the bylaw. College policies do not require approval of the Minister.

The one-way ANOVA of responses from the constituent groups produced a grand mean indicating solid agreement with the suggestion that the bylaw, and policy if appropriate, on conflict of interest was fair and workable. Significant difference was suggested among the constituents, but the post-hoc analysis failed to reveal any matched pairs. However, while all constituents gave positive responses there was a wide range of convictions from the appointees (tending toward strong agreement) to the presidents (with the weakest tendency toward agreement). It was notable that the students, who had been given something of a "carte blanche" in the bylaw, were not particularly enthusiastically in agreement either.

This statement brought a wide array of views from colleges and, for the first time in the study, the post-hoc analysis revealed several significant differences between pairs of institutions. Responses ranged from tendency toward strong agreement to tendency toward disagreement. Specifically, significant difference was identified between College $\mathrm{A}$ (strong agreement) and College M (disagreement); between College D (strong agreement) and College $M$; between College $G$ (strong agreement) and College $M$; between College I (strong agreement) and College $\mathrm{M}$; between College $\mathrm{K}$ (strong agreement) and College $M$; between College $L$ (strong agreement) and College $M$; and between College $\mathbf{N}$ (strong agreement) and College $\mathrm{M}$. It is not known by the researcher 
which colleges had developed policy to augment their bylaw and whether this would have had a bearing on the responses. Moreover, further research in this area would be warranted to determine if the negative views of College $M$, and College $P$ which expressed similar opinions, were based on actual experiences with the bylaw or just in principle.

This was a matched statement in the two studies and allowed for a twoway ANOVA. No significant difference was revealed between the studies, among the constituent groups, or in the interaction between the sources of data. However, it was noted that the constituents experienced differing shifts of opinion between the studies. Appointees, faculty, and education council chairs became more positive about the suggestion that the bylaw was fair and workable, while staff, students, and presidents became less positive. This issue is obviously still volatile within constituent groups and within particular colleges four years after the bylaw was handed down by the provincial government.

\section{1... Conflict of interest has not been a problem with my board.}

Many authors in literature reviewed in Chapter II suggested that the issue of conflict of interest which is attached to the internal members of boards was the single greatest threat to successful shared governance. This final statement in this section of the study was plain and simple. Had conflict of interest been a problem? The grand mean of responses from the constituent groups was a fairly 
solid tendency toward agreement that conflict of interest had NOT been a problem. Four of the constituents--appointees; faculty; staff; and education council chairs-signaled agreement, while students and presidents tended toward disagreement. The disparity between the appointees and the presidents, as the "independent reporters" on potential "unionized members' conflict of interest", was interesting. Of course, presidents, even without any union affiliation might also be considered as internal members with conflict of interest. But somehow, at least in literature, the presidents were seen to be on a higher ground solely in pursuit of the common good. It all depends how they are perceived by their board colleagues. The position of the students was equally interesting and worthy of further study to determine the nature of the problem they had acknowledged.

The one-way ANOVA of colleges' responses indicated significant difference within the wide range of opinions. The Scheffe test revealed significant difference between College $K$ (strong agreement) and College $M$ (strong disagreement). Both colleges had, of course, differed on the previous statement concerning the fairness and workability of their bylaw on conflict of interest. Consequently, the difference on de facto conflict of interest was perhaps not so surprising. Three other colleges were in the strong agreement range, seven colleges were in agreement, two colleges were neutral, two colleges were in disagreement, and one other college was in strong disagreement. Hence, there was a very wide range of responses indicating very differing climates at 
campuses. This volatility was subsequently examined in the financial and labour relations environments.

\section{Summary}

In this section, clear, unanimous support was found for the non-voting status of the presidents on college boards in preference to any contemplation of voting status. In contrast, there was less emphatic support for similar treatment of the education council chairs, and that support was changing over time suggesting that we may not be far away from the point where voting status would be advocated. Indeed, the education council chairs, themselves, had shifted over the two studies to now be in support of full voting status. All constituent groups, with varying degrees of enthusiasm, agreed that their bylaw, and policy if it existed, on conflict of interest was considered to be fair and workable. However, only four of the constituents agreed that conflict of interest has not been a problem in their institutions. Students and presidents suggested that there had been problems. And, that suggestion also emerged among colleges. Four institutions strongly disagreed on the statement and significant difference was revealed between College $M$ (among the four) and seven colleges which agreed with the statement. This polarization of opinions on one of the most contentious aspects of shared governance would be further explored later in the study to seek reasons for the different outcomes on certain campuses. 
In this section, the most positive colleges were College G, College N, and College $P$ and, taking into account all the data so far, College $A$, College $G$, and College $\mathrm{K}$ had emerged as the most positive institutions toward shared governance in general. In contrast, the most negative colleges, in this section, were College J, College M, and College Q, while overall College E, College F, and College $Q$ were as the most negative. Thus, several colleges were having different experiences on conflict of interest in general board decision-making matters. Perhaps this was due simply to their culture and history or perhaps it was also due to the prescribed nature of the conflict of interest bylaw under which each institution must operate. The application of this regulation in the more volatile environments of financial affairs and labour relations matters was further explored in this study.

\section{Board Financial Matters:}

How Conflict of Interest

has been Addressed

\section{7...My board has dealt effectively with the issue of conflict of interest as it relates to student board members with respect to financial matters between the board and the student union, such as tuition and other fees.}

The government prescribed bylaw on conflict of interest stated that student board members were not to be considered in conflict of interest and 
should be allowed to vote on tuition fee issues. The rationale for this clause was that tuition decisions affect all students, not just the student board members themselves. In addition, many student board members are also student union executives which makes for a potentially difficult time when boards are engaged in discussions with student unions over financial matters, including potential tuition fee increases. (It should be noted that tuition had been frozen in British Columbia by the provincial government for the last two years for reasons including heavy lobbying by the Canadian Federation of Students.) This potential area of tension for boards was examined in this question. The grand mean indicated solid agreement with the suggestion that boards had handled the situation effectively. Furthermore, all constituent groups were in agreement including the appointees, who tended toward strong agreement. Given the expansive nature of the conflict of interest bylaw in terms of student members' rights, it was somewhat surprising that all board members felt that they had effectively dealt with the issue of conflict of interest.

Colleges were also positive about how the student situation had been handled. Five colleges expressed strong agreement, while nine colleges expressed agreement. Further, two colleges remained neutral, and one college, College $Q$, tended toward disagreement. The two-way ANOVA of data from the two studies indicated that there was no significant difference between the studies, among the constituent groups, or in the interaction between the two sources of study. The individual groups reported very marginal shifts in their 
views between the two studies, although some moved in a positive direction and others toward negative.

\section{8...The College and institute Act provision that students may vote on proposed tuition fee increases is appropriate.}

This question was a straight forward exploration of views of the appropriateness of the government prescribed bylaw which allows student board members to vote on tuition issues. This provision appeared to fly in the face of accepted standards of conflict of interest with regard to pecuniary interests in an issue to which board members were being asked to vote. The study found very modest agreement overall with the appropriateness of the provision. The oneway ANOVA, however, indicated significant difference among the respondents. And, the post-hoc analysis revealed the difference between appointees (showing solid tendency toward agreement) and the presidents (tendency toward strong disagreement). Thus, the erstwhile joint proponents of shared governance in the previous study and the natural allies according to the literature appeared once again to be headed in different philosophical directions. Furthermore, staff also disagreed with the statement and, hence, not for the first time in this study sided with the presidents. Faculty, students, and education council chairs were all fairly solidly in agreement.

The one-way ANOVA of colleges' responses also revealed significant difference, but this could not be pinpointed among any pairs of institutions in the 
post-hoc analysis. However, the analysis revealed a range of responses from a tendency toward strong agreement (College $K$ and College $L$ ) to a tendency toward disagreement (College $E$, College $H$, College $M$, College $N$, and College O) and strong disagreement from College $F$. Therefore, this issue produced a set of fairly polarized responses to what was a question of principle but may have been answered based on particular experiences at individual campuses.

\begin{abstract}
29.. Elected student board members should be disqualified from simultaneously holding office in their respective student unions because of the perceived conflict of interest on financial matters.
\end{abstract}

This final question in this section on conflict of interest in the context of financial decision-making was, again, an issue of principle, although the responses were always likely to be influenced by particular experiences at the local board level. The Canadian Federation of Students, the parent body of some but not all local student unions, made it very clear from the minute that shared governance was contemplated in British Columbia that it saw the opportunity to unite with the trade unions in order to wrest power away from appointed boards, and probably administrators as well. In addition, it was clear that the Federation saw its board members as being representative of the union movement rather than in pursuit of the common good. Consequently, a large number of student board members are also student union executives. The study found a weak tendency overall toward disagreement with the notion that students should be 
disqualified from simultaneously holding office in both organizations. However, again staff and presidents went against the tide to agree with the statement. Perhaps the former felt the way they did through a sense of what is appropriate based on old fashioned union values of labour and management roles. That would be tested in a later question. Other constituent groups were all in agreement with the statement.

The one-way ANOVA of colleges' views again indicated significant difference, but the conservative Scheffe test did not reveal any differences among the matched pairs of colleges, probably due to small population sizes. However, the analysis did produce a wide range of responses from tendency to strong agreement (College $\mathrm{H}$ ) and agreement (College $P$ and College $Q)$ through to disagreement (10 colleges) and strong disagreement (College K). The twoway ANOVA of responses from the two studies revealed no significant difference between the studies, among the constituent groups, or in the interaction between the two sources of data. However, the means indicated that staff and presidents had experienced modest movement toward agreement with the statement over the two studies, while students and education council chairs had experienced modest movement in the opposite direction. 


\section{Summarx}

This section on conflict of interest in the context of the boards' financial decision-making concentrated on the role of the student members. Weak agreement overall was recorded on the appropriateness of students being able to vote on matters concerning tuition, a provision prescribed by the provincial government. This issue brought out significant difference between the oft cited allies, appointees and presidents, with the latter being in strong disagreement. Similarly, there was weak disagreement with the notion that student members should be disqualified from simultaneously holding office on the boards and student unions. However, both staff and presidents dissented from the general views on both the issue of voting and dual office. All constituent groups felt that boards had effectively handled the de facto conflict of interest of student members when dealing with the student unions on financial matters.

Colleges continued, in this area of examination of conflict of interest, to exhibit trends which reflected the overall trends in the study to a large extent. Accordingly, two of the three most positive colleges in this section (College A and College $K$ ) were also the most positive overall. Further, College $L$ emerged as positive here but College $G$ remained, on average, more positive overall. On the negative side, College $F$, College $M$, and College $Q$ emerged in this section with College $F$ and College $M$ continuing their trend over all sections so far. College $\mathrm{E}$ had also shown consistent negative trends overall. 


\section{Board Labour Relations:}

How Conflict of Interest

has been Addressed

\section{1.eThe elected and ex-officio board members have lived up to their oath of office to the board in contributing to my board's role in labour relations.}

The inclusion of an oath of office for all board members to swear was a controversial and surprising element of Bill 22, the legislation which introduced shared governance to British Columbia. Oaths of office are not a big part of Canadian culture, being more common in American public life. No doubt, however, the insertion of an oath into the college governance environment was intended to head off problems faced by the new internal members with their almost inherent perceived conflict of interest. What the oath did not really address was the fundamental ethical dilemma of whether a person can serve two causes when they might be in competition with one another. That point was not lost on some union executives who expressed concern with the need to swear allegiance to their boards (as well as to their unions).

The study found that there was overall tendency toward strong agreement that the elected and ex-officio board members had lived upto their oath of office in contributing to their boards' role in labour relations. However, there was a significant difference among the responses and the Scheffe post-hoc test 
revealed it to be between the appointees (strong agreement) and the presidents (very weak tendency toward agreement) and between the faculty (strong agreement) and the presidents. Thus, the presidents extremely lukewarm acknowledgment of the internal members' honouring of the oath set the chief executive officers aside from all the other constituent groups and continued to demonstrate their diminishing values of shared governance in general and the ethical performance of the internal members in particular.

The one-way ANOVA of responses by colleges also indicated significant difference. However, the post-hoc analysis did not reveal any difference between the matched pairs of colleges, all of which were in agreement or strong agreement with the exception of College $F$ which remained neutral. Eleven of the institutions indicated strong agreement with the statement, suggesting clear compliance with the oath of office at those campuses.

\section{My board has dealt effectively with the issue of conflict of interest as it relates to elected and ex-officio board members with respect to matters of administering collective agreements.}

This question built on the oath of office issue and really approached conflict of interest from another angle, namely have boards taken adequate steps to eliminate conflict of interest from decision-making on labour matters? The constituent groups produced a grand mean which tended solidly toward agreement with the statement. However, once again there was significant 
difference between the appointed members, tending toward strong agreement, and the presidents, tending toward disagreement. Accordingly, the once strong allies were again torn apart on a fundamental issue surrounding shared governance, demonstrating the philosophical and practical gulf which had developed between the two constituents.

Responses from the colleges produces a number of significant differences reflecting the varying experiences at the campus level. The differences were between College $\mathrm{A}$ (strong agreement) and College $\mathrm{Q}$ (strong disagreement), between College $D$ (strong agreement) and College $M$ (disagreement), Between College $\mathrm{D}$ and College $\mathrm{Q}$, between College I (strong agreement) and College $\mathrm{Q}$, between College $K$ (strong agreement) and College $M$, between College $K$ and College $Q$, and between College $L$ (strong disagreement) and College $Q$. Clearly, College $M$ and College $Q$, in particular, had developed very tense labour relations environments in the context of shared governance. The two-way ANOVA of responses from the $1995 / 96$ and current studies revealed no significant difference between the two studies, among the constituent groups, or in the interaction between the two sources of data. The means of the constituent groups over the two studies showed that there had been very marginal positive and negative shifts among the respondents. 


\section{My board has employed a personnel or labour relations committee from which some board members are excluded on the basis of their perceived or real conflict of interest.}

One possible avenue available to boards within the provisions of the College and Institute Act and the provincially prescribed conflict of interest bylaw, should they wish to isolate internal members from labour relations decisionmaking, was to create an executive committee for that purpose. For, the composition of that committee would be at the discretion of the majority of board members. The findings of the study were disagreement with the statement that the option had been taken. Strangely though, there was a range to the responses of what was a question of fact, with faculty tending toward agreement and students remaining neutral.

Local differences in approach to this issue were always more likely to be revealed in the analysis of colleges' responses. And, that emerged in the findings with significant difference between College $I$, in strong agreement, and College $M$, in strong disagreement. In addition, two other institutions indicated by their strong agreement that they had adopted the executive committee model. The vast majority of colleges indicated, however, that had not gone that route. 


\section{6... Elected employee members and ex-officio members should be disqualified from simultaneously holding office in their respective trade unions.}

This final question in the section on labour relations was similar to that concerning student members in financial affairs in that it suggested employee members should be disqualified from simultaneously holding office on boards and trade unions. The grand mean indicated weak tendency toward agreement but consisted of an even split in views between appointees, students, and presidents (in agreement) and faculty, staff, and education council chairs (in disagreement). Accordingly, the results meant that staff had favoured student disqualification but not their own, while students had favoured staff disqualification but not their own. Interesting too, was the agreement on the part of the three non-trade union constituent groups as to the proposed disqualification of the three trade union groups.

Colleges' responses were well spread out, with College $M$ indicating strong agreement and seven institutions in agreement. Conversely, in addition to two neutral colleges, six colleges were in disagreement and College $\mathrm{K}$ strongly disagreed. Therefore, this philosophical issue, which may well have been influenced by local experiences, produced quite a split among the colleges. The two-way ANOVA of responses from the two studies did not reveal any significant difference between the studies, among the constituent groups, or in the 
interaction between the two sources of data. There was very little movement on the constituents' views over the two studies with the exception of students who changed from disagreement to agreement and education council chairs who changed in the opposite direction.

\section{Summary}

This was the ninth and final section of the study to explore decisionmaking and aspects of leadership by constituent group and college. In this case, labour relations matters and how conflict of interest has been addressed were the areas of focus. Constituent groups were in strong agreement that the internal members have lived upto their oath of office when being involved in decisionmaking concerning labour relations and, in particular, their own collective agreements. Further, the constituents were in agreement that boards had dealt effectively with the inherent conflict of interest faced by internal members in the same area of board business. However, both statements once again brought out significant difference in the views between the appointees and the presidents, with the latter very weakly agreeing with the first statement and disagreeing with the second statement. These findings were final confirmation of the extreme reservation, and at times outright disagreement, about the ability of the internal members to lay aside their personal agendas in favour of the pursuit of the common good. These fundamental weaknesses in the shared governance 
infrastructure appeared to exist in principle and in practice according to the presidents. There was disagreement among the constituents that boards have chosen to adopt executive committees, which would exclude those members deemed to be in conflict of interest, as the vehicle for dealing with labour relations matters. And, this was confirmed in the analysis of college returns where it was suggested that only three colleges had formed such committees while fourteen colleges had not. Finally, there was weak agreement among the constituents that internal employee members should be disqualified from simultaneously holding office on boards and trade unions. This view contrasted with the view on student members in regard to student unions which met with weak disagreement. However, the statement firmly divided the constituents with the non-trade union members--appointees, students, and presidents--being in favour and the trade-union members-faculty, staff, and education council chairs (the latter most likely drawn from faculty)--being against the notion. The alignment of the students on this issue was surprising and out of character with the rest of the findings in the study.

Analysis of the colleges' returns revealed consistency of responses over the statements concerning conflict of interest in the labour relations context, but in patterns which were not necessarily totally consistent over the entire study. Therefore, it can be concluded that the impact of shared governance on aspects of leadership and decision-making contexts was situational and affected different colleges differently, both in principle and in practice, to a certain extent. 
However, there were also discernible trends of generally positive views and negative views. College $G$, College $K$, and College $L$ were the most positive colleges with regard to addressing conflict of interest in labour relations, and they proved also to be the most positive institutions overall. Conversely, College $H$, College $\mathrm{I}$, and College $\mathrm{Q}$ were the least positive, with the last named also being one of the three least positive overall. College $E$ and College $F$ were the other two institutions to fall into the category of least positive throughout this entire section of the study.

\section{Summary of the Assessment \\ of Own Boards' Effectiveness \\ in Aspects of Leadership}

In this section of the study, participants were asked to indicate the extent of the existence in their own boards' culture of various themes, which the researcher contended would contribute to a board's effectiveness in certain aspects of leadership within a shared governance model. A range of responses was possible from non-existence, minimal existence, neutral, moderate existence though to strong existence. The aspects of leadership covered were the sharing of power, the effectiveness of the shared decision-making process, and how conflict of interest has been addressed. 
The themes suggested by the researcher in this section of the study were drawn from the first section. So, in effect, the first section of the study was somewhat philosophical in nature and called for responses from the participants which were both value and experience based. And, in the second section, participants were asked to reflect on the actual existence of selected themes in their own particular boards.

Throughout this section of the chapter relating to own boards' effectiveness, reference should be made to the following appendices:

- Appendix L: Summary of the Assessment of Own Boards' Effectiveness in Aspects of Leadership, by Constituent Group; and

- Appendix N: Summary of the Assessment of Own Boards' Effectiveness in Aspects of Leadership, by College (A to Q).

\section{Sharing of Power}

The undernoted themes were suggested as contributing to a board's effectiveness in the sharing of power in a shared governance model:

- A climate of trust among all board members;

- Equal contribution by all board members;

- Independence of all board members from their constituency;

- Board members not bringing vested interests to the board table; and

- Management/labour relations not infiltrating the board culture. 
The grand means of constituent groups indicated moderate existence of all the themes within their own boards' cultures. There were no significant differences among the constituents and, in fact, relatively few examples of any notable dispersion from the mean. Exceptions to the trend included education council chairs who noted strong existence of the climate of trust and faculty who noted minimal existence of equal contribution by all members. Additionally, both faculty and presidents cited minimal existence of independence of members from their constituencies. Constituents, therefore, appeared to be relatively comfortable with the existence of contributors to effective power sharing at the local level.

These sentiments were largely shared by the colleges. The one-way ANOVA indicated a significant difference among colleges only on the issue of a climate trust. However, the post-hoc test did not identify any matched pairs. As in the case of the analysis of constituent groups, there was relatively little dispersion from the means of moderate existence on all themes, indicating homogeneity among colleges which might not have been forecasted. However, there were exceptions as always. Seven institutions noted a strong existence of a climate of trust and, conversely, two institutions expressed minimal trust. On the question of equal contribution, three colleges cited strong existence but four colleges opted for minimal existence as the descriptor for their own experience. Similarly, the theme of independence had strong existence at one institution, yet minimal existence at five other institutions. Two colleges noted minimal existence of members not bringing vested interests to the table, while two colleges were 
split on the issue of management/ labour relations with one citing strong existence and the other citing minimal existence. There was, therefore, confirmation of the moderate existence across the colleges of the themes that contribute to effective sharing of power. If strong existence of these themes is characterized as evidence of colleges which are positive toward shared governance in general, the section on sharing of power indicated that College $A$, College $D$, and College $G$ emerged as the most positive while College $F$, College $O$, and College $Q$ were the least positive.

\section{Effectiveness of the Shared}

\section{Decision-Making Process}

The undernoted themes were suggested as contributing to a board's effectiveness in the shared decision-making process in a shared governance model:

- Clear rules of boardsmanship, consistently applied;

- Accountability for board decision-making;

- Meeting obligations of the College and Institute Act;

- Coping with the tendency toward centralized (provincial) decisionmaking;

- No bias shown by employee board members in dealing with budget issues and distribution of resources; 
- No bias shown by student board members in dealing with budget issues and distribution of resources;

- Understanding the distinction between leadership and management and acknowledging the role of the board and administration; and

- The college having a history of informal shared governance thereby easing the introduction of legislated shared decision-making.

All of the responses from the constituent groups were positive overall in this section of the study. Moderate existence was noted for all themes except for meeting legislative obligations, which rated a strong existence and would be of comfort to the provincial government. No significant differences were revealed among the constituents, illustrating again the commonality of the views on shared governance in actual practice as opposed to any philosophical differences identified earlier in the study. In the case of clear rules, consistently applied, both appointees and staff expressed strong existence and those two constituent groups noted the same for accountability. The grand mean for meeting legislative obligations was strong existence although students, presidents, and education council chairs were slightly less positive, each citing moderate existence. In the case of no bias being shown ioy employee board members, only staff, who expressed strong existence, differed from the rest of the groups. And finally, faculty and education council chairs noted only minimal existence of a history of informal shared governance in contrast to the other constituents who cited moderate existence. So, again there was a sense of 
general comfort with the shared decision-making processes adopted at local campuses with virtually no indication of problem areas.

The findings from the one-way ANOVA of colleges' responses suggested slightly less unified views with four of the eight themes revealing significant differences among the institutions. However, the Scheffe test did not identify any significant difference at all between the matched pairs. There was a fair range of responses on some of the themes as might have been expected, given the uniqueness of the institutions and the looseness of the shared governance legislation. In the case of clear rules, consistently applied, seven colleges noted strong existence, while two colleges leaned toward only minimal existence. Similarly, the same seven institutions expressed strong existence of accountability, while one institution again expressed minimal existence. That latter college was only neutral on meeting legislative obligations unlike all the other colleges which identified moderate or strong existence. In the case of coping with the tendency toward centralized decision-making, one college noted strong existence, fifteen colleges noted moderate existence, while one college (College Q) maintained its negative views in this section by noting only minimal existence. Four colleges cited strong existence of no bias being shown by employee board members, while all the other colleges cited moderate existence. The similar theme of no bias being shown by student members was noted in moderate existence by all colleges, except one which noted strong existence and an other which noted only minimal existence. The theme of understanding 
roles brought a slightly more dispersed response with five institutions expressing strong existence, nine institutions expressing moderate existence, one institution remaining neutral, and two institutions expressing minimal existence. Finally, two colleges cited strong existence of a past history of informal shared governance, while three colleges cited minimal existence. Thus, there again was fairly consistent reporting among the colleges toward solid existence of the themes which would contribute to effective shared decision-making processes. There were very few instances of minimal existence expressed, except consistently from College $Q$ whose reporting members obviously were not supportive of the practices in effect at their institution. This section on decision-making process revealed College $G$, College $K$, and College $L$ as the most positive toward shared governance at the local level, while College $B$, College $F$, and, as previously noted, College $Q$ were revealed as the least positive. Over the two sections relating to sharing of power and decision-making process, College $D$, College $G$, and College $L$ appeared to be most positive in contrast to College $F$, College $O$, and College $Q$, which were the least positive.

\section{How Conflict of Interest}

has been Addressed

The undernoted themes were suggested as contributing to a board's effectiveness in addressing conflict of interest in a shared governance model: 
- A clearly understood and accepted bylaw and/or policy on conflict of interest having been developed by the board;

- Elected board members as members-at-large and not representing their constituencies;

- The oath of office, sworn by each member, preventing management/labour problems among board members;

- A personnel or labour relations committee, with restricted membership, preventing management/labour problems among board members;

- The president being able to make a full contribution to board affairs; and

- The education council chair being able to make a full contribution to board affairs.

In this section on conflict of interest, grand means ranged from minimal existence to strong existence according to the theme discussed. The clearly understood and accepted bylaw elicited a grand mean of moderate existence, a view shared by all the constituents except students who noted strong existence. Both the members-at-large and oath themes resulted in all constituents citing moderate existence, however, the labour relations committee brought a minimal existence response from all constituents except students who remained neutral. And finally, both themes concerning full participation by presidents and education council chairs, respectively, elicited responses of strong existence from all constituents except presidents who accorded both themes moderate existence 
and faculty who gave presidents only moderate existence. The one-way ANOVA identified significant difference in the case of the presidents' contribution, however, the post-hoc analysis did not identify any of the matched pairs. There was considerable consensus among the constituent groups in this potentially volatile area of boardsmanship in contrast to the first section of the study where participants were expressing their personal values to a greater extent.

The one-way ANOVA of colleges' responses revealed an anticipated wider array of views than for the constituent groups with four of the six themes indicating significant difference, one of which was confirmed by the Scheffe test. The most volatile theme, by far, in this section for colleges was that of a clearly understood and accepted bylaw. The grand mean was moderate existence, but views ranged from absolute strong existence (mean score of 5.000 ) all the way down to tendency toward non-existence. The post-hoc analysis revealed the following significant differences: between College A (strong existence) and College M (non-existence); between College A and College Q (non-existence); between College $C$ (strong existence) and College $M$; between College $D$ (strong existence) and College $M$; between College $D$ and College $Q$; between College $E$ (strong existence) and College $M$; between College $G$ (strong existence) and College M; between College I (moderate existence) and College M; between College $\mathrm{J}$ (strong existence) and College $\mathrm{M}$; between College $\mathrm{K}$ (strong existence) and College $M$; between College $L$ (strong existence) and College $M$; between College $L$ and College $Q$; between College $M$ and College $N$ (strong 
existence); between College $M$ and College $O$ (moderate existence); and finally between College $\mathbf{N}$ and College $\mathbf{Q}$. Accordingly, the large number of significant differences were due to the extreme views, focusing on College $M$ and College $Q$, both of which tended to non-existence of an understood and accepted bylaw. The members-at-large theme, in contrast, elicited a response of moderate existence from all the colleges, with exception of one college which cited minimal existence. The oath of office theme produced an array of responses, with significant difference indicated. However, the post-hoc test did not reveal any significant difference between the pairs of institutions. Nevertheless, the range was considerable with five colleges citing strong existence, ten colleges citing moderate existence, one college citing minimal existence, and one college citing non-existence. Clearly, the oath has had different impacts at different institutions. The theme of an executive committee produced an obvious split between the institutions, with three colleges noting moderate existence and all the other noting minimal and non-existence. Finally, the two themes of contribution to boards by the presidents and the education council chairs, respectively, elicited the same kind of responses from colleges as they did from the constituent groups. All institutions were positive, citing either moderate or strong existence with the exception of one college which remained neutral on both themes. This section on how conflict has been addressed produced more extreme views than the other two aspects of leadership. Accordingly, College A, College G, and College L emerged as the most positive toward shared governance in this 
section in contrast to College $B$, College $M$, and College $Q$ which were the least positive. Taking the three aspects of leadership overall, the most positive institutions were College $A$, College $D$, and College $G$, while the least positive were College $F$, College $H$, and College $Q$. Thus, College M's noticeable difficulties with the conflict of interest were not repeated elsewhere.

\section{Summary}

Analysis of the data from both the constituent groups and the colleges appeared to confirm the existence at the local campuses of all of the themes identified by the researcher as contributing to effective shared governance. Among the constituents, there was considerable consensus on the moderate existence of most themes and there was next to no instance of extreme views or any trends in views away from the mainstream.

Colleges, inevitably, were a little more disparate in their views, but really aside from the extreme negative views of College $F$ and College $Q$, in general, and College $M$, in relation to the conflict of interest issue, there was a fair degree of consensus among the institutions as well. These findings bode well for the future of shared governance in British Columbia based on the actual trends to date. 


\section{Practical Significance of the Study}

Shared governance will only be successful as a leadership model in the college setting if all the constituent groups believe what they are doing is important and is contributing to a common good of scholarship and student learning success. Furthermore, it will only be successful if the constituents practise diligently all of the characteristics of open, honest, effective shared decision making. As Fife (1998) remarked "shared governance... has a purpose and a mission. With shared governance there must be shared values and vision for the organization" (p. 2). Thus, a governance structure, and in particular how it functions, reflects the culture of a college. And if the structure is truly to be one of shared governance, then the culture must be collegial with all constituents on a board of governors-appointees, faculty, staff, students, presidents, and education council chairs--willing to work together in pursuit of common goals.

This study sought the views of the board members themselves. So, it is a one-dimensional perspective, which could in time be augmented by the views of other stakeholders. But, it is likely to be a very important indicator of how successful shared governance is, and will be, in British Columbia. For, it is an expression of the views of the very participants who can make shared governance successful or unsuccessful. Government can legislate shared decision-making, but it cannot legislate successful shared decision-making. The study was focused on the following desired outcomes: 
- Obtaining board members' views of how boards are constituted and how they operate, on both a philosophical and practical level and over studies two years apart, the study sought to determine if the commitment and the accomplishment of members was in evidence to assure effective shared governance;

- Analyzing the considerable amount of data derived from the sixtyseven statement questionnaire as well as nineteen matched statements from the previous study, the study sought to reveal findings of significant difference and other findings of comparative value in order to chart the progress of shared governance and provide some prediction of its future development;

- Individual board members and constituent groups will be able to ascertain how they compare to their colleagues. Such information, and the ramifications of their values and actions to date, may serve to tailor their own future behaviour and thereby influence the direction and effectiveness of shared decision-making in the post-secondary education sector;

- Interested and associated parties, such as the Government of British Columbia, the Canadian Federation of Students, and faculty and staff unions at both the local and provincial level may be able to evaluate the affect of their influence on shared decision-making through the views and actions of their appointees and elected members. Such 
evaluation may serve to focus future influence on pursuit of the common good and to the betterment of all parties associated with higher education.

Colleges, in common with universities and schools, are organizations of varying democratic degree, depending upon their history and the nature of the relationships among their constituent groups. However, irrespective of whether any particular college falls into the very democratic or the not-so democratic variety, it is probable that it has a governance structure that is more open and accessible if not participative than its counterparts in business, industry, and government. Such is the nature of the shared governance environment. And yet, colleges are coming under increasing pressure from the outside to act like businesses rather than the self-serving, non-accountable, gourmands of the public trough that they are all too frequently perceived to be. Unfortunately, if colleges are to become corporations, they are in danger of having to abandon their democratic cultures. As Newquist (1998) noted "Collegiality, which means shared governance or shared authority, is a casualty of applying corporate management concepts to universities [and colleges]" ( $p .1)$. This changing environment in which colleges find themselves was the backdrop to how the institutions in British Columbia entered the era of shared governance. In addition, they faced the compounding pressures of a government set on transferring power from the local campuses to the capitol and significant change occurring rapidly in the deeply rooted labour relations of the province. 
Thus, legislated shared governance was born. The legislation, itself, was alternatively loose and highly prescriptive. That ambiguity, together with colleges' natural propensity to develop things like governance structures to suit their individual identities and cultures provided the distinct likelihood of differing results of success and failure. The study, therefore, was further focused on the following outcomes:

- Identifying colleges' views, on both a philosophical and a practical level, the study sought to determine the degree of commonality among the institutions of British Columbia;

- Analyzing the comprehensive data, the study sought to reveal findings of significant difference and other differences of comparative value in order to chart the progress of shared governance and to provide indicators as to the future development of shared governance at the institutional level;

- In spite of the anonymity afforded them in the findings, college board members probably have a sense of which boards are doing well in their governance development and which are not doing well. The results of more successful institutions emerging in this study, particularly in terms of their identified strengths, may stimulate others to change their approach based on philosophy and themes of effectiveness; and 
- As noted previously, associated bodies, such as the government of British Columbia and the unions, may be able to draw on the findings from college to college to shape the kind of influence they will have in the future in regard to institutional governance.

The overriding purpose of the study, therefore, was to provide the beginnings of an evaluation process that will serve to further strengthen the governance structure and process throughout the post-secondary system. The findings will provide as many questions as they do answers, but will, hopefully, generate the stimulus among all the players to seek continuous improvement. Furthermore, the findings will contribute to the growing body of knowledge which will have some application beyond the province of British Columbia.

\section{Summary}

This chapter contained analysis of the considerable volume of data derived from the study. The descriptive statistics section revealed adequate representation from the six constituent groups and seventeen colleges and university colleges in terms of questionnaire returns to permit meaningful findings to be extracted from the data. These findings not only served to explain the British Columbia situation under review but also allowed additions to the body of knowledge and some generalization to post-secondary systems throughout North America. 
The summary of board experience showed that there has been considerable turnover in all areas of constituent membership and, therefore, the relative inexperience of board members would have had some impact on the responses offered. However, the volume and quality of actual responses would suggest that the steep learning curve in college boardsmanship is fairly manageable and board members seemed to feel comfortable and qualified in completing the questionnaire judging by the comments attached to many submissions.

Analysis of the comparative statistics was divided into two sections. The first section tracked three aspects of leadership, namely sharing of power; the effectiveness of the shared decision-making process; and how conflict of interest has been addressed, within three distinct board decision-making contexts, namely general matters; financial matters; and labour relations matters. The three dimensional focus of the study was completed by comparing data among the constituent groups, among the colleges, and among the constituent groups in certain matched statements contained in the current study and in a similar study carried out by the researcher in 1995/96. The second section contained the participants' assessments of their own boards' effectiveness in the same three aspects of leadership noted above. The data were analyzed by constituent groups and colleges.

The comparative data produced a great number of differences among the constituents and among the colleges, and between the two studies which served 
to explain the varied evolution of shared governance in British Columbia and to provide pointers to its future development. In addition, a good number of statistically significant differences were revealed throughout the findings. In fact, the diagram below illustrates that significant differences were found in fourteen of the twenty-seven areas of the three dimensional model of inquiry.

\section{Diagram 4: Location of Significant Differences in the Study}

\begin{tabular}{|c|c|c|c|c|c|c|c|c|c|}
\hline & \multicolumn{3}{|c|}{$\begin{array}{l}\text { Decision-Making on General } \\
\text { Matters }\end{array}$} & \multicolumn{3}{|c|}{$\begin{array}{l}\text { Decision-Making on Financial } \\
\text { Matters }\end{array}$} & \multicolumn{3}{|c|}{$\begin{array}{l}\text { Decision-Making on Labour } \\
\text { Relations Matters }\end{array}$} \\
\hline & $\begin{array}{c}\text { Among } \\
\text { Constituent } \\
\text { Groups }\end{array}$ & $\begin{array}{l}\text { Among } \\
\text { Colleges }\end{array}$ & $\begin{array}{l}\text { Between } \\
\text { Two } \\
\text { Studies }\end{array}$ & $\begin{array}{l}\text { Among } \\
\text { Constituent } \\
\text { Groups }\end{array}$ & $\begin{array}{l}\text { Among } \\
\text { Colleges }\end{array}$ & $\begin{array}{l}\text { Between } \\
\text { Two } \\
\text { Studies }\end{array}$ & $\begin{array}{c}\text { Among } \\
\text { Constituent } \\
\text { Groups }\end{array}$ & $\begin{array}{l}\text { Among } \\
\text { Colloges }\end{array}$ & $\begin{array}{l}\text { Between } \\
\text { Two } \\
\text { Studies }\end{array}$ \\
\hline $\begin{array}{l}\text { Sharing of } \\
\text { Power }\end{array}$ & $\mathrm{X}$ & & $x$ & & & & $X$ & & $\mathbf{X}$ \\
\hline $\begin{array}{l}\text { Effectiveness } \\
\text { of the Shared } \\
\text { Decision- } \\
\text { Making } \\
\text { Process }\end{array}$ & $\bar{x}$ & & $\bar{x}$ & & & $\bar{x}$ & $\bar{x}$ & & $\bar{x}$ \\
\hline $\begin{array}{l}\text { How Conflict } \\
\text { of Interest has } \\
\text { been } \\
\text { Addressed }\end{array}$ & & $\bar{x}$ & $\bar{x}$ & $\bar{x}$ & & & $\bar{x}$ & $\bar{x}$ & \\
\hline
\end{tabular}

These significant differences, which are fully explored in Chapter V, provide the basis for evaluating the development of the shared governance model in 
colleges in British Columbia over the past four years. In addition, the significant differences suggest the areas that are going to be contentious as boards continue to refine their structures and methods of operating. However, there is also information in the findings to suggest that the introduction of shared governance has been successful and has contributed to the ongoing effectiveness of the institutions and enriched their cultures. It is hoped by the researcher that the findings of the study will not only serve as simple results but will also be seen as tools which can be used to further develop the governance structure in the province. 


\title{
CHAPTER V SUMMARY, CONCLUSIONS, AND RECOMMENDATIONS
}

\author{
Introduction
}

In this chapter, the summary, conclusions, and recommendations are presented. The summary is a condensed version of the contents of Chapter I, II, III, and IV containing discussion of the problem under review in this study, a review of literature germane to the research questions prompted by the problem, details of the methodology adopted by the researcher to provide the data from which the findings could be elicited, and, finally, discussion of the findings in the context of the research questions. The conclusions were based on an in-depth exposure of the study findings to the nine hypotheses, spawned from the research questions, and are discussed in the context of generalizability to the post-secondary education system of British Columbia and beyond to that of North America. Finally, the recommendations take the form of two sets of practical suggestions. The first set includes recommendations to the colleges and university colleges of British Columbia on how their shared governance development could be enriched and enhanced through the knowledge gained from the findings of the study. And, the second set of recommendations relates to that body of knowledge which has been accumulated through this study and 
offers suggestions as to how and where that body of knowledge might be enlarged through additional research. Thus, the culmination of this study represents not the beginning of the end, but, rather, the end of the beginning of building a body of knowledge which will inform and support the continuous improvement process in relation to governance of the province's public colleges and university colleges.

\section{Summary}

This study focused on the legislated shared governance system which was introduced to post-secondary education in British Columbia in early 1995. Change within institutions touched the composition and powers of the governing boards and spawned the creation of education councils (which are senate-like bodies) to assume some of the former powers of boards and to share with boards in decision-making in certain areas. The study concentrated on the boards and how they have dealt with this significant change according to the perceptions of the board members themselves. It examined the impacts of change through selected aspects of leadership--sharing of power, the effectiveness of the shared decision-making process, and how conflict of interest has been addressed--in the context of selected areas of decision-making-general board matters, financial matters, and labour relations matters. 
The legislative amendment to the College and Institute Act of British Columbia, known as Bill 22, was a mixture of heavily prescribed elements, such as the rules on how to consider internal members' real or perceived conflict of interest, and loosely described elements, such as the new powers of the boards in relation to education councils and the Ministry of Advanced Education, Training, and Technology. Accordingly, the legislation deliberately allowed colleges to develop their own variations on the shared governance model. However, there was no real mechanism to carry out systemic evaluation of the new governance structure with all its potential local differences and this study sought to begin that process.

In addition to the potential uniqueness of the shared governance model on each campus, it should also be noted that the new legislation came about during a period of volatility and change in the provincial post-secondary education sector. Fiscal restraint, labour relations unrest, labour relations centralization, centralization of individual college boards' powers in general, and an open alliance between trade unions and student unions to wrest power away from appointed boards and administrations all served as a backdrop to the arrival of shared governance. And, all of these ingredients provided much of the focus for the study and constituted the basis for the research questions to be explored:

1. Is there a difference among British Columbia colleges in certain aspects of boardsmanship, namely the sharing of power, the effectiveness of the shared decision-making process, and how real or perceived conflict 
of interest of employee and student board members has been addressed when it comes to decision-making in respect to general matters of business, financial matters, and labour relations matters?

2. Is there a difference among board members, according to the constituency from which they are drawn, i.e. appointed members; elected faculty; elected support staff; elected students; presidents; and education council chairs, in certain aspects of boardsmanship, namely the sharing of power, the effectiveness of the shared decision-making process, and how real or perceived conflict of interest of employee and student board members has been addressed when it comes to decision-making in respect to general matters of business, financial matters, and labour relations matters?

3. Is there a difference between the views elicited from this study and those from an earlier study in respect to certain aspects of boardsmanship, namely the sharing of power, the effectiveness of the shared decision-making process, and how real or perceived conflict of interest of employee and student board members has been addressed when it comes to decision-making in respect to general matters of business, financial matters, and labour relations matters.

The study was limited to the views of board members by design and encountered several factors along the way which placed further limitations on its scope. These factors included an unusually high instance of turnover of board 
membership just around the time of the study and the exceptional occurrence of five of the potential seventeen participating college presidents announcing their retirement or resignation during the same period. All of these limitations may have had a positive or negative affect on the study and its results, but it is extremely difficult to quantify the affect. In addition, the closeness of the researcher to the subject matter on account of his position and the highly charged political nature of the subject matter also may have had some impact on the study.

An extensive review of literature revealed a wealth of information about the gradual evolution of shared governance, initially in the university setting and later in the college setting. Shared governance may be seen as the epitome of democracy in higher education and its path to the present day appears to have been as rocky as that of societal democracy. This was particularly true of colleges and the passage of time since shared governance became topical in the community college context has made interesting reading in the considerable amount of literature available on the subject. It seems that the tentativeness and philosophical diversity of the 70's was replaced by a dogged determination to make shared governance work in the 80's and that, in turn, has been replaced by a period of reflection and, not a little, doubt in the 90 's. Throughout the three decades, authors have divided into proponents, standing on the side of inclusiveness and even moral justification, and detractors, citing the very real 
issue of self-interest on the part of board members who coincidentally are members of the faculty, support staff, and student constituencies.

There has been much questioning of the role of boards of governance in colleges. And, if one is to accept that the role is one of adopting the high level, long term perspective in setting the direction of colleges (a view which is not universally shared), and one is prepared to acknowledge the moral right of the stakeholders to be included in such direction setting, then most authors concluded that the notion of shared governance is appropriate. However, it was noted that the combination of internal, usually elected, members and external, appointed or elected, members does not necessarily make for a marriage made in heaven. A clear and ongoing, if not permanent, clash of values between the internal and external members was cited in terms of commitment to the board mission, knowledge of boardsmanship, philosophical foundation, and actual behaviour at the board table. In addition, it was suggested that the very existence of shared governance has been instrumental in undermining the office of the presidents, regardless of their actual role in shared decision-making.

The consistent message that emerged from literature was that for shared governance to stand any chance of operating effectively in a college, there must be clear, accepted, and consistently applied procedures on shared decisionmaking that firmly establish responsibilities and roles. In addition, the issue of the inherent conflict of interest faced by the internal members must be addressed if the governance model is to have integrity. The importance of these requirements 
has been stressed since the inception of shared governance and yet they seem to be still cited today, across the continent, as problematic and the barrier to effective and harmonious institutional democracy. Authors noted that students have really made little progress in becoming accepted as equal members of the governing family, while support staff suffer from a form of inferiority complex when it comes to interaction with faculty and external members. Staff, and to some degree faculty, have had difficulty dealing with the overlapping interests of boards and trade unions which is a more prominent issue in colleges than universities due to the firm foothold which unions have established in the former. Pursuit of self interest rather than that of the common good has long been the charge leveled at internal members and this, perhaps, has been the greatest challenge to the general acceptance of shared governance. The areas where friction has been most pronounced have been financial affairs and labour relations, two areas where personal gain for internal members might be seen as most likely. These challenges to the notion of democratic governance which abounded in literature became the main focus of inquiry in this study.

The methodology adopted for the study was intended to provide a rigorous examination of shared governance in British Columbia, based on a three dimensional model of inquiry. The model allowed for evaluation of the governance experience through three lenses, namely three aspects of board leadership in three decision-making contexts examined by constituent group, college, and through the passage of time between two similar studies carried out 
by the researcher. The study centred around a sixty-seven item questionnaire based on a Lickert-type attitude inventory, which included statements related to nine hypotheses drawn from the three research questions. The researcher's familiarity with the provincial post-secondary education system facilitated access to the board member population and, consequently seventeen colleges and university colleges and two hundred and fifty-five members were included in the study. The participants' personal identity and the identity of the colleges were protected in the study process and all subsequent reports. A protocol statement that detailed the proposed process of protection was submitted to the Committee on the Protection of Human Subjects, University of San Diego for approval and was subsequently granted. In addition, the protocol statement was also submitted, as a requirement of the researcher's own institutional policy, to the Research and Ethics Committee, Malaspina University College, British Columbia and received the necessary approval. Finally, the approved process was described in the statement of informed consent which each potential participant was asked to endorse and return with his/her completed questionnaire. Special additional protection was afforded the internal members of the researcher's own college in order to avoid any sense of pressure emanating from his position in the organization.

All of the data from the surveys was processed using the Statview SE+ Graphics Program on Apple hardware. Manipulation of the data permitted oneway ANOVA statements to be produced by constituency group and college. 
Furthermore, a two-way ANOVA of matched statements from this study and the $1995 / 96$ study was prepared. The structure of the survey instrument and the specific questions asked focused solely on the research questions and, consequently, provided accurate and consistent data to allow concise analyses and conclusions.

The return rate of questionnaires was $40 \%$ with all constituent groups represented, ranging from $77 \%$ of the presidents to $20 \%$ of the students. In addition, all colleges were represented with the range extending from $69 \%$ of the College $\mathrm{M}$ membership to $21 \%$ of the College $\mathrm{P}$ membership. The mean of years of experience on boards came in at $\mathbf{2 . 9 0 9}$ underscoring the high turnover rate of board membership and the relative inexperience of participating members.

Analysis of the data produced a great many trends, both of a positive and negative variety toward shared governance, and also a substantial amount of differences, many of a statistically significant nature, among constituent groups and colleges, and between the two studies. Colleges tended to vary a little in specific areas but, overall, clear trends emerged as to several consistently positive institutions and several consistently negative institutions in regard to shared governance from a philosophical standpoint. And, these views were essentially repeated when participants assessed their own particular boards' characteristics in shared decision-making. The most positive institutions were College $D$, College $G$, College $K$, and College $L$ and the least positive institutions were College E, College F, and College Q. 
The grand means of the constituent groups generally tended toward positive attitudes on all of the aspects of shared governance, however there were several areas where one or another of the constituents had dissimilar views and there emerged a very obvious trend of presidents espousing no more than lukewarm responses and occasional very negative responses. The presidents were particularly concerned about the lack of independence from their constituencies shown by internal members, the impact of the heavily unionized environment on the governance environment, the actions and accountability of the democratized boards, internal members showing bias in relation to the budget process, the (legislated) ability of student members to vote on tuition issues, and the questions as to whether the internal members have lived up to their oath of office. The last concern struck at the very integrity of the governance process and coincided with the contentious issues raised in literature. The presidents' dramatic shift in their views was noted as one of the changes between the two studies. In 1995/96, presidents and appointees were noted as being clearly positive about the fledgling governance structures, while students were neutral and faculty, staff, and education council chairs were decidedly cautious. Little more than two years later, appointees had largely been joined by all the constituents, except the presidents, on the positive side while the presidents stood alone, generally neutral and frequently negative. The very stark gulf in philosophical and practical values between the appointees and the 
presidents in the current study appeared to contradict the traditional alliance noted in literature as crucial to the success of shared governance.

Other less dramatic trends to emerge included overall concern about the diminution of the boards' powers as a result of governmental centralization, general unease around the government prescribed treatment of conflict of interest, and the widespread practice of internal members simultaneously holding office in their respective trades and student unions. On a more narrow focus, staff seemed to have trouble with aspects of the students' approach to governance, in particular their role in labour relations, and education council chairs were quite negative toward the democratized boards' openness and accountability on financial matters. Generally, all constituent groups assessed that their own particular boards were demonstrating moderate existence of the various qualities identified by the researcher in this study as contributing to the effectiveness of governing boards. Confirmation of the existence of these qualities, while it might have flown in the face of some of the philosophical values espoused, did suggest reasonable progress had been made in the development of shared governance in British Columbia.

The significance of this study was the attempt to understand the values, commitment, and actions of board members in the shared governance structure in order to evaluate the progress to date and to provide some prediction for the future of shared decision-making in the province. In addition, the identification of views and practices within constituent groups and colleges might serve to 
influence the behaviour of not only the direct governance players, the members themselves, but also the indirect players which have an influence on the outcomes, such as government and the trades and student unions.

\section{Conclusions}

This study focused on three specific questions in order to assess how shared governance has been developed in British Columbia. Those three questions each spawned three hypotheses for a total of nine hypotheses. Further, each hypothesis existed in three decision-making contexts resulting in twenty-seven variables within the three-dimensional model of inquiry. This section of the chapter condensed all of the findings into the structure of the primary research questions.

1. Is there a difference among British Columbia colleges in certain aspects of boardsmanship, namely the sharing of power, the effectiveness of the shared decision-making process, and how real or perceived conflict of interest of employee and student board members has been addressed when it comes to decision-making in respect to general matters of business, financial matters, and labour relations matters?

Analysis of the data found that there were no significant differences among colleges on the sharing of power in any one of the three decision-making contexts. The null hypothesis was, therefore, tenable. Local differences and 
nuances notwithstanding, it was reasonable to conclude that all colleges were generally comfortable with the fundamental requirement of distributing authority in a fair and equitable manner. This level of comfort, which is crucial to the existence of shared governance, seemed to extend beyond decision-making on general matters to the more contentious areas of financial matters and labour relations matters.

No significant differences were found among the colleges concerning the effectiveness of the shared decision-making process. Accordingly, it could be assumed that colleges were generally comfortable with the processes of shared decision-making which have evolved in each of the three contexts under review. In the context of general matters of board business, significant difference was found among eight colleges on the issue of whether the conflict of interest bylaw was generally accepted by all board members as fair and workable. There was, also, significant difference between two colleges on whether conflict of interest in this decision-making context has been an actual problem at the campus level. Further, there were no significant differences among colleges relating to conflict of interest in the context of financial decision making. However, there was significant difference among eight colleges on whether boards had dealt effectively with the inherent conflict of interest of internal members in decision-making on labour relations matters. And, in addition, there was significant difference between two colleges on whether an executive committee, excluding internal members, should be adopted to deal with labour 
relations matters. Furthermore, there was significant difference among thirteen colleges on whether an executive committee had actually been adopted at the local site. On the basis of finding powerful disparities among colleges in two of the three decision-making contexts, it was reasonable to reject the null hypothesis and conclude that conflict of interest had caused differences among the institutions.

It can be concluded that there was no discernible difference among colleges in two of the aspects of board leadership, namely the sharing of power and the creation of effective shared decision-making processes. However, there was significant difference with profound undertones among the colleges on how conflict of interest has been addressed. The importance of the third aspect of leadership is such that it must be concluded that there was, indeed, far-reaching difference among colleges, overall, even though it was not evident in the other two aspects. The rationale for this conclusion is that dealing with conflict of interest has been noted in the literature in Chapter II as fundamental to the success of shared governance and lack of consensus among the colleges as to how it has been addressed represents a serious division within the postsecondary education system.

2. Is there a difference among board members, according to the constituency from which they are drawn, i.e. appointed members; elected faculty; elected support staff; elected students; presidents; and 
education council chairs, in certain aspects of boardsmanship, namely the sharing of power, the effectiveness of the shared decision-making process, and how real or perceived conflict of interest of employee and student board members has been addressed when it comes to decisionmaking in respect to general matters of business, financial matters, and labour relations matters?

Analysis of the data revealed significant difference on the issue of power sharing in the context of decision-making on general matters between appointees and the presidents and between support staff and the presidents. This occurred in the matter of whether employee board members should get release time as compensation for board service and showed staff to be in strong agreement, appointees in agreement, and presidents in strong disagreement. There was no significant difference among the constituent groups on sharing of power in financial decision-making. Finally, significant difference was revealed between appointees and presidents and between faculty and presidents in terms of labour relations. This occurred in the proposition that shared governance is inherently difficult in a unionized environment with presidents expressing agreement, appointees expressing disagreement, and faculty expressing strong disagreement. On the basis of the differences revealed, chiefly involving appointees and presidents, it was reasonable to reject the null hypothesis and conclude that there was difference among constituent groups on the sharing of power. 
Four separate instances of significant difference were found among constituent groups in the context of the shared decision-making process on general matters. Student board members differed with the presidents on the contention that the (democratic) composition of boards makes a contribution toward effective governance, with the former in strong agreement and the latter in strong disagreement. There was significant difference between the appointees (strong agreement) and the presidents (weak agreement) on the question of whether the newly constituted boards had managed to make some difficult decisions during the last two years. Furthermore, there was again difference between the appointees and the presidents on whether boards had been accountable to their internal and external communities. On this issue, appointees again expressed strong agreement while presidents again offered only weak agreement. Finally, there was significant difference on the question of whether boards had fulfilled their general obligations under the College and Institute Act between appointees and presidents and between students and presidents with the positive constituents expressing strong agreement and the presidents, with considerable reserve, noting only weak agreement. There were no significant differences on the effectiveness of the shared decision-making process in the context of financial matters. This result was somewhat surprising given the suggestion in Chapter II that shared governance commonly comes under threat in the financial decision-making area. However, there were three examples of significant difference related to labour relations matters. On the issue of whether 
boards would have adopted a different labour relations direction had there been no internal members, appointees and education council chairs differed with the former disagreeing and the latter agreeing. There was significant difference between the faculty and presidents and between the faculty and education council chairs on the contention that boards would have adopted a different labour relation direction had the tendency toward provincial centralization of decision-making not been in evidence. This difference was revealed as strong disagreement from faculty and agreement from presidents and education council chairs. Lastly, the suggestion that boards would have adopted a different direction in labour relations had neither internal members nor centralization of decision-making existed brought significant difference again between faculty, in strong disagreement, and presidents and education council chairs, both in agreement. The overwhelming evidence of significant differences in both general board matters and labour relations matters substantiated the conclusion that the null hypothesis should be rejected and that difference among constituent groups was considerable in relation to the effectiveness of the shared decision-making process in the shared governance model.

There were no significant differences among the constituent groups in how conflict of interest had been addressed in the area of general decisionmaking. However, in the financial context, the issue of the appropriateness of the student members being able to vote on tuition matters revealed difference between appointees and presidents, with the former agreeing but the latter 
strongly disagreeing. There were two instances of significant difference in the area of decision-making on labour relations, the first of which concerned whether internal members had lived upto their oath of office. This issue which strikes at the very integrity of the shared governance model revealed appointees and faculty to be in strong agreement but presidents expressed only weak agreement. Appointees and presidents also differed on whether boards had dealt effectively with the conflict of interest inherent to internal members with the former espousing strong agreement in contrast to the presidents' disagreement. In light of yet another series of examples of significant difference between appointees and presidents, it appears prudent to reject the null hypothesis in favour of a conclusion that there was, indeed, noticeable difference among constituents on how conflict of interest had been addressed.

It can safely be concluded that there was profound and widespread difference among the constituent groups relative to shared governance in British Columbia. The consistent divergence between appointees and presidents and the frequent isolation of the latter in contrast to all the other constituent groups served to underscore the sense of deep division that appeared to exist. Furthermore, the largely negative opinions of the titular educational leaders, that the presidents represent, does not bode well for the future success of shared governance in the province nor, perhaps, for education in general.

In contrast, however, most of the other constituent groups consistently reported positive views toward the aspects of shared governance, in particular 
the appointees and the faculty members. The concurrence of views among the appointees and internal members in general is somewhat surprising given the trends suggested in Chapter II and may be attributable to the fact that the government in power, which is making the appointments, would be described as left-of-centre and more likely to have philosophies parallel to those of the internal members than might a right-of-centre government.

3. Is there a difference between the views elicited from this study and those from an earlier study in respect to certain aspects of boardsmanship, namely the sharing of power, the effectiveness of the shared decisionmaking process, and how real or perceived conflict of interest of employee and student board members has been addressed when it comes to decision-making in respect to general matters of business, financial matters, and labour relations matters.

Analysis of the data confirmed that there was significant difference between the 1995/96 study and the current study on the sharing of power in general board matters, and more specifically in relation to the appropriateness of the six year aggregate term for appointees. The $1997 / 98$ study showed a generally more positive response from all constituents within the area of agreement. Furthermore, the same statement resulted in significant difference among the constituent groups over the two studies with appointees, staff and presidents expressing agreement, faculty and education council chairs remaining 
neutral, and students expressing disagreement. There were no significant differences in relation to the sharing of power on financial matters. However, there was significant difference relative to labour relations on the contention that shared governance is inherently difficult to develop in a unionized environment. The difference was among the constituents over the two studies and extended to agreement (presidents and students), disagreement (appointees, staff, and education council chairs) and strong disagreement (faculty). The existence of significant difference in two of the three decision-making contexts was considered sufficient to suggest that the null hypothesis should be rejected. Consequently, it would appear that there was difference between the two studies on the sharing of power, mainly relating to the relationship among the constituent groups.

Areas of significant difference were discovered in all three decisionmaking contexts relative to the effectiveness of the shared decision-making process. In the case of general board matters, there was significant interaction among the constituents on the contention that the new composition of boards made a contribution toward effective governance. While four of the constituent groups moved in a negative direction between the two studies, students and education council chairs moved in a positive direction thereby causing the interaction affect (see Appendix Q). Similarly, there was significant interaction on the companion statement that the manner in which boards operated made a contribution to effective governance (see Appendix R). In this case, the same 
four groups moved in a negative direction over the two studies while students again moved in a positive direction. There were two significant differences within the financial decision-making context. The first was among constituents over the two studies on whether boards had fulfilled their fiscal obligations under the College and Institute Act. Students and education council chairs, who expressed weakish agreement, contrasted with the other groups' strong agreement. The second instance of difference was again among constituents on the contention that boards had discharged their fiduciary responsibilities to the student population at large in relation to matters concerning fees collected. With the exception of student members who were in disagreement, all other groups agreed or strongly agreed with the statement. In the case of decision-making on labour relations matters, there were two significant differences related to the question of whether boards had fulfilled their labour relation obligations under the College and Institute Act. In the first difference, among the constituent groups over the two studies, appointees were in strong agreement while all the other groups were in agreement. In addition, there was significant interaction with presidents adopting a more negative position in the later study while all the other groups adopted a more positive position (see Appendix S). The extent of the significant differences and interactions prompted the researcher to conclude that this null hypothesis should be rejected, and, rather, that it was reasonable to infer that there was discernible difference between the findings of the two studies 
in relation to the effectiveness of the shared decision-making process and its impact on shared governance.

Analysis of the data revealed two significant differences between the studies on how conflict of interest has been addressed in relation to general board decision-making. The first occurred on the contention that education council chairs should be non-voting members of boards, as they are currently legislated. The grand mean of responses moved from 3.916 in the earlier study to 3.578 in the current study signaling a noticeable shift in thinking on the matter. In a similar vein, there was also significant difference on the contention that education council chairs should be full voting members. In this case, the grand mean shifted from 2.075 to 2.485 indicating change of opinion which was the reciprocal of the previous statement. There were no significant differences in either financial matters or labour relations matters. As a consequence of these findings, it would appear that this hypothesis was tenable and, indeed, there was no difference between the studies on how conflict of interest had been addressed.

There were a considerable number of significant differences and interactions in the leadership aspects of power sharing and ensuring the effectiveness of the shared decision-making process to outweigh the relative absence of differences in how conflict of interest had been addressed. Consequently, the researcher would argue that there was a marginal overall difference in the findings from the two studies. And, on balance, the general 
direction of the findings was toward a more positive attitude, overall, on shared governance emerging in the current study. This direction was established in spite of the fact that the presidents' views had clearly moved from a positive position in $1995 / 96$ to a negative position in 1997/98.

The following findings from the study fell short of statistical significance but were, nevertheless, worthy of note because they underscore the main conclusions that have been reached in relation to the research questions:

1. All differences, both significant and otherwise, among colleges tended to establish identifiable trends which separated colleges with generally positive attitudes toward shared governance from colleges with less than positive attitudes. Those trends are tabulated in Appendix P.

2. Similarly, Appendix $P$ also illustrates how all the differences among constituent groups conformed to very clear patterns. The most stark observation from this table is the consistent placement of the presidents as the least positive of the constituent groups. In addition, the following trends were noted:

- Appointees and presidents were generally far apart on philosophical matters unlike the findings in the 1995/96 study which placed them close together and positive toward shared governance.

- Support staff and presidents shared some general skepticism toward the role of students on college boards in relation to the students' ability 
to vote on tuition matters and their right to simultaneously hold office on boards and student union executive committees.

- Although not causing significant statistical difference, presidents believed that budgets were more difficult to balance in a shared governance environment. They also disagreed with the suggestion that internal members had not shown bias in financial matters, thereby striking at the integrity of the shared decision-making ideal.

- Education council chairs were quite negative toward boards having ensured access of stakeholders to financial information and boards having kept stakeholders adequately informed about financial matters. This negativity was, however, largely out of character for this constituent group.

- Faculty and education council chairs frequently differed even though the latter are most commonly also faculty members.

3. There was only one significant difference in the assessment of own boards' effectiveness in aspects of leadership, pertaining to thirteen colleges and the existence of a clearly understood and accepted bylaw on conflict if interest. Further, in spite of widely differing philosophies on the characteristics of effective shared governance revealed among colleges and constituent groups, there was almost total agreement that colleges were actually exhibiting those characteristics in practice. This particular set of findings 
would be very appropriate to test against the views of other stakeholder groups.

In conclusion, the findings of the study were that material differences existed between both colleges and constituent groups, and to a lesser extent between the two studies, in relation to all three important aspects of board leadership. The sharing of power was marginally less problematic than the effectiveness of the shared decision-making process and how conflict of interest had been addressed. In addition, there were also material differences among the three decision-making contexts, but, surprisingly, financial matters appeared to be noticeably less problematic than general matters and labour relations matters. The degree of differences, as expressed in the number with statistical significance, would appear to present clear warning to everyone associated with education in British Columbia. And, that warning would be that, although much progress has been made, the development of shared governance is not proceeding as smoothly and evenly as might have been desired. But then again, it might be concluded that the progress to date is conforming very closely to the pattern throughout North America as evidenced in thirty years of literature. 


\section{Recommendations}

This final section of the chapter contains practical suggestions for implementation and further pursuit of the findings from the study and suggestions for areas of further research to build upon those findings.

A study which is evaluative in nature should be expected to produce findings which can be applied in a practical way to improve the subject under review. And, that is the case with this study of shared governance in the British Columbia post-secondary education system. There were clear messages to emerge from the findings and these should be directed back to the system from which they were drawn. First, it is important to note that shared governance has been relatively well introduced to the province. That was confirmed by the board members in noting the moderate existence at each college site of most of the qualities associated with successful shared decision-making. However, not all qualities were recognized at all campuses and, in addition, there were very different philosophical views expressed by constituent groups and colleges. It is in this area of personal values that most attention should be paid because these personal values held by board members are likely to become the actual characteristics of tomorrow's governing boards. There are clear divergences of values held by the presidents of institutions and in certain colleges.

Conflict of interest in principle, directed at the internal members, is an obvious problem area, as is the shared decision-making process which is often 
affected by conflict of interest. The fundamental sharing of power appears not to be such a great problem, although the role of students did come under some critical scrutiny. Problems were detected in two of the decision-making areas, namely general matters and, in particular, labour relations matters. Somewhat surprisingly, financial matters did not seem to be such a problem, but must inevitably be impacted by the conflict of interest issue noted earlier.

\section{Suggestions for Implementation and Further Pursuit of the Findings of the Study}

1. College trustees should study the results of this evaluation carefully. Notwithstanding the anonymity, boards can probably relate their own known culture to the findings. Colleges should use the findings as building blocks for the future, starting with structured evaluation of their own performance. And, the evaluation would be most effective were it to include all stakeholder groups including the public-at-large and perhaps even representatives of the provincial government. In this case, the Advanced Education Council of British Columbia could assume a leadership role in facilitating the development of common evaluation tools to assist boards. This evaluation task should be separate from the all-encompassing, and relatively ineffectual, five-year self studies which colleges presently undertake. 
2. Out of the evaluation should come, as a minimum, action plans to draw up clear rules of operating and responsibilities including policy on conflict of interest, even if the universal conflict of interest bylaw cannot be changed immediately. The bylaw should, however, be subjected to rigorous review as it clearly is a bone of contention and, perhaps, the Achilles heel of shared governance right now. The more clarity that can be instilled in board objectives and procedures, the less likelihood there is of ongoing problems.

3. If colleges can establish cultural norms of shared governance, not only might some of teething problems, currently being experienced, tend to diminish but also the problems of frequent turnover of the memberships may be alleviated. Orientation of new members, and this is just as important for internal members as external members, would be an effective tool in creating and sustaining a democratic culture. Again, AECBC would appear to have a role to play whether it is in focusing more on the issues of shared governance in the orientation sessions which it sponsors in Vancouver or assisting in the development of orientation packages which can be used at the local board level where all members are more likely to be in attendance.

4. Finally, it would appear that boards need to revisit their relationships with the constituencies that have impact on them, including education councils; the Ministry of Advanced Education, Training, and Technology, and other branches of government; and student and trade unions, on both a local and provincial level. Development of those relationships would surely lead to 
better definition of the roles of internal members on college boards and, thereby, address one of the fundamental weaknesses of shared governance which was identified in literature and is now manifesting itself in British Columbia. That weakness relates to the tendency of internal members to pursue the interest of their constituencies rather than that of the common good. One obvious solution to the problem might lie in consideration of the notion that employees and students serving simultaneously as board members and union officials is an impossible and undesirable clash of interests and loyalties.

5. The presidents have to regroup and consider what would improve their views and actions in shared decision-making. Clearly, given the power of their office, shared governance will not fully prosper if they continue to see it in a negative light. However, the governance structure is sufficiently well established already to suggest that change will not come about if the presidents take a back seat. It would appear that some presidents, at least, have adopted what was identified in literature as bury-one's-head-in-the-sand response to the perception of having their power changed in shared governance. The presidents need to reassess this inactivity and explore the value of taking charge, of assuming a leadership role in engaging the other constituents to work together in pursuit of a common good. This engagement resonates with the notion of collaborative leadership espoused by Rost (1993) and Scherr (1994). Arguably, the presidents have the station and the 
reputation for independence to provide the spark for true democratization of all the players and the pursuit of the advantages of shared decision-making. The current structure in British Columbia which sees the Council of Chief Executive Officers and the Council of Board Governors meet individually and jointly under the auspices of $A E C B C$ would provide the ideal vehicle for initial exploration of the kind of governance development envisaged. And, it would also present the opportunity to start to close the gap which has emerged between the presidents and provincially appointed members in particular. Key players among the presidents group could well be the five newly hired presidents who should bring a fresh perspective and, thus, start to turn around an apparently deteriorating situation.

\section{Suggestions for Areas of Further Research}

Shared governance is an evolving concept, even with thirty years experience in some provinces and states. Its continued evolution is very dependent upon the changes going on in education as a whole as well as the real world outside of education. This study merely scratches the surface as others have done before. And, it poses more questions at its conclusion than it does provide answers.

1. In terms of a total perspective on shared governance in British Columbia, there is a fruitful field of research possible in examining the subject through 
other stakeholder groups, individually or as a whole. The views of the general populations of faculty, staff, and students as well those of the public-at-large, media, and government would provide a rich and, in all probability, contrasting picture to augment the findings of this study.

2. In addition, a follow-up on this study in approximately three years, which could include both current board members and former members, would expand the knowledge base of this study and determine if patterns of views and behaviours are still in a fluid mode. Such a study would also serve to allay any concerns about the relative inexperience of the current study's participants, expressed in a grand mean of 2.909 years.

3. The apparent extreme negative views of the college presidents toward shared governance would suggest that a more intensive qualitative study of their views might reveal what can be done to bring the presidents on-side. One would imagine that the provincial government might be interested in sponsoring such research given the importance of the presidents at the heart of the education system.

4. Conflict of interest is well documented as perhaps the greatest barrier to truly effective shared governance. Consequently, this issue represents a potentially fruitful area of research, particularly in examining where there has been successful introduction of shared governance into a highly unionized environment elsewhere in North America. 
5. The findings of this study revealed colleges which were positive toward shared governance, both philosophically and in practice, and colleges which were negative. A case study of one or more of the positive colleges may well reveal the cultural characteristics and established procedures which could be developed as standards for the less positive colleges to adopt. This would, of course, require some colleges to waive the anonymity which they were given in this study.

Several specific areas were identified during the analysis of the data in the study which prompted the need for further research. This research could be done independently or be part of the basis for a follow-up study.

- The participants were firmly split down the middle (positive, neutral, and negative) on whether the tendency toward provincial centralization of boards' decision-making powers had spared the boards, to any extent, difficulties in decision-making due to the inclusion of internal members. Further research should be undertaken to determine if the absence of difficulties, where noted, was due to the centralization or any other positive factors within a board's culture.

- Since most colleges reported that they had been able to deal with the trend toward provincial centralization and, consequent, diminution of their powers, further research might reveal how institutions are evolving from being hierarchical organizations with substantial local power to become democratic organizations within a hierarchical education system where power 
increasingly resides elsewhere, such as with the provincial government both within the Ministry of Advanced Education, Training and Technology and other ministries. This type of inquiry would lend itself to a qualitative study.

- Appointees and education council chairs tended toward disagreement that the remuneration of the former was appropriate. It would be interesting to determine if the two constituents had the same reason for their negative view toward the level of remuneration.

- The issue of boards meeting their fiduciary obligations to the student population in terms of dealing with student unions when two students are frequently members of both bodies prompted the need for more information than was forthcoming in the study. Student respondents were neutral and it would take further research to determine if the reason for neutrality went along with a lack of knowledge of the boards' legal fiduciary obligations, reservation as to the appropriateness of those obligations, or reservation as to whether boards had, indeed, discharged the obligations.

- Finally, the general disquiet around conflict of interest, which permeates the findings of this study, would naturally prompt further questions:

- Two colleges disagreed that the bylaw was accepted as fair and workable. Further research to determine if the opinions were founded on principle only or on practical experiences at their particular campuses might provide new information which would assist colleges in dealing with this major issue. Such findings might form the basis of 
new local policies to codify the responsibilities and expectations of internal members.

- Similarly, the students stood out in isolation in disagreeing with the contention that conflict of interest had not been a de facto problem at campuses. It would interesting to find out more about the problems observed by this unique group of board members.

Consequently, the questions posed above would appear to confirm that the quest for information on the shared governance concept is not yet at an end. 


\section{REFERENCES}

Academic Senate for California Community Colleges (1996). Developing a model for effective senate/union relations. Sacramento. CA. (ERIC Reproduction Service No. 395 628).

Acebo, S. (1992). The team as hero: A paradigm shift in college leadership, in D. Doucette (Ed.). Leadership Abstracts 5 (1-10).

Advanced Education Council of British Columbia. (1994). Four basic principles on governance. Brief to provincial government. Vancouver, BC.

Allen, L. (1991, April). Implementing shared governance: Models for empowering teachers. Paper presented at the Annual Meeting of the American Educational Research Association, Chicago, IL.

Allen, L. \& Glickman, C. D. (1992). School improvement: The elusive faces of shared governance. NASSP Bulletin, 76(542), 80-87.

American Association of University Professors. (1987). Statement on academic government for institutions engaged in collective bargaining. Academe. 73(6), 25-26.

Ary, D., Jacobs, L. C, \& Razavieh, A. (1990). Introduction to research in education. Fort Worth, TX: Holt, Rinehart, and Winston Inc. 
Bergquist, W. H. (1993). The postmodern organization: Mastering the art of irreversible change. San Francisco, CA : Jossey-Bass.

Bogen, G., \& Moskus J. (1992). Preventing problems in board-president relationships, in D. Doucette (Ed.) Leadership Abstracts 5 (1-10).

Boggs, G. R. (1995). The president and the board: A team of leaders, in G. A. Baker III (Ed.). Team building for quality: Transitions in the American community college. Washington, DC: American Association of Community Colleges, National Centre for Higher Education.

British Columbia (1991). College and Institute Act. Statutes of British Columbia, Chapter 53. Victoria, BC: Queen's Printer for British Columbia.

British Columbia (1994). Bill 22: College and Institute Amendment Act. Statutes of British Columbia. Victoria, BC: Queen's Printer for British Columbia.

Cameron, D. M. (1996). Academic freedom and the Canadian university. The Association of Universities and Colleges of Canada Research File. 1(3).

Canadian Federation of Students (1992). Democratic governance in postsecondary institutions in BC. Brief to provincial government. Vancouver, BC. 
Carver, J. (1997). Boards that make a difference: A new design for leadership in nonprofit and public organizations (2nd ed.). San Francisco, CA: Jossey-Bass Inc.

Chaffee, E. E. (1982,March). Rational budgeting? The Stanford case. Paper presented at the Annual Meeting of the American Educational Research Association, New York, NY.

Cohen, A. M. (1996). Projecting the future of community colleges. ERIC Clearinghouse for Community Colleges, Available HTTP: http://www.ase.ucla.edu/ERIC/digests/dig9601.html\#GOVERNANCE

College and Institute Educators' Association of British Columbia (1994). College and institute Act Amendment 1994. Brief to provincial government. Vancouver, BC: CIEA Committee on Governance Implementation.

Collins, C. C. (1970). Student rights and freedoms: Toward implementation models. California : University of California, Berkeley.

Comer, J. P., Haynes, N. M., Joyner, E. T., \& Ben-Avie, M. (1996). Rallying the whole village: The Comer process for reforming education. New York, NY : Teachers College Press.

Committee on Governance in Colleges and Institutes (1993). Recommendations for revised governance structures, Brief to government. Victoria, BC. 
Covey, S. R. (1996, September 12, October 1, 23, November 15). The First Worldwide Lessons in Leadership Series, Live via Satellite. MICA Management Resources, Vancouver, B.C.

Deas, E. (1997). Individualism: How it affects the virtue of boardsmanship. Unpublished doctoral paper, University of San Diego, CA.

Deas, E. (1996a). Shared decision making: A comparative case study, Unpublished doctoral paper, University of San Diego, CA.

Deas, E. (1996b). Shared govemance and the affects of Bill 22 on the post-secondary system of British Columbia. Canada. Unpublished doctoral paper, San Diego State University, CA.

Deas, E. (1994). Board and administration relationships contributing to community college climate: A case study. Community College Review. 22(1), 4452.

Debow-Makino, G., Hill, H., Atwood, G., Murdoff, R., \& Westphal, E. (1993). Attitudes on staff participation and the acceptance of women and minorities at Delta College. Stockton, CA: San Joaquin Delta Community College District, Office of Institutional Research and Planning. 
Dennison, J. D. (1997, August) The university college in British Columbia: Cultural compromise and the legitimation of applied knowledge. Paper presented at the 19th Annual Forum of the European Higher Education Society, University of Warwick, UK.

Dennison, J. D. (1994). The case for democratic governance in Canada's community colleges. Interchange. 25/1, 32-33.

Dennison, J. D., \& Gallagher, P. (1986). Canada's community colleges: A critical analysis. Vancouver, BC: University of British Columbia Press.

Dominguez, G. M. (1975). A faculty plan for changing membership of the board of trustees. Unpublished doctoral practicum, Nova University, Florida.

Douglas, J. M. (1979). The impact of collective bargaining on governance. Information Bulletin of the National Center for the Study of Collective Bargaining in Higher Education. 2(1). New York : City University of New York.

Draper, B., \& Van Groningen, I. (1990). Collaborative governance: Structures for success. The California and Yosemite Community College District experience. California Yosemite Community College District, Joint CEO/Trustee Committee.

Drummond, M. E. \& Reitsch, A. (1995). The relationship between shared governance models and faculty and administrator attitudes. Journal for Higher Education Management. 11(1(Summer/Fall 1995)), 49-58. 
Edelfelt, R. A. (1982). Review and evaluation. Staff development for school improvement program 1981-82. Eastern Michigan University, National Center on Teaching and Learning.

Epp, J.R. (1992, January). Teacher participation in school government: A central element in educational reform. Paper presented at the Annual Meeting of the International Congress for School Effectiveness and Improvement, Victoria, BC.

Fife, J. D. (1998, January) Colloquy: The end of shared governance? The Chronicle of Higher Education Available HTTP: http://chronicle.com/colloquy/98/sharedgov/12.htm

Filan, G. L. (1992). The trick to being a community college chair, in D. Doucette (Ed.). Leadership Abstracts 5(1-10).

Flanigan, P. K. (1994). California community colleges faculty role in shared governance. California : Unpublished executive summary of doctoral dissertation.

Giles, V. (1981). The case against college boards. College Canada, May, 22-23.

Gregory T. (1996). What is policy governance? Irustee Quarterly 1996(1), 3-4. 
Griffith, R. (1993). Budget cuts and shared governance : An administrator's perspective. Academe. 79(6), 15-17.

Gulassa, C. (1989). Collaborative governance in the Foothills/DeAnza Comminity College District. Management report 1988-89. California : Association of California Community College Administrators.

Hackmann, D. G., \& Berry, J. E. (1994, November). A university/school collaboration model for systemic change through site-based management. Paper presented at the Annual Meeting of the National Conference on School/College Collaboration of the American Association for Higher Education, Washington, DC.

Hawley, P. (1993). Being bright is not enough. Springfield, IL: Thomas.

Harris, M. (1996). Proclaim jubilee: A spirituality for the twenty-first century, Louisville, KY: Westminster John Knox Press.

Hodgkinson, H. L. (1974). The campus senate: Experiment in democracy. University of California, Berkeley, Center for Research and Development in Higher Education.

Huck S. W. \& Cormier, W. H. (1996). Reading statistics and research. New York, NY: Harper Collins. 
Hunt, S. M. (1984). The role of leadership in the construction of reality, in B. Kellerman (Ed). Leadership: Multidisciplinary perspectives. Englewood Cliffs, NJ : Prentice-Hall.

Jasiek, C. R., Wisgoski, A., \& Andrews, H. A. (1985). The trustee role in college personnel management, in Gary F. Petty (Ed). Active trusteeship for a changing era. New Directions for Community Colleges, 51, 87-96. San Francisco, CA : Jossey-Bass.

Kanter, M. J. (1994). Instuctional programs, in A. M. Cohen, F. B. Brawer, et al. (Ed). Managing community colleges. (pp. 229-230). San Francisco, CA : Jossey-Bass.

Lappe, F. M., \& Du Bois, P. M. (1994). The quickening of America, San Francisco, CA: Jossey-Bass Inc.

Lau, R, 1996). Shared governance and Compton Community College District. Unpublished doctoral paper. Pepperdine University, CA.

Lavine, J. M., \& Lemon, W. L. (1975). Report of the regents task force on university governance and collective bargaining. Washington, DC : Association of Governing Boards of Universities and Colleges, Regents Task Force.

Liontos, L. B. (1994). Shared decision-making. ERIC Digest 87, Available HTTP : http://darkwing.uoregon.edu:80/ ericcem/digest87.html 
Lovas, J. C. (1994, July). Shared governance: The next generation. Paper presented at the 'Leadership 2000'Annual International Conference of the League for Innovation in the Community College, San Diego, CA.

MacDonald, J. B. (1962). Higher education in British Columbia and a plan for the future. Vancouver, BC: University of British Columbia Press.

Mahon, J. P. (1994, February). Shared leadership and TQM. Paper presented at the Annual Meeting of the National Association of Secondary School Principals, New Orleans, LA.

Malaspina University College (1993). Malaspina University College: The next generation. Unpublished discussion paper. Malaspina University College, Nanaimo, BC.

Manilla, S. J. (1979, April-May). Governance and leadership in the 80's: Role of planning management, and evaluation in decision-making. Paper presented at the Annual Convention of the American Association of Community and Junior Colleges, Chicago, IL.

Mann, J. (1968). Faculty participation in college governance: Two small catholic colleges. ( ERIC Document Reproduction Service No. ED 025201 ).

McConnell, T. R. (1970). Campus govemance-faculty participation. University of California, Berkeley, Center for Research and Development in Higher Education. 
Messina, R. C. Jr., Cearfoss, C., Trueblood, N., \& Young, S. (1994,June). Opening up the decision-making process through shared governance. Paper presented at the Annual Summer Institute on Institutional Effectiveness and Student Success, Atlantic City, N.J.

Miller, G. R. (1993). Budget cuts and shared governance: A faculty member's perspective. Academe, 79(6), 12-14.

Miller, M., McCormack, T., \& Newman, R. (1996). Faculty involvement in governance: A comparison of two faculties. Joumal of Staff. Program.\& Organization Development. 13(4), 269-276.

Mitchell, G. N., Grant, A. B., \& Rossa, M. (1992). Shared governance: Keys to a successful process, in D. Doucette (Ed.). Leadership Abstracts 5 (110).

Munitz, B. (1995). Wanted: New leadership for higher education. Planning for Higher Education, 24(Fall 1995), 10.

National Association of Scholars. (1995). AAUP charged with jeapordizing academic freedom. National Association of Scholars, Available HTTP : http://www.nas.org/pressreleases/aaup.html

New Democrats (1990). Post-secondary education priorities for the 90's. Political manifesto. Vancouver, BC: New Democratic Party. 
Newquist, D. L. (1998, January) Colloquy: The end of shared governance? The Chronicle of Higher Education Available HTTP: http://chronicle.com/colloquy/98/sharedgov/04.htm

Nussbaum, T. J. (1995). The evolution of shared governance at the local level. California. (ERIC Document Reproduction Service No. 397 922).

Perley, J. E. (1995). Tenure, academic freediom, and governance. Academe. 81(1), 43-47.

Phelan, D. J., Kirkland, T. P., \& Freed, J. E. (1993). Strategic planning tactics for shared governance. Community Services Catalyst.23(4), 12-17.

Phillips, M. R. (1996, November). A study of shared governance and its implications for South Gwinnett High School's school improvement initiative. Paper presented at the Annual Meeting of the Mid-South Educational Research Association, Tuscaloosa, AL.

Piland, W. E. (1994). The governing board, in A. M. Cohen, F. B. Brawer, et al. (Ed). Managing community colleges. (p97). San Francisco, CA : JosseyBass.

Piland, W. E., \& Butte, H. (1991). Trustee views on finance, governance, and educational issues. Community College Review. 18(4), 6-12. 
Piland, W. E., Lovell, N. B., \& James, L. (1981). Team management bargaining model. Community and Junior College Review. 52(1), 16-20.

Polishook, I. H., \& Naples, C. J. (1989). Governance: Senates and unions. Newsletter of the National Center for the Study of Collective Bargaing in Higher Education and Professions. 17(3).

Reil, D., \& Soderman, J. D. (1993, February). Decisions ! Decisions! Decisions ! Shared governance: A blessing for implementing year-round schooling. Paper presented at the Annual Meeting of the National Association for Year-Round Education, Las Vegas, NV.

Reyes, P., \& McCarty, D. J. (1986, April). Governing academic organizations: The academic dean and the president review the current state of college governance. Paper presented at the Annual Meeting of the American Educational Research Association, San Francisco. CA.

Rhoades, G. (1993). Retrenchment clauses in faculty union contracts. Journal of Higher Education. 64(3), 312-347.

Richardson, R. C. Jr., \& Wolverton, M. (1994). Leadership strategies, in A. M. Cohen, F. B. Brawer, et al. (Ed). Managing community colleges. (p46). San Francisco, CA : Jossey-Bass. 
Rollins, C. E. (1972, August). Fiscal planning at the community college level. Paper presented at the Seventh Annual Conference of the Society for College and University Planning, Atlanta, GA.

Roueche, J. E., \& Baker, G. A. (1987). Access and excellence: The open door college. Washington, DC: Community College Press.

Rost, J. C. (1993). Leadership for the twenty first century. Westport, CT: Praeger.

Scherr, M. W. (1994). Building community support: Crucial task for new superintendent. California. (ERIC Document Reproduction Service No. 375 490).

Seitz, J. E. (1993). Effective board participation, Lanham, MD: University Press of America Inc.

Senge, P. M. (1996, September 12, October 1, 23, November 15). The First Worldwide Lessons in Leadership Series, Live via Satellite. MICA Management Resources, Vancouver, BC.

Shark, A. R., Brouder, K., \& Miller, L (1975). Research project on students and collective bargaining. Final report year one New York: City University of New York Research Foundation. 
Smith, D. K. (1975, December). Academic program audit and review as a means of resource reallocations. Paper presented at a Seminar for State Leaders in Post-Secondary Education, Denver, Colo.

Southern Methodist University. (1979). The governance of Southern Methodist University, Dallas, Texas : Author.

Stamm, J. A. (1989). Centralization of authority in the San Diego Community College District: 1974-1977 and 1984-1987. Unpublished doctoral dissertation, University of California, Los Angeles.

Starrat, R. J. (1996). Iransforming educational administration: meaning. community, and excellence. New York, NY: McGraw-Hill.

Stevens, L. P., \& Piland, W. E. (1988). Reform in community college governance : The California story. Community/Junior College Quarterly of Research and Practice. 12(3), 251-261.

Sumner, J. (1991). Shared governance at Sierra College. California. (ERIC Reproduction Service No. 336 144).

Taylor, B. E. (1988). Working with trustees. ERIC Digest. Washington, DC: ERIC Clearinghouse on Higher Education. ( ERIC Document Reproduction Service No. ED 301138 ). 
Thomas, M. D. (1979). Are you ready to share power and responsibility with your employees ? Executive Educator. 1(3), 27-28.

van Toor, M. (1997). The development of post-secondary education in British Columbia. Unpublished manuscript. Malaspina University College, Nanaimo, BC.

Trani, E. P. (1997). Creating a broader model of shared governance. Chronicle of Higher education. XLIII(18), 16.

Weisbord, M. R., \& 35 international co-authors. (1993). Discovering common ground. San Francisco, CA : Berrett-Koehler.

Wirth, P. L. (1991). Shared governance: Promises and perils. Marysville, CA : Yuba Community College District.

Wood, D.D. (1995). Power and participative governance: A study of faculty, student, and support staff representation on college boards. Journal of Educational Administration and Foundations. 10(1), 33-55.

Wood, D. D. (1991). Eaculty, student and support staff participation in college governance: A study in the politics of organizations. Unpublished doctoral thesis. University of Alberta, Edmonton, Alberta.

Wood, M. M. (1984). Crosscurrents and undercurrents in the trusteepresident relationship. Educational Record. 65(1), 38-42. 
Young, R. J., \& Thompson M. J. (1982). A study of relationships between characteristics of elected and appointed trustees and their beliefs.

Community/Junior College Quarterly, 6(2), 21-28. 
September 17, 1997

«Title» «FirstName» «LastName»

«Address1»

«Address2》

«City», «State»

«PostalCode»

Dear «FirstName» «LastName»:

As a current member of the board of a community college or university college, you are invited to participate in my research study on shared governance in the British Columbia post-secondary system. In addition to my position as Vice President and Bursar of Malaspina University College, I am a doctoral student at the University of San Diego and this study will form the basis of my dissertation.

Enclosed with this letter, you will find a form of consent to act as a research subject, a questionnaire, and a postage paid, return envelope. The consent form serves two purposes. Firstly, more information about the purpose and procedures of the study is detailed. Secondly, should you agree to participate, and I want to stress strongly that participation is entirely voluntary, you are requested to indicate to that affect on the form and return it with the completed questionnaire in the envelope provided as noted below.

It is my hope that this study will not only provide the basis for the completion of my degree but will also contribute to the body of knowledge which will assist governance in particular, and post-secondary education in general, areas in which we share a common interest. I should add that I have received every encouragement in my endeavor from the Advanced Education Council of British Columbia and look forward to sharing the results of the study with members in various forums.

This field of research is entirely grounded in the knowledge and views which you are acquiring as a board member, and I sincerely hope that you will volunteer to participate. If you have any questions or comments please contact me at my home ([250]-758-3853) or office ([250]-755-8730) or my dissertation director, Dr. William E. Piland, Professor of Education, San Diego State University ([619]-5943071). 
Completed consent forms and questionnaires should be returned in the envelope provided no later than October 10, 1997. Thank you, in advance, for your participation.

Yours Sincerely,

\section{Edwin Deas}

Enclosures 
September 17, 1997

«FirstName» «LastName»

«Address 1 »

«Address2》

"City», «State»

«PostalCode»

Dear «FirstName» «LastName»:

As a recent member of the board of a community college or university college, you are invited to participate in my research study on shared governance in the British Columbia post-secondary system. In addition to my position as Vice President and Bursar of Malaspina University College, I am a doctoral student at the University of San Diego and this study will form the basis of my dissertation.

Enclosed with this letter, you will find a form of consent to act as a research subject, a questionnaire, and a postage paid, return envelope. The consent form serves two purposes. Firstly, more information about the purpose and procedures of the study is detailed. Secondly, should you agree to participate, and I want to stress strongly that participation is entirely voluntary, you are requested to indicate to that affect on the form and return it with the completed questionnaire in the envelope provided as noted below.

It is my hope that this study will not only provide the basis for the completion of my degree but will also contribute to the body of knowledge which will assist governance in particular, and post-secondary education in general, areas in which we share a common interest. I should add that I have received every encouragement in my endeavor from the Advanced Education Council of British Columbia and look forward to sharing the results of the study with members in various forums.

This field of research is entirely grounded in the knowledge and views which you have acquired as a board member, and I sincerely hope that you will volunteer to participate. If you have any questions or comments please contact me at my 
home ([250]-758-3853) or office ([250]-755-8730) or my dissertation director, Dr. William E. Piland, Professor of Education, San Diego State University ([619]-5943071).

Completed consent forms and questionnaires should be returned in the envelope provided no later than October 10,1997. Thank you, in advance, for your participation.

Yours Sincerely,

Edwin Deas

Enclosures 
September 17, 1997

«FirstName» «LastName»

"Address1"

«Address2》

«City», «State»

«PostalCode»

Dear «FirstName» «LastName»:

As a current or recent, elected or ex-officio member of the board of Malaspina University College, you are invited to participate in my research study on shared governance in the British Columbia post-secondary system. As you know, in addition to my position as Vice President and Bursar of Malaspina University College, I am a doctoral student at the University of San Diego and this study will form the basis of my dissertation.

Enclosed with this letter, you will find a form of consent to act as a research subject, a questionnaire, and a postage paid, return envelope. The consent form serves two purposes. Firstly, more information about the purpose and procedures of the study is detailed. Secondly, should you agree to participate, and I want to stress strongly that participation is entirely voluntary, you are requested to indicate to that affect on the form and return it with the completed questionnaire in the envelope provided as noted below.

Please be aware that I have included additional safeguards in the study process to protect your anonymity given our close on-going relationship. Your envelope containing the completed consent form and questionnaire will be directed unopened to a consultant in Vancouver who is responsible for the processing of all data. The consultant, not I, will input your data and process it along with all the other data which I will input. When I receive the processed data, it should be virtually impossible for me to identify your input. Therefore, not only will your anonymity be maintained in my dissertation and any other reports (as will that of other participants), in your case I will also not be personally aware of any of the 
content. In addition, your questionnaire will be retained in Vancouver and ultimately disposed of once the study has been concluded.

It is my hope that this study will not only provide the basis for the completion of my degree but will also contribute to the body of knowledge which will assist governance in particular, and post-secondary education in general, areas in which we share a common interest. I should add that I have received every encouragement in my endeavor from the Advanced Education Council of British Columbia and look forward to sharing the results of the study with members in various forums.

This field of research is entirely grounded in the knowiedge and views which you are acquiring or have acquired as a board member and I sincerely hope that you will volunteer to participate. If you have any questions or comments please contact me at my home ([250]-758-3853) or office ([250]-755-8730) or my dissertation director, Dr. William E. Piland, Professor of Education, San Diego State University ([619]-594-3071).

Completed consent forms and questionnaires should be returned in the envelope provided no later than October 10,1997 . Thank you, in advance, for your participation.

Yours Sincerely,

\section{Edwin Deas}

Enclosures 


\section{QUESTIONNAIRE}

Section 1 : Board decision-making on general matters, but excluding business related to financial matters and labour relations matters.

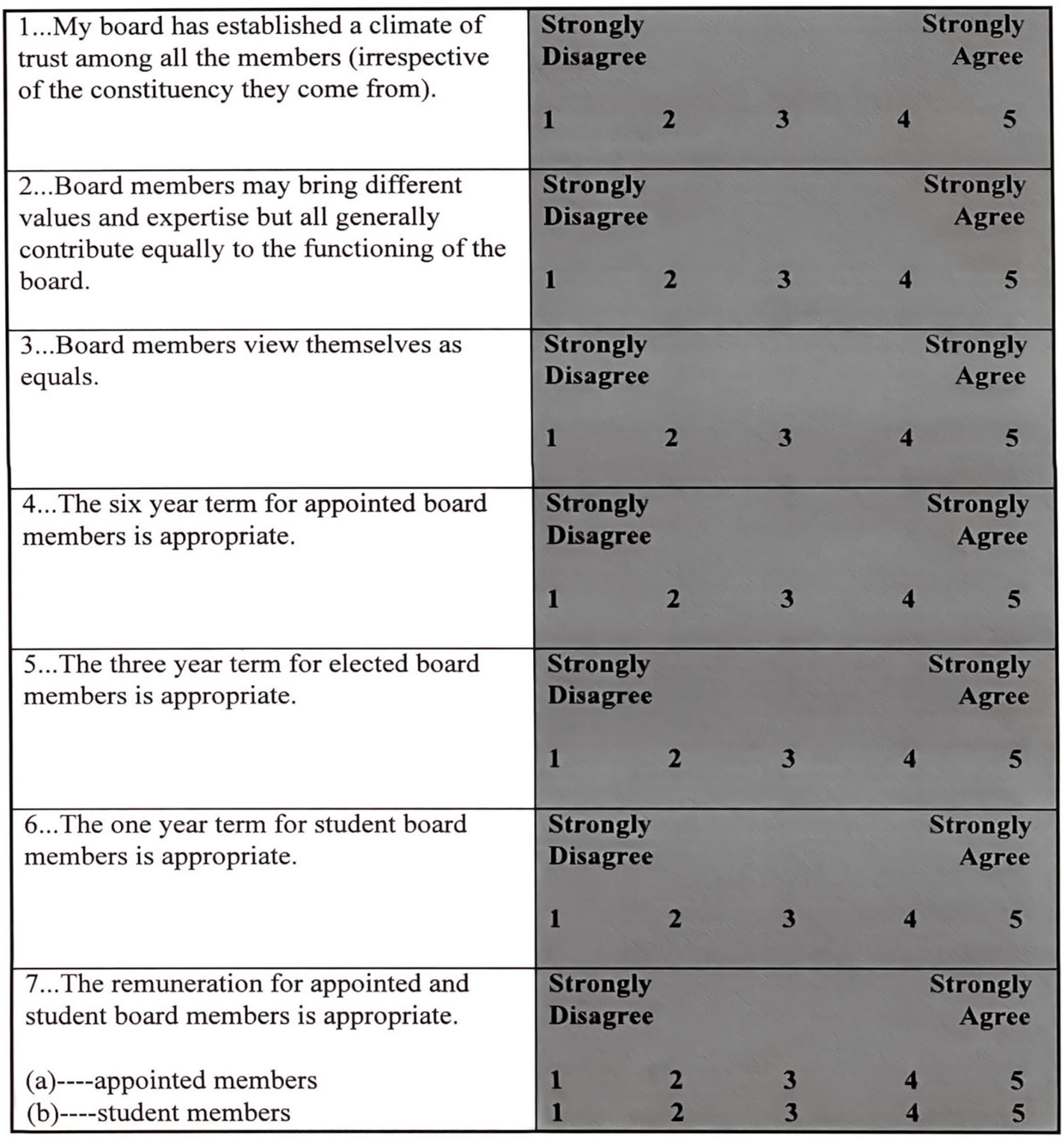




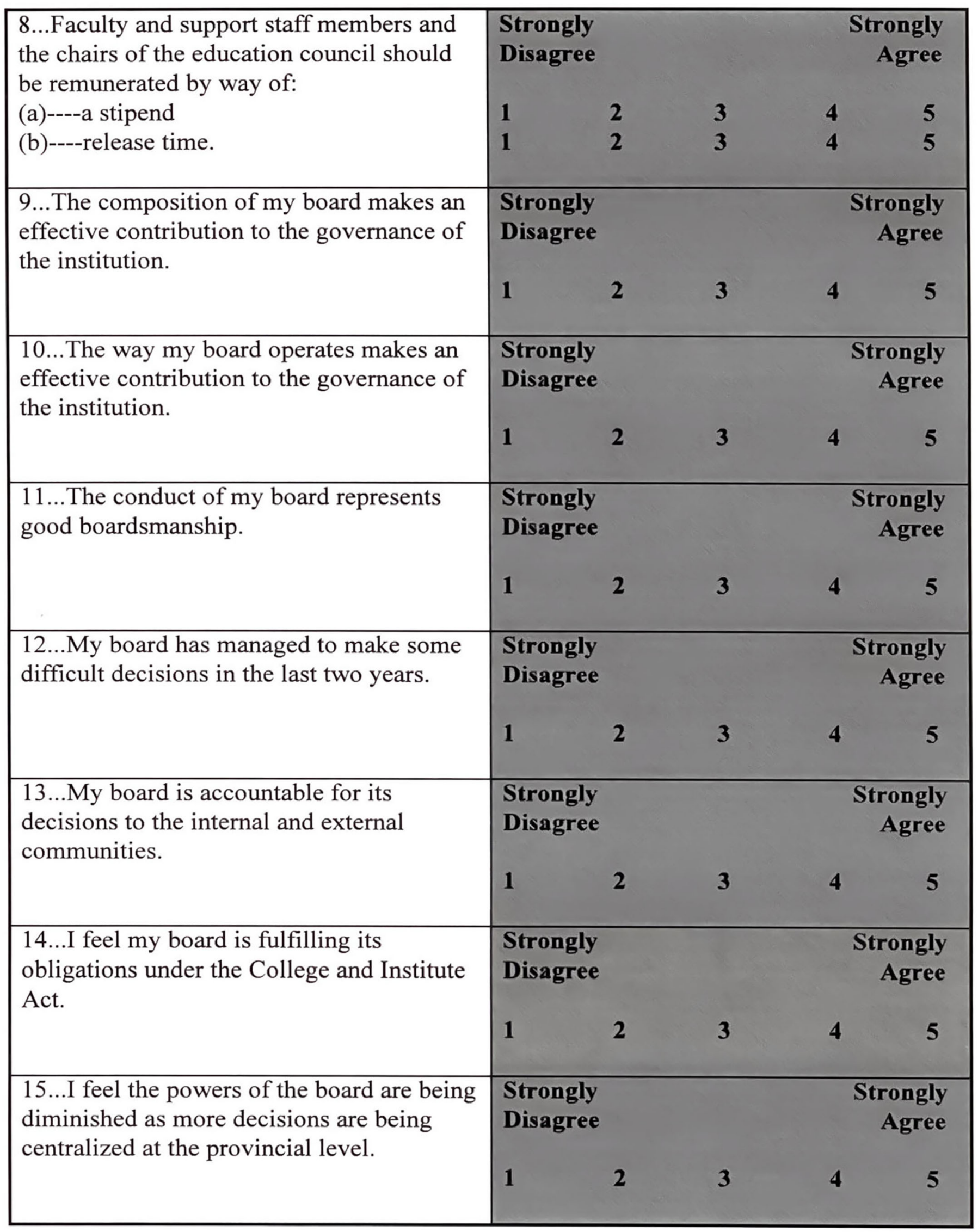




\begin{tabular}{|c|c|c|c|c|}
\hline \multirow[t]{2}{*}{$\begin{array}{l}\text { 16...The president should be a non-voting } \\
\text { ex-officio member of the board. }\end{array}$} & \multicolumn{2}{|l|}{$\begin{array}{l}\text { Strongly } \\
\text { Disagree }\end{array}$} & \multicolumn{2}{|c|}{$\begin{array}{r}\text { Strongly } \\
\text { Agree }\end{array}$} \\
\hline & 1 & 3 & 4 & 5 \\
\hline \multirow[t]{2}{*}{$\begin{array}{l}\text { 17...The president should be a full voting } \\
\text { member of the board. }\end{array}$} & \multicolumn{2}{|l|}{$\begin{array}{l}\text { Strongly } \\
\text { Disagree }\end{array}$} & \multicolumn{2}{|c|}{$\begin{array}{r}\text { Strongly } \\
\text { Agree }\end{array}$} \\
\hline & 1 & 3 & 4 & 5 \\
\hline \multirow{2}{*}{$\begin{array}{l}\text { 18...The chair of the education council } \\
\text { should be a non-voting ex-officio member } \\
\text { of the board. }\end{array}$} & \multicolumn{2}{|l|}{$\begin{array}{l}\text { Strongly } \\
\text { Disagree }\end{array}$} & \multicolumn{2}{|c|}{$\begin{array}{r}\text { Strongly } \\
\text { Agree }\end{array}$} \\
\hline & 1 & 3 & 4 & 5 \\
\hline \multirow{2}{*}{$\begin{array}{l}19 . . \text { The chair of the education council } \\
\text { should be a full voting member of the } \\
\text { board. }\end{array}$} & \multicolumn{2}{|l|}{$\begin{array}{l}\text { Strongly } \\
\text { Disagree }\end{array}$} & \multicolumn{2}{|c|}{$\begin{array}{r}\text { Strongly } \\
\text { Agree }\end{array}$} \\
\hline & 1 & 3 & 4 & 5 \\
\hline $\begin{array}{l}20 \ldots \text { The bylaw and/or policy regarding } \\
\text { conflict of interest adopted at my institution } \\
\text { is generally accepted by all board members } \\
\text { as fair and workable. }\end{array}$ & \multicolumn{2}{|l|}{$\begin{array}{l}\text { Strongly } \\
\text { Disagree }\end{array}$} & \multicolumn{2}{|c|}{$\begin{array}{r}\text { Strongly } \\
\text { Agree }\end{array}$} \\
\hline \multirow[t]{2}{*}{$\begin{array}{l}21 . . \text { Conflict of interest has not been a } \\
\text { problem with my board. }\end{array}$} & $\begin{array}{l}\text { Strongly } \\
\text { Disagree }\end{array}$ & & \multicolumn{2}{|c|}{$\begin{array}{r}\text { Strongly } \\
\text { Agree }\end{array}$} \\
\hline & 1 & 3 & 4 & 5 \\
\hline
\end{tabular}

\section{Section 2: Board decision-making related solely to financial matters}

\begin{tabular}{|l|lllr|r|}
\hline $\begin{array}{l}22 \ldots \text { All members of my board have equal } \\
\text { independence and disinterest when it comes } \\
\text { to dealing with budget issues. }\end{array}$ & $\begin{array}{l}\text { Strongly } \\
\text { Disagree }\end{array}$ & & & $\begin{array}{r}\text { Strongly } \\
\text { Agree }\end{array}$ \\
& 1 & 2 & 3 & 4 & 5 \\
\hline
\end{tabular}




\begin{tabular}{|c|c|c|c|c|}
\hline $\begin{array}{l}23 \ldots \text { Elected and ex-officio board members } \\
\text { have an inevitable vested interest when } \\
\text { dealing with budget issues. }\end{array}$ & \multicolumn{2}{|l|}{$\begin{array}{l}\text { Strongly } \\
\text { Disagree }\end{array}$} & \multicolumn{2}{|c|}{$\begin{array}{r}\text { Strongly } \\
\text { Agree }\end{array}$} \\
\hline $\begin{array}{l}24 \ldots \text { I feel that elected and ex-officio board } \\
\text { members have generally NOT shown bias } \\
\text { towards their own department, area, or } \\
\text { constituency (trade or student union) when } \\
\text { dealing with budget issues. }\end{array}$ & $\begin{array}{l}\text { Strongly } \\
\text { Disagree }\end{array}$ & 3 & 4 & ee \\
\hline $\begin{array}{l}25 \ldots \text { I feel my board effectively discharges } \\
\text { its fiscal responsibilities under the College } \\
\text { and Institute Act. }\end{array}$ & $\begin{array}{l}\text { Strongly } \\
\text { Disagree }\end{array}$ & 3 & 4 & ee \\
\hline $\begin{array}{l}26 \ldots \text { My board discharges its fiduciary } \\
\text { responsibility to all students from whom it } \\
\text { collects student union fees when dealing } \\
\text { with that organization. }\end{array}$ & $\begin{array}{l}\text { Strongly } \\
\text { Disagree } \\
1\end{array}$ & 3 & 4 & $\begin{array}{l}\text { ly } \\
\text { ee }\end{array}$ \\
\hline $\begin{array}{l}\text { 27...My board has dealt effectively with the } \\
\text { issue of conflict of interest as it relates to } \\
\text { student board members with respect to } \\
\text { financial matters between the board and the } \\
\text { student union, such as tuition and other } \\
\text { fees. }\end{array}$ & $\begin{array}{l}\text { Strongly } \\
\text { Disagree }\end{array}$ & 3 & 4 & ee \\
\hline $\begin{array}{l}28 \ldots \text { The College and Institute Act } \\
\text { provision that students may vote on } \\
\text { proposed tuition fee increases is } \\
\text { appropriate. }\end{array}$ & $\begin{array}{l}\text { Strongly } \\
\text { Disagree } \\
1\end{array}$ & 3 & 4 & ee \\
\hline $\begin{array}{l}29 . . \text { Elected student board members should } \\
\text { be disqualified from simultaneously } \\
\text { holding office in their respective student } \\
\text { unions because of the perceived conflict of } \\
\text { interest on financial matters. }\end{array}$ & $\begin{array}{l}\text { Strongly } \\
\text { Disagree } \\
1\end{array}$ & 3 & 4 & ee \\
\hline $\begin{array}{l}30 \ldots \text { The board's role is to approve the } \\
\text { parameters and underlying assumptions of } \\
\text { the budget, but otherwise to leave assembly } \\
\text { of the numbers to administration. }\end{array}$ & $\begin{array}{l}\text { Strongly } \\
\text { Disagree } \\
1\end{array}$ & 3 & 4 & ee \\
\hline
\end{tabular}




\begin{tabular}{|l|lllr|r|}
\hline $\begin{array}{l}31 \ldots \text { My board ensures that all stakeholder } \\
\text { groups have advisory input into the budget } \\
\text { process. }\end{array}$ & $\begin{array}{l}\text { Strongly } \\
\text { Disagree }\end{array}$ & 2 & 3 & 4 & 5 \\
\hline $\begin{array}{l}32 \ldots \text { I feel that all stakeholder groups are } \\
\text { adequately informed about financial } \\
\text { matters. }\end{array}$ & $\begin{array}{l}\text { Strongly } \\
\text { Disagree }\end{array}$ & $\mathbf{2}$ & 3 & 4 & $\begin{array}{r}\text { Strongly } \\
\text { Agree }\end{array}$ \\
\hline $\begin{array}{l}33 \ldots \text { The composition of the board has } \\
\text { made it more difficult to balance the budget } \\
\text { in these tight financial times. }\end{array}$ & $\begin{array}{l}\text { Strongly } \\
\text { Disagree }\end{array}$ & 1 & & $\begin{array}{r}\text { Strongly } \\
\text { Agree }\end{array}$ \\
& 1 & 3 & 4 & 5 \\
\hline
\end{tabular}

Section 3 : Board decision-making related solely to labour relations matters

\begin{tabular}{|c|c|c|c|c|}
\hline \multirow{2}{*}{$\begin{array}{l}34 \ldots \text { Shared governance as a broad goal is } \\
\text { difficult to achieve in a unionized } \\
\text { environment. }\end{array}$} & \multicolumn{2}{|l|}{$\begin{array}{l}\text { Strongly } \\
\text { Disagree }\end{array}$} & \multicolumn{2}{|c|}{$\begin{array}{r}\text { Strongly } \\
\text { Agree }\end{array}$} \\
\hline & 1 & 3 & 4 & 5 \\
\hline $\begin{array}{l}35 . . . \text { Labour relations, in particular the } \\
\text { negotiation and administering of collective } \\
\text { agreements, has caused division among the } \\
\text { members of my board. }\end{array}$ & $\begin{array}{l}\text { Strongly } \\
\text { Disagree } \\
1\end{array}$ & 3 & 4 & $\begin{array}{l}\text { ly } \\
\text { ee }\end{array}$ \\
\hline $\begin{array}{l}36 . . \text { Labour relations has largely become a } \\
\text { centralized provincial issue, hence my } \\
\text { board has not experienced any difficulties } \\
\text { in decision-making due to the presence of } \\
\text { elected and ex-officio members. }\end{array}$ & $\begin{array}{l}\text { Strongly } \\
\text { Disagree }\end{array}$ & 3 & 4 & ly \\
\hline $\begin{array}{l}37 . . \text { I feel my board effectively discharges } \\
\text { its labour relations responsibilities under } \\
\text { the College and Institute Act. }\end{array}$ & $\begin{array}{l}\text { Strongly } \\
\text { Disagree } \\
1\end{array}$ & 3 & 4 & ty \\
\hline
\end{tabular}




\begin{tabular}{|c|c|c|c|c|}
\hline $\begin{array}{l}38 \ldots \text {... feel my board would have generally } \\
\text { adopted a different direction in labour } \\
\text { relations over the last two years if the board } \\
\text { did not include elected and ex-officio } \\
\text { members. }\end{array}$ & $\begin{array}{l}\text { Strongly } \\
\text { Disagree }\end{array}$ & 3 & 4 & $\begin{array}{r}\text { trongly } \\
\text { Agree }\end{array}$ \\
\hline $\begin{array}{l}39 . . \text { I feel my board would have generally } \\
\text { adopted a different direction in labour } \\
\text { relations over the last two years if } \\
\text { provincial centralization had not taken } \\
\text { place. }\end{array}$ & $\begin{array}{l}\text { Strongly } \\
\text { Disagree }\end{array}$ & 3 & 4 & $\begin{array}{r}\text { trongly } \\
\text { Agree }\end{array}$ \\
\hline $\begin{array}{l}40 . . \text { I feel my board would have generally } \\
\text { adopted a different direction in labour } \\
\text { relations over the last two years if the board } \\
\text { did not include elected and ex-officio } \\
\text { members and if provincial centralization } \\
\text { had not taken place. }\end{array}$ & $\begin{array}{l}\text { Strongly } \\
\text { Disagree }\end{array}$ & 3 & 4 & $\begin{array}{r}\text { trongly } \\
\text { Agree }\end{array}$ \\
\hline $\begin{array}{l}41 \ldots \text { The elected and ex-officio board } \\
\text { members have lived up to their oath of } \\
\text { office to the board in contributing to my } \\
\text { board's role in labour relations. }\end{array}$ & $\begin{array}{l}\text { Strongly } \\
\text { Disagree } \\
1\end{array}$ & 3 & 4 & $\begin{array}{r}\text { trongly } \\
\text { Agree } \\
5\end{array}$ \\
\hline $\begin{array}{l}42 . . . \text { My board has dealt effectively with the } \\
\text { issue of conflict of interest as it relates to } \\
\text { elected and ex-officio board members with } \\
\text { respect to matters of administering } \\
\text { collective agreements. }\end{array}$ & $\begin{array}{l}\text { Strongly } \\
\text { Disagree } \\
1\end{array}$ & 3 & 4 & $\begin{array}{r}\text { trongly } \\
\text { Agree } \\
5\end{array}$ \\
\hline $\begin{array}{l}\text { 43...My board has employed a personnel or } \\
\text { labour relations committee from which } \\
\text { some board members are excluded on the } \\
\text { basis of their perceived or real conflict of } \\
\text { interest. }\end{array}$ & $\begin{array}{l}\text { Strongly } \\
\text { Disagree } \\
1\end{array}$ & 3 & 4 & $\begin{array}{r}\text { Agrongly } \\
\text { Agree }\end{array}$ \\
\hline $\begin{array}{l}44 . . \text { Student board members should play a } \\
\text { full part in decision-making on labour } \\
\text { relations issues. }\end{array}$ & $\begin{array}{l}\text { Strongly } \\
\text { Disagree } \\
1\end{array}$ & 3 & 4 & $\begin{array}{r}\text { Agree } \\
\text { Agly }\end{array}$ \\
\hline
\end{tabular}




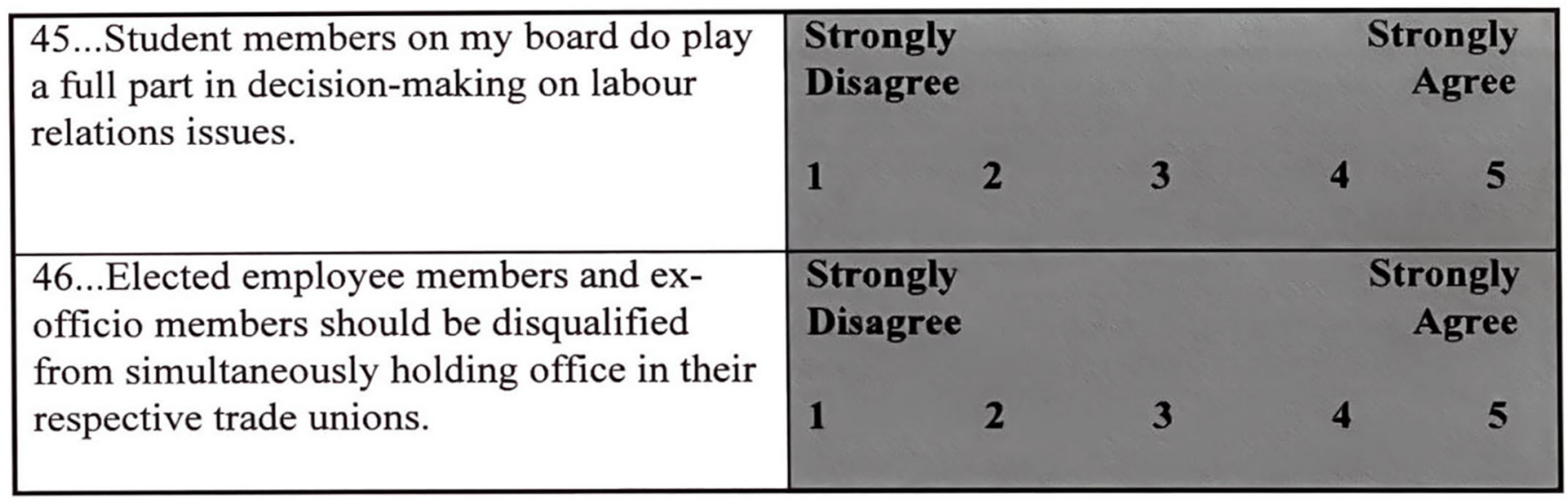

\section{Section 4: Board effectiveness in the sharing of power}

47...The undernoted themes can be considered to contribute to a board's effectiveness in dealing with the sharing of power in a shared governance model. Please indicate the degree to which these themes contribute to your board's success:

(a)...A climate of trust among all board members;

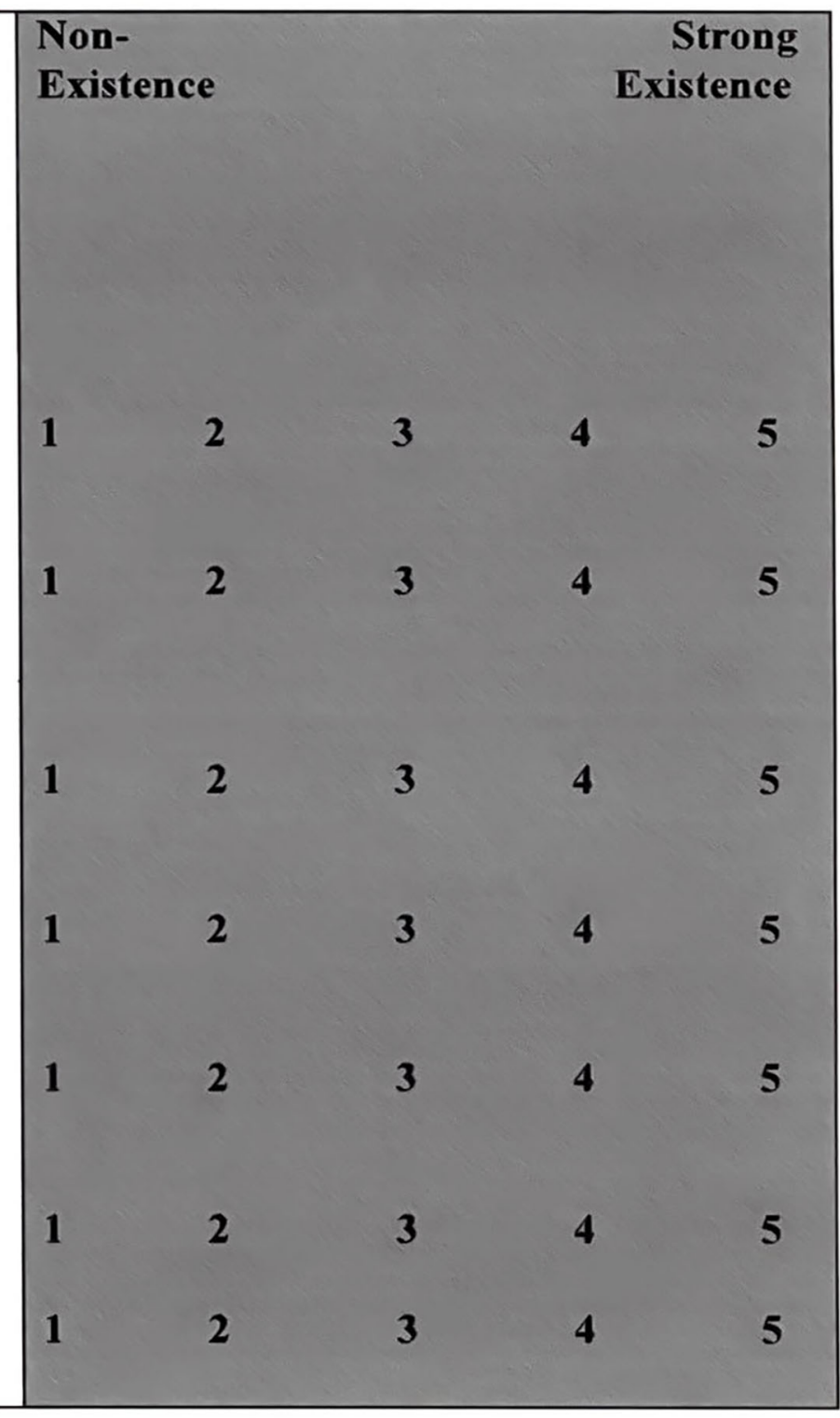

(b)...Equal contribution by all board members;

(c)...Independence of all board members from their constituency;

(d)...Board members not bringing vested interests to the board table;

(e)...Management/labour relations not infiltrating the board culture; and

(f)...Other themes (please list). 


\section{Section5 : Board effectiveness in shared decision-making}

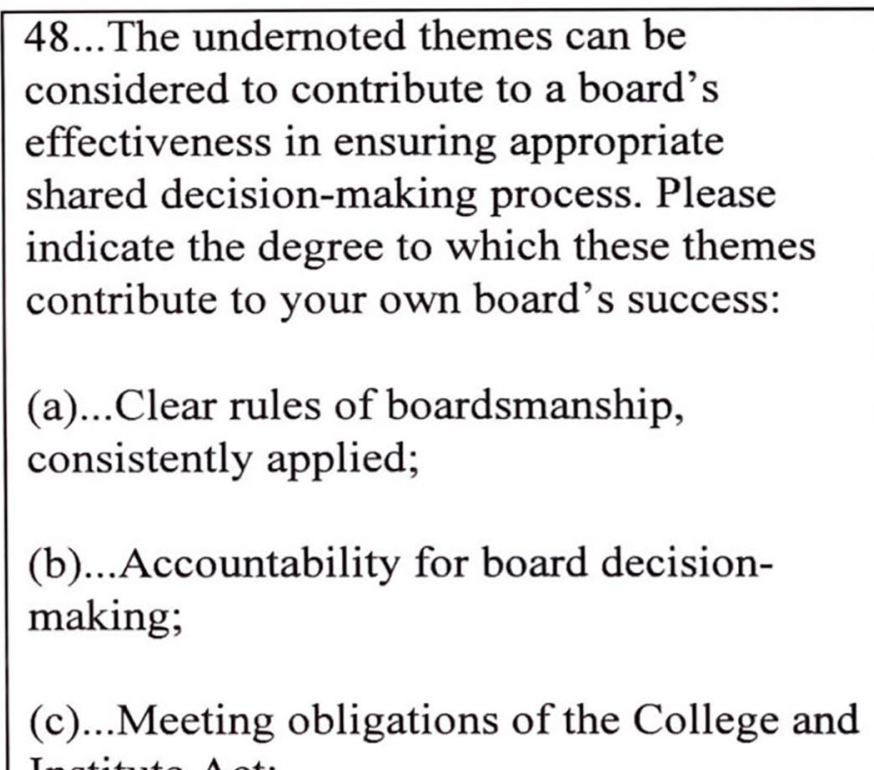


Section 6: Board effectiveness in dealing with the real or perceived conflict of interest of employee and student board members

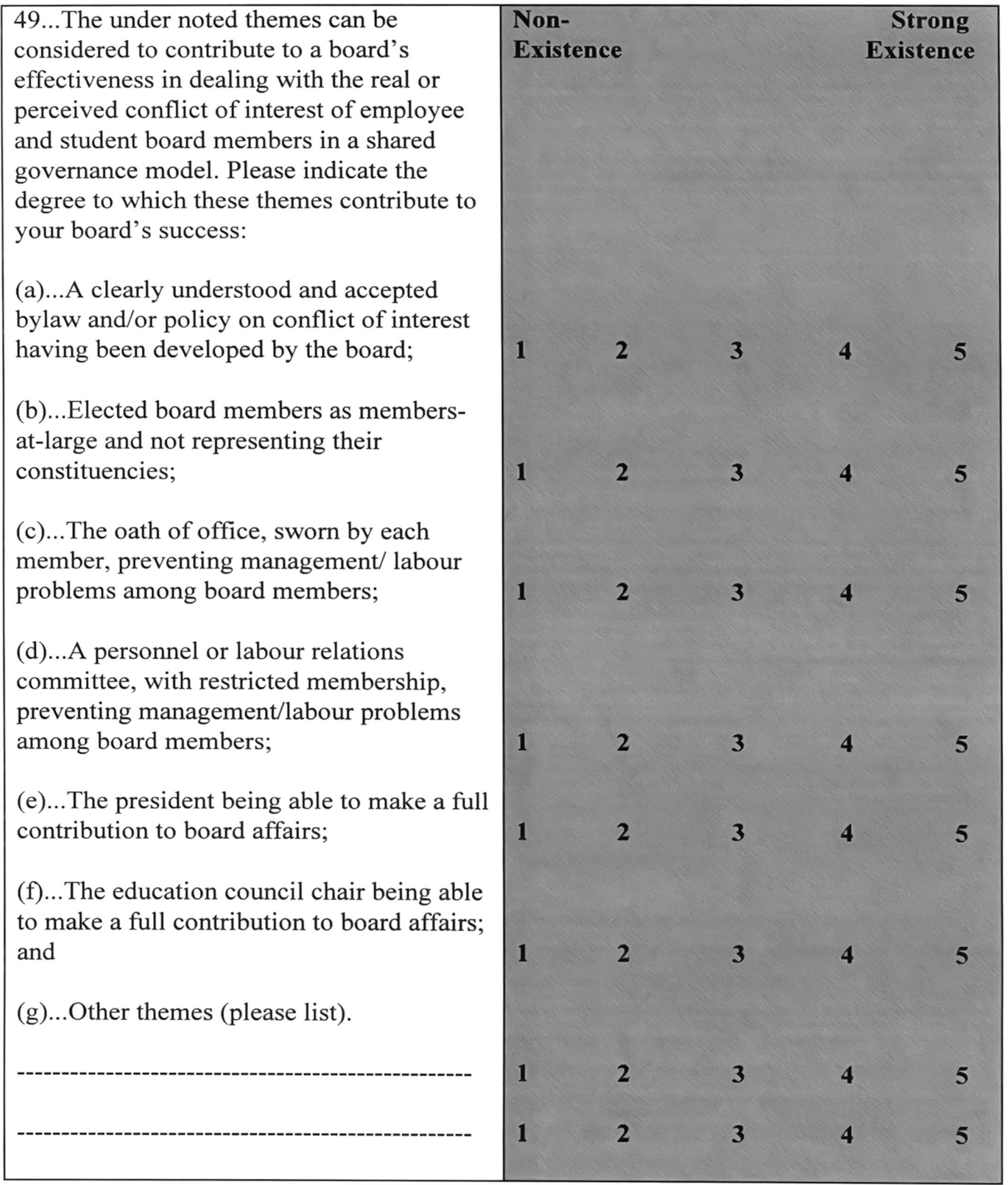




\section{PERSONAL PARAMETERS \\ (OF PARTICIPANTS)}

Status of board membership

Check Where Applicable

Appointed

Elected - Faculty

- Support Staff

- Student

President

Chair of Education Council

Name of Institution

Number of Years on Board of Current Institution

\section{IMPORTANT INFORMATION FOR THE PARTICIPANT :}

Details concerning your status and the name of your institution are crucial to this study because two of the main focuses are to look at comparisons between members of different status and between institutions. The researcher is aware that there is only one faculty member, one support staff, one president, and one education council chair on each board and by giving the above information your identity may be revealed. However, the researcher undertakes to all participants to maintain complete anonymity of person and institution in the study findings, dissertation, and any other paper or presentation resulting from the study. For more information on this issue, please refer to the Consent to Act as a Research Subject form or contact the researcher, Edwin Deas, at [250]-758-3853 or [250]-755-8730 or his dissertation director, Dr. William E. Piland, at [619]-594-3071. 


\section{UNIVERSITY OF SAN DIEGO}

\section{CONSENT TO ACT AS A RESEARCH SUBJECT}

Edwin Deas, a doctoral student in the School of Education at the University of San Diego, is conducting a research study of shared governance in the British Columbia post-education system. The purpose of this study is to examine three aspects of leadership through shared governance, namely the sharing of power, the quality of the shared decision-making process, and the dealing with real or perceived conflict of interest on account of the employment or student status of some of the board members. These aspects of leadership will be studied in three particular contexts; board decision-making in general matters of business, in financial matters, and in the field of labour relations.

The impact of the change in membership of the boards as a result of the legislative amendment. Bill 22, will be ascertained through the views and experiences of board members. The researcher will seek to find if differences emerge among colleges and board members, the latter according to their status. Finally, the results of the study will be compared with a similar study conducted by the researcher in early 1996 to see if the passage of time since Bill 22 has changed board members' views.

As a participant in this study, I understand that I will be completing a survey questionnaire containing forty nine questions. The duration of the exercise for me should be between thirty and forty five minutes and only one such exercise will be required of me. Participation will not involve any added risks or discomforts to me other than the commitment of time. I can benefit from the opportunity to be part of the study by contributing what I have learned during my tenure as a board member and by receiving the analysis of the data collected from around the province which may assist my boardsmanship in the future.

My participation in this study is totally voluntary and I understand my choice to participate is completely unrelated to my status as a board member and, where applicable, to my status as an employee or student of a college or institute included in this study. Further, I understand that I may refuse to participate by simply not completing the questionnaire and I may withdraw at any time without jeopardy by informing the researcher, whereupon my questionnaire and all data from it will be removed from the study and destroyed.

I understand that my questionnaire will be kept completely confidential and all data derived from it will not reveal my name or that of my institution or any other information that would purport to be attributable to me personally. All questionnaires will be destroyed at the conclusion of the study. I acknowledge that my identity may be 
known to the researcher and accept his assurance that I shall enjoy complete anonymity in all reports of this study. [N.B. In the case of elected employee and student members and ex-officio members of the Malaspina University-College board, special arrangements will be made so that even their identity is not revealed to the researcher.]

Further information on this study, or on any aspect of participation in it, will readily be made available by Edwin Deas at his home ([250]-758-3853) or office ([250]755-8730), or by his dissertation director, Dr. William E. Piland, Professor of Education. San Diego State University ([619]-594-3071).

There are no other agreements, written or verbal, related to this study beyond that expressed on this consent form, and I have received a copy of this consent document.

I, the undersigned, understand the above explanations and, on that basis, I give consent to my voluntary participation in this research.

$\overline{\text { Signature of Subject }} \overline{\text { Date }} \overline{\text { Signature of Researcher }} \overline{\text { Date }}$


October 14,1997

\author{
«FirstName» «LastName» \\ «Address1» \\ «Address2》 \\ «City», «State» \\ «PostalCode»
}

Dear «FirstName» «LastName»:

In September 1997, I wrote to you to invite you to participate in my research study on shared governance in the British Columbia post-secondary system. In addition to my position as Vice President and Bursar of Malaspina University College, I am a doctoral student at the University of San Diego and this study will form the basis of my dissertation. It is my hope that this study will not only provide the basis for the completion of my degree but will also contribute to the body of knowledge which will assist governance in particular, and postsecondary education in general, areas in which we share a common interest.

Because of the nature of the study process, I have no way of knowing whether or not you have participated. However, if you have participated I would like to thank you sincerely for taking the trouble. If you have not yet done so, for whatever reason, I would like to ask you one more time to consider volunteering. Your views and knowledge of shared governance are important and can contribute to the richness of the study. Participation is entirely voluntary but I hope you will give it serious consideration. Should you wish to discuss the study or need another consent form and questionnaire, please contact me at my home ([250]758-3853) or office ([250]-755-8730).

Completed consent forms and questionnaires should be returned in the envelope provided no later than October 31,1997 . Thank you very much.

Yours sincerely,

Edwin Deas 


\section{Memo}

To: Board Chairs and College \& Institute Presidents (as noted below)

From: Edwin Deas, Vice-President Administration

Date: March 20, 1998

Re: Research Study of Shared Governance in the BC Post-Secondary Education System

I want to take the opportunity to provide a progress report on my study and with it extend thanks to all those board members who have participated to date. As of October 31, 1997, the original deadline, questionnaire returns have been received from the undemoted institutions:

\section{Name of College/lnstitute}

Number of Returns

Camosun College

Capilano College

College of New Caledonia

College of the Rockies

Douglas College

Emily Carr

Kwantlen University-College

Langara College

Malaspina University-College

North Island College

Northem Lights College

Northwest Community College

Okanagan University College

Selkirk Community College

University College of the Cariboo

University College of the Fraser Valley

Vancouver Community College

Unspecified

TOTAL

\section{4}

1

5

1

6

3

4

4

7

3

5

5

7

6

7

2

3

1

74 
Naturally, I am a little concerned about the number of returns at this stage which amounts to approximately $28 \%$ of the total board member population. The overall richness of the study will be enhanced by greater participation. In addition, the diversity of analysis by institution and constituency membership will also be enhanced and more meaningful through larger numbers.

To that end, I would like to request that you emphasize the importance of participation to the members of your board, and encourage those who have not already done so to complete and submit a questionnaire. In the event that a board member needs a questionnaire, the quickest approach would be to call me at 250-755-8730 (office) or 250-758-3853 (home). We are now facing the possibility of a postal strike in the coming days; therefore. I would suggest that completed questionnaires and consent forms should be sent by fax transmission to 250-741-2730. In order to encourage further participation, the deadline for submissions has been extended to November 30, 1997.

Thank you for your assistance.

ED/dvb 
Summary of Questionnaire Returns, by Constituency Group

\begin{tabular}{|l|c|c|c|c|}
\hline Constituency Group & Potential Count & Actual Count & $\begin{array}{c}\text { Percentage Distribution } \\
\text { of Actual Count }\end{array}$ & $\begin{array}{c}\text { Actual Count as Percentage } \\
\text { of Potential Count }\end{array}$ \\
\hline Appointees & 153 & 59 & $58 \%$ & $39 \%$ \\
\hline Elected Faculty & 17 & 7 & 7 & 42 \\
\hline Elected Staff & 17 & 8 & 8 & 48 \\
\hline Elected Students & 34 & 6 & 6 & 18 \\
\hline Presidents & 17 & 13 & 12 & 77 \\
\hline Council Chairs & 17 & 9 & 9 & 53 \\
\hline All & 255 & 102 & $100 \%$ & $40 \%$ \\
\hline
\end{tabular}


Summary of Questionnaire Returns, by College (A to Q)

\begin{tabular}{|c|c|c|c|c|}
\hline College & Potential Count & Actual Count & $\begin{array}{c}\text { Percentage Distribution } \\
\text { of Actual Count }\end{array}$ & $\begin{array}{c}\text { Actual Count as Percentage } \\
\text { of Potential Count }\end{array}$ \\
\hline A & 16 & 5 & $5 \%$ & $31 \%$ \\
\hline B & 13 & 3 & 3 & 23 \\
\hline C & 16 & 5 & 5 & 31 \\
\hline D & 16 & 8 & 5 & 50 \\
\hline E & 15 & 5 & 4 & 27 \\
\hline F & 15 & 4 & 5 & 33 \\
\hline G & 15 & 5 & 6 & 38 \\
\hline H & 16 & 6 & 9 & 67 \\
\hline I & 15 & 10 & 5 & 38 \\
\hline J & 13 & 5 & 6 & 43 \\
\hline K & 14 & 6 & 7 & 47 \\
\hline L & 15 & 7 & 10 & 69 \\
\hline M & 16 & 11 & 8 & 53 \\
\hline N & 15 & 8 & 7 & 44 \\
\hline O & 16 & 7 & 3 & 21 \\
\hline P & 14 & 3 & 4 & 27 \\
\hline Q & 15 & 4 & $100 \%$ & $40 \%$ \\
\hline ALL & 255 & 102 & & \\
\hline
\end{tabular}




\section{Summary of Board Experience, by Years and Percentage-Frequency Distribution}

\begin{tabular}{|l|c|c|}
\hline \multicolumn{1}{|c|}{ Experience } & Count & Percentage-Frequency Distribution \\
\hline Less than two years & & $27 \%$ \\
\hline Between two and three years & 26 & 20 \\
\hline Between three and four years & 20 & 18 \\
\hline Between four and five years & 18 & 12 \\
\hline Between five and six years & 12 & 19 \\
\hline Greater than six years & 19 & 4 \\
\hline Total & 4 & $100 \%$ \\
\hline
\end{tabular}

\begin{tabular}{|l|l|}
\hline Mean & 2.909 years \\
\hline Standard Deviation & 1.610 \\
\hline
\end{tabular}

Notes:

1. Not all participants responded to this question.

2. Slight ambiguity in the questions precludes differentiation between one and two years. 
Summary of Data by Decision-Making Context, Aspect of Leadership and Percentage-Frequency Distribution

\begin{tabular}{|c|c|c|c|c|c|c|c|c|}
\hline & \begin{tabular}{|c} 
Statement $^{1}$ \\
\end{tabular} & $\begin{array}{l}\text { Grand } \\
\text { Mean }\end{array}$ & $\mathbf{S D}^{2}$ & $\begin{array}{l}\text { Strongly } \\
\text { Disagree }\end{array}$ & Disagree & Neutral & Agree & $\begin{array}{l}\text { Strongly } \\
\text { Agree }\end{array}$ \\
\hline \multicolumn{9}{|c|}{ General Matters of Board Business: Sharing of Power } \\
\hline 1 & $\begin{array}{l}\text { My board has established a climate of trust } \\
\text { among all members (irrespective of the } \\
\text { constituency they come from). }\end{array}$ & 3.730 & 1.004 & $2 \%$ & $10 \%$ & $25 \%$ & $39 \%$ & $24 \%$ \\
\hline 2 & $\begin{array}{l}\text { Board members may bring different values and } \\
\text { expertise but all generally contribute equally to } \\
\text { the functioning of the board. }\end{array}$ & 3.406 & 1.124 & $4 \%$ & $21 \%$ & $24 \%$ & $33 \%$ & $18 \%$ \\
\hline 3 & Board members view themselves as equals. & 3.644 & 1.054 & $2 \%$ & $15 \%$ & $23 \%$ & $37 \%$ & $23 \%$ \\
\hline 4 & $\begin{array}{l}\text { The six year term for appointed board members } \\
\text { is appropriate. }\end{array}$ & 3.574 & 1.306 & $12 \%$ & $8 \%$ & $20 \%$ & $31 \%$ & $29 \%$ \\
\hline 5 & $\begin{array}{l}\text { The three year term for elected (employee) } \\
\text { board members is appropriate. }\end{array}$ & 3.784 & 1.087 & $6 \%$ & $6 \%$ & $19 \%$ & $43 \%$ & $26 \%$ \\
\hline$\overline{6}$ & $\begin{array}{l}\text { The one year term for student board members is } \\
\text { appropriate. }\end{array}$ & 3.520 & 1.210 & $7 \%$ & $16 \%$ & $18 \%$ & $36 \%$ & $23 \%$ \\
\hline $7 a$ & $\begin{array}{l}\text { The remuneration for appointed board members } \\
\text { is appropriate. }\end{array}$ & 3.050 & 1.366 & $19 \%$ & $17 \%$ & $20 \%$ & $28 \%$ & $16 \%$ \\
\hline $7 b$ & $\begin{array}{l}\text { The remuneration for student board members is } \\
\text { appropriate. }\end{array}$ & 3.263 & 1.290 & $14 \%$ & $14 \%$ & $23 \%$ & $31 \%$ & $18 \%$ \\
\hline $8 a$ & $\begin{array}{l}\text { Faculty and support staff members and the } \\
\text { chairs of the education council should be } \\
\text { remunerated by way of a stipend. }\end{array}$ & 2.772 & 1.513 & $30 \%$ & $19 \%$ & $12 \%$ & $22 \%$ & $17 \%$ \\
\hline $8 b$ & $\begin{array}{l}\text { Faculty and support staff members and chairs of } \\
\text { the education council should be remunerated by } \\
\text { way of release time. }\end{array}$ & 3.521 & 1.451 & $17 \%$ & $7 \%$ & $18 \%$ & $24 \%$ & $34 \%$ \\
\hline
\end{tabular}




\begin{tabular}{|c|c|c|c|c|c|c|c|c|}
\hline \multicolumn{9}{|c|}{ Board Financial Matters: Sharing of Power } \\
\hline 22 & $\begin{array}{l}\text { All members of my board have equal } \\
\text { independence and disinterest when it comes to } \\
\text { dealing with budget issues. }\end{array}$ & 3.146 & 1.187 & $9 \%$ & $21 \%$ & $30 \%$ & $25 \%$ & $15 \%$ \\
\hline 23 & $\begin{array}{l}\text { Elected and ex-officio board members have an } \\
\text { inevitable vested interest when dealing with } \\
\text { budget issues. }\end{array}$ & 3.604 & 1.011 & $2 \%$ & $15 \%$ & $22 \%$ & $43 \%$ & $18 \%$ \\
\hline$\overline{33}$ & $\begin{array}{l}\text { The composition of the board has made it more } \\
\text { difficult to balance the budget in these tight } \\
\text { financial times. }\end{array}$ & 2.224 & 1.145 & $31 \%$ & $38 \%$ & $14 \%$ & $13 \%$ & $4 \%$ \\
\hline \multicolumn{9}{|c|}{ Board Labour Relations Matters: Sharing of Power } \\
\hline$\overline{34}$ & $\begin{array}{l}\text { Shared governance as a broad goal is difficult to } \\
\text { achieve in a unionized environment. }\end{array}$ & 2.627 & 1.342 & $24 \%$ & $29 \%$ & $17 \%$ & $18 \%$ & $12 \%$ \\
\hline$\overline{35}$ & $\begin{array}{l}\text { Labour relations, in particular the negotiation } \\
\text { and administering of collective agreements, has } \\
\text { caused division among the members of my } \\
\text { board. }\end{array}$ & 2.376 & 1.190 & $26 \%$ & $36 \%$ & $19 \%$ & $12 \%$ & $7 \%$ \\
\hline$\overline{44}$ & $\begin{array}{l}\text { Student board members should play a full part in } \\
\text { decision-making on labour relations issues. }\end{array}$ & 3.653 & 1.204 & $8 \%$ & $9 \%$ & $21 \%$ & $34 \%$ & $28 \%$ \\
\hline 45 & $\begin{array}{l}\text { Student members on my board do play a full } \\
\text { part in decision-making on labour relations } \\
\text { issues. }\end{array}$ & 3.626 & 1.282 & 9\% & $10 \%$ & $22 \%$ & $26 \%$ & $33 \%$ \\
\hline \multicolumn{9}{|c|}{ General Matters of Board Business: Effectiveness of the Shared Decision-Making Process } \\
\hline 9 & $\begin{array}{l}\text { The composition of my board makes an } \\
\text { effective contribution to the governance of the } \\
\text { institution. }\end{array}$ & 3.782 & 1.145 & $5 \%$ & $10 \%$ & $19 \%$ & $34 \%$ & $32 \%$ \\
\hline
\end{tabular}




\begin{tabular}{|c|c|c|c|c|c|c|c|c|}
\hline 10 & $\begin{array}{l}\text { The way my board operates makes an effective } \\
\text { contribution to the governance of the institution. }\end{array}$ & 3.735 & 1.014 & $2 \%$ & $9 \%$ & $29 \%$ & $33 \%$ & $27 \%$ \\
\hline 11 & $\begin{array}{l}\text { The conduct of my board represents good } \\
\text { boardsmanship. }\end{array}$ & 3.743 & 0.997 & $2 \%$ & $7 \%$ & $32 \%$ & $32 \%$ & $27 \%$ \\
\hline 12 & $\begin{array}{l}\text { My board has managed to make some difficult } \\
\text { decisions in the last two years. }\end{array}$ & 4.141 & 0.926 & $0 \%$ & $9 \%$ & $9 \%$ & $40 \%$ & $42 \%$ \\
\hline 13 & $\begin{array}{l}\text { My board is accountable for its decisions to the } \\
\text { internal and external communities. }\end{array}$ & 4.049 & 0.999 & $1 \%$ & $10 \%$ & $12 \%$ & $38 \%$ & $39 \%$ \\
\hline 14 & $\begin{array}{l}\text { I feel my board is fulfilling its obligations under } \\
\text { the College and Institute Act. }\end{array}$ & 4.137 & 0.955 & $2 \%$ & $4 \%$ & $16 \%$ & $35 \%$ & $43 \%$ \\
\hline 15 & $\begin{array}{l}\text { I feel the powers of the board are being } \\
\text { diminished as more decisions are being } \\
\text { centralized at the provincial level. }\end{array}$ & 3.696 & 1.097 & $4 \%$ & $9 \%$ & $29 \%$ & $29 \%$ & $29 \%$ \\
\hline \multicolumn{9}{|c|}{ Board Financial Matters: Effectiveness of the Shared Decision-Making Process } \\
\hline 24 & $\begin{array}{l}\text { I feel that elected and ex-officio members have } \\
\text { generally NOT shown bias towards their own } \\
\text { department, area, or constituency (trade or } \\
\text { student union) when dealing with budget issues. }\end{array}$ & 3.594 & 1.168 & $7 \%$ & $11 \%$ & $22 \%$ & $36 \%$ & $24 \%$ \\
\hline 25 & $\begin{array}{l}\text { I feel my board effectively discharges its fiscal } \\
\text { responsibilities under the College and Institute } \\
\text { Act. }\end{array}$ & 4.200 & 0.910 & $1 \%$ & $5 \%$ & $12 \%$ & $37 \%$ & $45 \%$ \\
\hline 26 & $\begin{array}{l}\text { My board discharges its fiduciary responsibility } \\
\text { to all students from whom it collects student } \\
\text { union fees when dealing with that organization. }\end{array}$ & 3.938 & 0.938 & $2 \%$ & $3 \%$ & $25 \%$ & $39 \%$ & $31 \%$ \\
\hline 30 & $\begin{array}{l}\text { The board's role is to approve the parameters } \\
\text { and underlying assumptions of the budget, but } \\
\text { otherwise to leave the assembly of the numbers } \\
\text { to administration. }\end{array}$ & 4.020 & 1.157 & $5 \%$ & $9 \%$ & $9 \%$ & $34 \%$ & $43 \%$ \\
\hline
\end{tabular}




\begin{tabular}{|c|c|c|c|c|c|c|c|c|}
\hline 31 & $\begin{array}{l}\text { My board ensures that all stakeholder groups } \\
\text { have advisory input into the budget process. }\end{array}$ & 3.762 & 1.167 & $5 \%$ & $12 \%$ & $17 \%$ & $34 \%$ & $32 \%$ \\
\hline 32 & $\begin{array}{l}\text { I feel that all stakeholder groups are adequately } \\
\text { informed about financial matters. }\end{array}$ & 3.755 & 1.085 & $4 \%$ & $11 \%$ & $18 \%$ & $41 \%$ & $26 \%$ \\
\hline \multicolumn{9}{|c|}{ Board Labour Relations Matters: Effectiveness of the Shared Decision-Making Process } \\
\hline 36 & $\begin{array}{l}\text { Labour relations has become a centralized } \\
\text { provincial issue, hence my board has not } \\
\text { experienced any difficulties in decision-making } \\
\text { due to the presence of elected and ex-officio } \\
\text { members. }\end{array}$ & 2.980 & 1.101 & $9 \%$ & $27 \%$ & $28 \%$ & $29 \%$ & $7 \%$ \\
\hline 37 & $\begin{array}{l}\text { I feel my board effectively discharges its labour } \\
\text { relations responsibilities under the College and } \\
\text { Institute Act. }\end{array}$ & 4.059 & 0.830 & $1 \%$ & $3 \%$ & $17 \%$ & $48 \%$ & $31 \%$ \\
\hline 38 & $\begin{array}{l}\text { I feel my board would have generally adopted a } \\
\text { different direction in labour relations over the } \\
\text { last two years if the board did not include } \\
\text { elected and ex-officio members. }\end{array}$ & 2.307 & 1.129 & $28 \%$ & $34 \%$ & $21 \%$ & $13 \%$ & $4 \%$ \\
\hline 39 & $\begin{array}{l}\text { I feel my board would have generally adopted a } \\
\text { different direction in labour relations over the } \\
\text { last two years if provincial centralization had not } \\
\text { taken place. }\end{array}$ & 3.052 & 1.084 & $9 \%$ & $23 \%$ & $27 \%$ & $36 \%$ & $5 \%$ \\
\hline 40 & $\begin{array}{l}\text { I feel my board would have generally adopted a } \\
\text { different direction in labour relations over the } \\
\text { last two years if the board did not include } \\
\text { elected and ex-officio members and if provincial } \\
\text { centralization had not taken place. }\end{array}$ & 2.724 & 1.091 & $15 \%$ & $29 \%$ & $26 \%$ & $28 \%$ & $2 \%$ \\
\hline
\end{tabular}




\begin{tabular}{|c|c|c|c|c|c|c|c|c|}
\hline \multicolumn{9}{|c|}{ General Matters of Board Business: How Conflict of Interest has been Addressed } \\
\hline 16 & $\begin{array}{l}\text { The president should be a non-voting ex-officio } \\
\text { member of the board. }\end{array}$ & 4.188 & 1.255 & $8 \%$ & $6 \%$ & $5 \%$ & $22 \%$ & $59 \%$ \\
\hline 17 & $\begin{array}{l}\text { The president should be a full voting member of } \\
\text { the board. }\end{array}$ & 1.755 & 1.278 & $65 \%$ & $17 \%$ & $4 \%$ & $5 \%$ & $9 \%$ \\
\hline 18 & $\begin{array}{l}\text { The chair of education council should be a non- } \\
\text { voting ex-officio member of the board. }\end{array}$ & 3.578 & 1.595 & $19 \%$ & $11 \%$ & $6 \%$ & $20 \%$ & $44 \%$ \\
\hline 19 & $\begin{array}{l}\text { The chair of education council should be a full } \\
\text { voting member of the board. }\end{array}$ & 2.485 & 1.610 & $42 \%$ & $19 \%$ & $7 \%$ & $11 \%$ & $21 \%$ \\
\hline 20 & $\begin{array}{l}\text { The bylaw and/or policy on conflict of interest } \\
\text { adopted at my institution is generally accepted } \\
\text { by all board members as fair and workable. }\end{array}$ & 3.853 & 1.075 & $4 \%$ & $10 \%$ & $13 \%$ & $44 \%$ & $29 \%$ \\
\hline 21 & $\begin{array}{l}\text { Conflict of interest has not been a problem with } \\
\text { my board. }\end{array}$ & 3.424 & 1.348 & $10 \%$ & $20 \%$ & $14 \%$ & $29 \%$ & $27 \%$ \\
\hline \multicolumn{9}{|c|}{ Board Financial Matters: How Conflict of Interest has been Addressed } \\
\hline 27 & $\begin{array}{l}\text { My board has dealt effectively with the issue of } \\
\text { conflict of interest as it relates to student board } \\
\text { members with respect to financial matters } \\
\text { between the board and the student union, such } \\
\text { as tuition and other fees. }\end{array}$ & 3.887 & 0.988 & $2 \%$ & $5 \%$ & $27 \%$ & $34 \%$ & $32 \%$ \\
\hline 28 & $\begin{array}{l}\text { The College and Institute Act provision that } \\
\text { students may vote on proposed tuition fee } \\
\text { increases is appropriate. }\end{array}$ & 3.188 & 1.369 & $17 \%$ & $15 \%$ & $21 \%$ & $27 \%$ & $20 \%$ \\
\hline 29 & $\begin{array}{l}\text { Elected student board members should be } \\
\text { disqualified from simultaneously holding office } \\
\text { in their respective student unions because of the } \\
\text { perceived conflict of interest on financial } \\
\text { matters. }\end{array}$ & 2.810 & 1.390 & $20 \%$ & $30 \%$ & $16 \%$ & $17 \%$ & $17 \%$ \\
\hline
\end{tabular}




\begin{tabular}{|c|c|c|c|c|c|c|c|c|}
\hline \multicolumn{9}{|c|}{ Board Labour Relations Matters: How Conflict of Interest has been Addressed } \\
\hline 41 & $\begin{array}{l}\text { The elected and ex-officio board members have } \\
\text { lived upto their oath of office in contributing to } \\
\text { my board's role in labour relations. }\end{array}$ & 4.102 & 0.891 & $0 \%$ & $6 \%$ & $16 \%$ & $39 \%$ & $39 \%$ \\
\hline 42 & $\begin{array}{l}\text { My board has dealt effectively with the issue of } \\
\text { conflict of interest as it relates to elected and ex- } \\
\text { officio board members with respect to matters of } \\
\text { administering collective agreements. }\end{array}$ & 3.900 & 1.096 & $4 \%$ & $10 \%$ & $11 \%$ & $42 \%$ & $33 \%$ \\
\hline 43 & $\begin{array}{l}\text { My board has employed a personnel or labour } \\
\text { relations committee from which some board } \\
\text { members are excluded on the basis of their } \\
\text { perceived or real conflict of interest. }\end{array}$ & 2.753 & 1.554 & $29 \%$ & $25 \%$ & $10 \%$ & $14 \%$ & $22 \%$ \\
\hline$\overline{46}$ & $\begin{array}{l}\text { Elected employee members and ex-officio } \\
\text { members should be disqualified from } \\
\text { simultaneously holding office in their respective } \\
\text { trade unions. }\end{array}$ & 3.109 & 1.523 & $19 \%$ & $25 \%$ & $12 \%$ & $16 \%$ & $28 \%$ \\
\hline
\end{tabular}

Notes:

1. Statements from the survey questionnaire (See Appendix B).

2. Standard Deviation from the Mean. 
Summary of the Assessment of Own Boards' Effectiveness in Aspects of Leadership and Percentage-Frequency Distribution

\begin{tabular}{|c|c|c|c|c|c|c|c|c|}
\hline & Statement ${ }^{\prime}$ & $\begin{array}{l}\text { Grand } \\
\text { Mean }\end{array}$ & $\mathbf{S D}^{2}$ & $\begin{array}{c}\text { Non } \\
\text { Existence }\end{array}$ & $\begin{array}{l}\text { Minimal } \\
\text { Existence }\end{array}$ & Neutral & $\begin{array}{l}\text { Moderate } \\
\text { Existence }\end{array}$ & $\begin{array}{c}\text { Strong } \\
\text { Existence }\end{array}$ \\
\hline \multicolumn{9}{|c|}{ Sharing of Power } \\
\hline 47 & $\begin{array}{l}\text { The undernoted themes can be considered to } \\
\text { contribute to a board's effectiveness in the } \\
\text { sharing of power in a shared governance model: } \\
\text { (a)-A climate of trust among all board } \\
\text { members. }\end{array}$ & 3.911 & 0.918 & $1 \%$ & $8 \%$ & $17 \%$ & $47 \%$ & $27 \%$ \\
\hline 47 & (b)--Equal contribution by all board members. & 3.455 & 1.188 & $7 \%$ & $17 \%$ & $20 \%$ & $36 \%$ & $20 \%$ \\
\hline$\overline{47}$ & $\begin{array}{l}\text { (c)--Independence of all board members from } \\
\text { their constituency. }\end{array}$ & 3.290 & 1.076 & $6 \%$ & $17 \%$ & $31 \%$ & $34 \%$ & $12 \%$ \\
\hline 47 & $\begin{array}{l}\text { (d)--Board members not bringing vested interest } \\
\text { to the board table. }\end{array}$ & 3.416 & 1.013 & $5 \%$ & $12 \%$ & $32 \%$ & $39 \%$ & $12 \%$ \\
\hline 47 & $\begin{array}{l}\text { (e)-Management/labour relations not } \\
\text { infiltrating the board culture. }\end{array}$ & 3.400 & 0.955 & $3 \%$ & $15 \%$ & $34 \%$ & $35 \%$ & $13 \%$ \\
\hline \multicolumn{9}{|c|}{ Effectiveness of the Shared Decision-Making Process } \\
\hline 48 & $\begin{array}{l}\text { The undernoted themes can be considered to } \\
\text { contribute to a board's effectiveness in the } \\
\text { shared decision-making process in a shared } \\
\text { governance model: } \\
\text { (a)--Clear rules of boardsmanship, consistently } \\
\text { applied. }\end{array}$ & 3.869 & 1.007 & $1 \%$ & $11 \%$ & $18 \%$ & $40 \%$ & $30 \%$ \\
\hline 48 & (b)--Accountability for board decision-making. & 3.960 & 0.947 & $1 \%$ & $9 \%$ & $13 \%$ & $\overline{47 \%}$ & $30 \%$ \\
\hline 48 & $\begin{array}{l}\text { (c)--Meeting obligations of the College and } \\
\text { Institute Act. }\end{array}$ & 4.172 & 0.833 & $1 \%$ & $3 \%$ & $12 \%$ & $46 \%$ & $38 \%$ \\
\hline
\end{tabular}




\begin{tabular}{|c|c|c|c|c|c|c|c|c|}
\hline 48 & $\begin{array}{l}\text { (d)--Coping with the tendency toward } \\
\text { centralized (provincial) decision-making. }\end{array}$ & 3.510 & 0.846 & $1 \%$ & $11 \%$ & $34 \%$ & $45 \%$ & $9 \%$ \\
\hline 48 & $\begin{array}{l}\text { (e)--No bias shown by employee board members } \\
\text { in dealing with budget issues and distribution of } \\
\text { resources. }\end{array}$ & 3.825 & 0.990 & $2 \%$ & $8 \%$ & $22 \%$ & $41 \%$ & $27 \%$ \\
\hline 48 & $\begin{array}{l}\text { (f)-No bias shown by student board members in } \\
\text { dealing with budget issues and distribution of } \\
\text { resources. }\end{array}$ & 3.546 & 0.990 & $2 \%$ & $13 \%$ & $29 \%$ & $39 \%$ & $17 \%$ \\
\hline 48 & $\begin{array}{l}\text { (g)--Understanding the distinction between } \\
\text { leadership and management and acknowledging } \\
\text { the roles of the board and administration. }\end{array}$ & 3.714 & 1.112 & $3 \%$ & $13 \%$ & $21 \%$ & $34 \%$ & $29 \%$ \\
\hline 48 & $\begin{array}{l}\text { (h)--The college having a history of informal } \\
\text { shared governance, therefore, the introduction of } \\
\text { legislated shared decision-making was not } \\
\text { difficult. }\end{array}$ & 3.344 & 1.034 & $3 \%$ & $18 \%$ & $35 \%$ & $29 \%$ & $15 \%$ \\
\hline \multicolumn{9}{|c|}{ How Conflict of Interest has been Addressed } \\
\hline 49 & $\begin{array}{l}\text { The undernoted themes can be considered to } \\
\text { contribute to a board's effectiveness in dealing } \\
\text { with real or perceived conflict of interest of } \\
\text { employee and student board members in a } \\
\text { shared governance model: } \\
\text { (a)--A clearly understood and accepted bylaw } \\
\text { and/or policy on conflict of interest having been } \\
\text { developed by the board. }\end{array}$ & 3.889 & 1.203 & $7 \%$ & $8 \%$ & $11 \%$ & $36 \%$ & $38 \%$ \\
\hline 49 & $\begin{array}{l}\text { (b)--Elected board members as members-at- } \\
\text { large and not representing their constituencies. }\end{array}$ & 3.500 & 1.133 & $6 \%$ & $14 \%$ & $22 \%$ & $40 \%$ & $18 \%$ \\
\hline 49 & $\begin{array}{l}\text { (c)--The oath of office, sworn by each member, } \\
\text { preventing management/labour problems among } \\
\text { board members. }\end{array}$ & 3.582 & 1.121 & $8 \%$ & $5 \%$ & $28 \%$ & $39 \%$ & $20 \%$ \\
\hline
\end{tabular}




\begin{tabular}{|c|c|c|c|c|c|c|c|c|}
\hline 49 & $\begin{array}{l}\text { (d)--A personnel or labour relations committee, } \\
\text { with restricted membership, preventing } \\
\text { management/labour problems among board } \\
\text { members }\end{array}$ & 2.570 & 1.355 & $32 \%$ & $14 \%$ & $29 \%$ & $14 \%$ & $11 \%$ \\
\hline 49 & $\begin{array}{l}\text { (e)--The president being able to make a full } \\
\text { contribution to board affairs. }\end{array}$ & 4.323 & 0.967 & $1 \%$ & $7 \%$ & $8 \%$ & $26 \%$ & $58 \%$ \\
\hline 49 & $\begin{array}{l}\text { (f)--The education council chair being able to } \\
\text { make a full contribution to board affairs. }\end{array}$ & 4.162 & 0.987 & $0 \%$ & $9 \%$ & $14 \%$ & $28 \%$ & $49 \%$ \\
\hline
\end{tabular}

Notes:

1. Statements from the survey questionnaire (See Appendix B).

2. Standard Deviation from the Mean. 
Summary of Data by (Constituent Group, Decision-Niahing Context,

and Aspect of 1 .cudership

\begin{tabular}{|c|c|c|c|c|c|c|c|c|c|c|}
\hline \multicolumn{11}{|c|}{ Generul Malters of Bourd Business: Sharing of Power } \\
\hline & Statement' & Value & Appointees & $\begin{array}{l}\text { Elected } \\
\text { Facully }\end{array}$ & $\begin{array}{l}\text { Elected } \\
\text { Staff }\end{array}$ & $\begin{array}{l}\text { Elected } \\
\text { Students }\end{array}$ & Presidents & $\begin{array}{l}\text { Council } \\
\text { Chuirs }\end{array}$ & Total & $p^{2}$ \\
\hline$T$ & 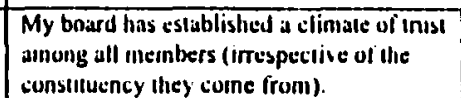 & $\begin{array}{l}\text { Mean' } \\
\text { SD' }^{\prime}\end{array}$ & $\begin{array}{l}3.7+6 \\
0.975\end{array}$ & $\begin{array}{l}3.571 \\
1.512\end{array}$ & $\begin{array}{l}3.875 \\
06+1\end{array}$ & $\begin{array}{l}4.01101 \\
1.0455\end{array}$ & $\begin{array}{l}3.333 \\
1.073\end{array}$ & $\begin{array}{l}4.1100 \\
0.926\end{array}$ & $\begin{array}{l}3.730 \\
1.004\end{array}$ & 6721 \\
\hline 2 & 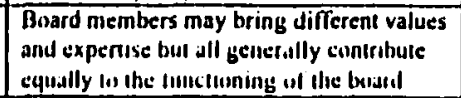 & $\begin{array}{l}\text { Mean } \\
\text { Sil) }\end{array}$ & $\begin{array}{l}3.569 \\
1.078\end{array}$ & $\begin{array}{l}2.857 \\
1.215\end{array}$ & $\begin{array}{l}3.750 \\
0.7117\end{array}$ & $\begin{array}{l}3.500 \\
1.37 k\end{array}$ & $\begin{array}{l}2.692 \\
1.104\end{array}$ & $\begin{array}{l}3.44 t \\
1.236\end{array}$ & $\begin{array}{l}3.4116 \\
1.124\end{array}$ & .1081 \\
\hline 3 & $\begin{array}{l}\text { Board members view themselves as } \\
\text { equals. }\end{array}$ & $\begin{array}{l}\text { Mein } \\
\text { SD }\end{array}$ & $\begin{array}{l}3.759 \\
0.961\end{array}$ & $\begin{array}{l}2.857 \\
1.574\end{array}$ & $\begin{array}{l}4.000 \\
0.926\end{array}$ & $\begin{array}{l}3.50110 \\
1.225\end{array}$ & $\begin{array}{l}3.385 \\
0.961\end{array}$ & $\begin{array}{l}3.667 \\
1.225\end{array}$ & $\begin{array}{l}3.044 \\
1.054\end{array}$ & $.27 \pi$ \\
\hline 4 & $\begin{array}{l}\text { The six year lerm for appoinied board } \\
\text { members is approprialc. }\end{array}$ & $\begin{array}{c}\text { Mean } \\
S D\end{array}$ & $\begin{array}{l}3.7+1 \\
1.319\end{array}$ & $\begin{array}{l}3 .+29 \\
1.272 \\
\end{array}$ & $\begin{array}{l}3.250 \\
1.389\end{array}$ & $\begin{array}{l}2.8 .33 \\
1.169\end{array}$ & $\begin{array}{l}3.385 \\
1.446 \\
\end{array}$ & $\begin{array}{l}3.667 \\
1.118 \\
\end{array}$ & $\begin{array}{l}3.574 \\
1.306\end{array}$ & .5911 \\
\hline 5 & $\begin{array}{l}\text { The three yeas leriul for elected (employec) } \\
\text { boiad meinbers is appropriate. }\end{array}$ & $\begin{array}{l}\text { Mciun } \\
\mathrm{SD}\end{array}$ & $\begin{array}{l}3.610 \\
1.204\end{array}$ & $\begin{array}{l}+000 \\
1.000\end{array}$ & $\begin{array}{l}1.375 \\
10.744\end{array}$ & $\begin{array}{l}7.167 \\
(0.41) 8\end{array}$ & $\begin{array}{l}3 .\left(0^{1}\right) 2 \\
0.947\end{array}$ & $\begin{array}{l}+111 \\
0.9+7\end{array}$ & $\begin{array}{l}3.784 \\
1.087\end{array}$ & .3297 \\
\hline 6 & $\begin{array}{l}\text { The one year term for student board } \\
\text { nembers is appropriate. }\end{array}$ & $\begin{array}{l}\text { Mean } \\
\text { SD }\end{array}$ & $\begin{array}{l}3.439 \\
1.225\end{array}$ & $\begin{array}{l}3.286 \\
1.380\end{array}$ & $\begin{array}{l}3.500 \\
0.535\end{array}$ & $\begin{array}{l}3.167 \\
1.835\end{array}$ & $\begin{array}{l}3.615 \\
1.044\end{array}$ & $\begin{array}{l}4.333 \\
1.118\end{array}$ & $\begin{array}{l}3.520 \\
1.210\end{array}$ & .3994 \\
\hline $7 a$ & $\begin{array}{l}\text { The reinunerainon for appoinied bourd } \\
\text { inembers is approporiate. }\end{array}$ & $\begin{array}{l}\text { Mein } \\
\operatorname{Sn}\end{array}$ & $\begin{array}{l}2.8+5 \\
1.399\end{array}$ & $\begin{array}{l}3.000 \\
1.155\end{array}$ & $\begin{array}{l}7.125 \\
0.835 \\
\end{array}$ & $\begin{array}{l}4.0010 \\
1.265 \\
\end{array}$ & $\begin{array}{l}3.0100 \\
1.291\end{array}$ & $\begin{array}{l}2.875 \\
1.458 \\
\end{array}$ & $\begin{array}{l}3.050 \\
1.366\end{array}$ & .0927 \\
\hline $7 \mathrm{~b}$ & $\begin{array}{l}\text { The remuncratlon for student board } \\
\text { neembers is appropriate. }\end{array}$ & $\begin{array}{c}\text { Me:al } \\
\text { SD }\end{array}$ & $\begin{array}{l}2.981 \\
1.339\end{array}$ & $\begin{array}{l}3.000 \\
1.155\end{array}$ & $\begin{array}{l}4.000 \\
0.926\end{array}$ & $\begin{array}{l}7.0010 \\
1.265\end{array}$ & $\begin{array}{l}3.385 \\
1.121\end{array}$ & $\begin{array}{l}4.000 \\
1.155\end{array}$ & $\begin{array}{l}3.263 \\
1.290\end{array}$ & .0753 \\
\hline $8 a$ & $\begin{array}{l}\text { Faculty and support staff members and the } \\
\text { chairs of the education council should be } \\
\text { remunerated by way of a supend }\end{array}$ & $\begin{array}{l}\text { Mean } \\
\text { SI) }\end{array}$ & $\begin{array}{l}2.759 \\
1 .+13\end{array}$ & $\begin{array}{l}3.400 \\
1.817\end{array}$ & $\begin{array}{l}3.000 \\
1.732\end{array}$ & $\begin{array}{l}4.000 \\
1.095\end{array}$ & $\begin{array}{l}2.077 \\
1.441\end{array}$ & $\begin{array}{l}2.429 \\
1.902\end{array}$ & $\begin{array}{l}2.772 \\
1.513\end{array}$ & .1487 \\
\hline $8 \mathrm{~b}$ & $\begin{array}{l}\text { Faculty and support stait' members and } \\
\text { chairs of the education council should be } \\
\text { renuunerated by way of release lime. }\end{array}$ & $\begin{array}{c}\text { Meian } \\
\text { SD }\end{array}$ & $\begin{array}{l}3.569^{\circ} \\
1.339\end{array}$ & $\begin{array}{l}3.800 \\
1.789\end{array}$ & $\begin{array}{l}4.571^{\circ} \\
0.787\end{array}$ & $\begin{array}{l}3.500 \\
1.517\end{array}$ & $\begin{array}{l}1.833^{*} \\
1.115\end{array}$ & $\begin{array}{l}4.625^{\circ} \\
0.744\end{array}$ & $\begin{array}{l}3.521 \\
1.451\end{array}$ & .0001 \\
\hline
\end{tabular}




\begin{tabular}{|c|c|c|c|c|c|c|c|c|c|c|}
\hline \multicolumn{11}{|c|}{ Board Financial Mallers: Sharing of Power } \\
\hline 22 & $\begin{array}{l}\text { All members of my buard have equal } \\
\text { independence and disinterest when it } \\
\text { connes to dealing with budyel tssues. }\end{array}$ & $\begin{array}{l}\text { Mean } \\
\text { SD }\end{array}$ & $\begin{array}{l}3.161 \\
1.2013\end{array}$ & $\begin{array}{l}3 .+29 \\
0.787\end{array}$ & $\begin{array}{l}3.571 \\
0.787\end{array}$ & $\begin{array}{l}3.400 \\
1.673\end{array}$ & $\begin{array}{l}2.538 \\
1.3311\end{array}$ & $\begin{array}{l}3.250 \\
1.035\end{array}$ & $\begin{array}{l}3.1+6 \\
1.187\end{array}$ & .229 \\
\hline 23 & $\begin{array}{l}\text { Clected ind ex-officio board members } \\
\text { have an inevitable vested interest when } \\
\text { dealing with budget issues }\end{array}$ & $\begin{array}{c}\text { Mean } \\
\text { SD }\end{array}$ & $\begin{array}{l}3.672 \\
1.033\end{array}$ & $\begin{array}{l}3.286 \\
1.380\end{array}$ & $\begin{array}{l}3.875 \\
0.835\end{array}$ & $\begin{array}{l}3.500 \\
0.837\end{array}$ & $\begin{array}{l}3.767 \\
0.927\end{array}$ & $\begin{array}{l}3.0100 \\
0.860\end{array}$ & $\begin{array}{l}3.601 \\
1.011\end{array}$ & .1024 \\
\hline 33 & $\begin{array}{l}\text { The composition of the looard has made it } \\
\text { more difficult to ballance the budget in } \\
\text { liese tiglill tinancial linnes. }\end{array}$ & $\begin{array}{c}\text { Mean } \\
\text { SD }\end{array}$ & $\begin{array}{l}2.121 \\
1.109\end{array}$ & $\begin{array}{l}1.857 \\
1.060\end{array}$ & $\begin{array}{l}2.125 \\
0.6+1\end{array}$ & $\begin{array}{l}1.607 \\
0.516\end{array}$ & $\begin{array}{l}3.231 \\
1 .+81\end{array}$ & $\begin{array}{l}2.167 \\
0.753\end{array}$ & $\begin{array}{l}2.224 \\
1.145\end{array}$ & $.0218^{\circ}$ \\
\hline \multicolumn{11}{|c|}{ Board Labour Retutions Matters: Sharing of Power } \\
\hline$\overline{34}$ & $\begin{array}{l}\text { Shared govemance as a bruad goal is } \\
\text { difficult to achieve in a unionized } \\
\text { environment. }\end{array}$ & $\begin{array}{c}\text { Mean } \\
\text { SD }\end{array}$ & $\begin{array}{l}2.508^{\circ} \\
1.251\end{array}$ & $\begin{array}{l}1.714^{\circ} \\
1.254^{\prime}\end{array}$ & $\begin{array}{l}2.375 \\
0.916\end{array}$ & $\begin{array}{l}2.833 \\
1.472\end{array}$ & $\begin{array}{l}3.816^{\circ} \\
1.214\end{array}$ & $\begin{array}{l}2.444 \\
1.590\end{array}$ & $\begin{array}{l}2.627 \\
1.3+2\end{array}$ & .078 \\
\hline 35 & $\begin{array}{l}\text { Labour relations, in paricular the } \\
\text { negutiation and administering of colleclive } \\
\text { agreements, has caused division among the } \\
\text { members of my board. }\end{array}$ & $\begin{array}{l}\text { Mean } \\
\text { SD }\end{array}$ & $\begin{array}{l}2.322 \\
1.121\end{array}$ & $\begin{array}{l}2.1+3 \\
1.345\end{array}$ & $\begin{array}{l}1.750 \\
0.463\end{array}$ & $\begin{array}{l}2.667 \\
1.506\end{array}$ & $\begin{array}{l}3.077 \\
1 .+41\end{array}$ & $\begin{array}{l}2.250 \\
1.165\end{array}$ & $\begin{array}{l}2.376 \\
1.190\end{array}$ & .1809 \\
\hline 44 & $\begin{array}{l}\text { Student board members should play a fuil } \\
\text { part in decision-making on labour relations } \\
\text { issues. }\end{array}$ & $\begin{array}{l}\text { Mean } \\
\text { SD }\end{array}$ & $\begin{array}{l}3.610 \\
1.160\end{array}$ & $\begin{array}{l}+.000 \\
1+14\end{array}$ & $\begin{array}{l}2.875 \\
1.642\end{array}$ & $\begin{array}{l}5.000 \\
0\end{array}$ & $\begin{array}{l}3.769 \\
1.013\end{array}$ & $\begin{array}{l}3.444 \\
1.014\end{array}$ & $\begin{array}{l}3.653 \\
1.204\end{array}$ & $.05+1$ \\
\hline 45 & $\begin{array}{l}\text { Student members un niy board do play a } \\
\text { full pan in decision-mahing un labour } \\
\text { relallons issues. }\end{array}$ & $\begin{array}{l}\text { Mean } \\
\text { SD) }\end{array}$ & $\begin{array}{l}3.759 \\
1.218\end{array}$ & $\begin{array}{l}3.286 \\
1.890\end{array}$ & $\begin{array}{l}2.875 \\
1.356\end{array}$ & $\begin{array}{l}+.200 \\
1.304\end{array}$ & $\begin{array}{l}3.846 \\
1.068\end{array}$ & $\begin{array}{l}3.000 \\
1.195\end{array}$ & $\begin{array}{l}3.626 \\
1.282\end{array}$ & .2093 \\
\hline \multicolumn{11}{|c|}{ General Mallers of Bourd Business: Effectiveness of the Shared Decision-Making Process } \\
\hline 9 & $\begin{array}{l}\text { The composillion of my board makes an } \\
\text { effective contribution to the govemance of } \\
\text { the institution. }\end{array}$ & $\begin{array}{l}\text { Mean } \\
\text { SD }\end{array}$ & $\begin{array}{l}3.898 \\
1.109\end{array}$ & $\begin{array}{l}3.286 \\
1.380\end{array}$ & $\begin{array}{l}3.750 \\
1.282\end{array}$ & $\begin{array}{l}4.833^{*} \\
0.4(1) 8\end{array}$ & $\begin{array}{l}2.917^{\circ} \\
0.996\end{array}$ & $\begin{array}{l}3.889 \\
0.928\end{array}$ & $\begin{array}{l}3.782 \\
1.1+5\end{array}$ & $.0130^{\circ}$ \\
\hline
\end{tabular}




\begin{tabular}{|c|c|c|c|c|c|c|c|c|c|c|}
\hline 10 & $\begin{array}{l}\text { The way iny board operates makes an } \\
\text { cifective cunturibution to the govermance of } \\
\text { the institurion. }\end{array}$ & $\begin{array}{l}\text { Mean } \\
\text { SD }\end{array}$ & $\begin{array}{l}3.966 \\
0.928\end{array}$ & $\begin{array}{l}2.857 \\
1.069\end{array}$ & $\begin{array}{l}3.025 \\
1.061\end{array}$ & $\begin{array}{l}+.333 \\
0516\end{array}$ & $\begin{array}{l}3.077 \\
0.862\end{array}$ & $\begin{array}{l}3.556 \\
1.236\end{array}$ & $\begin{array}{l}3.735 \\
1.014\end{array}$ & $.0043^{\circ}$ \\
\hline$\pi$ & $\begin{array}{l}\text { The conduct of my hoard represents good } \\
\text { boardstmalshbip. }\end{array}$ & $\begin{array}{l}\text { Mean } \\
\text { SD }\end{array}$ & $\begin{array}{l}3.845 \\
0.933\end{array}$ & $\begin{array}{l}3.571 \\
1.512\end{array}$ & $\begin{array}{l}3.875 \\
0.991\end{array}$ & $\begin{array}{l}4.500 \\
0.5+8\end{array}$ & $\begin{array}{l}3154 \\
0.801\end{array}$ & $\begin{array}{l}3.44 t \\
1.130\end{array}$ & $\begin{array}{l}3.7 .43 \\
0.997\end{array}$ & .0777 \\
\hline 12 & $\begin{array}{l}\text { My hoard has inanaged to mahe some } \\
\text { difficult decisions in the last two years. }\end{array}$ & $\begin{array}{l}\text { Mean } \\
\text { SD }\end{array}$ & $\begin{array}{l}+.322 \% \\
0.840\end{array}$ & $\begin{array}{l}7.286 \\
0.488\end{array}$ & $\begin{array}{l}4.250 \\
0.707\end{array}$ & $\begin{array}{l}+.800 \\
0.4+7\end{array}$ & $\begin{array}{l}3.308^{\circ} \\
1.032\end{array}$ & $\begin{array}{l}3.429 \\
1.134\end{array}$ & $\begin{array}{l}4.1+1 \\
0.926\end{array}$ & .0007 \\
\hline 13 & 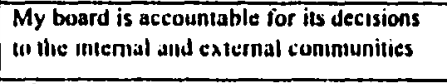 & $\begin{array}{c}\text { Mean } \\
\text { SII }\end{array}$ & $\begin{array}{l}4.288^{\circ} \\
0.720 \\
\end{array}$ & $\begin{array}{l}3571 \\
1.512\end{array}$ & $\begin{array}{l}3.875 \\
1.126 \\
\end{array}$ & $\begin{array}{l}4.667 \\
10816\end{array}$ & $\begin{array}{l}3.231^{\circ} \\
1.0131^{\circ}\end{array}$ & $\begin{array}{l}3.778 \\
1.394\end{array}$ & $\begin{array}{l}+(1+4) \\
(1.949)\end{array}$ & 010131 \\
\hline 14 & $\begin{array}{l}\text { Ifeel my board is filifilling in ubbitigations } \\
\text { under the College and Instiutule Act. }\end{array}$ & $\begin{array}{l}\text { Mean } \\
\text { SD }\end{array}$ & $\begin{array}{l}4.407^{\circ} \\
0.673^{\circ}\end{array}$ & $\begin{array}{l}3.429 \\
1.397\end{array}$ & $\begin{array}{l}4.125 \\
1.126 \\
\end{array}$ & $\begin{array}{l}4.83 .3 \% \\
0.408\end{array}$ & $\begin{array}{l}3.308^{\circ} \\
0.9+7\end{array}$ & $\begin{array}{l}3.667 \\
1.225\end{array}$ & $\begin{array}{l}+.137 \\
0.055\end{array}$ & .0001 \\
\hline 15 & $\begin{array}{l}\text { Tiecl the powers of the buard are being } \\
\text { diministhed as mure decisions are bemg } \\
\text { cenntralieced at the provincial level. }\end{array}$ & $\begin{array}{l}\text { Mean } \\
\text { SD }\end{array}$ & $\begin{array}{l}3.729 \\
1.096\end{array}$ & $\begin{array}{l}3.429 \\
0.535\end{array}$ & $\begin{array}{l}3.875 \\
0991\end{array}$ & $\begin{array}{l}3.500 \\
1.225\end{array}$ & $\begin{array}{l}7.077 \\
1.038\end{array}$ & $\begin{array}{l}3.111 \\
1.453\end{array}$ & $\begin{array}{l}3696 \\
1 .(1497\end{array}$ & 4223 \\
\hline \multicolumn{11}{|c|}{ Board Financial Matters: ECrectiveness of the Shared Decision-Making Process } \\
\hline 24 & 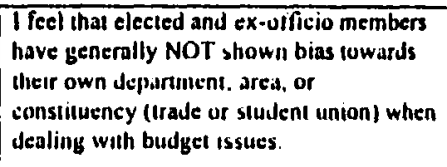 & $\begin{array}{l}\text { Mean } \\
\text { SD }\end{array}$ & $\begin{array}{l}3.483 \\
1.1+3\end{array}$ & $\begin{array}{l}+.429 \\
0.535\end{array}$ & $\begin{array}{l}+.250 \\
0.463\end{array}$ & $\begin{array}{l}3.500 \\
1.975\end{array}$ & $\begin{array}{l}2.923 \\
1.188\end{array}$ & $\begin{array}{l}4.111 \\
0.782\end{array}$ & $\begin{array}{l}3.594 \\
1.168\end{array}$ & 0222 \\
\hline 25 & $\begin{array}{l}\text { lieel my board efifectively discharges its } \\
\text { fiscal responsubilities under the College } \\
\text { and Instinute Acl. }\end{array}$ & $\begin{array}{l}\text { Mean } \\
\text { SD }\end{array}$ & $\begin{array}{l}4.404 \\
0.753\end{array}$ & $\begin{array}{l}++29 \\
0.535\end{array}$ & $\begin{array}{l}+375 \\
1.061\end{array}$ & $\begin{array}{l}3.667 \\
1.033\end{array}$ & $\begin{array}{l}3.769 \\
1.092\end{array}$ & $\begin{array}{l}3.550 \\
1.130\end{array}$ & $\begin{array}{l}7.200 \\
0.910\end{array}$ & $0190^{\circ}$ \\
\hline 26 & 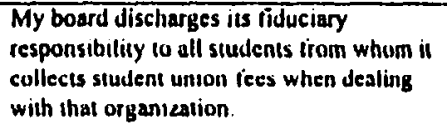 & $\begin{array}{l}\text { Mean } \\
\text { SD }\end{array}$ & $\begin{array}{l}4.073 \\
0.836\end{array}$ & $\begin{array}{l}+.000 \\
1.265\end{array}$ & $\begin{array}{l}+.000 \\
0.756\end{array}$ & $\begin{array}{l}3.0000 \\
1.581\end{array}$ & $\begin{array}{l}3.692 \\
1.032\end{array}$ & $\begin{array}{l}3.889 \\
0.782\end{array}$ & $\begin{array}{l}3.938 \\
0.938\end{array}$ & 2122 \\
\hline 30 & 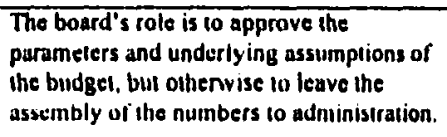 & $\begin{array}{l}\text { Mean } \\
\text { SD }\end{array}$ & $\begin{array}{l}4.103 \\
1.103\end{array}$ & $\begin{array}{l}3.714 \\
1.113\end{array}$ & $\begin{array}{l}4.250 \\
0.707\end{array}$ & $\begin{array}{l}3.500 \\
1.643\end{array}$ & $\begin{array}{l}+385 \\
0.870\end{array}$ & $\begin{array}{l}3.333 \\
1.658\end{array}$ & $\begin{array}{l}+.020 \\
1.157\end{array}$ & 2384 \\
\hline
\end{tabular}




\begin{tabular}{|c|c|c|c|c|c|c|c|c|c|c|}
\hline 31 & $\begin{array}{l}\text { My board ensures that all stakichulder } \\
\text { groups have advisory input into the budget } \\
\text { process. }\end{array}$ & $\begin{array}{l}\text { Mean } \\
\text { SD }\end{array}$ & $\begin{array}{l}3.966 \\
1.082\end{array}$ & $\begin{array}{l}3.571 \\
0.976\end{array}$ & $\begin{array}{l}3.571 \\
1.272\end{array}$ & $\begin{array}{l}3.500 \\
1.0+3\end{array}$ & $\begin{array}{l}3.923 \\
0.954\end{array}$ & $\begin{array}{l}2.667 \\
1.323\end{array}$ & $\begin{array}{l}3.762 \\
1.167\end{array}$ & $.05+2$ \\
\hline 32 & $\begin{array}{l}\text { Tfeel that all stakeholder groups are } \\
\text { adequately informed about financial } \\
\text { malters. }\end{array}$ & $\begin{array}{l}\text { Mean } \\
\text { SD }\end{array}$ & $\begin{array}{l}3.814 \\
1.058\end{array}$ & $\begin{array}{l}3.714 \\
1.254\end{array}$ & $\begin{array}{l}3.875 \\
0.835\end{array}$ & $\begin{array}{l}3.167 \\
1.329\end{array}$ & $\begin{array}{l}4.308 \\
0.751\end{array}$ & $\begin{array}{l}2.889 \\
1.167\end{array}$ & $\begin{array}{l}3.755 \\
1.085\end{array}$ & $.0439^{\circ}$ \\
\hline
\end{tabular}

\section{Board Labour Rclations Matters: Effectiveness of the Shared Decision-Making Process}

\begin{tabular}{|c|c|c|c|c|c|c|c|c|c|c|}
\hline 36 & 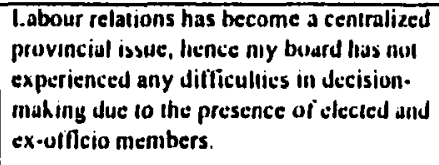 & $\begin{array}{l}\text { Mean } \\
\text { Si) }\end{array}$ & $\begin{array}{l}3.052 \\
1.083\end{array}$ & $\begin{array}{l}3.286 \\
1 .+1 \% 6\end{array}$ & $\begin{array}{l}2.857 \\
0.9(10)\end{array}$ & $\begin{array}{l}3.0010) \\
0.8044\end{array}$ & $\begin{array}{l}2.385 \\
1.121\end{array}$ & $\begin{array}{l}3.222 \\
\mid(\text { (N) }\end{array}$ & $\begin{array}{l}2980 \\
1.1111\end{array}$ & 1081 \\
\hline 37 & $\begin{array}{l}\text { I leel my bourd elfectively discharges its } \\
\text { labour relations I'sponsibilities under the } \\
\text { College and Institule Aci. }\end{array}$ & $\begin{array}{l}\text { Mean } \\
\text { Si) }\end{array}$ & $\begin{array}{l}4.288 \\
13.671\end{array}$ & $\begin{array}{l}3.857 \\
1.064\end{array}$ & $\begin{array}{l}3875 \\
\text { (0.)(W1 }\end{array}$ & $\begin{array}{l}+.000 \\
0.804\end{array}$ & $\begin{array}{l}3.538 \\
11.967\end{array}$ & $\begin{array}{l}3.667 \\
10.866\end{array}$ & $\begin{array}{l}f .1150 \\
11.830\end{array}$ & .0251 \\
\hline 38 & $\begin{array}{l}\text { Ifeel my board would have generally } \\
\text { adopled a different direction in labour } \\
\text { relallions over the last lwo years if the } \\
\text { board did not include elecied and ex. } \\
\text { officio members. }\end{array}$ & $\begin{array}{c}\text { Mean } \\
\text { SD }\end{array}$ & $\begin{array}{l}2.000^{\circ} \\
1.000\end{array}$ & $\begin{array}{l}2.000 \\
1 .+14\end{array}$ & $\begin{array}{l}3.250 \\
0.886\end{array}$ & $\begin{array}{l}2.400 \\
1.673\end{array}$ & $\begin{array}{l}2.462 \\
0.967\end{array}$ & $\begin{array}{l}3.444^{\circ} \\
0726\end{array}$ & $\begin{array}{l}2.307 \\
1.129\end{array}$ & .0007 \\
\hline 39 & $\begin{array}{l}\text { Tfeel my board would have generally } \\
\text { adopted a different direction in labour } \\
\text { relations over the last two years if } \\
\text { provincial centralization had not caken } \\
\text { place. }\end{array}$ & $\begin{array}{l}\text { Mean } \\
\text { SD }\end{array}$ & $\begin{array}{l}2.930 \\
1.015\end{array}$ & $\begin{array}{l}1.857^{\circ} \\
1.069\end{array}$ & $\begin{array}{l}3.1+3 \\
0.90(1)\end{array}$ & $\begin{array}{l}3.200 \\
1.789\end{array}$ & $\begin{array}{l}3.615^{4} \\
0.768\end{array}$ & $\begin{array}{l}3.875^{\circ} \\
0.641\end{array}$ & $\begin{array}{l}3.052 \\
1.084\end{array}$ & .0023 \\
\hline 40 & $\begin{array}{l}\text { T feel my board would have generally } \\
\text { adopted a different disection in labour } \\
\text { relutions over the last livo years if the } \\
\text { board did not include elected und ex. } \\
\text { oflieio members and if provincial } \\
\text { centralizasion had not taken place. }\end{array}$ & $\begin{array}{l}\text { Mean } \\
\text { SI) }\end{array}$ & $\begin{array}{l}2.500 \\
1.009\end{array}$ & $\begin{array}{l}1.714^{\circ} \\
0951\end{array}$ & $\begin{array}{l}3.125 \\
0.991\end{array}$ & $\begin{array}{l}2.800 \\
1.483\end{array}$ & $\begin{array}{l}3.462 \\
0.967\end{array}$ & $\begin{array}{l}3.444^{\circ} \\
0.726\end{array}$ & $\begin{array}{l}2.724 \\
1.091\end{array}$ & .0009 \\
\hline
\end{tabular}




\begin{tabular}{|c|c|c|c|c|c|c|c|c|c|c|}
\hline \multicolumn{11}{|c|}{ General Mauters of Bourd Business: How Confict of Interest has been Addressed } \\
\hline 16 & $\begin{array}{l}\text { The president should be a non-voling ex- } \\
\text { officio menterer of the board. }\end{array}$ & $\begin{array}{l}\text { Mean } \\
\text { SI) }\end{array}$ & $\begin{array}{l}4.186 \\
1.196\end{array}$ & $\begin{array}{l}+500 \\
0.5+8\end{array}$ & $\begin{array}{l}+.375 \\
1.408\end{array}$ & $\begin{array}{l}4.167 \\
1.6102\end{array}$ & $\begin{array}{l}3.692 \\
1.750\end{array}$ & $\begin{array}{l}4.550 \\
0.726\end{array}$ & $\begin{array}{l}+.188 \\
1.255\end{array}$ & .6554 \\
\hline 17 & $\begin{array}{l}\text { The presidenn should be a fill voling } \\
\text { member ut the toard. }\end{array}$ & $\begin{array}{l}\text { Mean } \\
\text { SI) }\end{array}$ & $\begin{array}{l}1.864 \\
1.332 \\
\end{array}$ & $\begin{array}{l}1.143 \\
0.378 \\
\end{array}$ & $\begin{array}{l}1.625 \\
1 .+108 \\
\end{array}$ & $\begin{array}{l}1.667 \\
1.033 \\
\end{array}$ & $\begin{array}{l}2.0010 \\
1 .+14 \\
\end{array}$ & $\begin{array}{l}1.3 \overline{3} \\
0.707 \\
\end{array}$ & $\begin{array}{l}1.755 \\
1.278 \\
\end{array}$ & .6162 \\
\hline 18 & $\begin{array}{l}\text { The chair of educalion council should be a } \\
\text { nun-voling ex-cilicio member of the } \\
\text { lhourd. }\end{array}$ & $\begin{array}{l}\text { Mean } \\
\text { SI) }\end{array}$ & $\begin{array}{l}3.814 \\
1 .+4 t\end{array}$ & $\begin{array}{l}3.286 \\
1.890\end{array}$ & $\begin{array}{l}3.125 \\
1.642\end{array}$ & $\begin{array}{l}3.167 \\
2.11+1\end{array}$ & $\begin{array}{l}3.615 \\
1.710\end{array}$ & $\begin{array}{l}2.889 \\
1.9010\end{array}$ & $\begin{array}{l}3.578 \\
1.505\end{array}$ & .5216 \\
\hline 19 & 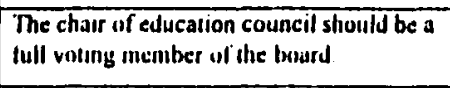 & $\begin{array}{l}\text { Mean } \\
\text { Si) }\end{array}$ & $\begin{array}{l}2.293 \\
1.4+49\end{array}$ & $\begin{array}{l}2.857 \\
1.773\end{array}$ & $\begin{array}{l}2.875 \\
1.0+2 \\
\end{array}$ & $\begin{array}{r}2.833 \\
2.11+1 \\
\end{array}$ & $\begin{array}{l}3.077 \\
1.553\end{array}$ & $\begin{array}{l}3.111 \\
1.878\end{array}$ & $\begin{array}{l}2.485 \\
1.010\end{array}$ & .3113 \\
\hline 20 & 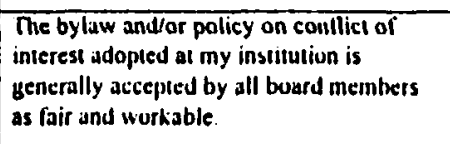 & $\begin{array}{l}\text { Mean } \\
\text { SD }\end{array}$ & $\begin{array}{l}7.085 \\
1.022\end{array}$ & $\begin{array}{l}3.857 \\
0.690\end{array}$ & $\begin{array}{l}3.750 \\
0.463\end{array}$ & $\begin{array}{l}3.333 \\
1.633\end{array}$ & $\begin{array}{l}3.077 \\
1.038\end{array}$ & $\begin{array}{l}3.889 \\
1.269\end{array}$ & $\begin{array}{l}3.853 \\
1.075\end{array}$ & $0+04)^{\circ}$ \\
\hline 21 & $\begin{array}{l}\text { Connicic oi interess has nor been a problem } \\
\text { with my board. }\end{array}$ & $\begin{array}{l}\text { Mean } \\
\text { SD }\end{array}$ & $\begin{array}{l}3.544 \\
1.324 \\
\end{array}$ & $\begin{array}{l}3.571 \\
1.134\end{array}$ & $\begin{array}{l}3.750 \\
0.707\end{array}$ & $\begin{array}{l}2.833 \\
1.722\end{array}$ & $\begin{array}{l}2.769 \\
1.636\end{array}$ & $\begin{array}{l}3.625 \\
1.768\end{array}$ & $\begin{array}{l}3.424 \\
1.348\end{array}$ & $37+5$ \\
\hline \multicolumn{11}{|c|}{ Board Financial Matters: How Conflict of Interest has been Addressed } \\
\hline 27 & 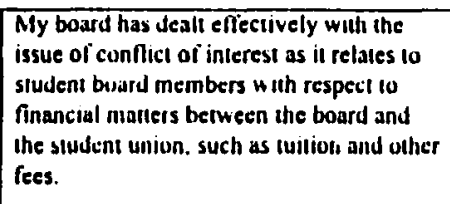 & $\begin{array}{l}\text { Mean } \\
\text { Si) }\end{array}$ & $\begin{array}{l}4.088 \\
0.872\end{array}$ & $\begin{array}{l}3.571 \\
1.134\end{array}$ & $\begin{array}{l}3.375 \\
1.061\end{array}$ & $\begin{array}{l}3.8011 \\
1.789\end{array}$ & $\begin{array}{l}3.538 \\
0.967\end{array}$ & $\begin{array}{l}3.857 \\
0.900\end{array}$ & $\begin{array}{l}3.887 \\
0.988\end{array}$ & 2303 \\
\hline 28 & $\begin{array}{l}\text { The Collegc and Institute Act provision } \\
\text { that sudents snay vole on proposed tuition } \\
\text { fee increases is appropriate. }\end{array}$ & $\begin{array}{c}\text { Mean } \\
\text { SD }\end{array}$ & $\begin{array}{l}3.431^{\circ} \\
1.224^{\circ}\end{array}$ & $\begin{array}{l}3 .+29 \\
1.272\end{array}$ & $\begin{array}{l}2.625 \\
1.302\end{array}$ & $\begin{array}{l}3.667 \\
2.066\end{array}$ & $\begin{array}{l}1.923^{\circ} \\
1.038^{\circ}\end{array}$ & $\begin{array}{l}3.444 \\
1.333\end{array}$ & $\begin{array}{l}3.188 \\
1.369\end{array}$ & 0060 \\
\hline 29 & 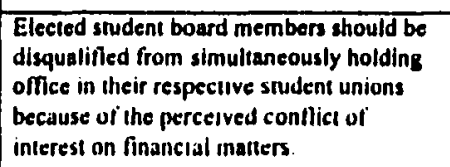 & $\begin{array}{c}\text { Mean } \\
\text { SD }\end{array}$ & $\begin{array}{l}2.860 \\
1.329\end{array}$ & $\begin{array}{l}2.286 \\
1.704\end{array}$ & $\begin{array}{l}3.250 \\
1.389\end{array}$ & $\begin{array}{l}1.833 \\
1.169\end{array}$ & $\begin{array}{l}3.231 \\
1.301\end{array}$ & $\begin{array}{l}2.556 \\
1.667\end{array}$ & $\begin{array}{l}2.810 \\
1.390\end{array}$ & .2781 \\
\hline
\end{tabular}




\begin{tabular}{|c|c|c|c|c|c|c|c|c|c|c|}
\hline \multicolumn{11}{|c|}{ Board Lubour Relations Mutters: How Conflict of Interest has been Addressed } \\
\hline$\pi$ & 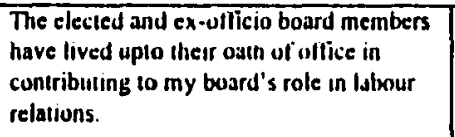 & $\begin{array}{l}\text { Mean } \\
\text { SI) }\end{array}$ & $\begin{array}{l}4.193^{\circ} \\
0.833^{\circ}\end{array}$ & $\begin{array}{l}4.711^{\circ} \\
0.418\end{array}$ & $\begin{array}{l}+250 \\
0.707\end{array}$ & $\begin{array}{l}4.000 \\
0.707\end{array}$ & $\begin{array}{l}3.154^{\circ} \\
0.987\end{array}$ & $\begin{array}{l}4.375 \\
0.74 t\end{array}$ & $\begin{array}{l}4.102 \\
0.801\end{array}$ & $.0008^{\circ}$ \\
\hline 42 & 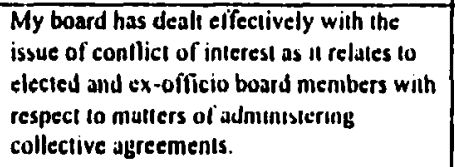 & $\begin{array}{l}\text { Mean } \\
\text { SD }\end{array}$ & $\begin{array}{l}4.190^{\circ} \\
0.868\end{array}$ & $\begin{array}{l}3.714 \\
1.380\end{array}$ & $\begin{array}{l}4.000 \\
0.756\end{array}$ & $\begin{array}{l}3.800 \\
1.304\end{array}$ & $\begin{array}{l}2.846^{\circ} \\
1.144\end{array}$ & $\begin{array}{l}3.667 \\
1.500\end{array}$ & $\begin{array}{l}3.900 \\
1.096\end{array}$ & $.0033^{\circ}$ \\
\hline$\overline{43}$ & 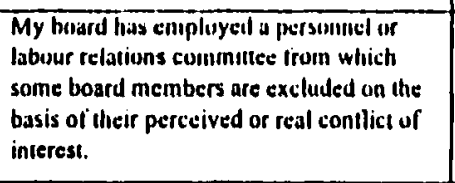 & $\begin{array}{l}\text { Mciall } \\
\text { Si) }\end{array}$ & $\begin{array}{l}2.8301 \\
1.5411\end{array}$ & $\begin{array}{l}3.333 \\
1.966\end{array}$ & $\begin{array}{l}2.667 \\
1.633\end{array}$ & $\begin{array}{l}3.010101 \\
2.309\end{array}$ & $\begin{array}{l}2.154 \\
1.345\end{array}$ & $\begin{array}{l}2.714 \\
1.380\end{array}$ & $\begin{array}{l}3.753 \\
1.554\end{array}$ & .7072 \\
\hline 76 & 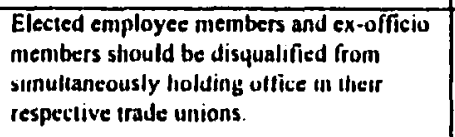 & $\begin{array}{c}\text { Mean } \\
\text { SD }\end{array}$ & $\begin{array}{l}3.203 \\
1.529\end{array}$ & $\begin{array}{l}2.857 \\
1.773\end{array}$ & $\begin{array}{l}2.250 \\
1.282\end{array}$ & $\begin{array}{l}3.200 \\
1.780\end{array}$ & $\begin{array}{l}3.538 \\
1.391\end{array}$ & $\begin{array}{l}2.778 \\
1.563\end{array}$ & $\begin{array}{l}3.109 \\
1.523\end{array}$ & .4954 \\
\hline
\end{tabular}

Notes:

1. Statements from the survey questionnaire (see Appendix B).

2. Level of Significance.

3. Standard Deviation from the Mean.

4. 1 = strongly disagree; 2 = disagrec; $3=$ neutral; $f$ agree; $j=$ strongly agree

$\rightarrow$ Indicates significant difference at the 0.5 confidence level.

- Indicates where Scheffe post hoc test has revealed significant difference at the 0.5 conlidence level between pair(s) of constituent groups. 
Sumumry of the Assessment of Own Bourds' Efrectiveness in Aspects of l.eudership, by Constituent (iroup

\begin{tabular}{|c|c|c|c|c|c|c|c|c|c|c|}
\hline \multicolumn{11}{|c|}{ Sharing of Power } \\
\hline & Stutement' & Value & Appointees & $\begin{array}{l}\text { Elected } \\
\text { Faculty }\end{array}$ & $\begin{array}{l}\text { Elected } \\
\text { Stuff }\end{array}$ & $\begin{array}{l}\text { Elected } \\
\text { Students }\end{array}$ & Presidents & $\begin{array}{l}\text { Council } \\
\text { Chairs }\end{array}$ & Total & $\mathrm{p}^{3}$ \\
\hline 47 & 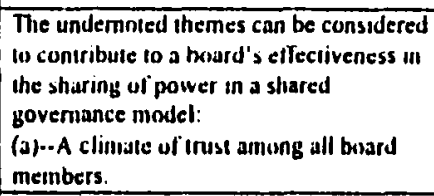 & $\begin{array}{l}\text { Mean' } \\
\text { SI }^{\prime}\end{array}$ & $\begin{array}{l}3.949 \\
0.918\end{array}$ & $\begin{array}{l}3.571 \\
1.512\end{array}$ & $\begin{array}{l}+.000 \\
1.535\end{array}$ & $\begin{array}{l}+000 \\
1.01010\end{array}$ & $\begin{array}{l}3.692 \\
10855\end{array}$ & $\begin{array}{l}4.111 \\
0.782\end{array}$ & $\begin{array}{l}3.911 \\
0.918\end{array}$ & .8072 \\
\hline 47 & $\begin{array}{l}\text { (b). - Equal contribulion by all board } \\
\text { members. }\end{array}$ & $\begin{array}{l}\text { Mean } \\
\text { SD }\end{array}$ & $\begin{array}{l}3.508 \\
1.223\end{array}$ & $\begin{array}{l}2.571 \\
1.397\end{array}$ & $\begin{array}{l}3.875 \\
01.991\end{array}$ & $\begin{array}{l}3.600 \\
1.140\end{array}$ & $\begin{array}{l}3.231 \\
1.013\end{array}$ & $\begin{array}{l}3.667 \\
1.118\end{array}$ & $\begin{array}{l}3.455 \\
1.118\end{array}$ & .3278 \\
\hline 47 & $\begin{array}{l}\text { (c)--Independence of all board members } \\
\text { from their constiluency. }\end{array}$ & $\begin{array}{l}\text { Meaul } \\
\text { SD }\end{array}$ & $\begin{array}{l}3.328 \\
1.008 \\
\end{array}$ & $\begin{array}{l}2.875 \\
1.3+5 \\
\end{array}$ & $\begin{array}{l}3.500 \\
0.756 \\
\end{array}$ & $\begin{array}{l}3.800 \\
1.304\end{array}$ & $\begin{array}{l}2.769 \\
1.092\end{array}$ & $\begin{array}{l}3.667 \\
0.500\end{array}$ & $\begin{array}{l}3.2401 \\
1.076\end{array}$ & 2379 \\
\hline 47 & $\begin{array}{l}\text { (d)-*Board members not bringing vestied } \\
\text { unteresi to the boasd table. }\end{array}$ & $\begin{array}{l}\text { Mean } \\
\text { SD }\end{array}$ & $\begin{array}{l}3.5+2 \\
1.056\end{array}$ & $\begin{array}{l}3.571 \\
1.272 \\
\end{array}$ & $\begin{array}{l}3.000 \\
0.756\end{array}$ & $\begin{array}{l}3.2(10) \\
0.837\end{array}$ & $\begin{array}{l}3.000 \\
0.816\end{array}$ & $\begin{array}{l}3.556 \\
1.014\end{array}$ & $\begin{array}{l}3+16 \\
1.013\end{array}$ & .1188 \\
\hline$\overline{47}$ & $\begin{array}{l}\text { (e)--Managemenulubour relations not } \\
\text { intiltratung the board culture. }\end{array}$ & $\begin{array}{c}\text { Mean } \\
\mathrm{SD}\end{array}$ & $\begin{array}{l}3.362 \\
1.055 \\
\end{array}$ & $\begin{array}{l}4.000 \\
1.155 \\
\end{array}$ & $\begin{array}{l}3.250 \\
0.707 \\
\end{array}$ & $\begin{array}{l}3.400 \\
0.894\end{array}$ & $\begin{array}{l}3.385 \\
0.961 \\
\end{array}$ & $\begin{array}{l}3.333 \\
0.866 \\
\end{array}$ & $\begin{array}{l}3.400 \\
0.995\end{array}$ & .7316 \\
\hline \multicolumn{11}{|c|}{ Effectiveness of the Shared Decision-Making Process } \\
\hline 48 & $\begin{array}{l}\text { The undemuted themes can be considered } \\
\text { to contribute to a board's effecliveness in } \\
\text { the shared decision-making process in a } \\
\text { shared governance inodel: } \\
\text { (a)-Clear rules of boardsmanship. } \\
\text { consisienily applied. }\end{array}$ & $\begin{array}{l}\text { Mean } \\
\text { SI) }\end{array}$ & $\begin{array}{l}4.060) \\
0.934\end{array}$ & $\begin{array}{l}3.286 \\
1.113\end{array}$ & $\begin{array}{l}+.125 \\
0.6+1\end{array}$ & $\begin{array}{l}3.250 \\
0.957\end{array}$ & $\begin{array}{l}3.385 \\
1.121\end{array}$ & $\begin{array}{l}3.778 \\
1.202\end{array}$ & $\begin{array}{l}3.8(1) \\
1.007\end{array}$ & .0780 \\
\hline 48 & $\begin{array}{l}\text { (b)-Accountability for board decision- } \\
\text { making. }\end{array}$ & $\begin{array}{l}\text { Mean } \\
\text { SD }\end{array}$ & $\begin{array}{l}4.138 \\
0.907\end{array}$ & $\begin{array}{l}3.714 \\
1.113\end{array}$ & $\begin{array}{l}4.125 \\
0.6+1\end{array}$ & $\begin{array}{l}3.750 \\
0.500\end{array}$ & $\begin{array}{l}3.538 \\
1.050\end{array}$ & $\begin{array}{l}3.556 \\
1.130\end{array}$ & $\begin{array}{l}3.960 \\
0.947\end{array}$ & .2070 \\
\hline
\end{tabular}




\begin{tabular}{|c|c|c|c|c|c|c|c|c|c|c|}
\hline 48 & $\begin{array}{l}\text { (c)-Meeting cbligations of the College } \\
\text { and Institure Acr. }\end{array}$ & $\begin{array}{l}\text { Meall } \\
\text { SD }\end{array}$ & $\begin{array}{l}4.328 \\
0.735\end{array}$ & $\begin{array}{l}4.143 \\
0.690\end{array}$ & $\begin{array}{l}+375 \\
0.518\end{array}$ & $\begin{array}{l}3.750 \\
0.500\end{array}$ & $\begin{array}{l}3.602 \\
1.032\end{array}$ & $\begin{array}{l}3.881) \\
1.260\end{array}$ & $\begin{array}{l}1.172 \\
0.833\end{array}$ & .1104 \\
\hline 48 & $\begin{array}{l}\text { (d)-Coping with the tendency loward } \\
\text { ceniralized (provincial) decision-making. }\end{array}$ & $\begin{array}{l}\text { Mean } \\
\text { SD }\end{array}$ & $\begin{array}{l}3.596 \\
0.821\end{array}$ & $\begin{array}{l}3 .+29 \\
0.976\end{array}$ & $\begin{array}{l}3.286 \\
0.488\end{array}$ & $\begin{array}{l}3.500 \\
1.000\end{array}$ & $\begin{array}{l}3.385 \\
1.044\end{array}$ & $\begin{array}{l}3.375 \\
0.916\end{array}$ & $\begin{array}{l}3.510 \\
0.846\end{array}$ & 9018 \\
\hline 48 & $\begin{array}{l}\text { (e)- No bius shown by employee buard } \\
\text { members in dealing willi budget issues and } \\
\text { distribution of resources. }\end{array}$ & $\begin{array}{l}\text { Mean } \\
\text { SD }\end{array}$ & $\begin{array}{l}3.842 \\
1.066\end{array}$ & $\begin{array}{l}+.000 \\
0.577\end{array}$ & $\begin{array}{l}+.250 \\
0.577\end{array}$ & $\begin{array}{l}3.250 \\
1.500\end{array}$ & $\begin{array}{l}3.692 \\
0.947\end{array}$ & $\begin{array}{l}3.625 \\
0.916\end{array}$ & $\begin{array}{l}3.825 \\
0.990\end{array}$ & .6148 \\
\hline 48 & $\begin{array}{l}\text { ( }) \text {-No bias sliown by student board } \\
\text { members in dealing w wh budbet issues and } \\
\text { distribution of resources. }\end{array}$ & $\begin{array}{l}\text { Mean } \\
\text { SD }\end{array}$ & $\begin{array}{l}3.579 \\
1.017\end{array}$ & $\begin{array}{l}3.429 \\
1.134\end{array}$ & $\begin{array}{l}3.500 \\
0.926\end{array}$ & $\begin{array}{l}3.250 \\
1.500\end{array}$ & $\begin{array}{l}3.162 \\
0.776\end{array}$ & $\begin{array}{l}3.750 \\
1.035\end{array}$ & $\begin{array}{l}3.546 \\
0.990\end{array}$ & .9672 \\
\hline 48 & $\begin{array}{l}\text { (b)-Understanding the distinction between } \\
\text { leadership and mianagement and } \\
\text { acknuwledging the roles of the bonard and } \\
\text { administration. }\end{array}$ & $\begin{array}{l}\text { Mean } \\
\text { SI) }\end{array}$ & $\begin{array}{l}3.931 \\
1.057\end{array}$ & $\begin{array}{l}3.1+3 \\
1.215\end{array}$ & $\begin{array}{l}3.875 \\
0.6+1\end{array}$ & $\begin{array}{l}3.750 \\
0.957\end{array}$ & $\begin{array}{l}3.231 \\
1.013\end{array}$ & $\begin{array}{l}3.250 \\
1.669\end{array}$ & $\begin{array}{l}3.714 \\
1.112\end{array}$ & $.1+96$ \\
\hline 48 & $\begin{array}{l}\text { (h)-The cullege having a history of } \\
\text { informal shiwed governance, therefiore, the } \\
\text { introduction of legislated shared decision- } \\
\text { mahing was not difficult. }\end{array}$ & $\begin{array}{l}\text { Mean } \\
\text { SD }\end{array}$ & $\begin{array}{l}3.129 \\
1.126\end{array}$ & $\begin{array}{l}2.857 \\
1.069\end{array}$ & $\begin{array}{l}3.385 \\
0.7+4\end{array}$ & $\begin{array}{l}3.500 \\
0.577\end{array}$ & $\begin{array}{l}.538 \\
0.877\end{array}$ & $\begin{array}{l}2.750 \\
0.886\end{array}$ & $\begin{array}{l}3.344 \\
1.034\end{array}$ & 7076 \\
\hline \multicolumn{11}{|c|}{ How Conflict of Interest has been Addressed } \\
\hline 49 & 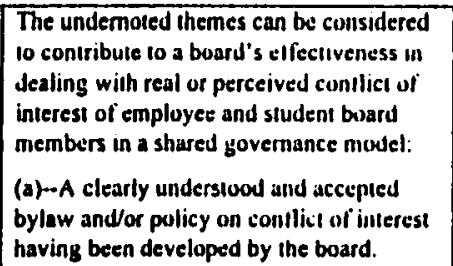 & $\begin{array}{l}\text { Meall } \\
\text { SD }\end{array}$ & $\begin{array}{l}3.983 \\
1.221\end{array}$ & $\begin{array}{l}3.857 \\
1 .+64\end{array}$ & $\begin{array}{l}4000 \\
0.577\end{array}$ & $\begin{array}{l}+200 \\
0.4+7\end{array}$ & $\begin{array}{l}3.462 \\
1.266\end{array}$ & $\begin{array}{l}3.667 \\
1.500\end{array}$ & $\begin{array}{l}3.889 \\
1.203\end{array}$ & .7552 \\
\hline 49 & $\begin{array}{l}\text { (b)-Elecied board members as members- } \\
\text { at-large and not representing their } \\
\text { constituencies. }\end{array}$ & $\begin{array}{l}\text { Mean } \\
\text { SD }\end{array}$ & $\begin{array}{l}3.526 \\
1.182\end{array}$ & $\begin{array}{l}3.429 \\
1.512\end{array}$ & $\begin{array}{l}3.625 \\
1.061\end{array}$ & $\begin{array}{l}3.800 \\
1.095\end{array}$ & $\begin{array}{l}3.231 \\
1.166\end{array}$ & $\begin{array}{l}3.500 \\
0.535\end{array}$ & $\begin{array}{l}3.500 \\
1.133\end{array}$ & .9445 \\
\hline
\end{tabular}

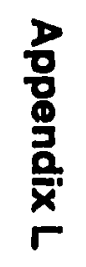




\begin{tabular}{|c|c|c|c|c|c|c|c|c|c|c|}
\hline 49 & $\begin{array}{l}\text { (c). - The osath of office, swam by cach } \\
\text { mermber, preventing mana gecencnulubour } \\
\text { problems among bourd members. }\end{array}$ & $\begin{array}{l}\text { Mean } \\
\text { SD }\end{array}$ & $\begin{array}{l}3.696 \\
1.043\end{array}$ & $\begin{array}{l}3.429 \\
1.272\end{array}$ & $\begin{array}{l}3.625 \\
1.302\end{array}$ & $\begin{array}{l}3.6010) \\
0.894\end{array}$ & $\begin{array}{l}3.385 \\
1.261\end{array}$ & $\begin{array}{l}3.222 \\
1.3 \% 4\end{array}$ & $\begin{array}{l}3.582 \\
1.121\end{array}$ & 8484 \\
\hline 49 & 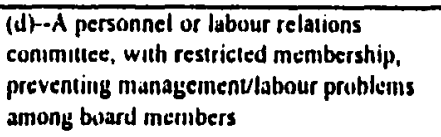 & $\begin{array}{l}\text { Mean } \\
\text { SD }\end{array}$ & $\begin{array}{l}2.564 \\
1.371\end{array}$ & $\begin{array}{l}2.857 \\
1.574\end{array}$ & $\begin{array}{l}2.0001 \\
1.414\end{array}$ & $\begin{array}{l}3.1100 \\
0.816\end{array}$ & $\begin{array}{l}2.538 \\
1.450\end{array}$ & $\begin{array}{l}2.714 \\
1.254\end{array}$ & $\begin{array}{l}2.570 \\
1.355\end{array}$ & 8507 \\
\hline 49 & $\begin{array}{l}\text { (e)-The president being ahte to make } \\
\text { full cunnrbutiun to board affars. }\end{array}$ & $\begin{array}{c}\text { Mean } \\
\text { SD }\end{array}$ & $\begin{array}{l}4.552 \\
0.841\end{array}$ & $\begin{array}{l}3.571 \\
1.618\end{array}$ & $\begin{array}{l}7500 \\
0.535\end{array}$ & $\begin{array}{l}+200 \\
0.837\end{array}$ & $\begin{array}{l}3.769 \\
0.927\end{array}$ & $\begin{array}{l}+125 \\
1.126\end{array}$ & $\begin{array}{l}4.232 \\
0.967\end{array}$ & .0253 \\
\hline 49 & 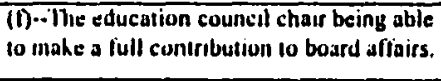 & $\begin{array}{c}\text { Meall } \\
\text { SD }\end{array}$ & $\begin{array}{l}4.310 \\
0.094\end{array}$ & $\begin{array}{l}4.1+33 \\
1.069\end{array}$ & $\begin{array}{l}7.2501 \\
1.035\end{array}$ & $\begin{array}{l}+.0001 \\
0.707\end{array}$ & $\begin{array}{l}3.538 \\
1.050\end{array}$ & $\begin{array}{l}+.125 \\
1.126\end{array}$ & $\begin{array}{l}4.162 \\
0.987\end{array}$ & 2434 \\
\hline
\end{tabular}

Notes:

1. Statements from the survey questionnaire (sce Appendix B).

2. Level of Significance.

3. Standard Deviation from the Mean.

t. $1=$ strongly disagree; $2=$ disagree; $3=$ neutral; $t=$ agree; $5=$ strungly agree.

$\dot{*}$ Indicates signiticant difference at the $0 . j$ confidence level.

- Indicales where Scheffe post hoc lest has revealed significant difference at the 0.5 contidence level helween pair(s) of constituent groups 
Summary of Data by College (A to Q), Decision-Mlaking Context, and $A$ spect of l.eaderstip

General Matters of Bourd Business: Shuring of Power

\begin{tabular}{|c|c|c|c|c|c|c|c|c|c|c|c|c|c|c|c|c|c|c|c|c|}
\hline Statemen!' & Vulue & $A$ & B & $\mathrm{C}$ & D & $\mathbf{E}$ & $F$ & G & II & 1 & .1 & $K^{\prime}$ & l. & $\mathbf{M}$ & $N$ & 0 & $\mathbf{P}$ & $Q$ & Totul & $p^{2}$ \\
\hline 1 & $\begin{array}{c}\text { Mean } \\
\text { SD' }^{\prime}\end{array}$ & $\begin{array}{l}7.600 \\
0.548\end{array}$ & $\begin{array}{l}3.667 \\
0.577\end{array}$ & $\begin{array}{l}3.100 \\
0.894\end{array}$ & $\begin{array}{l}7.571 \\
0.535\end{array}$ & $\begin{array}{l}2.600 \\
0.548\end{array}$ & $\begin{array}{l}3.5001 \\
0.577\end{array}$ & $\begin{array}{l}7.6(10) \\
0.548\end{array}$ & $\begin{array}{l}3.800 \\
0.837\end{array}$ & $\begin{array}{l}3.6(10) \\
0843\end{array}$ & $\begin{array}{l}4.200 \\
0.837\end{array}$ & $\begin{array}{l}4.333 \\
1.0133 \\
\end{array}$ & $\begin{array}{l}4.143 \\
1.060 \\
\end{array}$ & $\begin{array}{l}3818 \\
0.874\end{array}$ & $\begin{array}{l}3.750 \\
0.886\end{array}$ & $\begin{array}{l}3.143 \\
0.010)\end{array}$ & $\begin{array}{l}2.000 \\
1.0001 \\
\end{array}$ & $\begin{array}{l}2.250 \\
0.957 \\
\end{array}$ & $\begin{array}{l}3.7301 \\
1.004\end{array}$ & $.0(0) 1$ \\
\hline 2 & $\begin{array}{c}\text { Mean } \\
\text { SD }\end{array}$ & $\begin{array}{l}4.200 \\
0.837 \\
\end{array}$ & $\begin{array}{l}3.333 \\
0.577 \\
\end{array}$ & $\begin{array}{l}3.400 \\
1.342 \\
\end{array}$ & $\begin{array}{l}3.750 \\
1.165\end{array}$ & $\begin{array}{l}3.000 \\
0.707 \\
\end{array}$ & $\begin{array}{l}2.750 \\
1.258 \\
\end{array}$ & $\begin{array}{l}4.200 \\
0.837 \\
\end{array}$ & $\begin{array}{l}2.667 \\
0.816 \\
\end{array}$ & $\begin{array}{l}3.222 \\
0.972 \\
\end{array}$ & $\begin{array}{l}+.000 \\
1.0000 \\
\end{array}$ & $\begin{array}{l}+.667 \\
0.816 \\
\end{array}$ & $\begin{array}{l}4.0100 \\
1.155 \\
\end{array}$ & $\begin{array}{l}3.182 \\
1.070 \\
\end{array}$ & $\begin{array}{l}3.375 \\
0.744 \\
\end{array}$ & $\begin{array}{l}2.857 \\
1.215\end{array}$ & $\begin{array}{l}2.000 \\
1.000\end{array}$ & $\begin{array}{l}.500 \\
1.291\end{array}$ & $\begin{array}{l}3.406 \\
1.124\end{array}$ & $.0063^{\circ}$ \\
\hline 3 & $\begin{array}{c}\text { Mlean } \\
\text { SD }\end{array}$ & $\begin{array}{l}4.200 \\
0.447 \\
\end{array}$ & $\begin{array}{l}.667 \\
0.577 \\
\end{array}$ & $\begin{array}{l}3.2001 \\
0.837 \\
\end{array}$ & $\begin{array}{l}4.000 \\
0.756 \\
\end{array}$ & $\begin{array}{l}3.000 \\
0.707 \\
\end{array}$ & $\begin{array}{l}2.750 \\
0.500 \\
\end{array}$ & $\begin{array}{l}3.800 \\
0.4+7 \\
\end{array}$ & $\begin{array}{l}3.667 \\
1.033 \\
\end{array}$ & $\begin{array}{l}3.600 \\
1.265 \\
\end{array}$ & $\begin{array}{l}2.8001 \\
0.837 \\
\end{array}$ & $\begin{array}{l}.333 \\
0.816 \\
\end{array}$ & $\begin{array}{l}4.000 \\
1.155\end{array}$ & $\begin{array}{l}3.727 \\
0.905 \\
\end{array}$ & $\begin{array}{l}7.143 \\
0.910\end{array}$ & $\begin{array}{l}3.420 \\
1.272 \\
\end{array}$ & $\begin{array}{l}2.0000 \\
1.000 \\
\end{array}$ & $\begin{array}{l}3.500 \\
1.915 \\
\end{array}$ & $\begin{array}{l}3.6+4 \\
1.054 \\
\end{array}$ & 0297 \\
\hline 4 & $\begin{array}{l}\text { Mean } \\
\text { SI) }\end{array}$ & $\begin{array}{l}4.400 \\
0.548 \\
\end{array}$ & $\begin{array}{l}3.333 \\
1.155 \\
\end{array}$ & $\begin{array}{l}4.400 \\
0.548 \\
\end{array}$ & $\begin{array}{l}3.500 \\
1.414 \\
\end{array}$ & $\begin{array}{l}.200 \\
1.304 \\
\end{array}$ & $\begin{array}{l}2.750 \\
1.258 \\
\end{array}$ & $\begin{array}{l}3.200 \\
1.643 \\
\end{array}$ & $\begin{array}{l}3.500 \\
1.378 \\
\end{array}$ & $\begin{array}{l}.500 \\
1.354 \\
\end{array}$ & $\begin{array}{l}3.8010 \\
0.837 \\
\end{array}$ & $\begin{array}{l}4.500 \\
0.5+8 \\
\end{array}$ & $\begin{array}{l}+1.143 \\
0.900 \\
\end{array}$ & $\begin{array}{l}2.636 \\
1.286 \\
\end{array}$ & $\begin{array}{l}3.714 \\
1.380 \\
\end{array}$ & $\begin{array}{l}.429 \\
1.813 \\
\end{array}$ & $\begin{array}{l}.0001 \\
1.732 \\
\end{array}$ & $\begin{array}{l}.000 \\
1.633 \\
\end{array}$ & $\begin{array}{l}3.574 \\
1.306 \\
\end{array}$ & .2622 \\
\hline 5 & $\begin{array}{c}\text { Mean } \\
\text { SD }\end{array}$ & $\begin{array}{l}4.000 \\
1.225 \\
\end{array}$ & $\begin{array}{c}+.000 \\
0 \\
\end{array}$ & $\begin{array}{l}4.200 \\
0.447 \\
\end{array}$ & $\begin{array}{l}3.750 \\
0.886 \\
\end{array}$ & $\begin{array}{l}.600 \\
0.894 \\
\end{array}$ & $\begin{array}{l}.750 \\
0.957 \\
\end{array}$ & $\begin{array}{l}3.600 \\
1.517 \\
\end{array}$ & $\begin{array}{l}.667 \\
0.516 \\
\end{array}$ & $\begin{array}{l}3.700 \\
1.567 \\
\end{array}$ & $\begin{array}{l}+.200 \\
0.837 \\
\end{array}$ & $\begin{array}{l}+333 \\
0.816 \\
\end{array}$ & $\begin{array}{l}3.857 \\
1.464 \\
\end{array}$ & $\begin{array}{l}.727 \\
1.272 \\
\end{array}$ & $\begin{array}{l}3.625 \\
0.916 \\
\end{array}$ & $\begin{array}{l}.571 \\
1.397 \\
\end{array}$ & $\begin{array}{l}.333 \\
0.577 \\
\end{array}$ & $\begin{array}{l}1.250 \\
0.957 \\
\end{array}$ & $\begin{array}{l}3.784 \\
1.087 \\
\end{array}$ & 8716 \\
\hline 6 & $\begin{array}{c}\text { Mean } \\
\text { SD }\end{array}$ & $\begin{array}{l}3.600 \\
1.3+2 \\
\end{array}$ & $\begin{array}{l}2.667 \\
0.577 \\
\end{array}$ & $\begin{array}{l}3.800 \\
1.095 \\
\end{array}$ & $\begin{array}{l}4.125 \\
0.991 \\
\end{array}$ & $\begin{array}{l}.200 \\
1.304 \\
\end{array}$ & $\begin{array}{l}2.750 \\
0.957 \\
\end{array}$ & $\begin{array}{l}2.800 \\
1.095 \\
\end{array}$ & $\begin{array}{l}2.167 \\
1.169 \\
\end{array}$ & $\begin{array}{l}4.400 \\
0.843 \\
\end{array}$ & $\begin{array}{l}3.000 \\
1.225 \\
\end{array}$ & $\begin{array}{r}3.667 \\
0.816 \\
\end{array}$ & $\begin{array}{l}3.000 \\
1.5+1) \\
\end{array}$ & $\begin{array}{l}3.818 \\
1.328 \\
\end{array}$ & $\begin{array}{l}7.286 \\
0.488 \\
\end{array}$ & $\begin{array}{l}3.286 \\
1.113 \\
\end{array}$ & $\begin{array}{l}3.000 \\
1.732 \\
\end{array}$ & $\begin{array}{l}+.250 \\
0.957 \\
\end{array}$ & $\begin{array}{l}3.520 \\
1.210 \\
\end{array}$ & .0178 \\
\hline $7 a$ & $\begin{array}{c}\text { Mean } \\
\text { SD }\end{array}$ & $\begin{array}{l}2.800 \\
1.643 \\
\end{array}$ & $\begin{array}{l}4.000 \\
1.000\end{array}$ & $\begin{array}{l}3.400 \\
1.140 \\
\end{array}$ & $\begin{array}{l}1.571 \\
0.787 \\
\end{array}$ & $\begin{array}{l}2.800 \\
1.304 \\
\end{array}$ & $\begin{array}{l}2.750 \\
2.062 \\
\end{array}$ & $\begin{array}{l}1.200 \\
0.4+7 \\
\end{array}$ & $\begin{array}{r}3.333 \\
0.816 \\
\end{array}$ & $\begin{array}{l}4.000 \\
1.155 \\
\end{array}$ & $\begin{array}{l}3.250 \\
1.258 \\
\end{array}$ & $\begin{array}{l}2.833 \\
1+72 \\
\end{array}$ & $\begin{array}{l}.714 \\
0.488 \\
\end{array}$ & $\begin{array}{l}3.091 \\
1.578 \\
\end{array}$ & $\begin{array}{l}2.375 \\
1.408 \\
\end{array}$ & $\begin{array}{l}3.714 \\
1.113 \\
\end{array}$ & $\begin{array}{l}3.000 \\
1.000 \\
\end{array}$ & $\begin{array}{l}.0000 \\
0.816 \\
\end{array}$ & $\begin{array}{l}3.050 \\
1.366 \\
\end{array}$ & .0036 \\
\hline $7 b$ & $\begin{array}{l}\text { Mean } \\
\text { SD }\end{array}$ & $\begin{array}{l}3.000 \\
1.826\end{array}$ & $\begin{array}{l}3.333 \\
0.577\end{array}$ & $\begin{array}{l}3.400 \\
1.140\end{array}$ & $\begin{array}{l}2.571 \\
1.272\end{array}$ & $\begin{array}{l}3.0100 \\
1.225\end{array}$ & $\begin{array}{l}2.500 \\
1.291\end{array}$ & $\begin{array}{l}1.600 \\
0.894\end{array}$ & $\begin{array}{l}3.667 \\
0.516\end{array}$ & $\begin{array}{l}4.143 \\
1.215\end{array}$ & $\begin{array}{l}3.250 \\
1.258\end{array}$ & $\begin{array}{l}3.333 \\
1.211 \\
\end{array}$ & $\begin{array}{l}3.714 \\
1.254\end{array}$ & $\begin{array}{l}3.364 \\
1.502 \\
\end{array}$ & $\begin{array}{l}2.857 \\
1.464 \\
\end{array}$ & $\begin{array}{l}3.857 \\
1.215 \\
\end{array}$ & $\begin{array}{l}3.000 \\
1.000 \\
\end{array}$ & $\begin{array}{l}4.250 \\
0.957 \\
\end{array}$ & $\begin{array}{l}3.263 \\
1.290 \\
\end{array}$ & 1397 \\
\hline $8 u$ & $\begin{array}{l}\text { Mean } \\
\text { SD }\end{array}$ & $\begin{array}{l}1.750 \\
0.957\end{array}$ & $\begin{array}{l}3.000 \\
2.828\end{array}$ & $\begin{array}{l}1.750 \\
0.500\end{array}$ & $\begin{array}{l}2.875 \\
1.808\end{array}$ & $\begin{array}{l}4.500 \\
0.577\end{array}$ & $\begin{array}{l}1.250 \\
0.500\end{array}$ & $\begin{array}{l}3.400 \\
1.517\end{array}$ & $\begin{array}{l}2.333 \\
1.506\end{array}$ & $\begin{array}{l}2.5(1) 1 \\
1.512\end{array}$ & $\begin{array}{l}3.4(101 \\
0.894\end{array}$ & $\begin{array}{l}3.2001 \\
1.304\end{array}$ & $\begin{array}{l}3.1+3 \\
1.773\end{array}$ & $\begin{array}{l}3.5(1) \\
1.261)\end{array}$ & $\begin{array}{l}2.714 \\
1.796\end{array}$ & $\begin{array}{l}2.286 \\
1.890\end{array}$ & $\begin{array}{l}2.333 \\
1.528\end{array}$ & $\begin{array}{l}2.000 \\
1.732\end{array}$ & $\begin{array}{l}2.772 \\
1.513\end{array}$ & 1887 \\
\hline $8 \mathrm{~b}$ & $\begin{array}{c}\text { Mean } \\
\text { SD }\end{array}$ & $\begin{array}{r}3.000 \\
2.309 \\
\end{array}$ & $\begin{array}{c}5.000 \\
0 \\
\end{array}$ & $\begin{array}{l}4.200 \\
0.837 \\
\end{array}$ & $\begin{array}{l}3.500 \\
1.069 \\
\end{array}$ & $\begin{array}{l}2.800 \\
1.483 \\
\end{array}$ & $\begin{array}{l}3.750 \\
1.893 \\
\end{array}$ & $\begin{array}{l}3.750 \\
1.500 \\
\end{array}$ & $\begin{array}{l}3.833 \\
1.835 \\
\end{array}$ & $\begin{array}{r}2.889 \\
1.453 \\
\end{array}$ & $\begin{array}{l}3.800 \\
1.0055 \\
\end{array}$ & $\begin{array}{l}3.833 \\
0.753 \\
\end{array}$ & $\begin{array}{l}3.286 \\
1.6144 \\
\end{array}$ & $\begin{array}{l}3.222 \\
1.716 \\
\end{array}$ & $\begin{array}{l}3.750 \\
1.389 \\
\end{array}$ & $\begin{array}{l}3.667 \\
1.506 \\
\end{array}$ & $\begin{array}{r}2.667 \\
2.082 \\
\end{array}$ & $\begin{array}{l}3.750 \\
1.893 \\
\end{array}$ & $\begin{array}{l}3.521 \\
1.451 \\
\end{array}$ & .8597 \\
\hline the & ( & 0 & 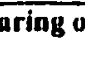 & $\mathrm{p}_{0}$ & & & & & & & & & & & & & & & & \\
\hline 22 & $\begin{array}{c}\text { Mean } \\
\text { SD }\end{array}$ & $\begin{array}{l}3.000 \\
1.000 \\
\end{array}$ & $\begin{array}{l}3.000 \\
1.414 \\
\end{array}$ & $\begin{array}{l}3.400 \\
1.140 \\
\end{array}$ & $\begin{array}{l}3.000 \\
1.265\end{array}$ & $\begin{array}{l}3.400 \\
1.140\end{array}$ & $\begin{array}{l}3.500 \\
0.577 \\
\end{array}$ & $\begin{array}{l}3.8001 \\
0.837\end{array}$ & $\begin{array}{l}3.167 \\
1.835 \\
\end{array}$ & $\begin{array}{l}3.300 \\
1.059\end{array}$ & $\begin{array}{l}3.200 \\
0.837\end{array}$ & $\begin{array}{l}+000 \\
1.225 \\
\end{array}$ & $\begin{array}{l}2.857 \\
1.345 \\
\end{array}$ & $\begin{array}{l}3.000 \\
1 .+(9) \\
\end{array}$ & $\begin{array}{l}3.429 \\
1.272 \\
\end{array}$ & $\begin{array}{l}2.1+3 \\
1 .(161)\end{array}$ & $\begin{array}{l}2.667 \\
0577\end{array}$ & $\begin{array}{l}2.750 \\
1.258 \\
\end{array}$ & $\begin{array}{l}3.146 \\
1.187\end{array}$ & .7593 \\
\hline
\end{tabular}




\begin{tabular}{|c|c|c|c|c|c|c|c|c|c|c|c|c|c|c|c|c|c|c|c|c|}
\hline \multicolumn{21}{|c|}{ Board Financial Matters: Effectiveness of the Shared Decision-Making Process } \\
\hline \multirow[t]{2}{*}{24} & Mean & 2.750 & 3.667 & 3.800 & +.125 & 2.600 & 3.250 & 3.600 & 3.167 & 3.400 & $3 .+1010$ & 4.500 & 4.286 & 3.455 & 4.000 & 3.571 & 3.333 & 3.250 & 3.594 & 4062 \\
\hline & SD & 0.500 & 1.528 & 0.447 & 0.835 & 1.140 & 0.957 & 0.894 & 1.722 & 1.350 & $1.3+2$ & 0.837 & 1.254 & 1.293 & 0.535 & 0.976 & 1.155 & 2.0162 & 1.168 & \\
\hline \multirow[t]{2}{*}{25} & Mean & 4.500 & 4.1000 & 4.200 & 4.625 & 3.000 & 3.000 & 5.000 & 4.500 & 4300 & 3.800 & 1.667 & $4.71 \mathrm{t}$ & +1000 & 4.125 & 4.143 & 4.333 & 3.0010 & 1.200 & .0161 \\
\hline & SD & 0.577 & 1.000 & 0.837 & 0.744 & $1.3+2$ & 0.816 & 0 & 0.837 & 1.059 & 1.095 & 0.516 & 0.488 & $0.9+3$ & 0.354 & 0.690 & 0.577 & $1 .+14$ & 0.910 & \\
\hline \multirow[t]{2}{*}{26} & Mean & 4.500 & 3.333 & 4.000 & 4.625 & 3.600 & 3.250 & 3.600 & 4.167 & 4.100 & $3 .+100$ & 4.667 & 3.833 & $7.14 t$ & 3.750 & 3.857 & 3.667 & 2.500 & 3.938 & .0124 \\
\hline & SD & 0.577 & 0.577 & 0 & 0.518 & 0.894 & 0.5001 & 1.140 & 1.6012 & 0.876 & $1.1+0$ & 0.516 & 0.983 & 0.527 & 0.463 & 0.690 & 1.528 & 1.000 & 0.938 & \\
\hline \multirow[t]{2}{*}{30} & Mean & 4.000 & 2.667 & 4.000 & 4.000 & 3.800 & 3.500 & 4.800 & 4.333 & +300 & $3.6011)$ & 4.333 & 7.429 & $f(1) 1$ & 3.750 & 3.286 & +667 & 4.250 & 1.020 & .5624 \\
\hline & $\mathrm{SD}$ & 2.000 & 1.528 & 1.225 & 1.309 & 1.643 & 1.291 & 0.447 & 1.211 & $0.9+19$ & 1.673 & 0.516 & 0.787 & $1.04 t$ & 1.165 & 1.113 & 0.577 & 0.957 & 1.157 & \\
\hline \multirow[t]{2}{*}{31} & Aicurn & 4.800 & 4.333 & 4.400 & 3.750 & 3.200 & 3.000 & 3.800 & 4.500 & +200 & 3.600 & 3.333 & 3.333 & 7.091 & 2.875 & 3.143 & 7.000 & $3.750)$ & 3.762 & .1219 \\
\hline & ii & 0.447 & 0.577 & $0.5+8$ & 1.389 & 0.837 & 0.816 & 0.837 & 1.225 & 0.632 & $1.1+0$ & 1.211 & 1.506 & $1.0+4$ & 1.553 & 1.345 & 1.732 & 0.957 & 1.167 & \\
\hline \multirow[t]{2}{*}{32} & Mean & 4.400 & 4.333 & 4.400 & 4.125 & 3.000 & 2.500 & 4.200 & 4.333 & 4.500 & 3.000 & 3.000 & $3 .+29$ & 1.18? & 3.000 & 3.286 & 4.333 & 3.250 & 3.755 & 0011 \\
\hline & SD & 0.548 & 0.577 & 0.548 & 0.835 & 1.000 & 0.577 & 1.095 & 0.816 & 0.527 & 1.090 & 0.894 & 1.397 & 0.874 & 1.414 & 1.113 & 0.577 & 1.258 & 1.085 & \\
\hline \multicolumn{21}{|c|}{ Buard Lahour Relations Matters: Efrectiveness of the Shared Decision-Muking Process } \\
\hline \multirow[t]{2}{*}{36} & Mean & 3.800 & 3.5001 & 2.20010 & 2.750 & 2.600 & 2.000 & 3.400 & 3.000 & 2.900 & 3.6010 & 4.333 & 2.143 & 2.636 & 3.143 & 3.286 & 3.000 & 3.000 & 2.980 & 0261 \\
\hline & SD & 0.837 & 0.707 & 0.837 & 0.886 & $0.5+8$ & 0.816 & (1).894 & 0.894 & 1.197 & 0. $5+8$ & 0.516 & 1.215 & 1.286 & 0.960 & 1.113 & 1.732 & $1 .+14$ & 1.101 & \\
\hline \multirow[t]{2}{*}{37} & Mcian & 4.600 & 4.000 & 4.200 & 4.250 & 3.400 & 3.750 & 4.600 & 4.333 & +100 & 1.400 & +501 & $4.1+3$ & 3.727 & 4.125 & 3.571 & 4.333 & 3.000 & 4.050 & 0998 \\
\hline & SD & 0.548 & 0 & 0.447 & 0.707 & 0.548 & 0.500 & 0.548 & 0.816 & 0.876 & $0.5+8$ & 0.548 & 0.690 & 0.905 & 0.835 & 0.976 & 0.577 & 1.826 & 0.830 & \\
\hline \multirow[t]{2}{*}{38} & Mean & 2.000 & 2.333 & 3.000 & 2.750 & 2.800 & 2.750 & 2.000 & 2.167 & 2.700 & 2.2010 & 1.667 & $1.71 \mathrm{t}$ & 2.600 & 2.125 & 2.429 & 1.000 & 2.000 & 2.307 & .1718 \\
\hline & SD & 0.707 & 0.577 & 1.581 & 1.488 & 0.837 & 0.957 & 1.000 & 1.472 & $1.4 y_{4}$ & $0 .+47$ & 0.816 & 1.113 & 1.174 & 0.991 & 0.787 & 0 & 1155 & 1.129 & \\
\hline \multirow[t]{2}{*}{39} & Mean & 3.000 & 4.000 & 3.250 & 3.125 & 3.200 & 3.667 & 2.600 & 3.500 & 2.900 & 2.600 & 2.833 & 2.571 & 3.667 & 3.375 & 3.000 & 1.333 & 2.667 & 3.052 & .2255 \\
\hline & SD & 1.000 & 0 & 0.957 & 1.126 & 0.837 & 1.528 & 1.140 & 0.837 & 1.101 & 0.894 & 1.722 & 0.976 & 0.866 & 1.061 & 0.816 & 0.577 & 1.528 & 1.084 & \\
\hline \multirow[t]{2}{*}{40} & Mean & 2.400 & 3.333 & 2.800 & 2.875 & 2.800 & 3.000 & 2.200 & 2.667 & 3.000 & 2.600 & 2.500 & $2.1+3$ & 3.222 & 2.571 & 3.143 & 1.333 & 3.000 & 2.724 & .6185 \\
\hline & SD & 0.548 & 0.577 & 0.837 & 1.126 & 0.837 & 1.155 & 1.095 & 1.366 & 1.333 & 0.894 & 1.378 & 1.069 & 1.302 & 0.787 & 0.690 & 0.577 & 2.0000 & 1.091 & \\
\hline \multicolumn{21}{|c|}{ General Matiers of Bourd Business: How Conflict of Interest has been Addressed } \\
\hline \multirow[t]{2}{*}{16} & Mean & 4.600 & 4.0100 & 3.750 & 4.000 & 3.200 & 4.750 & $5.000)$ & 4.167 & $3.910)$ & 3.40010 & 3.833 & 3.857 & +273 & 4.875 & 4.857 & 5.000 & 3.750 & 4.188 & .3968 \\
\hline & SI) & $0.5+8$ & 1.000 & 1.8013 & 1.414 & 1.643 & 0.500 & & $1.16,4$ & 1.063 & 0.8104 & 1.835 & 1.345 & 1.272 & 11.35 .4 & 0.178 & $1)$ & 1.843 & $1.25 j$ & \\
\hline
\end{tabular}




\begin{tabular}{|c|c|c|c|c|c|c|c|c|c|c|c|c|c|c|c|c|c|c|c|c|}
\hline 17 & Mean & 1.400 & 1.667 & 2.000 & 2.125 & 2.800 & 1000 & 1.400 & 1.667 & 2.100 & 2.410 & 2.5010 & 1.714 & 1.545 & 1.125 & 1.000 & 1.333 & 2.01010 & 1.755 & (1) 39 \\
\hline & SI) & 0.548 & 1.155 & 1.225 & $1.6+2$ & 1.643 & & 0.548 & 1.033 & 1.063 & 1.140 & 1.043 & $1 .+1 \% 6$ & 1.214 & 0.354 & 0 & 0.577 & & 1.278 & \\
\hline \multirow[t]{2}{*}{18} & Mean & 3.800 & 3.333 & 3.200 & 4.500 & 3.600 & 4.750 & 4.410 & 3.500 & 3.01010 & 2.800 & 3.333 & 3.714 & 3.182 & 4.000 & 3.421 & 5.000 & 2.0010 & 3.578 & 3965 \\
\hline & SD & $1.6+3$ & 0.577 & $1.6+3$ & 1.069 & 1.949 & 0.500 & $1.3+2$ & 1.975 & $1.94 \mathrm{t}$ & 1.304 & 1.366 & $1.60 t$ & 1.834 & 1.309 & 1.718 & 0 & 2.000 & 1.595 & \\
\hline \multirow[t]{2}{*}{19} & Mean & 2.600 & 2.333 & 2.800 & 1.571 & 2.400 & 1.250 & 1.000 & 2.500 & 3.000 & 3.200 & 3.667 & 2.714 & 2.636 & 2.000 & 2.429 & 1.333 & 4.000 & 2.485 & 1897 \\
\hline & SD & 1.517 & 1.155 & 1.643 & 1.134 & 1.949 & 0.500 & 0 & 1.975 & $1.76+$ & 1.304 & 1.506 & 1.890 & 1.690 & 1.309 & 1.8 & 0.577 & 2.000 & 1.610 & \\
\hline \multirow[t]{2}{*}{20} & Mean & 4.400 & 4.000 & 3.800 & 4.375 & 3.800 & 3.500 & $4.600^{\circ}$ & 3.667 & $4.2010^{\circ}$ & 3.600 & $\$ 833^{\circ}$ & $4.429^{\circ}$ & $2.091^{\circ}$ & 4.500 & 3.571 & 4.333 & 2500 & 3.853 & 0001 \\
\hline & SD & 0.548 & $\mathbf{0}$ & 1.095 & 1.061 & 0.837 & 0.577 & 0.548 & 1.366 & $0 .+22$ & $0.5+8$ & 0.408 & 0.535 & 1.044 & 0.535 & 0.976 & 0.577 & 0.577 & 1.075 & \\
\hline \multirow[t]{2}{*}{21} & Mean & 3.200 & 3.000 & 3.600 & $\begin{array}{r}4.229 \\
\quad\end{array}$ & 3.800 & $\$ .250$ & 4.400 & 3.833 & 2.900 & 3.400 & $4.833^{\circ}$ & 3.500 & $1.800^{\circ}$ & 4.375 & & 3.000 & 1.500 & 3.424 & \\
\hline & SD & 1.304 & 1.000 & 1.517 & 1.134 & 0.837 & 0.957 & 0.894 & 1.169 & 1.370 & $0.8^{(9)+4}$ & 0.408 & $1.0+4$ & 1.033 & 0.518 & 1.215 & 1.732 & 0.577 & $1.3+8$ & \\
\hline
\end{tabular}
Board Financial Matters: How Conflict of Interest has been Addressed

\begin{tabular}{|c|c|c|c|c|c|c|c|c|c|c|c|c|c|c|c|c|c|c|c|c|}
\hline 27 & $\begin{array}{c}\text { Mean } \\
\text { SD }\end{array}$ & $\begin{array}{l}4.500 \\
0.577\end{array}$ & $\begin{array}{l}3.000 \\
1.000\end{array}$ & $\begin{array}{l}3.600 \\
0.894\end{array}$ & $\begin{array}{l}4.143 \\
0.378\end{array}$ & $\begin{array}{l}3.400 \\
0.548\end{array}$ & $\begin{array}{l}3.000 \\
0.816\end{array}$ & $\begin{array}{l}7.000 \\
1.0000\end{array}$ & $\begin{array}{l}7.000 \\
1.265\end{array}$ & $\begin{array}{l}4.100 \\
0.994\end{array}$ & $\begin{array}{l}3.800 \\
1.005\end{array}$ & $\begin{array}{l}4.667 \\
0.510\end{array}$ & $\begin{array}{l}.333 \\
1.033\end{array}$ & $\begin{array}{l}3.909 \\
1.221\end{array}$ & $\begin{array}{l}4.000 \\
0.535\end{array}$ & $\begin{array}{l}3.667 \\
1.211\end{array}$ & $\begin{array}{l}4.000 \\
1.0000\end{array}$ & $\begin{array}{l}2.333 \\
1.155\end{array}$ & $\begin{array}{l}3.887 \\
0.988\end{array}$ & .1020 \\
\hline 28 & Mean & $\begin{array}{l}3.500 \\
1010\end{array}$ & $\begin{array}{l}3.333 \\
05577\end{array}$ & 3.600 & 4.000 & $2.801)$ & 1.750 & 3.200 & 3.167 & 2.400 & 3.800 & 4.333 & 4.571 & 3.091 & 2.250 & 2.857 & 2.000 & 3.250 & 3.188 & .0075 \\
\hline 29 & $\frac{\text { SD }}{\text { Mean }}$ & $\begin{array}{l}\frac{1.291}{2.000} \\
1 .+14\end{array}$ & $\begin{array}{l}0.577 \\
3.000 \\
1.000\end{array}$ & $\begin{array}{l}0.894 \\
2.800 \\
1.643\end{array}$ & $\begin{array}{l}1.069 \\
2.750 \\
1.165\end{array}$ & $\begin{array}{l}0.837 \\
3.000 \\
1.000\end{array}$ & $\begin{array}{l}1.500 \\
2.500 \\
0.577\end{array}$ & $\begin{array}{l}1.483 \\
2.000 \\
1.000\end{array}$ & $\begin{array}{l}\frac{1.835}{4} \\
1.167 \\
1.329\end{array}$ & $\begin{array}{l}\frac{1.506}{3.000} \\
1.633\end{array}$ & $\begin{array}{l}0.837 \\
2.400 \\
1.140\end{array}$ & $\begin{array}{l}0.816 \\
1.667 \\
0.816\end{array}$ & $\begin{array}{l}0.535 \\
2.333 \\
1.211\end{array}$ & $\begin{array}{l}1.446 \\
2.818 \\
1.250\end{array}$ & $\begin{array}{l}1.282 \\
2.375 \\
1.408\end{array}$ & $\begin{array}{l}1.060 \\
2.000 \\
1.000\end{array}$ & $\begin{array}{l}1.000 \\
3.667 \\
1.528\end{array}$ & $\begin{array}{l}1.708 \\
1.000 \\
2.000\end{array}$ & $\begin{array}{l}1.369 \\
2.810 \\
1.390\end{array}$ & .0225 \\
\hline \multicolumn{21}{|c|}{ Board Labour Relations Matters: How Conflict of Interest has been Addressed } \\
\hline दा & $\begin{array}{c}\text { Mean } \\
\text { SD }\end{array}$ & $\begin{array}{l}4.600 \\
0.548 \\
\end{array}$ & $\begin{array}{l}3.667 \\
0.577 \\
\end{array}$ & $\begin{array}{l}.400 \\
0.894 \\
\end{array}$ & $\begin{array}{l}.571 \\
0.535 \\
\end{array}$ & $\begin{array}{l}3.200 \\
1.095 \\
\end{array}$ & $\begin{array}{l}3.000 \\
0.816 \\
\end{array}$ & $\begin{array}{l}+.400 \\
0.548 \\
\end{array}$ & $\begin{array}{l}3.833 \\
1.169 \\
\end{array}$ & $\begin{array}{l}3.800 \\
1.135 \\
\end{array}$ & $\begin{array}{l}7.100 \\
0.548\end{array}$ & $\begin{array}{l}4.667 \\
0.516 \\
\end{array}$ & $\begin{array}{l}.857 \\
0.378 \\
\end{array}$ & $\begin{array}{l}7.000 \\
1.118 \\
\end{array}$ & $\begin{array}{c}4.1000 \\
0\end{array}$ & $\begin{array}{l}3.714 \\
0.184\end{array}$ & $\begin{array}{l}4.333 \\
0.577 \\
\end{array}$ & $\begin{array}{l}4.000 \\
1.732 \\
\end{array}$ & $\begin{array}{l}4.102 \\
0.891 \\
\end{array}$ & .0182 \\
\hline 42 & $\begin{array}{c}\text { Mean } \\
\text { SD }\end{array}$ & $\begin{array}{l}4.600^{\circ} \\
0.548\end{array}$ & $\begin{array}{c}4.000 \\
0\end{array}$ & $\begin{array}{l}+.200 \\
0.447\end{array}$ & $\begin{array}{l}4.625 \\
0.518\end{array}$ & $\begin{array}{l}3.400 \\
1.140\end{array}$ & $\begin{array}{l}2.750 \\
0.500\end{array}$ & $\begin{array}{l}7.400 \\
0.548\end{array}$ & $\begin{array}{l}+.333 \\
0.816\end{array}$ & $\begin{array}{r}4.300^{\circ} \\
0.823\end{array}$ & $\begin{array}{l}3.600 \\
1.140\end{array}$ & $\begin{array}{l}4.833^{\top} \\
0.408\end{array}$ & $\begin{array}{l}7.429 \\
0.535\end{array}$ & $\begin{array}{l}2.500^{\circ} \\
1.179\end{array}$ & $\begin{array}{l}3.750 \\
0.886\end{array}$ & $\begin{array}{l}4.000 \\
1.000\end{array}$ & $\begin{array}{l}4.333 \\
0.577\end{array}$ & $\begin{array}{l}1.333^{\top} \\
0.577\end{array}$ & $\begin{array}{l}3.900 \\
1.096\end{array}$ & .0001 \\
\hline 43 & $\begin{array}{c}\text { Mean } \\
\text { SD }\end{array}$ & $\begin{array}{l}2.400 \\
1.673\end{array}$ & $\begin{array}{l}4.333 \\
0.577\end{array}$ & $\begin{array}{l}2.400 \\
1.517\end{array}$ & $\begin{array}{l}2.429 \\
1.272\end{array}$ & $\begin{array}{l}2.500 \\
1.000\end{array}$ & $\begin{array}{l}2.000 \\
0.816\end{array}$ & $\begin{array}{l}1.500 \\
1.000\end{array}$ & $\begin{array}{l}4.833 \\
0.408\end{array}$ & $\begin{array}{l}7.800^{\circ} \\
0.422\end{array}$ & $\begin{array}{l}3.000 \\
1.581\end{array}$ & $\begin{array}{l}2.400 \\
1.673\end{array}$ & $\begin{array}{l}1.667 \\
1.211\end{array}$ & $\begin{array}{l}1.429^{\circ} \\
0.535\end{array}$ & $\begin{array}{l}2 .+29 \\
1.272\end{array}$ & $\begin{array}{l}2.667 \\
1.633\end{array}$ & $\begin{array}{l}1.667 \\
1.155\end{array}$ & $\begin{array}{l}2.500 \\
2.121\end{array}$ & $\begin{array}{l}2.753 \\
1.554\end{array}$ & $.0001^{\circ}$ \\
\hline
\end{tabular}




\begin{tabular}{|c|c|c|c|c|c|c|c|c|c|c|c|c|c|c|c|c|c|c|c|c|c|c|}
\hline 46 & $\begin{array}{l}\text { Mean } \\
\text { SI) }\end{array}$ & $\begin{array}{l}3.800 \\
1.643\end{array}$ & $\begin{array}{l}2.667 \\
0.577\end{array}$ & $\begin{array}{l}3.200 \\
1.643\end{array}$ & $\begin{array}{l}2.875 \\
1.553\end{array}$ & $\begin{array}{l}3.200 \\
1.304\end{array}$ & $\begin{array}{l}2.000 \\
1.414\end{array}$ & $\begin{array}{l}3.000 \\
1.581\end{array}$ & $\begin{array}{l}3.667 \\
1.506\end{array}$ & $\begin{array}{l}3.200 \\
1.687\end{array}$ & $\begin{array}{l}2.600 \\
1.517\end{array}$ & $\begin{array}{l}1.833 \\
0.753\end{array}$ & $\begin{array}{l}3.429 \\
1.988\end{array}$ & $\begin{array}{l}+.305 \\
1.055\end{array}$ & $\begin{array}{l}3.00 \\
1.51\end{array}$ & & $\begin{array}{l}571 \\
.512\end{array}$ & $\begin{array}{l}3.66 \\
1.52\end{array}$ & & $\begin{array}{l}2.750 \\
2.062\end{array}$ & $\begin{array}{l}3.109 \\
1.523\end{array}$ & .37 \\
\hline
\end{tabular}

Notes:

1. Statements from the survey questionnaire (see Appendix B)

2. Level of Significance.

3. Standard Deviation from the Mean.

t. $1=$ strongly disagree; $2=$ disagree; $3=$ neutral; $t=$ agree; $j=$ strongly agree.

;) Indicales significani difference at the 0.5 contidence level.

- Indicales where Schelfie post hoc test has revealed signiticant difference at the 0.5 contidence level between pair(s) uf colleges. 
Summary of the Assessment of Own Boards' Effectiveness

in Aspects of Leadership, hy College (A II Q)

\begin{tabular}{|c|c|c|c|c|c|c|c|c|c|c|c|c|c|c|c|c|c|c|c|c|}
\hline \multicolumn{21}{|c|}{ Slauring of l'ower } \\
\hline Statement' & Valuce & A & B & $C$ & I) & $E$ & $F$ & (i & II & 1 & .1 & h' & I. & M & $N$ & (1) & 1 & $Q$ & Tintal & $p^{\prime}$ \\
\hline \multirow[t]{2}{*}{$47 a$} & Mean' & 4400 & 4.000 & 3.800 & 4.500 & 3.600 & 3.500 & 4.800 & 9.167 & 3.500 & 4.000 & 4.500 & $4 .+29$ & 3.800 & 4.125 & 3.143 & 2.667 & 2.750 & $3 . \overline{911}$ & .0008 \\
\hline & $S D^{\prime}$ & 0.548 & 0 & 0.447 & 0.535 & 1.140 & 0.577 & 0.447 & 0.753 & 0.850 & 0.707 & 0.8 .37 & 1.1 .34 & 0.919 & 0.354 & 0.000 & 1.528 & 0.957 & 0.918 & \\
\hline \multirow[t]{2}{*}{$47 b$} & Mean & 4.200 & 4.000 & 3.800 & 4.250 & 3.000 & 2.500 & 4.200 & 3.000 & 3.300 & 3.200 & 3.833 & 3.714 & 3.600 & 3.500 & 2.714 & 2.667 & 2.500 & 3455 & .1677 \\
\hline & SI & 0447 & 0 & 1.095 & 0.707 & 0.707 & 1.000 & 1.095 & 0.894 & 1.252 & 1.304 & 1.602 & 1.380 & 1.265 & 0.756 & 1.604 & 1.528 & 1.291 & 1.188 & \\
\hline \multirow[t]{2}{*}{$47 c$} & Mcan & 3.600 & 3.333 & 3.600 & 4.000 & $\overline{3.200}$ & 2.750 & 4.400 & 2.833 & 2.800 & 3.000 & 3.333 & 2.857 & 3.556 & 3.875 & $\overline{3.286}$ & 2.333 & 2.250 & 3.290 & .0639 \\
\hline & SI) & $(1.5+k$ & 0.577 & 0.548 & 0.535 & 0.837 & 0.957 & $0.89 \mathrm{~d}$ & 0.753 & 1.135 & 0.707 & 1.633 & 1.34 .5 & 0.882 & 0.83 .5 & 1.254 & 1.528 & 1.500 & 1.076 & \\
\hline \multirow[t]{2}{*}{$47 d$} & Meall & 3.400 & 3.333 & 3.400 & 3.875 & 3.200 & 2.750 & 4.000 & 2.83 .3 & 3.100 & 3.800 & 3.667 & 3.286 & 3.400 & 4.000 & 3.143 & 3.333 & 3.250 & 3.416 & .7170 \\
\hline & SD & 0.548 & 0.577 & 0.894 & 0.991 & 0.837 & 0.500 & 0.707 & 0.983 & 1.197 & 0.447 & 1.633 & 1.380 & 1.174 & 0.535 & 0.900 & 2.082 & 0.500 & 1.013 & \\
\hline \multirow[t]{2}{*}{$47 \mathrm{c}$} & Mean & 3.400 & $\overline{3.333}$ & 3.200 & 3.875 & 3.000 & 3.000 & 4.000 & 3.167 & 3.600 & $3.600)$ & 3.167 & 2.714 & 3.333 & 3.750 & 3.143 & 4.667 & 3.000 & 3400 & .3977 \\
\hline & SD & 0.894 & 0.577 & 0.837 & 1.246 & 0.707 & 0.816 & 0.707 & 1.472 & 0.966 & 0.548 & 1.169 & 1.380 & 1.000 & 0.886 & 0.900 & 0.577 & 0 & 0.995 & \\
\hline \multicolumn{21}{|c|}{ Effectiveness of the Shared Decision-Making Prucess } \\
\hline \multirow[t]{2}{*}{$48 a$} & Mean & +.600 & 2.667 & 3.800 & 4.500 & 3.800 & 3.250 & 4.600 & 3.833 & 3.600 & 3.6110 & 4.600 & 4.714 & 3.200 & 4.125 & $3.5(10)$ & 4.333 & 2.500 & 3.869 & .0005 \\
\hline & SD & 0.894 & 1.155 & 1.095 & 0.535 & 0.837 & 1.500 & 0.548 & .0753 & 0.699 & 1.140 & 0.548 & 0.488 & 1.033 & 0.641 & 1.049 & 0.577 & 1.291 & 1.007 & \\
\hline \multirow[t]{2}{*}{$48 \mathrm{~b}$} & Mean & +800 & 3.000 & 3.800 & 4.250 & 4.000 & 3.500 & 4.400 & 3.833 & 3.8010 & 3.800 & 4.400 & 4.837 & 3.800 & 4.125 & 3.500 & 4.333 & 2.250 & 3.960 & .0022 \\
\hline & SD & 0.447 & 1.732 & 1.095 & 0.463 & 0.707 & 1.291 & 0.894 & 0.983 & 0.632 & 0.837 & 0.548 & 0.378 & 1.135 & 0.354 & 1.049 & 0.577 & 0.957 & 0.947 & \\
\hline \multirow[t]{2}{*}{$48 c$} & Mean & 4.8010 & 3.667 & 4.200 & 4.750 & 4.200 & 3.750 & 4.4100 & 3.8 .33 & 4.2010 & 40010 & $4.6(101)$ & 4.714 & $4.2(10)$ & 3.875 & 3.667 & 4.333 & 3.0100 & 4.172 & .0384 \\
\hline & SI) & 0.447 & 1.528 & 0.447 & 0.463 & 0.837 & 0.957 & 0.894 & 0.4118 & 0.632 & 1.000 & 0.548 & 0.488 & 0919 & 0.901 & 0.516 & 0.577 & 1.414 & 0.833 & \\
\hline \multirow[t]{2}{*}{$48 d$} & Mcan & 3.800 & 3.000 & 3.400 & 3.750 & 3.600 & 3.250 & 3.800 & 3.500 & 3.300 & 3.200 & $3.8 \overline{00}$ & 4.143 & 3.778 & 3.429 & $3 . \overline{333}$ & 3.000 & 2.500 & 3.510 & 4002 \\
\hline & SD & 1.304 & 0 & 0.548 & 0.463 & 0.548 & 1.708 & 1.095 & $1.0+9$ & 1.160 & 0.447 & 0.447 & 0.690 & 0.441 & 0.535 & 0.816 & 1.000 & 0.577 & 0.846 & \\
\hline \multirow[t]{2}{*}{$48 \mathrm{e}$} & Mean & 4.000 & 3.000 & 4.000 & 4.000 & 3.400 & 3.000 & 4.600 & 3667 & 3.700 & 3.201 & $3 .(1001)$ & 4.857 & 3.500 & 4.125 & 3.500 & 4.333 & $4 .(10010$ & 3.825 & .1019 \\
\hline & SD & 0707 & 1.000 & 0.707 & 0.926 & 0.548 & 1.826 & 0.548 & 1.033 & 1.160 & 0.837 & 1.517 & 0.378 & 0.926 & 0.641 & 1.049 & 0.577 & 0.816 & 0.990 & \\
\hline \multirow[t]{2}{*}{$48 \mathrm{f}$} & Mean & 3.200 & 3.333 & 3.400 & 3.500 & 3.800 & 3.250 & 4.400 & 3.500 & 2.700 & 3.600 & 3.800 & 4.000 & 4.000 & 3.875 & 3.333 & 2.667 & 3.750 & 3.546 & .2184 \\
\hline & SD & $0+47$ & 0.577 & 1.140 & 1.195 & 0.447 & 0.957 & 0.548 & 1.049 & 1.059 & 0.894 & 1.643 & 0.816 & 0.926 & 0.835 & 1.033 & 1.155 & 0.500 & 0.990 & \\
\hline
\end{tabular}




\begin{tabular}{|c|c|c|c|c|c|c|c|c|c|c|c|c|c|c|c|c|c|c|c|c|}
\hline $48 g$ & $\begin{array}{l}\text { Mean } \\
\text { SD }\end{array}$ & $\begin{array}{l}4.200 \\
0.837\end{array}$ & $\begin{array}{l}3.667 \\
0.577\end{array}$ & $\begin{array}{l}3.600 \\
0.894\end{array}$ & $\begin{array}{l}4.429 \\
0.787\end{array}$ & $\begin{array}{l}4.000 \\
1.000\end{array}$ & $\begin{array}{l}2.500 \\
1.000\end{array}$ & $\begin{array}{l}4.800 \\
0.447\end{array}$ & $\begin{array}{l}3.000 \\
1.265\end{array}$ & $\begin{array}{l}3.300 \\
0.940\end{array}$ & $\begin{array}{l}3.800 \\
0.837\end{array}$ & $\begin{array}{l}4.800 \\
0+47\end{array}$ & $\begin{array}{l}4.857 \\
0.378\end{array}$ & $\begin{array}{l}3.400 \\
1.26 .5\end{array}$ & $\begin{array}{l}4.0010 \\
0.535\end{array}$ & $\begin{array}{l}3.000 \\
0632\end{array}$ & $\begin{array}{l}3.0000 \\
1.732\end{array}$ & $\begin{array}{l}2.000 \\
11.816\end{array}$ & $\begin{array}{l}3.714 \\
1.112\end{array}$ & .0001 \\
\hline $48 \mathrm{~h}$ & $\begin{array}{l}\text { Mean } \\
\text { SD }\end{array}$ & $\begin{array}{l}3.500 \\
0.577 \\
\end{array}$ & $\begin{array}{l}3.667 \\
0.577 \\
\end{array}$ & $\begin{array}{l}3.600 \\
1.140\end{array}$ & $\begin{array}{l}4.286 \\
0.756\end{array}$ & $\begin{array}{l}2.800 \\
0.447\end{array}$ & $\begin{array}{l}3.5(10 \\
1.291\end{array}$ & $\begin{array}{l}3.000 \\
1.581\end{array}$ & $\begin{array}{l}3.833 \\
0.983 \\
\end{array}$ & $\begin{array}{l}3.100 \\
0.994\end{array}$ & $\begin{array}{l}3.000 \\
1.000\end{array}$ & $\begin{array}{l}4.0011 \\
1.225\end{array}$ & $\begin{array}{l}3.286 \\
1.113\end{array}$ & $\begin{array}{l}2.667 \\
0.707\end{array}$ & $\begin{array}{l}3.125 \\
1.126\end{array}$ & $\begin{array}{l}3.500 \\
0.837\end{array}$ & $\begin{array}{l}4.333 \\
0.577\end{array}$ & $\begin{array}{l}2.500 \\
1.000\end{array}$ & $\begin{array}{l}3.344 \\
1.034\end{array}$ & .1015 \\
\hline \multicolumn{21}{|c|}{ How Conflict of Interest has been Addressed } \\
\hline $49 a$ & $\begin{array}{l}\text { Mean } \\
\text { SD }\end{array}$ & $\begin{array}{c}5.000 \\
0\end{array}$ & $\begin{array}{l}2.667 \\
1.155 \\
\end{array}$ & $\begin{array}{l}4.400^{\circ} \\
0.548\end{array}$ & $\begin{array}{l}4.500^{\circ} \\
0.756\end{array}$ & $\begin{array}{l}4.200^{\circ} \\
0.837\end{array}$ & $\begin{array}{l}3.500 \\
0.577\end{array}$ & $\begin{array}{l}4.400^{\circ} \\
0.894\end{array}$ & $\begin{array}{l}3.833 \\
1.169\end{array}$ & $\begin{array}{l}4.0000^{\circ} \\
0.243\end{array}$ & $\begin{array}{l}4.400^{\circ} \\
0.548\end{array}$ & $\begin{array}{l}4.400^{\circ} \\
0.548\end{array}$ & $\begin{array}{l}4.71 t^{\circ} \\
0.756\end{array}$ & $\begin{array}{l}1.667^{\circ} \\
0.866\end{array}$ & $\begin{array}{l}7.375^{\circ} \\
0.518\end{array}$ & $\begin{array}{l}3.857^{\circ} \\
0.900\end{array}$ & $\begin{array}{l}4.333 \\
0.577\end{array}$ & $\begin{array}{l}1.750^{\circ} \\
0.057\end{array}$ & $\begin{array}{l}3.889 \\
1.203\end{array}$ & .0001 \\
\hline $49 b$ & $\begin{array}{l}\text { Mean } \\
\text { SI) }\end{array}$ & $\begin{array}{l}3.800 \\
0.447\end{array}$ & $\begin{array}{l}3.333 \\
1.155\end{array}$ & $\begin{array}{l}4000 \\
0.707\end{array}$ & $\begin{array}{l}3.625 \\
1.302\end{array}$ & $\begin{array}{l}3.000 \\
0.707\end{array}$ & $\begin{array}{l}3.250 \\
1.7018\end{array}$ & $\begin{array}{l}4.000 \\
0.707\end{array}$ & $\begin{array}{l}3.167 \\
0.753\end{array}$ & $\begin{array}{l}3.667 \\
1.225\end{array}$ & $\begin{array}{l}3.8016 \\
0.837\end{array}$ & $\begin{array}{l}3.4001 \\
1.517\end{array}$ & $\begin{array}{l}3.714 \\
1604\end{array}$ & $\begin{array}{l}3.778 \\
1202\end{array}$ & $\begin{array}{l}3.875 \\
0.835\end{array}$ & $\begin{array}{l}2.424 \\
0.787\end{array}$ & $\begin{array}{l}3.000 \\
2.00100\end{array}$ & $\begin{array}{l}3.0000 \\
1 .+14\end{array}$ & $\begin{array}{l}3.501 \\
1.131\end{array}$ & .6203 \\
\hline $49 \mathrm{c}$ & $\begin{array}{l}\text { Mean } \\
\text { SD }\end{array}$ & $\begin{array}{r}4.400 \\
0.548 \\
\end{array}$ & $\begin{array}{r}4.333 \\
0.577 \\
\end{array}$ & $\begin{array}{l}3.800 \\
0.837 \\
\end{array}$ & $\begin{array}{l}4.125 \\
0.835 \\
\end{array}$ & $\begin{array}{l}3.400 \\
0.548 \\
\end{array}$ & $\begin{array}{l}3.250 \\
1.258 \\
\end{array}$ & $\begin{array}{l}3.600 \\
1.342 \\
\end{array}$ & $\begin{array}{l}2.0001 \\
1.0001\end{array}$ & $\begin{array}{l}3.800 \\
1.03 .3 \\
\end{array}$ & $\begin{array}{l}3.600 \\
0.5+8\end{array}$ & $\begin{array}{l}+.200 \\
0.4+7\end{array}$ & $\begin{array}{l}4.143 \\
0.900\end{array}$ & $\begin{array}{l}3.100 \\
1.370\end{array}$ & $\begin{array}{l}3.750 \\
1165 \\
\end{array}$ & $\begin{array}{l}3.500 \\
0.548\end{array}$ & $\begin{array}{l}4.0000 \\
1.000\end{array}$ & $\begin{array}{l}1.500 \\
1.00101\end{array}$ & $\begin{array}{l}3.582 \\
1.121\end{array}$ & .00015 \\
\hline $79 d$ & $\begin{array}{l}\text { Me:an } \\
\text { SI) }\end{array}$ & $\begin{array}{l}2.250 \\
1.893\end{array}$ & $\begin{array}{l}4.000 \\
1.000\end{array}$ & $\begin{array}{l}2.600 \\
1.817\end{array}$ & $\begin{array}{l}2.333 \\
1.211\end{array}$ & $\begin{array}{l}2.800 \\
0.447\end{array}$ & $\begin{array}{l}2.000 \\
1.155\end{array}$ & $\begin{array}{l}1.800 \\
1.095\end{array}$ & $\begin{array}{l}3.667 \\
1.506\end{array}$ & $\begin{array}{l}4.000 \\
0.816\end{array}$ & $\begin{array}{l}3.0010 \\
0.707\end{array}$ & $\begin{array}{l}2.200 \\
0.837\end{array}$ & $\begin{array}{l}1.857 \\
1.574\end{array}$ & $\begin{array}{l}2.000 \\
0.926\end{array}$ & $\begin{array}{l}1.500 \\
0.837\end{array}$ & $\begin{array}{l}2.286 \\
1.254\end{array}$ & $\begin{array}{l}4.000 \\
1.000\end{array}$ & $\begin{array}{l}1.500 \\
1.000\end{array}$ & $\begin{array}{l}2.570 \\
1.355\end{array}$ & .0007 \\
\hline 490 & $\begin{array}{l}\text { Mean } \\
\text { SD }\end{array}$ & $\begin{array}{c}5.1000 \\
0\end{array}$ & $\begin{array}{l}3.667 \\
1.528\end{array}$ & $\begin{array}{l}4.400 \\
0.548\end{array}$ & $\begin{array}{l}4.875 \\
0.354\end{array}$ & $\begin{array}{l}4.200 \\
0.837\end{array}$ & $\begin{array}{l}4.000 \\
1.155\end{array}$ & $\begin{array}{l}4.800 \\
0.447\end{array}$ & $\begin{array}{l}4.000 \\
0.894\end{array}$ & $\begin{array}{l}4.100 \\
1.287\end{array}$ & $\begin{array}{l}7.000 \\
1.225\end{array}$ & $\begin{array}{l}4.600 \\
0.548\end{array}$ & $\begin{array}{l}4.429 \\
1.134\end{array}$ & $\begin{array}{l}4.333 \\
1.000\end{array}$ & $\begin{array}{l}4.625 \\
0.744\end{array}$ & $\begin{array}{l}4.143 \\
0.690\end{array}$ & $\begin{array}{l}4.6677 \\
0.577\end{array}$ & $\begin{array}{l}3.000 \\
1.826\end{array}$ & $\begin{array}{l}+.323 \\
0.967\end{array}$ & .2423 \\
\hline $49 f$ & $\begin{array}{l}\text { Mean } \\
\text { SD }\end{array}$ & $\begin{array}{c}5.000 \\
0\end{array}$ & $\begin{array}{l}4.333 \\
0.577\end{array}$ & $\begin{array}{l}4.400 \\
0.5+8\end{array}$ & $\begin{array}{c}5.000 \\
0\end{array}$ & $\begin{array}{l}3.200 \\
1.304\end{array}$ & $\begin{array}{l}3.750 \\
0.957\end{array}$ & $\begin{array}{l}4.600 \\
0.548\end{array}$ & $\begin{array}{l}3.833 \\
0.753\end{array}$ & $\begin{array}{l}3.700 \\
1.252\end{array}$ & $\begin{array}{l}3.600 \\
1.140\end{array}$ & $\begin{array}{l}4.600 \\
0.548\end{array}$ & $\begin{array}{l}4.857 \\
0.378\end{array}$ & $\begin{array}{l}4.000 \\
0.866\end{array}$ & $\begin{array}{l}4.250 \\
1.165\end{array}$ & $\begin{array}{l}3.857 \\
1.1649\end{array}$ & $\begin{array}{l}4.667 \\
0.577\end{array}$ & $\begin{array}{l}3.000 \\
1.155\end{array}$ & $\begin{array}{l}4.162 \\
0.987\end{array}$ & 0033 \\
\hline
\end{tabular}

Notes:

I. Statements from the survey questionnaire (see Appendix B).

2. Level of significance.

3. Standard deviation from the Mean.

t. 1 a strongly disagrec; 2 = disagrec; $3=$ neutral; 4 - agrec; $S=$ strongly agree.

$\because$ Indicates significant difference at the 0.5 confidence level.

- Indicates where Scheffe post hoc iest has revealed significant difference at the 0.5 confidence level between pair(s) of colleges. 


\section{Summary of Matched Statements in the 1995/96 and 1997/98 Studies,}

By Constituent Group

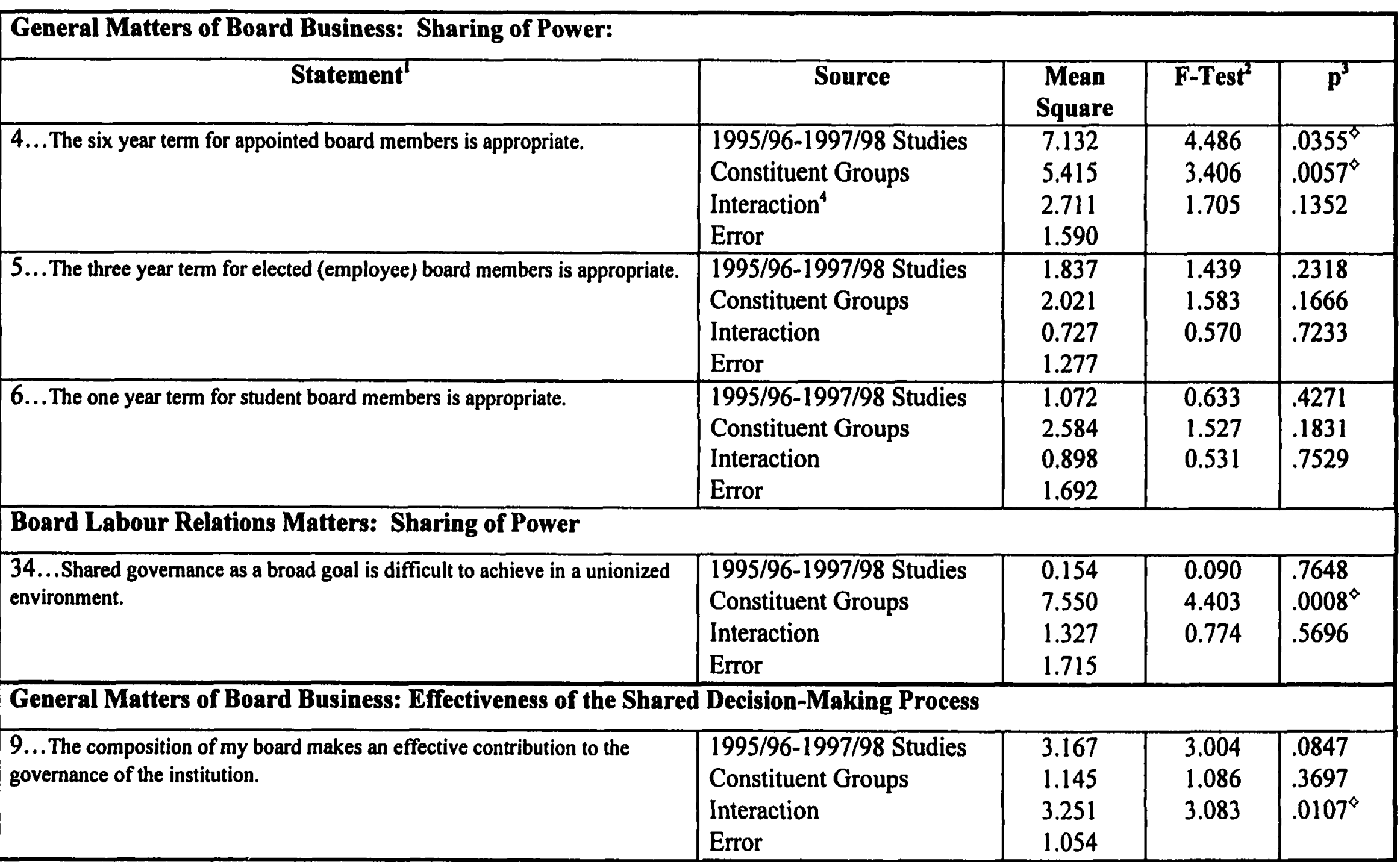




\begin{tabular}{|c|c|c|c|c|}
\hline $\begin{array}{l}\text { 10... The way my board operates makes an effective contribution to the } \\
\text { governance of the institution. }\end{array}$ & $\begin{array}{l}\text { 1995/96-1997/98 Studies } \\
\text { Constituent Groups } \\
\text { Interaction } \\
\text { Error }\end{array}$ & $\begin{array}{l}2.821 \\
1.887 \\
2.349 \\
0.969\end{array}$ & $\begin{array}{l}2.912 \\
1.948 \\
2.425\end{array}$ & $\begin{array}{l}.0896 \\
.0883 \\
.0370^{\circ}\end{array}$ \\
\hline \multicolumn{5}{|c|}{ Board Financial Matters: Effectiveness of the Shared Decision-Making Process } \\
\hline $\begin{array}{l}25 . . . \text { I feel my board effectively discharges its fiscal responsibilities under the } \\
\text { College and Institute Act. }\end{array}$ & $\begin{array}{l}\text { 1995/96-1997/98 Studies } \\
\text { Constituent Groups } \\
\text { Interaction } \\
\text { Error }\end{array}$ & $\begin{array}{l}0.413 \\
2.913 \\
1.467 \\
0.743\end{array}$ & $\begin{array}{l}0.556 \\
3.920 \\
1.974\end{array}$ & $\begin{array}{l}.4569 \\
.0021^{\circ} \\
.0845\end{array}$ \\
\hline $\begin{array}{l}\text { 26...My board discharges its fiduciary responsibility to all students from } \\
\text { whom it collects student union fees when dealing with that organization. }\end{array}$ & $\begin{array}{l}\text { 1995/96-1997/98 Studies } \\
\text { Constituent Groups } \\
\text { Interaction } \\
\text { Error }\end{array}$ & $\begin{array}{l}1.571 \\
3.759 \\
1.122 \\
0.964\end{array}$ & $\begin{array}{l}1.630 \\
3.900 \\
1.164\end{array}$ & $\begin{array}{l}.2033 \\
.0022^{\diamond} \\
.3287\end{array}$ \\
\hline $\begin{array}{l}30 . . \text { The board's role is to approve the parameters and underlying } \\
\text { assumptions of the budget, but otherwise to leave the assembly of the numbers } \\
\text { to administration. }\end{array}$ & $\begin{array}{l}\text { 1995/96-1997/98 Studies } \\
\text { Constituent Groups } \\
\text { Interaction } \\
\text { Error }\end{array}$ & $\begin{array}{l}0.717 \\
1.884 \\
1.521 \\
0.998\end{array}$ & $\begin{array}{l}0.719 \\
1.889 \\
1.524\end{array}$ & $\begin{array}{l}.3975 \\
.0982 \\
.1842\end{array}$ \\
\hline \multicolumn{5}{|c|}{ Board Labour Relations Matters: Effectiveness of the Shared Decision-Making Process } \\
\hline $\begin{array}{l}37 . . . \text { f feel my board effectively discharges its labour relations responsibilities } \\
\text { under the College and Institute Act. }\end{array}$ & $\begin{array}{l}\text { 1995/96-1997/98 Studies } \\
\text { Constituent Groups } \\
\text { Interaction } \\
\text { Error }\end{array}$ & $\begin{array}{l}0.498 \\
3.371 \\
2.050 \\
0.702\end{array}$ & $\begin{array}{l}0.710 \\
4.803 \\
2.921\end{array}$ & $\begin{array}{l}.4007 \\
.0004^{\diamond} \\
.0146^{\diamond}\end{array}$ \\
\hline \multicolumn{5}{|c|}{ General Matters of Board Business: How Conflict of Interest has been Addressed } \\
\hline 16...The president should be a non-voting ex-officio member of the board. & $\begin{array}{l}\text { 1995/96-1997/98 Studies } \\
\text { Constituent Groups } \\
\text { Interaction } \\
\text { Error }\end{array}$ & $\begin{array}{l}1.378 \\
1.255 \\
1.146 \\
1.328\end{array}$ & $\begin{array}{l}1.038 \\
1.021 \\
0.110\end{array}$ & $\begin{array}{l}.3096 \\
.4066 \\
.9901\end{array}$ \\
\hline
\end{tabular}




\begin{tabular}{|c|c|c|c|c|}
\hline 17... The president should be a full voting member of the board. & $\begin{array}{l}\text { 1995/96-1997/98 Studies } \\
\text { Constituent Groups } \\
\text { Interaction } \\
\text { Error }\end{array}$ & $\begin{array}{l}1.037 \\
1.691 \\
0.246 \\
1.295\end{array}$ & $\begin{array}{l}0.801 \\
1.306 \\
0.190\end{array}$ & $\begin{array}{l}.3719 \\
.2630 \\
.9662\end{array}$ \\
\hline $\begin{array}{l}\text { 18... The chair of education council should be a non-voting ex-officio } \\
\text { member of the board. }\end{array}$ & $\begin{array}{l}\text { 1995/96-1997/98 Studies } \\
\text { Constituent Groups } \\
\text { Interaction } \\
\text { Error }\end{array}$ & $\begin{array}{r}11.586 \\
1.761 \\
1.947 \\
2.271 \\
\end{array}$ & $\begin{array}{l}5.102 \\
0.776 \\
0.857\end{array}$ & $\begin{array}{l}.0250^{8} \\
.5684 \\
.5109\end{array}$ \\
\hline $\begin{array}{l}19 . . \text { The chair of education council should be a full voting member of the } \\
\text { board. }\end{array}$ & $\begin{array}{l}\text { 1995/96-1997/98 Studies } \\
\text { Constituent Groups } \\
\text { Interaction } \\
\text { Error }\end{array}$ & $\begin{array}{r}10.708 \\
1.700 \\
1.850 \\
2.275\end{array}$ & $\begin{array}{l}4.706 \\
0.747 \\
0.813\end{array}$ & $\begin{array}{l}.0313^{\gamma} \\
.5890 \\
.5415\end{array}$ \\
\hline $\begin{array}{l}20 . . \text { The bylaw and/or policy on conflict of interest adopted at my institution } \\
\text { is generally accepted by all board members as fair and workable. }\end{array}$ & $\begin{array}{l}\text { 1995/96-1997/98 Studies } \\
\text { Constituent Groups } \\
\text { Interaction } \\
\text { Error }\end{array}$ & $\begin{array}{l}0.062 \\
1.713 \\
1.781 \\
1.097\end{array}$ & $\begin{array}{l}0.056 \\
1.562 \\
1.623\end{array}$ & $\begin{array}{l}.8127 \\
.1730 \\
.1558\end{array}$ \\
\hline \multicolumn{5}{|c|}{ Board Financial Matters: How Conflict of Interest has been Addressed } \\
\hline $\begin{array}{l}27 . . . \text { My board has dealt effectively with the issue of conflict of interest as it } \\
\text { relates to student board members with respect to financial matters between the } \\
\text { board and the student union, such as tuition and other fees. }\end{array}$ & $\begin{array}{l}\text { 1995/96-1997/98 Studies } \\
\text { Constituent Groups } \\
\text { Interaction } \\
\text { Error }\end{array}$ & $\begin{array}{l}0.487 \\
0.883 \\
0.968 \\
0.986\end{array}$ & $\begin{array}{l}0.494 \\
0.896 \\
0.982\end{array}$ & $\begin{array}{l}.4832 \\
.4851 \\
.4301\end{array}$ \\
\hline $\begin{array}{l}29 . . \text { Elected student board members should be disqualified from } \\
\text { simultaneously holding office in their respective student unions because of the } \\
\text { perceived conflict of interest on financial matters. }\end{array}$ & $\begin{array}{l}\text { 1995/96-1997/98 Studies } \\
\text { Constituent Groups } \\
\text { Interaction } \\
\text { Error }\end{array}$ & $\begin{array}{l}0.066 \\
2.660 \\
1.885 \\
1.994 \\
\end{array}$ & $\begin{array}{l}0.033 \\
1.334 \\
0.945\end{array}$ & $\begin{array}{l}.8555 \\
.2516 \\
.4529\end{array}$ \\
\hline
\end{tabular}




\begin{tabular}{|c|c|c|c|c|}
\hline \multicolumn{5}{|c|}{ Board Labour Relations Matters: How Conflict of Interest has been Addressed } \\
\hline $\begin{array}{l}42 . . \text { My board has dealt effectively with the issue of conflict of interest as it } \\
\text { relates to elected and ex-officio board members with respect to matters of } \\
\text { administering collective agreements. }\end{array}$ & $\begin{array}{l}\text { 1995/96-1997/98 Studies } \\
\text { Constituent Groups } \\
\text { Interaction } \\
\text { Error }\end{array}$ & $\begin{array}{l}0.061 \\
1.415 \\
2.125 \\
1.056\end{array}$ & $\begin{array}{l}0.058 \\
1.340 \\
2.013\end{array}$ & $\begin{array}{l}.8105 \\
.2489 \\
.0785\end{array}$ \\
\hline $\begin{array}{l}\text { 46...Elected employee members and ex-officio members should be } \\
\text { disqualified from simultaneously holding office in their respective trade } \\
\text { unions. }\end{array}$ & $\begin{array}{l}\text { 1995/96-1997/98 Studies } \\
\text { Constituent Groups } \\
\text { Interaction } \\
\text { Error }\end{array}$ & $\begin{array}{l}0.039 \\
3.945 \\
0.252 \\
2.170\end{array}$ & $\begin{array}{l}0.018 \\
1.818 \\
0.116\end{array}$ & $\begin{array}{l}.8929 \\
.1110 \\
.9888\end{array}$ \\
\hline
\end{tabular}

1. Statements from the survey questionnaire (see Appendix B).

2. Ratio of True to Error Variance based on Mean Square.

3. Level of Significance.

4. Interaction between the pre/post test and constituent groups.

$\checkmark$ Indicates Significant Statistical Difference 
Summary of the Most Positive and Least Positive Attitudes ${ }^{1}$ in General Toward Shared Governance, by College ${ }^{3}$ and Constituent Group ${ }^{2}$

\begin{tabular}{|c|c|c|c|c|c|c|}
\hline & \multicolumn{6}{|c|}{ Colleges } \\
\hline & \multicolumn{3}{|c|}{$\begin{array}{c}\text { Most Positive } \\
\text { (Top Three Institutions) }\end{array}$} & \multicolumn{3}{|c|}{$\begin{array}{c}\text { Least Positive } \\
\text { (Bottom Three Institutions) }\end{array}$} \\
\hline Board Members' Views & $1^{\text {st }}$ & $2^{\text {nd }}$ & $3^{\text {rd }}$ & $15^{\text {th }}$ & $16^{\text {th }}$ & $17^{\text {th }}$ \\
\hline $\begin{array}{l}\text { General Matters ) } \\
\text { Financial Matters ) Sharing of Power } \\
\text { Labour Matters ) }\end{array}$ & $\begin{array}{l}\mathrm{K} \\
\mathrm{G} \\
\mathrm{K}\end{array}$ & $\begin{array}{l}\mathbf{B} \\
\mathrm{K} \\
\mathrm{P}\end{array}$ & $\begin{array}{l}\mathrm{L} \\
\mathbf{J} \\
\mathrm{D}\end{array}$ & $\begin{array}{l}\mathrm{G} \\
\mathrm{H} \\
\mathrm{Q}\end{array}$ & $\begin{array}{l}\mathrm{F} \\
\mathrm{P} \\
\mathrm{B}\end{array}$ & $\begin{array}{l}\mathrm{P} \\
\mathrm{B} \\
\mathrm{I}\end{array}$ \\
\hline $\begin{array}{l}\text { General Matters ) Effectiveness of } \\
\text { Financial Matters ) Shared Decision- } \\
\text { Labour Matters ) Making Process }\end{array}$ & $\begin{array}{l}\mathrm{G} \\
\mathrm{D} \\
\mathrm{P}\end{array}$ & $\begin{array}{l}\mathrm{K} \\
\mathrm{G} \\
\mathrm{K}\end{array}$ & $\begin{array}{l}\mathrm{L} \\
\mathrm{H} \\
\mathrm{G}\end{array}$ & $\begin{array}{l}\mathrm{P} \\
\mathrm{Q} \\
\mathrm{E}\end{array}$ & $\begin{array}{l}\mathrm{F} \\
\mathrm{E} \\
\mathrm{M}\end{array}$ & $\begin{array}{l}\mathrm{Q} \\
\mathrm{F} \\
\mathrm{F}\end{array}$ \\
\hline $\begin{array}{l}\text { General Matters ) } \\
\text { Financial Matters ) Conflict of Interest } \\
\text { Labour Matters ) Addressed }\end{array}$ & $\begin{array}{l}\mathrm{G} \\
\mathrm{K} \\
\mathrm{K}\end{array}$ & $\begin{array}{l}\mathrm{P} \\
\mathrm{L} \\
\mathrm{G}\end{array}$ & $\begin{array}{l}\mathrm{N} \\
\mathrm{A} \\
\mathrm{L}\end{array}$ & $\begin{array}{l}\mathrm{J} \\
\mathrm{P} \\
\mathrm{I}\end{array}$ & $\begin{array}{c}\mathrm{M} \\
\mathrm{F} \\
\mathrm{Q}\end{array}$ & $\begin{array}{l}\mathrm{Q} \\
\mathrm{Q} \\
\mathrm{H}\end{array}$ \\
\hline OVERALL & $\bar{K}$ & $\mathrm{G}$ & $\mathrm{L}$ & $\mathrm{E}$ & $\mathbf{F}$ & $\bar{Q}$ \\
\hline \multicolumn{7}{|c|}{ Board Members' Views of Own Board's Effectiveness } \\
\hline Sharing of Power & $\mathbf{G}$ & $\bar{D}$ & $\mathrm{~A}$ & 0 & $\bar{F}$ & $\bar{Q}$ \\
\hline $\begin{array}{l}\text { Effectiveness of Shared-Decision Making } \\
\text { Process }\end{array}$ & $\mathrm{L}$ & $\mathrm{G}$ & $\mathbf{K}$ & $\bar{B}$ & $\mathrm{~F}$ & $\bar{Q}$ \\
\hline Conflict of Interest Addressed & $\mathrm{A}$ & $\mathrm{L}$ & $\mathbf{G}$ & $\bar{M}$ & $\bar{B}$ & $\bar{Q}$ \\
\hline OVERALL & $\mathbf{G}$ & $\overline{\mathrm{D}}$ & $\bar{A}$ & $\overline{\mathrm{H}}$ & $\bar{F}$ & $\bar{Q}$ \\
\hline TOTAL OVERALL & $\mathrm{K}$ & $\mathbf{G}$ & $\bar{D}$ & $\mathrm{E}$ & $\mathrm{F}$ & $\mathbf{Q}$ \\
\hline
\end{tabular}

1. Attitude is measured by the net aggregate of mean scores on all questions in the survey-See Appendix B. Net aggregate is the sum of all the positive questions less all the negative questions.

2. Constituent Group Key: $A=$ Appointees; $F=$ Faculty; $S S=$ Support Staff; $S=$ Students; $P=$ Presidents; $C=$ Education Council Chairs.

3. The seventeen participating colleges were named $A$ through $Q$. 


\begin{tabular}{|c|c|c|c|c|c|c|}
\hline \multirow[b]{3}{*}{ Board Members' Views } & \multicolumn{6}{|c|}{ Constituent Groups } \\
\hline & \multicolumn{3}{|c|}{$\begin{array}{c}\text { Most Positive } \\
\text { (Top Three Constituent Groups) }\end{array}$} & \multicolumn{3}{|c|}{$\begin{array}{c}\text { Least Positive } \\
\text { (Bottom Three Constituent Groups) }\end{array}$} \\
\hline & $1^{14}$ & $2^{\text {nd }}$ & $3^{\text {nd }}$ & $4^{\mathrm{th}}$ & $5^{\text {th }}$ & $6^{\text {th }}$ \\
\hline $\begin{array}{l}\text { General Matters ) } \\
\text { Financial Matters ) Sharing of Power } \\
\text { Labour Matters ) }\end{array}$ & $\begin{array}{c}\text { SS } \\
\text { F } \\
\text { S }\end{array}$ & $\begin{array}{l}\mathrm{C} \\
\mathrm{S} \\
\mathrm{F}\end{array}$ & $\begin{array}{l}\mathrm{S} \\
\mathrm{C} \\
\mathrm{A}\end{array}$ & $\begin{array}{l}\text { A } \\
\text { SS } \\
\text { C }\end{array}$ & $\begin{array}{c}\mathrm{F} \\
\mathrm{A} \\
\mathrm{SS}\end{array}$ & $\begin{array}{l}\mathrm{P} \\
\mathrm{P} \\
\mathrm{P}\end{array}$ \\
\hline $\begin{array}{l}\text { General Matters ) Effectiveness of } \\
\text { Financial Matters ) Shared Decision- } \\
\text { Labour Matters ) Making Process }\end{array}$ & $\begin{array}{c}\text { S } \\
\text { SS } \\
\text { F }\end{array}$ & $\begin{array}{l}\mathrm{A} \\
\mathrm{F} \\
\mathrm{A}\end{array}$ & $\begin{array}{l}\text { SS } \\
\text { A } \\
\text { S }\end{array}$ & $\begin{array}{l}\mathrm{C} \\
\mathrm{P} \\
\mathrm{SS}\end{array}$ & $\begin{array}{l}\mathrm{F} \\
\mathrm{C} \\
\mathrm{P}\end{array}$ & $\begin{array}{l}\mathbf{P} \\
\mathbf{S} \\
\mathrm{C}\end{array}$ \\
\hline $\begin{array}{l}\text { General Matters ) } \\
\text { Financial Matters ) Conflict of Interest } \\
\text { Labour Matters ) Addressed }\end{array}$ & $\begin{array}{c}\text { A } \\
\text { S } \\
\text { SS }\end{array}$ & $\begin{array}{l}\mathrm{F} \\
\mathrm{C} \\
\mathrm{C}\end{array}$ & $\begin{array}{l}\text { SS } \\
\text { F } \\
\text { A }\end{array}$ & $\begin{array}{l}\mathrm{C} \\
\mathrm{A} \\
\mathrm{F}\end{array}$ & $\begin{array}{c}\text { P } \\
\text { SS } \\
\text { S }\end{array}$ & $\begin{array}{l}\mathbf{S} \\
\mathbf{P} \\
\mathbf{P}\end{array}$ \\
\hline OVERALL & $\mathrm{S}$ & $\mathrm{A}$ & $\mathrm{F}$ & SS & $\mathrm{C}$ & $\mathbf{P}$ \\
\hline
\end{tabular}

\section{Board Members' Views of Own Board's Effectiveness}

\begin{tabular}{|l|c|c|c|c|c|c|}
\hline Sharing of Power & C & S & A & SS & F & P \\
\hline $\begin{array}{l}\text { Effectiveness of Shared-Decision Making } \\
\text { Process }\end{array}$ & SS & A & F & S & C & P \\
\hline Conflict of Interest Addressed & SS & A & S & C & F & P \\
\hline OVERALL & SS & A & S & C & F & P \\
\hline TOTAL OVERALL & A & SS & S & F & C & P \\
\hline
\end{tabular}

1. Attitude is measured by the net aggregate of mean scores on all questions in the survey-See Appendix B. Net aggregate is the sum of all the positive questions less all the negative questions.

2. Constituent Group Key: $A=$ Appointees; $F=$ Faculty; $S S=$ Support Staff; $S=$ Students; $P=$ Presidents; $C=$ Education Council Chairs

3. The seventeen participating colleges were named $A$ through $Q$. 
Strongly

Agree

Agree

Neutral

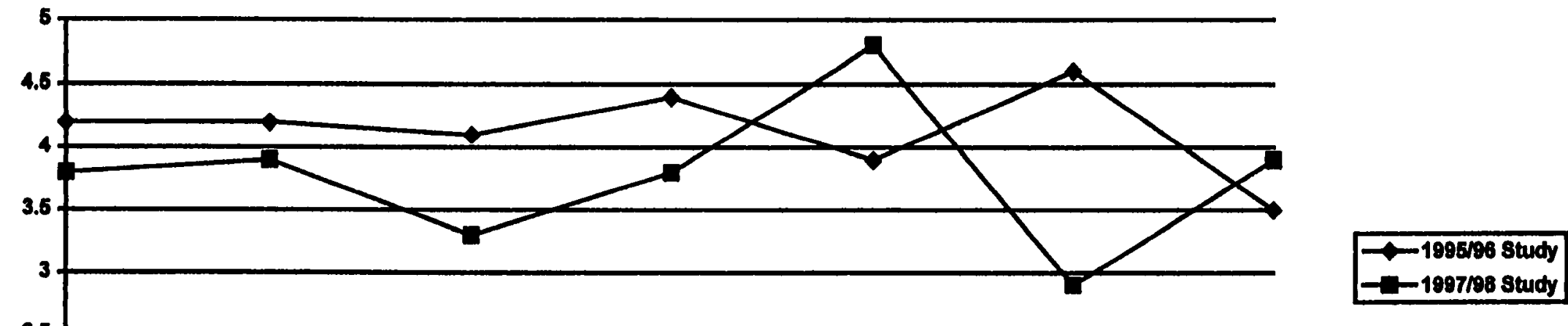

음
$\mathbf{8}$
$\frac{2}{\bar{x}}$
0

Disagree

Strongly

Disagree

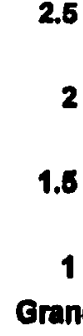

1.8

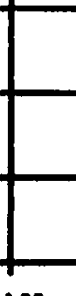

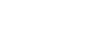
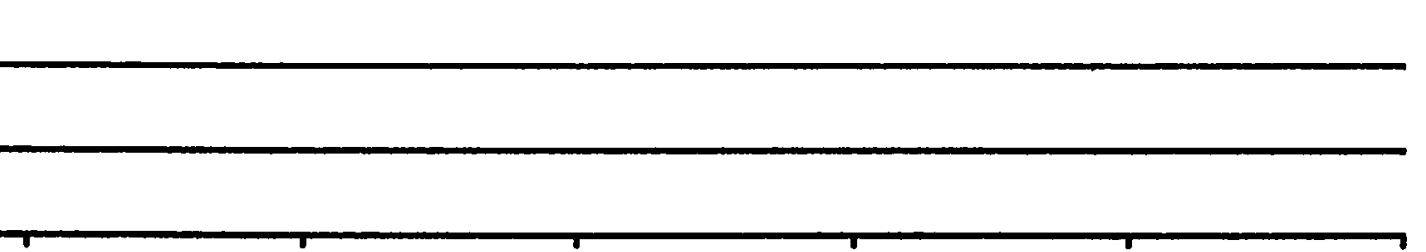

Appointees

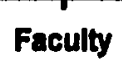

Staff

Students

Prosidente

Councll Chalrs 


Question 10: The way my board operates makes an effective contribution to the governance
of the institution.

Strongly

Agree

Agree

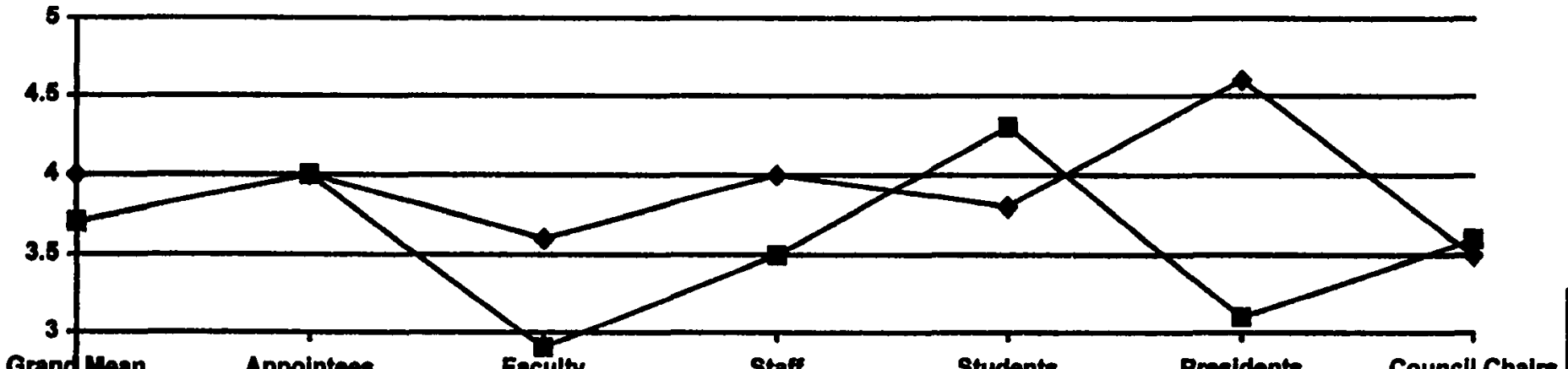

- -1995/26 Study

Neutral

Grand Mean

Appointoes

Faculty

Studonts

Presidonts

Councll Chairs -1997198 study

$\frac{8}{8}$
$\frac{0}{2}$
$\frac{2}{x}$
D

Disagree

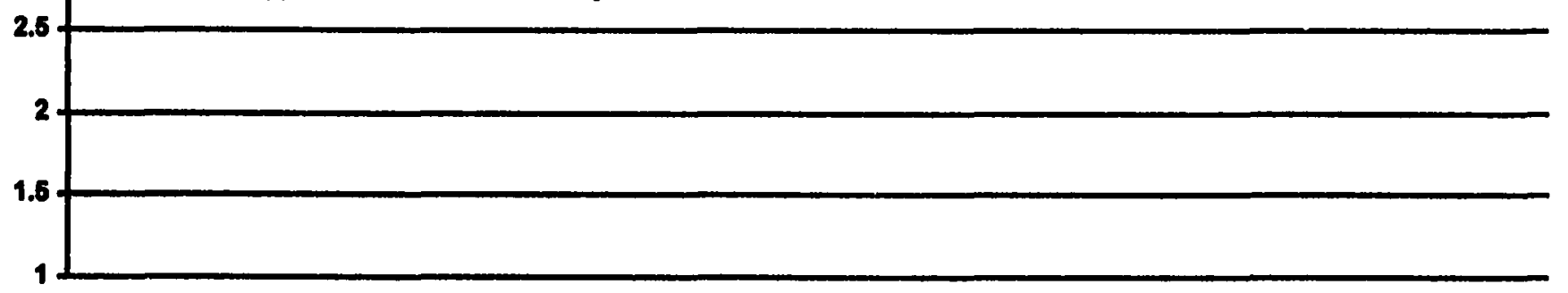




\section{Question 37: I feel my board effectively discharges its labour relations responsibilities}

under the College and Institute Act.

Strongly

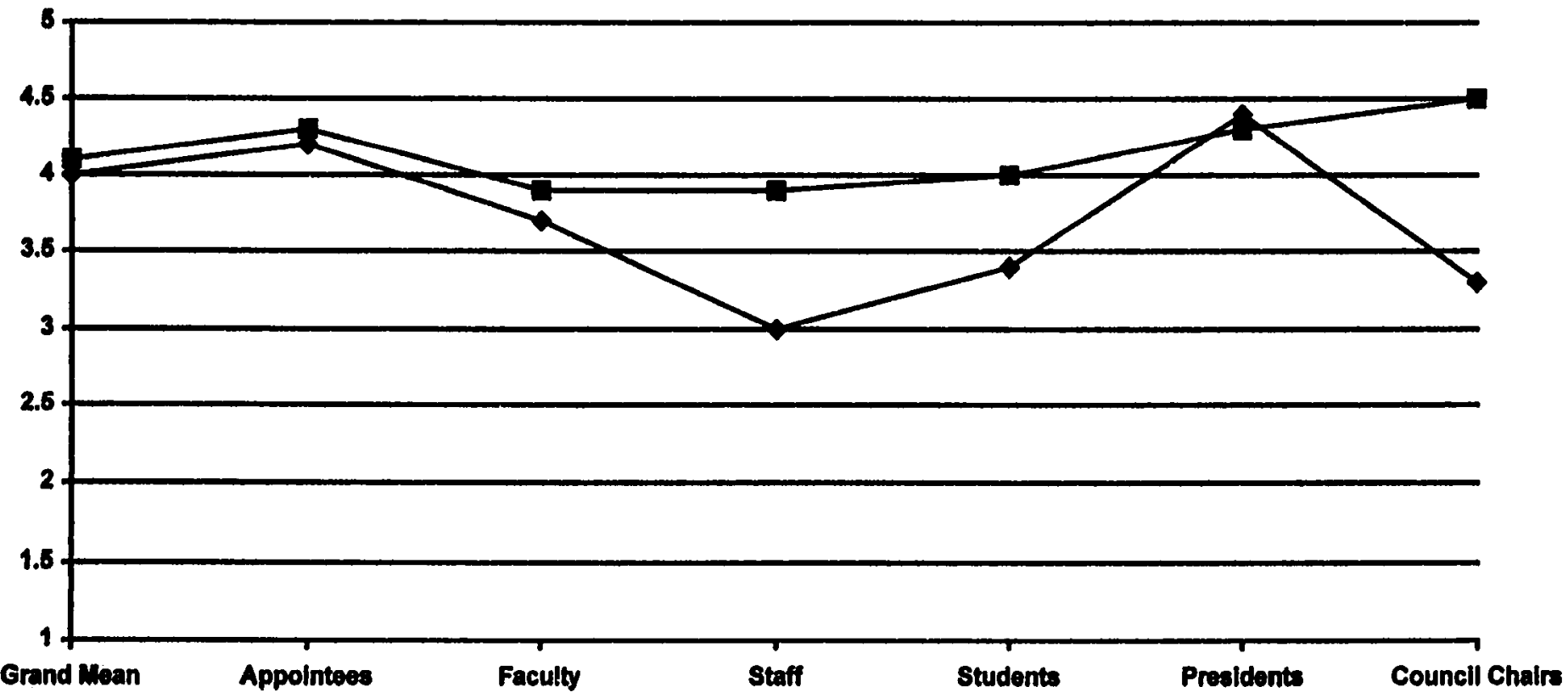

